\title{
Flavonoids seen through the energy perspective
}

Citation for published version (APA):

$\mathrm{Li}$, Z. (2021). Flavonoids seen through the energy perspective. [Doctoral Thesis, Maastricht University]. Maastricht University. https://doi.org/10.26481/dis.20210310zl

Document status and date:

Published: 01/01/2021

DOI:

10.26481/dis.20210310zl

Document Version:

Publisher's PDF, also known as Version of record

\section{Please check the document version of this publication:}

- A submitted manuscript is the version of the article upon submission and before peer-review. There can be important differences between the submitted version and the official published version of record.

People interested in the research are advised to contact the author for the final version of the publication, or visit the DOI to the publisher's website.

- The final author version and the galley proof are versions of the publication after peer review.

- The final published version features the final layout of the paper including the volume, issue and page numbers.

Link to publication

\footnotetext{
General rights rights.

- You may freely distribute the URL identifying the publication in the public portal. please follow below link for the End User Agreement:

www.umlib.nl/taverne-license

Take down policy

If you believe that this document breaches copyright please contact us at:

repository@maastrichtuniversity.nl

providing details and we will investigate your claim.
}

Copyright and moral rights for the publications made accessible in the public portal are retained by the authors and/or other copyright owners and it is a condition of accessing publications that users recognise and abide by the legal requirements associated with these

- Users may download and print one copy of any publication from the public portal for the purpose of private study or research.

- You may not further distribute the material or use it for any profit-making activity or commercial gain

If the publication is distributed under the terms of Article $25 \mathrm{fa}$ of the Dutch Copyright Act, indicated by the "Taverne" license above, 


\section{Flavonoids seen through the energy perspective}

ZhengWen Li

李正文 
(C) ZhengWen Li, 2021

Flavonoids seen through the energy perspective

Thesis, Maastricht University, Maastricht, the Netherlands

Layout: ZhengWen Li

Cover design: Perfect imperfection star 17, ZhengWen Li

Printed by: Gildeprint, Enschede

ISBN: $\quad$ 978-94-6419-163-9

All rights are reserved. For articles published, the copyright has been transferred to the respective publisher. No parts of this thesis may be reproduced, stored in a retrieval system or transmitted in any form or by any means, without prior permission from the author. 


\section{Flavonoids seen through the energy perspective}

\section{DISSERTATION}

To obtain the degree of Doctor at Maastricht University,

on the authority of the Rector Magnificus Prof.dr. Rianne M. Letschert in accordance with the decision of the Board of Deans,

to be defended in public on Wednesday 10th of March 2021 at 10.00 hours

by

ZhengWen Li

李正文

born on 14 August 1991

in Mian Yang, China 


\section{Promotor}

Prof. dr. Guido R.M.M. Haenen

\section{Co-promotor}

Dr. Mohamed Moalin

Dr. Ming Zhang

\section{Beoordelingscommissie}

Prof. dr. Harry Steinbusch (Voorzitter), Maastricht University

Prof. dr. Leon J. Schurgers, Maastricht university

Dr. Gertjan J.M. den Hartog, Maastricht University

Prof. dr. Bashir Mahmoud Rezk Atteia, Southern University at New Orleans

Dr. Gino van Strijdonck, Zuyd Hogeschool

The research described in this thesis was conducted at Department of Pharmacology and Toxicology, NUTRIM School of Nutrition and Aachen Maastricht Institute for Biobased Materials of Maastricht University. The work in this thesis was financially supported by China Scholarship Council (CSC, File No. 201606910079). 
Amor fati, 命運之愛 



\section{Content}

$\begin{array}{lr}\text { Preface } & 9\end{array}$

$\begin{array}{lll}\text { Chapter } 1 & \text { General Introduction } & 13\end{array}$

Chapter 2 Antibacterial strategies for wound dressing: preventing 45 infection and stimulating healing

Chapter 3 Delocalization of the Unpaired Electron in the Quercetin 83 Radical: Comparison of Experimental ESR Data with DFT Calculations

Chapter 4

The flow of the redox energy in Quercetin during its antioxidant activity in water

Chapter 5

The antioxidant activity of 'simple' phenolic compounds

145 towards peroxynitrite, refining the structure activity relationship

$\begin{array}{lll}\text { Chapter } 6 & \text { General discussion and summary } & 165\end{array}$

$\begin{array}{lll}\text { Chapter } 7 & \text { Nederlandse samenvatting en algemene discussie } & 171\end{array}$

$\begin{array}{ll}\text { Impact paragraph } & 177\end{array}$

$\begin{array}{lr}\text { Acknowledgment } & 185\end{array}$

$\begin{array}{lr}\text { List of publications } & 189\end{array}$

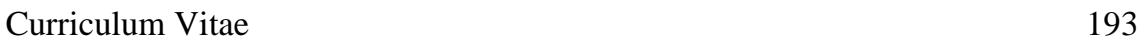





\section{Preface}

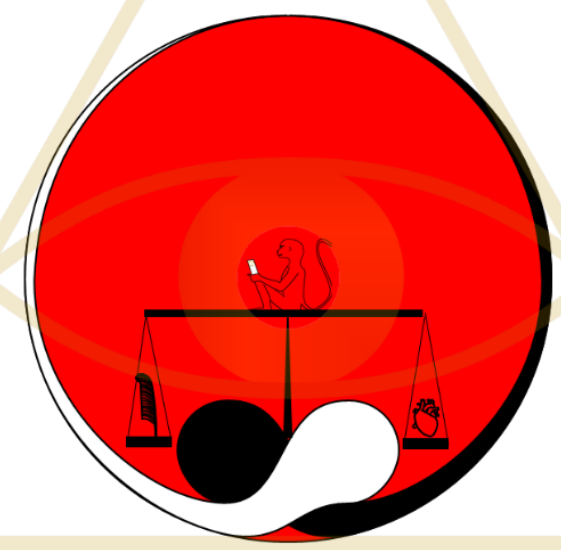




\section{Aim and outline of the thesis}

As researchers with knowledge on redox biology, we are privileged because we know that we do not have to be afraid of burning in Hell. We know this already happens on Earth. In first instance the accusing finger points to an unusual suspect, Oxygen, which we considered to be a good friend. Actually, Oxygen is not the culprit, it is the redox energy that is liberated when nutrients are oxidized with the help of Oxygen. But then again, we know that this redox energy is essential for us, because it fuels all the biochemical processes that our lives depend on. Actually, the fact that we ourselves are not able to safely channel the energy is the real reason why we slowly burn.

The uncontrolled, deranged redox energy that escapes our antioxidant defense is damaging, and this damage is pivotal in ageing and the manifestation of all kinds of diseases. In a healthy body the oxidizing and reducing forces are - to a large extend - balanced and generate a reasonably controlled energy flow in which the accumulation of oxidative damage is kept within limits and we can enjoy a healthy life for on average 80 years.

It should be noted that we also use the lethal potency of the redox energy to our benefit in the killing bacteria and viruses. In addition, the deranged redox energy appears to play a key role in the healing process, and the redox 'damage' of DNA is tough to be a driving force in evolution.

Within this playfield of opposing internal and external forces that contain both good and bad (Yin and Yang), we are gifted with the ability to intervene to some extend at our own free will, and to do our 'best' by choosing the right lifestyle, diet or 'therapy'. This thesis is dedicated to extending our knowledge on the modulation of the redox processes by a specific class of antioxidants, namely the flavonoids. For the reasons given above, this is done from the energy perspective.

In Chapter 1, the fundament of this thesis is laid by reviewing various perspectives on the redox modulation by flavonoids, to 'see' where there is overlap, and where the missing links are. Based on this fundament, we choose our research path aiming to 'understand' the redox modulating profile of specific flavonoids, so we ultimately can optimize the use of the redox modulating power of flavonoids.

To display a biological activity, the flavonoids need to be directed to the site where they have to display their redox modulating activity. In Chapter 2, the trends in the strategy to safely administer compounds, including flavonoids, by wound dressing is reviewed. By local administration systemic toxicity is prevented, and the therapy is expected to be more effective.

Chapters 3 to 5 deal with the pharmacodynamics of flavonoids. In Chapter $\mathbf{3}$, it is examined how in the antioxidant activity of the flavonoid quercetin, the energy quercetin has picked up is stabilized in the quercetin radical by delocalization of the unpaired electron. The importance of the functional groups of quercetin in the stabilization of the energy is examined, by combining experimentally obtained spin resonance spectroscopy (ESR) measurements with theoretical density functional theory (DFT) calculations.

As outlined in Chapter 1, most studies on the antioxidant activity of flavonoids like quercetin do not consider that it comprises of a series of sequential reactions. Therefore, we 
examined in Chapter 4 how the redox energy flows through the molecule during quercetin's antioxidant activity, again by combining experimental data with quantum calculations.

In Chapter 5, the structure activity relationship of the antioxidant activity of 'simple' phenolic compounds was reexamined. The use of the new perspective provided by quantum chemical calculation revealed that even within this group of structurally closely related compounds, different molecular mechanisms are involved in the antioxidant activity. Understanding the mechanisms of the antioxidant activity of these 'simple' phenolic compounds will form the fundament to the understanding of the mechanism of more complex phenolic antioxidants, such as quercetin. Ultimately, this will help to unveil the biological profile of these compounds, so we will be able to select the 'right' antioxidant to protect against the uniquely deranged energy flow involved a specific pathology. 


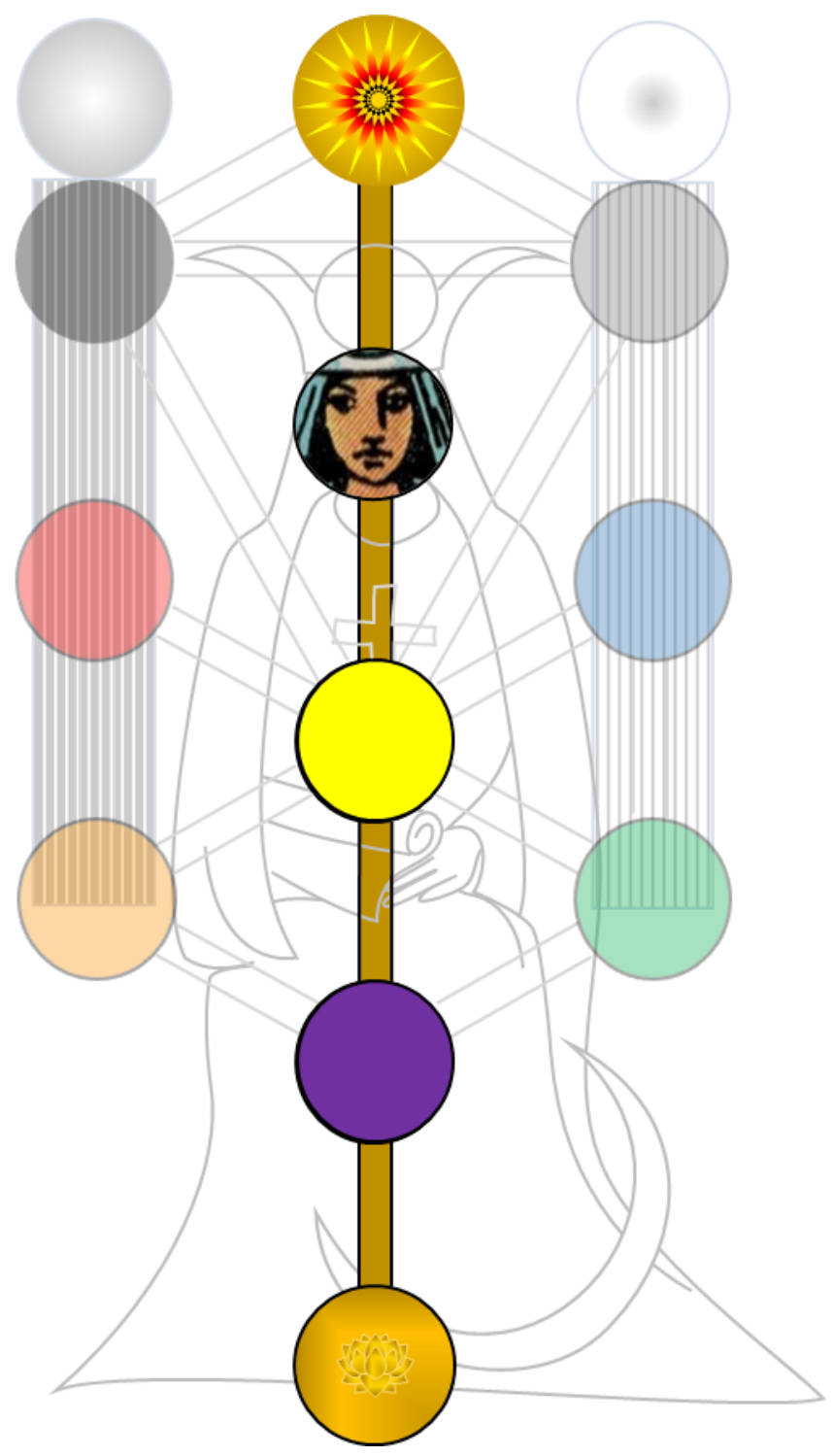




\section{Chapter 1}

\section{Introduction: Flavonoids seen through the energy perspective}

Zhengwen Li ${ }^{1}$, Guido R.M.M. Haenen ${ }^{1}$, Mohamed Moalin ${ }^{1,2}$, Lily $\operatorname{Vervoort~}^{1}$ and $^{\text {, }}$ Ming Zhang ${ }^{1}$

1 Department of Pharmacology and Toxicology, Faculty of Health, Medicine and Life Sciences, Maastricht University, P.O. Box 616, 6200 MD Maastricht, The Netherlands.

2 Research Centre Material Sciences, Zuyd University of Applied Sciences, 6419 DJ Heerlen, The Netherlands 


\section{The dual nature of oxygen and antioxidants}

Oxygen is indispensable for us, because the reaction of oxygen with nutrients generates the redox energy which ultimately fuels all of our biochemical processes. Remarkably, this 'burning' of nutrients is only partly controlled. Part of the liberated energy gives rise to reactive oxygen species (ROS) [1, 2] and reactive nitrogen species [3, 4]. This uncontrolled energy can damage vital biomacromolecules such as DNA, lipids and proteins, and this is how we slowly 'burn' during our life. So, oxidation has two faces, good as well as bad. Luckily, there is also a counterforce to the damaging oxidative power of reactive oxygen species and other oxidants: the reductive power of antioxidants.

In a healthy body these opposing forces of oxidation and reduction are - to a large extend - balanced and generate a reasonably controlled energy flow in which the accumulation of oxidative damage is kept within limits and we can enjoy a healthy life for on average 80 years. However, due to inflammation, infection, trauma and other challenges, the flow can run out of control; the production of free radicals rises and greatly outbalances the antioxidant protection. Despite inflicting damage, an enhanced radical flow is essential for e.g. the killing of bacteria. Therefore, despite collateral damage to surrounding 'healthy' tissue, the enhanced radical flow can also be qualified as 'good'. Moreover, the enhanced radical flow can also switch on redox-regulated transcription factors [5] that act as master switches that turn on the healing process and even adapt us for a second challenge. The body also 'learns' e.g. by the adaptive immune system that can make the body immune against an invading microorganism that also increases our resilience. In fact, the static perspective that health means the absence of disease has been adjusted by adding a dynamic perspective to it; health also includes the ability to adapt to the challenges you have faced. However, there appears to be a limit to this ability to adapt or 'learning', as after multiple hard challenges, or a chronic mild challenge, the accumulated damage is too severe to be repaired and the ultimate 'adaptation' is death. This is advantageous because 'death' prevents that a too severely damaged cell thrives and unrestrictedly proliferates to induce cancer. A comforting thought is that we might pass on what is learned to next generations e.g. by (epi) genetic 'improvements' of the information contained in our common DNA pool. 


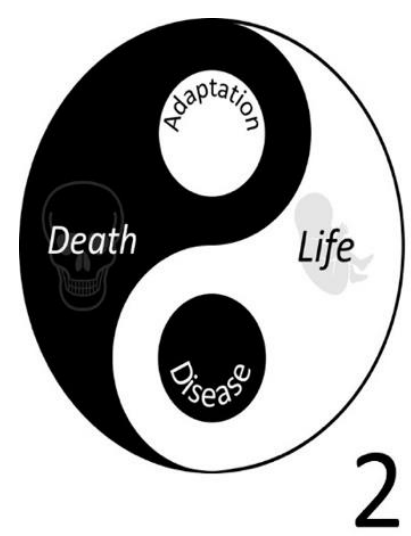

Fig 1. A new symbol for Oxygen that reflects its dual nature. In the new symbol the chemical symbol of Oxygen is merged with the Taiji symbol.

Within this playfield of opposing internal and external forces that contain both good and bad, we are gifted with the ability to intervene to some extend at our own will, and to do our 'best' by choosing the right lifestyle, diet or 'therapy'. Our research is focused on the modulation of these redox processes by antioxidants.

Probably the most important antioxidant is vitamin E, which is directly linked to life as it was identified as a dietary factor essential for reproduction. Therefore, it was the named

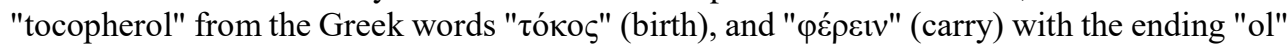
that refers to the aromatic hydroxyl group that is essential for its antioxidant activity. Vitamin E nicely illustrates the link between life and the environment that food provides. A limitation of food supply with sufficient vitamins will restrict an uncontrolled growth of the population.

For humans, vitamin $\mathrm{C}$ is also a dietary antioxidant essential for life. It seems logical that this is related to a plentiful supply of vitamin $\mathrm{C}$ from dietary sources. It is intriguing that our inability to make ascorbate is merely due to one nonfunctional enzyme, L-gluconolactone oxidase, the last enzyme in the synthesis of vitamin C. It is puzzling what the evolutionary advantage of this mutation is. Interestingly, L-gluconolactone oxidase generates $\mathrm{H}_{2} \mathrm{O}_{2}$ in the synthesis of ascorbate. So, obtaining ascorbic acid from the diet reduces the endogenous formation of reactive oxygen species. In evolution, our inability to synthesize ascorbic acid coincided with our inability to convert uric acid into allantoin. This implies that one antioxidant (vitamin C) is partly replaced by another (uric acid), with another antioxidant profile. The consequence and 'reason' for this replacement are still enigmatic[6].

Another example of redox modulators is the group of flavonoids. Although these compounds do not fulfill the criteria to be labeled as vitamin, they can protect us. A higher intake of these compounds has been associated with a reduced incidence of oxidative stress related diseases such as cardiovascular diseases and cancer. This group comprises over 5.000 different compounds. Despite extensive research on one of the most studied flavonoids, quercetin, for over several decades, much about quercetin and the other flavonoids is still unknow. We tentatively know that each flavonoid has its own unique 'biochemical profile', but these biochemical profiles are only partly unveiled. Moreover, we tentatively know that in different diseases different types of oxidative stress are involved, but we still do not know 
how to choose the flavonoid(s) that best corrects a specific deranged energy flow. In addition, the therapy should not merely be based on the disease the "patient" has, but also on the patient that has the disease. Finally, there is no reason that the 'Yin Yang' principle of Chinese philosophy, that also forms the basis of Traditional Chinese Medicine, does not apply to the effect flavonoids have on our health. The dual nature of therapeutic compounds was also acknowledged in the West some 500 years ago by Paracelsus who stated: "A very good thing worth to be acquired, first has to be separated from the bad. The art is such that nothing good can be acquired without a price. To get what you want, you must face also that you do not want." Actually, the dual nature of antioxidants is already clearly evidenced by various reports on the adverse effects and even toxicity of antioxidants[7].

In this review flavonoids are seen though different perspectives.

\section{Flavonoids seen through the current Western concept of drug action}

The current concept of drug action, developed in the last century in our Western society, has been very successful in the development of drugs. In the Western perspective, three phases have been identified between administration of the drug and the final physiological effect. These are (i) the pharmaceutical phase (ii) the pharmacokinetic phase, and (iii) the pharmacodynamic phase (Fig. 2)[8].

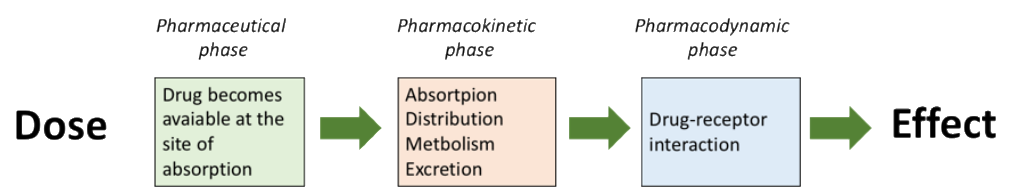

Fig 2. The three phases between the administration of a bioactive compound (drug) and the physiological effect of the bioactive compound.

\subsection{The pharmaceutical phase}

The pharmaceutical phase describes the process in which the drug becomes available from its dosage form for absorption. In e.g. retard release pills, the drug is slowly released in the intestine and becomes gradually available for absorption. This is used to prolong the physiological effect of drugs with a relatively short half-life. The equivalent in nutrition is the bio-accessibility of a compound. Food processing can affect this. For example, enzymatic processing of wheat can drastically increase the bio-accessibility of ferulic acid and the potential impact of wheat on health[9].

\subsection{The pharmacokinetic phase}

The pharmacokinetic phase describes what the body does to drug. The processes involved are summarized in the acronym ADME, that stands for Absorption, Distribution, Metabolism and Excretion. Due to metabolism, the chemical structure of the compound changes, and therefore also its physico-chemical properties as well as its biochemical profile. After absorption, compounds are often metabolized in the liver into relatively much more 
hydrophilic metabolites. These hydrophilic metabolites are subsequently more readily excreted by the kidney than the absorbed compound. In this way liver and kidney cooperate. The liver makes an exogenous compound hydrophilic, and the hydrophilic metabolite is readily exerted in the urine. This is how the body strives for a 'homeostatic' inner environment.

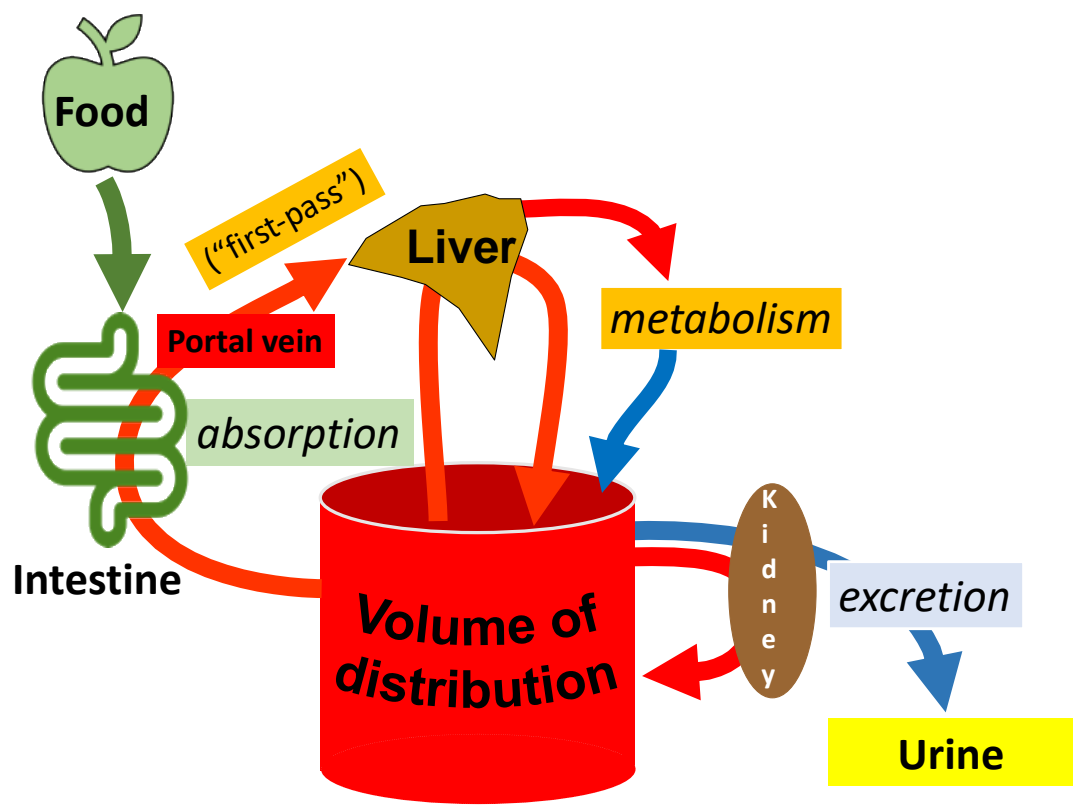

Fig 3. The general pathway of bioactive compounds in the body during the pharmacokinetic phase, illustrating the ADME principle. After consumption of food, the bioactive compounds that are absorbed in the intestine are transported in the portal vein and directed to the liver. During this 'first passage' though the liver, part the absorbed compounds are metabolized before they enter the central circulation and are distributed over the whole body. About one fifth of the blood flow of the central circulation goes through the liver. This is how the bioactive compounds that have escaped the 'first pass' effect, and are distributed over the whole body, are ultimately also metabolized. Due to metabolism, the absorbed compounds are converted in hydrophilic metabolites, that are readily excreted by the kidney in the urine.

For oral administered compounds, the bioavailability, i.e. the relative amount of a compound that reaches the central circulation, is important. The bioavailability can be low because (i) the compound is not absorbed, e.g. because it is too polar to diffuse over the lipid bilayer membrane of the epithelial cells in the intestine (ii) the compound is degraded in the GI trat e.g. due to the acid environment in the stomach, and (iii) the compound has a high first pass effect (Fig 3). The first pass effect is thought to protect us against toxic compounds present in our food, as in their 'first passage' through the liver these toxins are already metabolized, which often leads to detoxification. By filtering portal blood by metabolizing absorbed compounds before they reach the central circulation, the first pass effect contributes to the homeostasis of our inner environment. 


\subsubsection{Absorption}

In our food, flavonoids are often coupled by an O-glycosidic bond to sugar molecules. Due to the sugar moiety, these flavonoid-glycosides are relatively hydrophilic which limits their passive diffusion over lipid membranes. This affects their absorption in the intestine and thus their bioavailability. It has been reported that quercetin bound with one glucose molecule, such as in quercetin 3-glucoside and quercetin 4'-glucoside, can be absorbed in epithelial cells of the small intestine by the help of transporters that actively transport the hydrophilic compounds over the lipid membrane. In these cells the quercetin-glucosides are split into glucose and the quercetin-aglycone. Flavonoids-glycosides may also be deglycosylated by hydrolases located at the intestinal brush border membrane, followed by absorption of the flavonoid aglycon[10-12]. Quercetin-monoglycosides with a sugar other than glucose or flavonoid-disaccharides or flavonoid-oligosaccharides often pass the small intestine and reach the large intestine. There the sugars are split of by enterobacteria and the liberated quercetin-aglycone can be absorbed. Flavonoids, that escape these routes, are converted in the large intestine by bacteria into small phenolic compounds.

\subsubsection{Metabolism}

Most of the flavonoid aglycons taken up are extensively metabolized by glucuronidation, methylation of sulphation and do not reach the central circulation. The awareness that glucuronidated, methylated, sulphated and other metabolites greatly contribute to the beneficial health effect of flavonoids is growing.

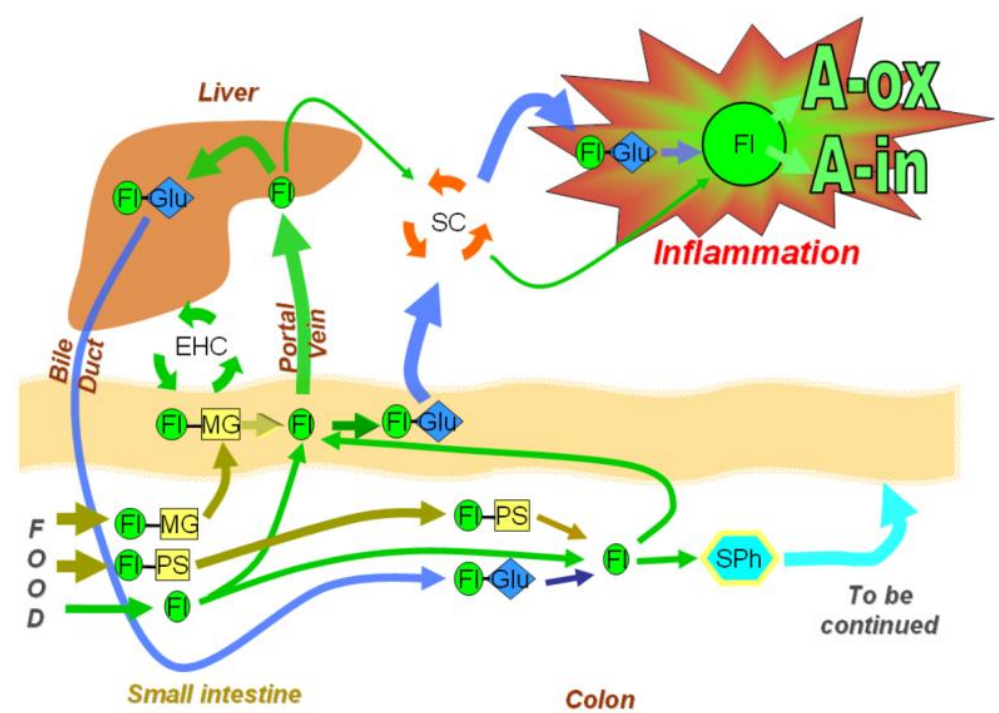

Fig 4. Schematic representation of the human metabolism of flavonols with emphasis on glucuronidation. The arrows show the potential route for flavonol circulation. Fl=flavonol, Fl-MG=monoglucosides, FLPS=polysaccharides, Fl- Glu=glucuronides, SPh=small phenolics, SC=systemic circulation, EHC=enterohepatic circulation, A-Ox=anti-oxidation, A-In=anti-inflammation. Figure are taken from the Chapter 1 of the PhD thesis of Mohamed Moalin[13]. 


\subsubsection{Glucuronidation}

Glucuronide conjugation (Fig.4) is the major conjugation reaction involved in flavonoid metabolism[14-18]. Even though the liver has the greatest capacity for glucuronidation[19, 20] most evidence points toward the intestine as the principal site for flavonoid glucuronidation in humans after dietary consumption[17, 21, 22]. Glucuronides formed in the intestine tend to enter the systemic circulation (Fig. 4). In contrast, glucuronides formed in the liver are predominantly excreted into the bile and go back to the intestine. In the intestine, the glucuronidase activity of bacteria can remove the glucuronide, and the freed flavonoid aglycon can be reabsorbed again, followed by re-glucuronidation in the liver. This is known as entero-hepatic circulation (EHC). The flavonoid seems to be trapped in the EHC[23]. However, the aglycons formed in the intestine can be glucuronidated in the intestinal cells, which takes the flavonoid out of the EHC and directs the flavonoidglucuronide to the systemic circulation[24]. The EHC prolongs the half-life of flavonoids and probably contributes to presence of relatively low levels of flavonoid glucuronides in the blood long after the consumption of the flavonoid containing food[24].

In general, flavonoid glucuronides are worse redox modulators compared to their aglycones. So glucuronidation reduces the direct physiological activity of the flavonoid. Moreover, glucuronidation drastically increases the water solubility of the flavonoid. Therefore, glucuronides are in general effectively excreted by the kidney, which results in a relatively short half-life. Interestingly, inflammatory cells such as neutrophiles possess substantial $\beta$-glucuronidase activity, that can split flavonoid glucuronides and liberate the flavonoid aglycon at the inflammatory site[25]. This would mean that the relatively more potent aglycone is released locally from the flavonoid glucuronide at the site of inflammation where the neutrophils are attracted to. This is important because there the flavonoid has to display its redox modulating activity. Because the aglycon is much more lipophilic that the aglycon, the aglycon is also not readily removed by the blood flow from the site of inflammation where it is formed. Due to this 'bioactivation' and 'targetting' the flavonoid is specifically directed to the site of action. Therefore, relatively low levels of flavonoid glucuronides in the blood might still have a significant modulating effect. 


\subsubsection{Methylation}

O-Methylation is the second most significant conjugation reaction of flavonoids aglycons[16, 26].

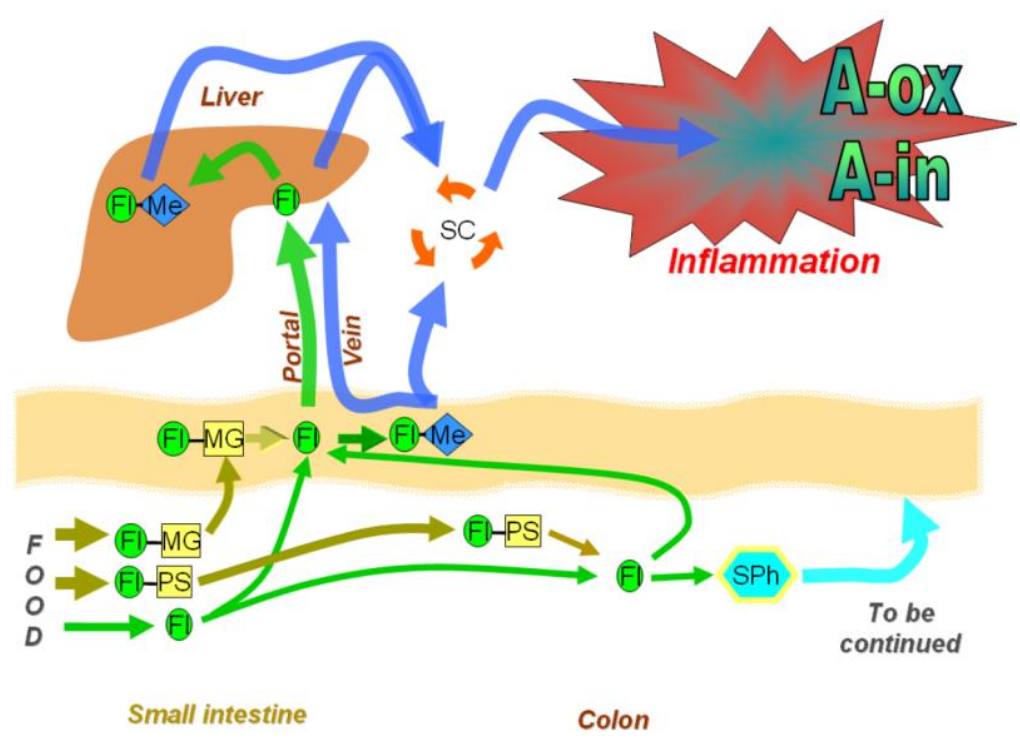

Fig 5. Schematic representation of the human metabolism of flavonol with emphasis on methylation. The arrows show the potential route for flavonol circulation. Fl=flavonol, Fl-MG=monoglucosides, FL-PS=polysaccharides, Fl$\mathrm{Glu}=$ glucuronides, $\mathrm{SPh}=$ small phenolics, $\mathrm{SC}=$ systemic circulation, $\mathrm{EHC}=$ enterohepatic circulation, A-Ox=antioxidation, A-In=anti-inflammation. Figure are taken from the Chapter 1 of the PhD thesis of Mohamed Moalin[13].

Methylation predominantly occurs the liver, but also the intestine has a substantial methylation capacity [27](Fig 5). Of quercetin, the hydroxyl groups in the B-ring are the main ones methylated[28].

Unlike glucuronidation and sulfation, methylation makes the aglycone more lipophilic which increases the uptake in cell. The increased lipophilicity is also expected to increase the volume of distribution. Moreover, methylation of the hydroxyl group prevents glucuronidation and sulphation at this site, which increases the 'metabolic stability' of the aglycones. The increased volume of distribution and metabolic stability will extend the halflife. Methylation of one hydroxyl group can already have a drastic impact on the redox modulating profile of a flavonoid[29]. In general, the capacity as well as the rate at which a methylated flavonoid scavenges reactive species are less compared to that of the corresponding 'free' un-methylated flavonoid. Moreover, methylation makes that the energy captured in the methylated flavonoid is relatively more 'hard'. 


\subsubsection{Sulfation}

Sulfation of flavonoids predominates at a relatively low dose (indicative for a low $\mathrm{K}_{\mathrm{m}}$ value), and it has a relatively low capacity[30] (indicative for a low $V_{\max }$ value). Sulfotransferases are cytosolic enzymes widely distributed throughout the body[24]. There is evidence that sulfation occurs in the enterocyte before reaching the systemic circulation[24]. Not much is known on the impact of flavonoid-sulphates on health.

\subsubsection{Small phenolics}

After circumventing the routes described above, flavonoids can reach the colon (Fig 6). As described above, the indigenous microflora in the colon is able to cleave the glycoside bond from flavonoid glycosides, and the free aglycone can be absorbed [31-33]. Additionally, the colonic bacteria can also extensively metabolize flavonoids producing a wide range of small phenolic, which then can be absorbed[34-37]. In the liver they undergo secondary metabolism[38]. In addition, the lymphatic system can also contribute to the transport of flavonoid metabolites around the body[39]. The small phenolic compounds are expected contribute to the physiological effect of flavonoids, but their exact impact is enigmatic.

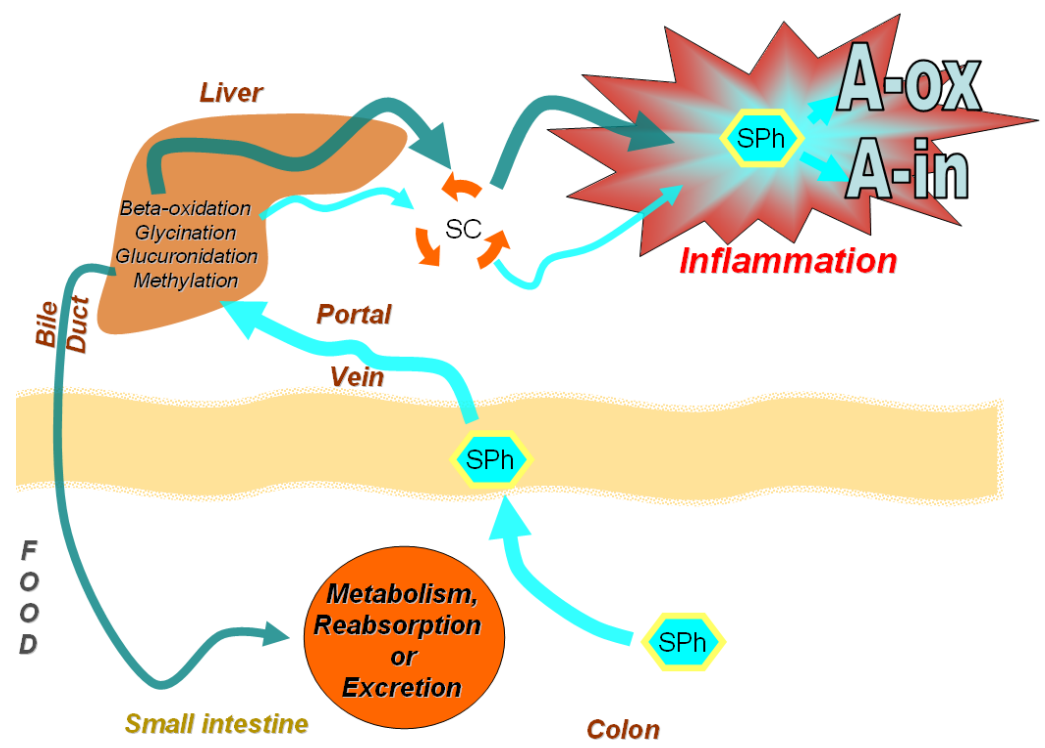

Fig 6. The circulation and possible metabolism of the small phenolics. $\mathrm{SPh}=\mathrm{small}$ phenolics, $\mathrm{SC}=$ systemic circulation, A-Ox=anti-oxidation, A- In=anti-inflammation. Figure are taken from the Chapter 1 of the $\mathrm{PhD}$ thesis of Mohamed Moalin[13].

\subsubsection{Strategies to improve the bioavailability}

A simple way to effectively direct a bioactive flavonoid to its site of action is to locally administer the compound, e.g. in wound dressings. In this way not only the first pass effect is circumvented, also systemic toxicity is prevented, and the therapy is expected to be more effective. Newly developed wound dressings contain a mixture of anti-inflammatory and antibacterial agents (e.g. flavonoids), growth factors, immune factors, moisture in a multi- 
layer. The main complications are the large variation in exudates, bacterial infection, moisture, and the unpredictable microenvironment. Most of the advanced dressings are still under development, and their performance in clinical practice still needs to be tested[40].

\subsection{The pharmacodynamics phase}

The last phase is the pharmacodynamic phase. This phase describes what the bioactive compound does to the body; and finally gives the physiological effect of the drug that has gone through the three phases. Usually, this is the interaction of the drug with a large biomolecule, such as a receptor or enzyme. The paradigm coined by Paul Ehrlich is "corpora non agit nisi fixata" the drug has to bind to its biotarget to give its effect. For the bioactivity of compounds, he envisioned that "only such substances can be anchored at a particular part of an organism, as fit into molecules of the recipient complex like a piece of mosaic finds its place in a pattern".

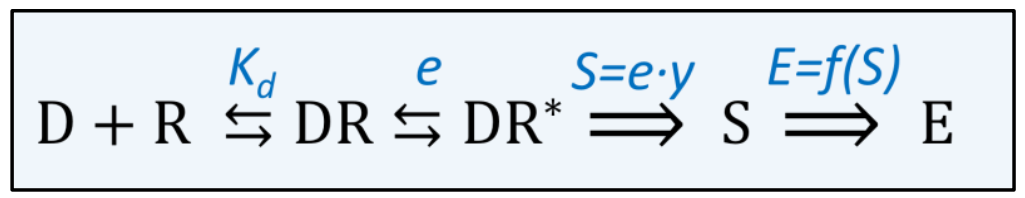

Fig 7. Scheme of the processes in the pharmacodynamic phase of a drug. The drug (D) binds to its receptor (R) and forms a drug-receptor complex (DR). The affinity of the drug for the receptor is described by the dissociation constant $\left(\mathrm{K}_{\mathrm{d}}\right)$. After binding to the receptor, the receptor can be activated $\left(\mathrm{R}^{*}\right)$. The potency of a drug to activate the receptor is described by the efficacy (e) of the drug. The activated drug-receptor complex generates a stimulus (S) which is proportional to the efficacy of the drug multiplied by the number of receptors occupied (y). The stimulus generates an effect $(E)$, which is described by a stimulus effect relationship $(E=f(S))$ that depends on the organ and the type of receptor.

The interaction of a drug with its receptor are subsequently (i) binding of the drug to the receptor, (ii) activation of the receptor that (iii) triggers a signal cascade of reactions that lead to the actual effect (Fig. 7). The binding of a drug to the receptor is governed by the Law of Mass Action[41]. This law dictates that the rate at which the drug binds to a specific receptor (the rate of association) is dependent on the concentration of drug. With a specific concentration of the drug an equilibrium is reached in time, namely when the rate of association and the rate of dissociation of the drug-receptor complex are equal. The equilibrium is usually described by $\mathrm{K}_{\mathrm{d}}$, the apparent dissociation constant of a drug for a receptor. At a drug concentration equal to the $\mathrm{K}_{\mathrm{d}}, 50 \%$ of the receptors are bound by the drug. Or, perhaps more accurately, during a specific time span, each receptor is then bound to the drug during, on average, half of this time span.

Binding of the drug to the receptor might activate the receptor. According to the theory of Stephenson, receptor activation produces a certain input stimulus (S). The magnitude of the input stimulus induced by a certain drug-receptor complex depends on the drug used. Antagonists - in contrast to agonists - do not activate the receptor and consequently do not induce a stimulus when they bind to the receptor. Moreover, the input stimulus generated by binding of a full agonist is greater compared to that of a partial agonist. Stephenson used the term "efficacy" to express the extent of receptor activation by binding of a certain drug to a particular receptor. In the concept of Stephenson, it is assumed that the contribution of a 
certain receptor-drug complex does not depend on the activation of other receptors. This means that the input stimulus that is produced depends on the efficacy of the drug and the number of receptors occupied[42].

Finally, the Stimulus generated by binding of an agonist to the receptor has to be translated into a physiological response. Often this is a cascade of biochemical reaction. In each reaction the input signal is amplified, so that a relatively small number of receptors is able to generate a physiological relevant effect. In principle it might possible to determine how the input signal is amplified in each reaction of the signal transduction cascade.

When these functions are combined, it is known how the stimulus is transformed into an effect. However, this approach is too complicated to be practically applicable. Stephenson tackled this by describing the stimulus-effect transfer as a whole. For a specific receptor in a specific tissue, the stimulus is transferred by an unknow function (f) into an effect (E), in formula:

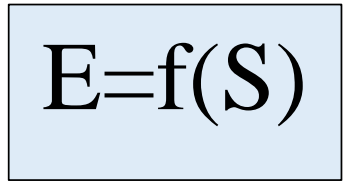

Each drug that acts on a specific receptor in a specific organ makes use of the same stimulus-effect function. A high concentration of a certain type receptor in a tissue, as well as an efficient stimulus-effect transduction of this receptor in a specific organ can direct the effect of a drug that has a high affinity and efficacy for this receptor to this organ[43].

For radical scavenging, redox modulating compounds, the paradigm described above does not fit. To start with, redox modulators they do not bind to the energy, they 'absorb' the energy. Therefore, the paradigm "corpora non agit nisi fixate" does not seem to fit. Their activity is often expressed by the rate at which antioxidants react with reactive species. In principle, this reaction rate is also governed by the Law of Mass Action, but in contrast to the dissociation constant, this is not an equilibrium constant. Another parameter describing the activity of free radical scavenging compounds is the capacity, i.e. the number of reactive species that the compound can scavenge. The equivalent for the efficacy is the way an antioxidant modulates the energy. The way this modulated energy is transformed into an effect involves a complex cascade of biochemical reactions. This looks like the way a drugreceptor complex produces an effect. Therefore, modeling the transformation of redox modulation by antioxidants into a physiological effect probably asks for a similar pragmatic solution as the stimulus-effect function introduced by Stephenson for drugs. It should be noted that the simple the elegant stimulus-effect concept of Stephenson had to be adjusted over the years to incorporate phenomena such as receptor dimerization, receptor desensitization and cross talk between receptor systems. Interestingly, redox modulation also affects receptor function and signal transduction[44], and flavonoids can protect against the effect of oxidative stress on the anti-inflammatory respons of glucocorticoids[45]. The necessity to make 'adjustments' to incorporate 'abnormalities' is a fundamental characteristic of all paradigms. The strategy to 'learn' from our knowledge of the mode of action of drug 
to try to better understand the mode of action of redox modulators appears fruitful, however, our gut feeling indicates that to ultimately come to a 'General Unifying Theory' is probably a utopia.

In the next paragraph, the pharmacodynamics of flavonoids is reviewed by looking through the radical perspective.

\section{Flavonoids seen through the radical perspective}

The best way to reduce oxidative damage is to prevent radical formation by staying healthy and to behave sensible by refraining from 'bad' things such as smoking and drinking too much alcohol. Since we cannot stop breathing, we cannot completely prevent oxidative damage and, in the end, oxidative stress related diseases and death are inevitable. The only opportunity we have is that we might postpone the inevitable by tuning up the endogenous protection by redox modulators such as flavonoids.

\subsection{The molecular mechanism of the endogenous protection}

The endogenous protection is made up of enzymes and endogenous scavenging antioxidants, such as vitamin E, vitamin $\mathrm{C}$ and glutathione (GSH). The most important antioxidant enzymes are Superoxide dismutase (SOD), catalase (CAT) and glutathione peroxidase (GPX). The molecular mechanisms of these enzymes have been extensively studied. SOD and CAT catalyze an auto redox reaction of the reactive oxygen species. With SOD, one superoxide anion donates an electron to the enzyme and is converted into oxygen. A second superoxide anion accepts the electron from the reduced SOD and is converted into hydrogen peroxide. With CAT, hydrogen peroxide is converted into water and oxygen. An advantage of these enzymes is that they do not need a reductive cofactor, and therefore they have an unlimited capacity to degrade oxidative species.

GPX uses the reductive power of glutathione (GSH) that is oxidized to glutathione disulfide (GSSG), to reduce hydrogen peroxide into water, or a lipid hydroperoxide into the corresponding alcohol. The concentration of GSH in cells is relatively high and can mount to concentrations up to $10 \mathrm{mM}$ or even higher. The concentration of GSH is kept high by GSH-reductase that catalyzes the reduction of GSSG into GSH at the expense of NADPH. The ability to maintain the GSH concentration at a high level, indicates that GPX also has a high capacity.

In the antioxidant enzymes mentioned above, Cupper, Iron and Selenium are key in their catalytic site. These atoms shuttle between an oxidized form and a reduced form. For example, the Cupper in SOD shuttles between $\mathrm{Cu}^{2+}$ and $\mathrm{Cu}^{+}$, and this is how the electrons are accepted and donated to the oxidative species. One of the ways advocated to boots this enzymatic defense is to use supplements e.g. of Selenium to increase Selenium-dependent GPX activity. Inorganic forms of Selenium may increase plasma GPX activity more effectively than organic forms. However, currently, there is no evidence of long-term health benefits of Selenium-enriched foods In supplementing Selenium, also its toxicity should be taken into account as its 'therapeutic window' (i.e. the difference between the minimal effective dose and the toxic dose) is relatively small[46]. Oral administration of e.g. SOD, which is still advertised in some media, is of course not sensible, because after oral administration the 
enzyme will be readily digested in the GI tract. Therefore, the enzyme is not bioavailable, and its oral administration will be without a physiological effect.

Endogenous radical scavenging antioxidants reduce oxidizing species, and in this way neutralize them. In this reaction the antioxidant is consumed as it is oxidized. This means that the capacity of these radical scavenging antioxidants is limited. For example, the antioxidant capacity of vitamin $\mathrm{E}$ found in most capacity assays is that one vitamin E molecule can only scavenge two radicals. Luckily, these radical scavenging antioxidants do not act in isolation, together they form an intricate network in which the energy of the oxidizing species is captured and transferred form one compound to another. For example, in the antioxidant network oxidized vitamin $\mathrm{E}$ can be reduced by vitamin $\mathrm{C}$, to form again the reduced, active Vitamin E. In this reaction Vitamin $\mathrm{C}$ is converted into dehydroascorbate. On its turn, dehydroasorbate can be reduced to vitamin $\mathrm{C}$ by $\mathrm{NADH}$, a reductant formed during the oxidation of nutrients. So, the energy of the reactive oxygen species is picked up and safely shuttled through the antioxidant network to be ultimately neutralized in the metabolic network. This interplay between compounds in these networks means that also the capacity of radical scavengers to absorb energy can be virtually unlimited.

\subsection{The molecular mechanism of flavonoids}

Exogenous antioxidants may be used to protect against increased radical production during challenges and to prevent that too much radicals escape the endogenous protection and inflict excessive damage. The molecular mechanisms of flavonoid antioxidants are described in the next paragraphs. It covers a broad spectrum, from reduction of radical formation to empowering the endogenous protection.

\subsubsection{Reduction of radical formation}

Exogenous compounds can prevent oxidative damage by the inhibition of radical generating enzymes. An example is the inhibition of the superoxide generating enzyme xanthine oxidase by flavonoids[47]. Also, chelation of iron should be considered, as iron is involved in formation of the most reactive ROS, the hydroxyl radical, in the Fenton reaction. The chelation of iron by the flavonoid monoHER greatly reduces the ability of iron to generate the hydroxyl radical. It has been speculated that this also involves 'site specific radical scavenging'. Because the hydroxyl radical is formed on the iron atom, and the flavonoid is bound to the iron, the flavonoid is at the site where the highly reactive hydroxyl radical is formed. Their close proximity makes that the iron-chelating flavonoid can 'sitespecifically' scavenge the hydroxyl radical at exceptionally high rates that seem to exceed the diffusion rate constant[48].

\subsubsection{Free radical scavenging}

In scavenging a free radical, a flavonoid neutralizes the energy of the radical. The flavonoid does so by donating an electron, with or without simultaneously donating a proton, to the radical. The three well-established mechanisms proposed for this are: (i) Hydrogen atom transfer (HAT), (ii) single electron transfer followed by proton transfer (SET-PT), and (iii) sequential proton loss electron transfer (SPLET). Also other mechanisms have been proposed, such as proton coupled electron transfer (PCET) $[49,50]$, sequential proton loss 
hydrogen atom transfer (SPLHAT)[51]. The actual mechanism for and efficiency of the scavenging reaction of a specific flavonoid is not only governed by its chemical characteristics, it is also dependent on its environment. For example, dissolved in water at a low $\mathrm{pH}$, quercetin hardly displays antioxidant activity, while quercetin dissolved in water at a neutral or higher $\mathrm{pH}$, is a strong antioxidant. This suggests that fully protonated quercetin and partially deprotonated quercetin have a different antioxidant profile, probably also with a different mechanism. Moreover, several conformations of the quercetin molecule exist, and each conformer has its unique redox modulating profile. These differences can be predicted and 'understood' using quantum calculations.

It should be note that the by radial scavenging the flavonoids is oxidized and takes over part of the energy of the reactive species that has been scavenged. It is hypothesized that this is how flavonoids can selectively direct the energy to redox controlled master switches, as further elaborated in paragraph 3.2.6.

\subsubsection{Interaction with the endogenous antioxidant network}

In scavenging a free radical, a flavonoid neutralizes the energy of the radical by taking over the energy of the radial. As illustrated above in the paragraph on the endogenous antioxidant network, antioxidants do not act in isolation. In the intricate network they form, the energy that is captured is safely transferred form one compound to another, and finally the energy is neutralized. Flavonoids interact with the endogenous network as e.g. oxidized quercetin quickly reacts with vitamin $\mathrm{C}$ to regenerate quercetin. As flavonoids are very efficient scavengers, they are expected to be the first scavengers to capture the energy of reactive oxygen species. By their efficient scavenging, flavonoids will protect by directing more energy to the endogenous antioxidant network.

Antioxidants might also strengthen the endogenous network by facilitating the energy transfer, as has been suggested for hydroxytyrosol, the most potent antioxidant found in olive oil. There is clinical evidence for a protective effect against oxidative damage of LDL particles by olive oil consumption[52]. This has been linked to the antioxidant activity and physico-chemical properties of hydroxytyrosol. Due to its amphiphilic nature, hydroxytyrosol will be positioned in the lipid-water interphase of the LDL particle and it is hypothesized that this will facilitate the energy transfer form vitamin E, located in the lipid environment of the LDL particle, to vitamin C, located in the water phase[53] (Fig 8). 


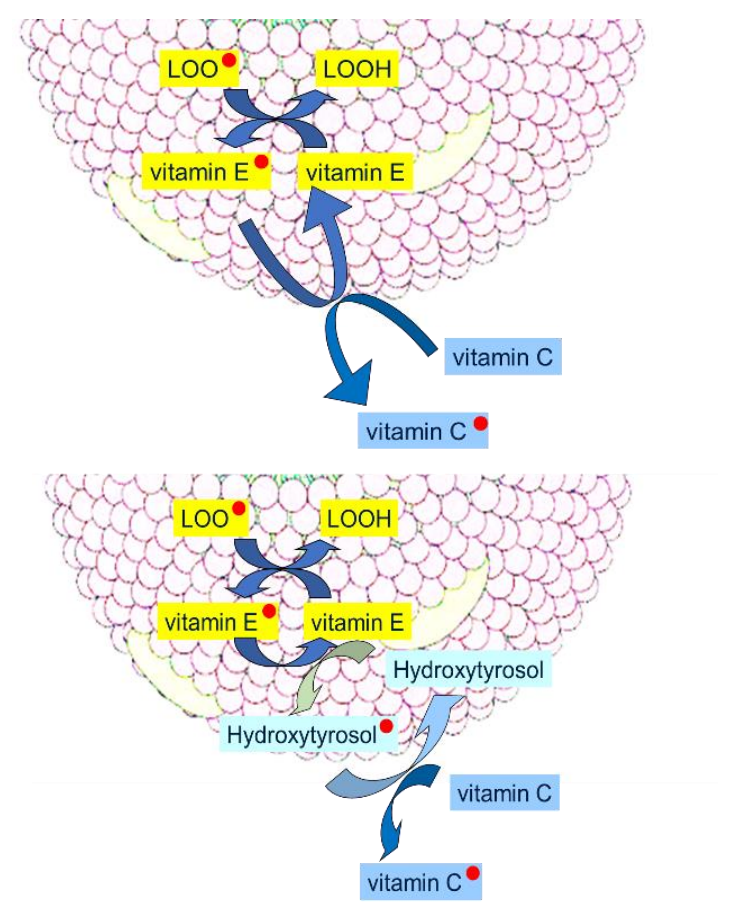

Fig 8. Protection against LDL oxidation by the interplay of endogenous antioxidants vitamin $\mathrm{E}$ and vitamin $\mathrm{C}$ and the reinforcement of this protection by hydroxytyrosol. The lipophilic vitamin E efficiently scavenges lipid peroxyl radicals in the LDL particle, and the energy (visualized by the red dot, representing the unpaired electron) is transferred to hydrophilic vitamin $\mathrm{C}$ in the plasma. Hydroxytyrosol can facilitate the energy transfer between both compounds because of its positioning in the lipid-water interphase[53].

\subsubsection{Interaction between exogenous antioxidants}

When you administer a single antioxidant, the effect will not only be due to the parent compound. This is because the antioxidant will be metabolized, and the metabolites formed can greatly contribute to the physiological activity of the antioxidant. The importance of this dynamic interaction between parent compound and metabolites was illustrated above in discussion on the pharmacokinetic phase of the flavonoids.

Moreover, often herbs are used that contain a mix of antioxidants. Undoubtedly, these antioxidants will have all sorts of interactions with each other, as well as with the antioxidants of the endogenous antioxidant network. The interactions will increase exponentially with the number of compounds, and it is undoable to examine all interactions with the traditional, reductionistic research strategy of looking at each interaction separately. Also, omics approaches seem to fall short. More pragmatic, wholistic approaches are warranted, similar to the stimulus-effect relationship that Stepheson coined for drugs. Although we are not able to clearly understand these interactions, tentatively, we know that they have a huge impact. 


\subsubsection{Repair}

Damaged proteins are usually mopped up and dismantled in separate amino acids, that are recycled to rebuild new proteins. This seems very inefficient from an energy perspective. The metaphor used is that this is like 'fixing' a relative minor damage to a car by totally taking the car apart and then rebuild a new car from scratch using the parts of the damaged car. The alternative would be that there is a repair mechanism for each possible form of oxidative damage to any protein, which is probably also inefficient. Therefore, the cell only has repair mechanism that deal with the most occurring damage, e.g. repair of the easily oxidized methionine residues by protein methionine sulfoxide reductase, which can use the antioxidant dihydrolipoic acid as cofactor[54]. The advantage of the general 'repair' by recycling the individual amino acids is that it can be applied for all proteins and all types of damage, and a high turnover of proteins increases the flexibility of the cell to adapt.

Compared to the protein repair, the DNA repair machinery of the cell is much more elaborate. This is probably because the information stored in the DNA needs to be preserved. It has been reported that flavonoids may stimulate DNA repair, and that flavonoids can prevent DNA oxidation by scavenging the reactive species damage the DNA, or by reacting with reactive DNA intermediates to interrupt the DNA oxidation process. There is no example known of direct repair of oxidized DNA using the reductive power of flavonoids.

The processes involved in the DNA repair, e.g. by the Poly (ADP-ribose) polymerases (PARP), are however very energy consuming. In chronic diseases that induce to a lingering PARP-1 (over)activation, the drastically increasing NAD+ turnover results in an increased demand on ATP production for re-synthesis of NAD+. This can provoke an energy crisis in the cells affected. In has been suggested that partial inhibition of PARP-1 by dietary flavonoids can mitigate this energy crisis[55]. It should be noted that it has been reported that flavonoids may form adducts with DNA. In addition, teratogenic effects of flavonoids have been reported[56-59].

\subsubsection{Empowering the endogenous adaptation}

As described above, cells contain an antioxidant network that forms a defense system that protects them by absorbing most of the deranged energy flow. When the flow of deranged energy increases, the cell will not only be damaged; the cells also adapt. The hard energy also turns on a protective sensor, KEAP1, by reacting with the thiol group on the sensor. This will activate the Nuclear factor erythroid 2-related factor (Nrf2) pathway, and the cell will make more antioxidants which increases its resilience to the hard energy[60, 61](Fig 9).

By scavenging the radicals, flavonoids take over the hard energy of the reactive oxidizing species and convert it into soft energy. Because the hard energy taken up by the flavonoids flows through the redox modulator, the hard energy becomes "soft". Because the soft energy cannot damage the cell, the cell is protected against a deranged energy flow. Moreover, the soft energy can very efficiently turn on the protection sensor, KEAP1, to finally make more antioxidants[62, 63]. With flavonoids, the cell more efficiently adapts to a deranged energy flow by turning on the protection KEAP1 switch without being damaged. In this way, flavonoids can empower the endogenous defense when it is needed and where it is needed. 
During cancer therapy, the high energy produced by radiation is aimed to kill tumor cells by turning on a suicide switch of the tumor cell, e.g. GAPDH[64, 65]. Because flavonoids will also soften the energy produced by radiation, it is expected that flavonoids will turn on the protection switch in tumor cells, and also prevent that the emergency switch is turned on by radiation. Therefore, it is advised not to take flavonoids during cancer therapy. However, in tumor cells even without radiation, the energy flow is already greatly outbalanced. This has already turned on the protection KEAP1 switch. It is one of the reasons that tumor cells are more resistant than healthy cells to chemotherapy and radiotherapy[66]. Moreover, it also implies that the redox modulating effect of flavonoids will be different in tumor cells compared to healthy cells. Interestingly, some findings point out that flavonoids can actually improve cancer therapy.

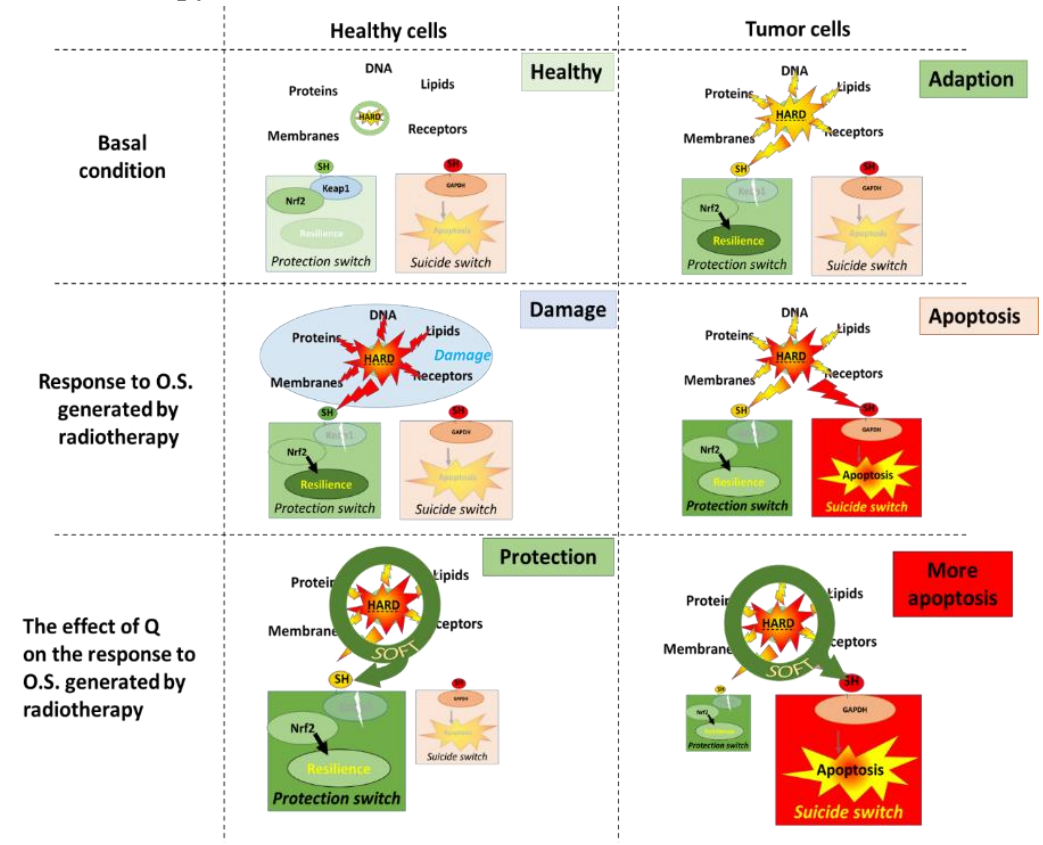

Fig 9. The molecular mechanism that underlies our hypothesis on the difference in the effect of $Q$ on healthy cells and tumor cells. In basal condition, there is a redox equilibrium between oxidative stress and antioxidant protection. Radiotherapy will damage healthy cells although the cells will adapt by turning on the protection KEAP1 switch. In healthy cells, Q will prevent the damage and increase the protective response which will increase the resilience of these cells. In tumor cells, the adaptive switch is already turned on in basal condition. This reduces the efficacy of antitumor therapies which are aimed to induce apoptosis. In tumor cells, Q increases the efficacy of antitumor therapies by turning on the emergency GAPDH suicide switch that induces apoptosis.

In contrast to healthy cells where energy is primarily generated by mitochondria, tumor cells primary depend on glycolysis for their energy generation, and GAPDH is a pivotal enzyme in this energy generation[63, 67, 68]. We hypothesize that by focusing the hard energy to GAPDH flavonoids (i) turn on the emergency GAPDH suicide switch and (ii) block the major route for the energy supply. Both effects are specific for tumor cells and will strengthen instead of weakening the antitumor therapy. As outlined above, flavonoids will increase the protection of healthy cells by turning on the protection KEAP1 switch. This will 
mitigate the deleterious side effects of antitumor therapy on healthy tissue. At the moment we are putting this hypothesis to the test.

\subsubsection{Other activities of flavonoids}

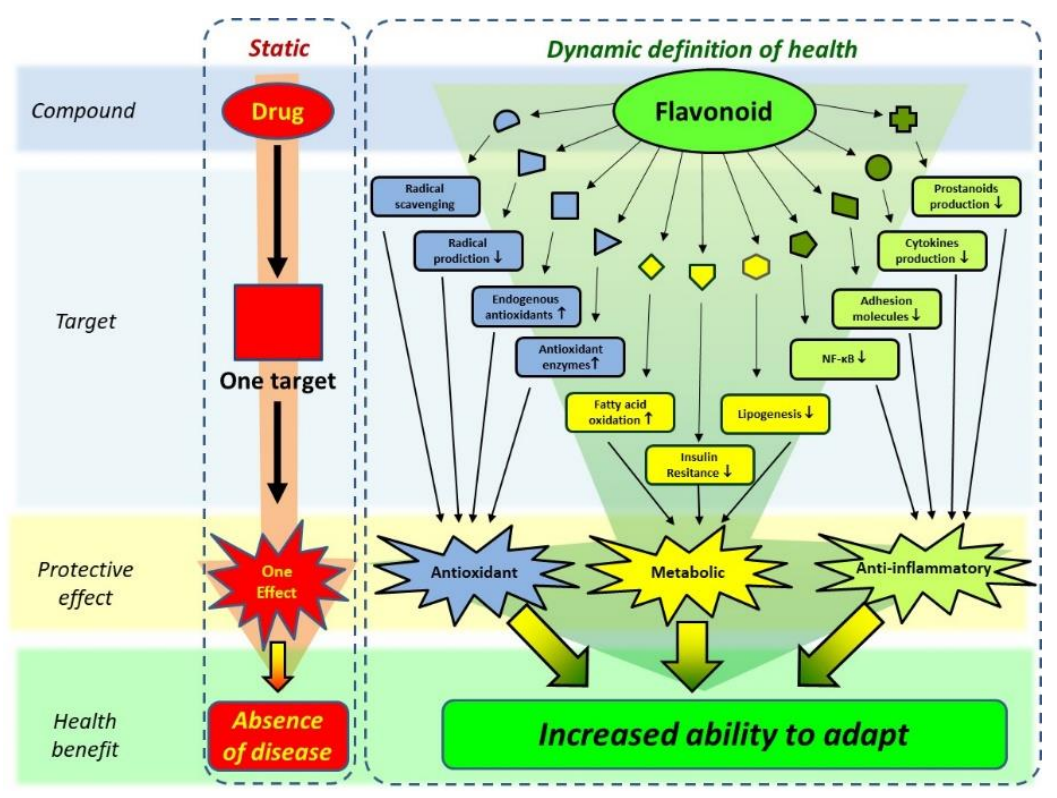

Fig 10. The "traditional" concept of the action of a drug versus the contemporary concept of action of bioactives such as flavonoids. While traditional drugs are developed to act on a single target, aimed to cure or prevent a disease, flavonoids are thought to act on multiple targets, affecting diverse pathological processes, as well as increasing the ability to adapt. The latter seamlessly fits in the new concept of health, which also includes this dynamic aspect. Adapted from Van de Wier et al[69]

As depicted in figure 10, a myriad of activities of flavonoids have been discovered. It has been speculated that together these effects, although each effect might be relatively small, are responsible for the actual health effect. In in vitro experiments, flavonoids can inhibit any enzyme. This is due to the relatively large number of hydroxyl groups present on a flavonoid, that can form relatively strong hydrogen bounds with proteins. It has been reported that especially proline residues in proteins are involved in the binding (Haslam) [70, 71]. This ability to bind to proteins is also responsible for the astringent effect of flavonoids. The physiological relevance of the direct inhibition of enzymes found in the in vitro experiments is often doubtful, as relatively large concentrations of flavonoids are needed. Also, a great deal of the results found with flavonoids in cell culture experiments need to be critically evaluated because of the relatively high concentrations used. Up to date, no receptors for flavonoids have been found. So, it is likely that there is no specific direct effect of flavonoids. Nevertheless, an unspecific, minor inhibition of all enzymes and processes in the cell will slow down the energy spending of all cells and consequently reduce all cell functions, including the formation of reactive species. This nonspecific inhibitory 'hormetic' effect may explain the direct reductive effect flavonoids have on the production of reactive species by inflammatory cells, as well as the toxicity of flavonoids. 
The inhibition of NF-kB activation and most of the other 'specific' effects depicted in figure 10, can be explained by a redox-modulating effect of flavonoids and not by the binding or direct inhibition of a protein by the flavonoids. As described in the previous paragraph, this might be explained by selectively directing redox energy to redox controlled master switches. Interestingly, after administration, flavonoids seem to be retained for a relatively long time in a specific part of the body. This is indicative for some sort of specific binding. For example, after i.v. administration of the flavonoid monoHER to mice, some of the flavonoid seems to be retained in the nucleus of endothelial and muscle cells of the vascular wall, long after all of the flavonoid monoHER has been removed from the central circulation. In addition, monoHER in a relatively very low concentration $\left(\left(\mathrm{EC}_{50}=60 \mathrm{nM}\right)\right.$ is able to protect cells against what seems to be an excess of reactive oxygens species, namely $200 \mu \mathrm{M}$ $\mathrm{H}_{2} \mathrm{O}_{2}$. It has been speculated that is due to 3 characteristics of monoHER, namely location, location and location: (i) location on the molecular level; monoHER is at the right location for site specific radical scavenging at a rate that seems to outdo the diffusion rate constant, (ii) location at the supramolecular level; monoHER is located at a pivotal position in the antioxidant network, and (iii) location at the cellular level; monoHER is located in the endothelial and smooth muscle cells in the vascular wall[48]. More research is needed to examine this hypothesis. In this way the redox modulator monoHER seems to fit in the concept that "bioactive substances should be anchored at a particular part of an organism, as fit into molecules of the recipient complex like a piece of mosaic finds its place in a pattern". Looking through this perspective, the concept of Ehrlich seems also applicable for redox modulators.

\section{Flavonoids, future perspectives}

As already stated above, despite a long history of research on the health effect of the redox modulation of flavonoids, much has remained enigmatic. To progress, our research strategies have to evolve. Nowadays, still research is done in which single antioxidants (e.g. GSH) or, better, the ratio of the reduced and the oxidized antioxidants (e.g. the GSH/GSSG ratio) in the blood of patients and health volunteers is measured and compared. Although this is valuable, it only gives a narrow, static picture. To illustrate this, the metaphor of examining the effect of water in a house comes to mind, although we are aware that metaphors always give a distorted view. By measuring the GSH levels, you measure the volume of water in the piping system. The GSH/GSSG ratio gives you the water pressure in the piping system. Better is to look at how the taps (redox controlled master switches) are used to control to the dynamics of the flow of water through the waterpipes (the energy flow through the redox reactions of GSH/GSSG and other redox couples in the networks). It is even better is to decipher the mechanism by which water (energy) sustains the live of the people living in the house, and how it is used to water the plants to make life more beautiful.

The way to go is to invent new tools to examine redox modulators. The new perspectives this generates should be connected to the perspectives created using the old tools. To come closer to the solution, the different views should be combined to create a more complete picture (Fig 11). 


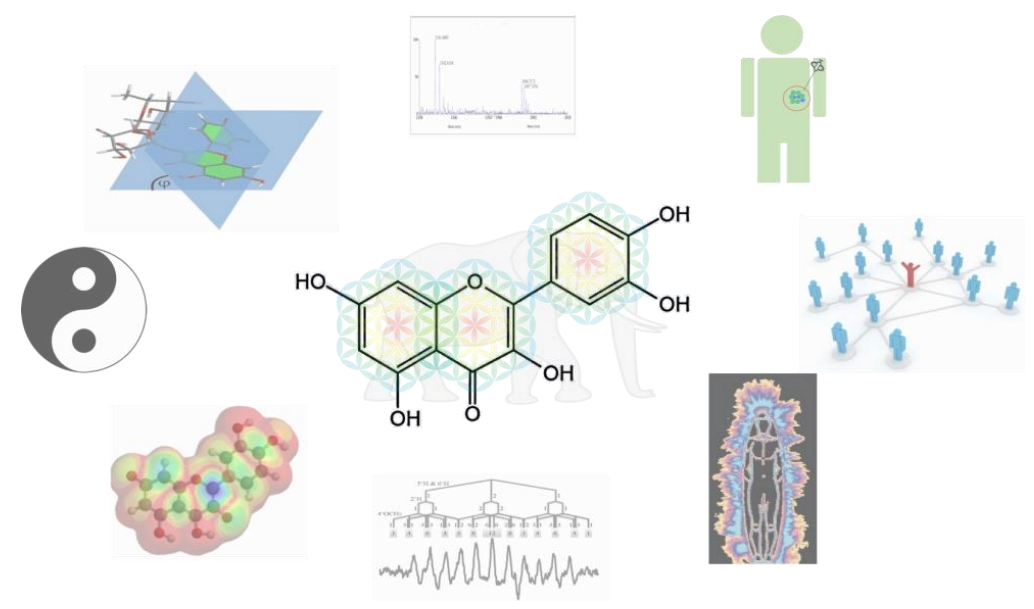

Fig 11. By combining the results obtained with different techniques and from different perspectives, a more complete picture on the redox modulating nature of flavonoids can be obtained. Like in the metaphor, you than see that it is not a tree, a wall, a snake or a rope; it is an elephant. And when you look even closer you notice it is alive and has feelings.

An important new tool is quantum chemical calculation that has evolved tremendously. This can be used to determine where the energy taken up by the radical scavenging is concealed in a flavonoid molecule. Moreover, it can give insight on how the energy flows though the molecule during this process. One of the major restrictions is that it is still not possible to accurately determine the impact of the solvent on the redox behavior of flavonoids.

\subsection{The structure-activity relationship}

An important strategy to elucidate the mode of action of redox modulators is to establish the relationship between the chemical structure and the effect. Back in 1869, Brown and Fraser[72] already stated "It is obvious that there must exist a relation between the chemical constitution and the physiological action of a substance" Intuitively they put this in a 'mathematical' equation:$$
\Phi=\mathrm{f}(\mathrm{C})
$$

In this equation $\Phi$, the physiological action of a compound, depends on the "chemical constitution of the compound (which we now would name the chemical properties of the compound) presented by ' $\mathrm{C}$ ', and the 'constitution' is converted into an physiological response by an unknown function f. Interestingly, both the vision and equation of Brown and Fraser are identical to the vision and equation of Stephenson. Moreover, both concur within the vision of Ehrlich that physiological active compounds have to fit within the molecules of the organism 'like a piece of mosaic finds its place in a pattern'. 
The structure activity relationship (SAR) has gained a pivotal role in studying the physiological activity of compounds. Linking the difference in activity to differences in the chemical structure of compounds gives clues for the interaction of the compounds with the biological system they are interacting with. The groups of both the compound and the biological target that are important for the activity can be identified, as well as the type of their interaction, and the consequence of this interaction to e.g. the change in conformation of the biotarget and the consequence of this. Ultimately, this may lead to the molecular mechanism of the activity of the compounds and an "understanding" of the activity of the compounds. Moreover, the SAR gives clues for the design of more active compounds than the ones tested. In addition, using the SAR it can predicted that blocking or removing a specific group will make a compound lose its activity. Synthesizing and testing this modified compound can be used to try to falsify and refine the SAR used.

In compounds that display the same activity via a similar molecular mechanism, in general a part of the molecule is identical in all these compounds. This is the 'pharmacophore'. The pharmacophore is essential for the physiological activity, and this is part of the biological active compounds that fits in the pattern of the mosaic of the organism. Differences in the activities of compounds can be related to the difference in effect that the various substituents have on this 'fit'. For redox modulators this includes steric, lipophilic and, especially, electronic effects of the substituent.

The use of SARs has been very successful for e.g. the development of drugs that act on a receptor, enzyme or other large biomolecules. As already outlined above, for radical scavenging, redox modulating compounds, the constructing of a SAR is more complex. This is because the 'biologically active compound' they react with is much more 'fluid' than e.g. the receptor of drugs. This is probably why most of the numerous SARs on redox modulation are descriptive, only stressing the importance of a particular double bound and the presence of substituents at specific places. Another complication is that there might be more than one 'pharmacophore' for redox modulation within one molecule, as proposed for quercetin (Fig 12). Moreover, these different pharmacophores probably affect each other, and together might form a new 'pharmacophore'. 


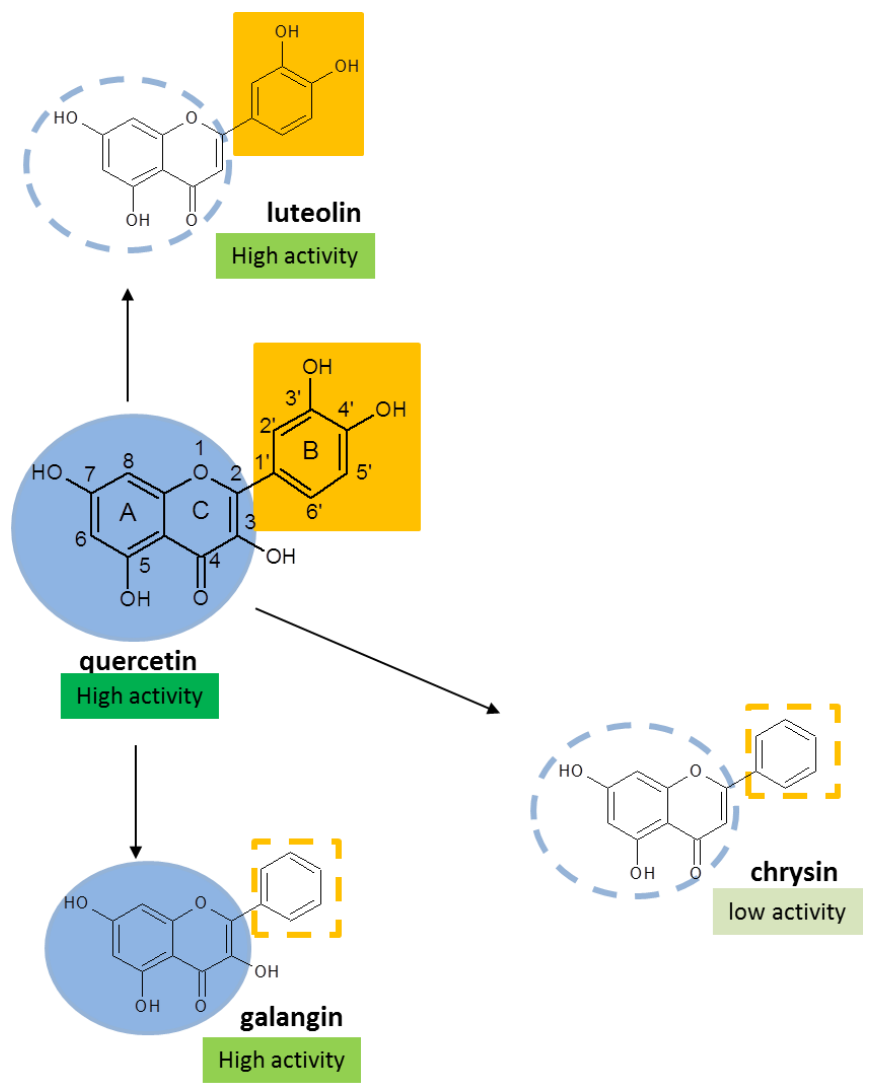

Fig 12. Demonstration of the presence of two antioxidant pharmacophores in quercetin (Q), the AC-ring (shown in blue) and the B-ring (shown in orange). Q is a very potent antioxidant in the prevention of lipid peroxidation or the peroxynitrite scavenging. Galangin, which does not have the $3^{\prime} \mathrm{OH}$ and $4^{\prime} \mathrm{OH}$ groups, also has a high activity, demonstrating that the AC-ring of $\mathrm{Q}$ is a pharmacophore. Chrysin, without the $3 \mathrm{OH}$ group, has a much lower activity than galangin. This shows the importance of the $3 \mathrm{OH}$ group in the $\mathrm{AC}$-ring pharmacophore. Luteolin that does not have the active AC-ring pharmacophore because it misses the $3 \mathrm{OH}$ group, is still a very effective antioxidant. This can be ascribed to the B-ring that is a catechol group, the other pharmacophore. In Q, that has both pharmacophores, the pharmacophores interact, creating a 'new' pharmacophore. The antioxidant activities presented in the figure are taken from Heijnen et al. [73]

In fundamental research new compounds that do not fit in established relationships are important, as these 'outliers' can be used to 'discover' a new class of compounds with a new mode of action. Also, well established SARs should be carefully scrutinized as they might be flawed. For example, even in a series of closely related, simple phenolic compounds, there are indication that their redox modulation activity does not proceed via the same molecular mechanism. Meticulously exploring the activity of relatively 'simple' phenolic compounds provides the fundament to finally construct an accurate SAR of the redox modulation of more complex phenolic compounds such as quercetin. 


\subsection{The dimension of time}

Homeostasis is not a static equilibrium, because energy has to flow to fuel life. This is probably best evidenced by the rise in body temperature when you die. When in an organism every reaction is in a perfect equilibrium, the organism is not alive anymore. To be able to live and to adapt, there always has to be some energy in the tank.

However, life cannot be modeled as a simple chemical reaction that slowly reaches its equilibrium. It is better modeled as a complex autocatalytic, oscillating reaction in which the driving force slowly fades when we age. This means that not only time is an important dimension, also timing is relevant. Time is also relevant because the only constant of life on earth is that our environment was, is, and never will be constant. Also because of this, life has to continuously adapt[74].

The dynamic 'oscilating equilibrium' in which compounds are constantly synthesized, modified, broken down and resynthesized is flexible and versatile. Therefore, oscillating systems seem well-tailored to cope with, and adapt to diverse changes. As reviewed previously, several molecular mechanisms that act on a different time scale are operative to mitigate a deranged energy flow[74]. An instant type of adaptation is activation of enzyme activity. This is seen for the microsomal GSH transferase 1. Oxidation or alkylation of a thiol 'sensor' in the enzyme by ROS or electrophiles, can increase the activity of the protective enzyme several times. Interestingly, an excess of ROS or electrophiles inhibits the enzyme. So, by increasing the dose, the response shifts form protection to adaptation, and finally to cell death (Fig 13). When the cell survives, the adaptation can be reversed by the cycle in which proteins are constantly broken down and resynthesized. This all adds to the flexibility of this type of adaptation.

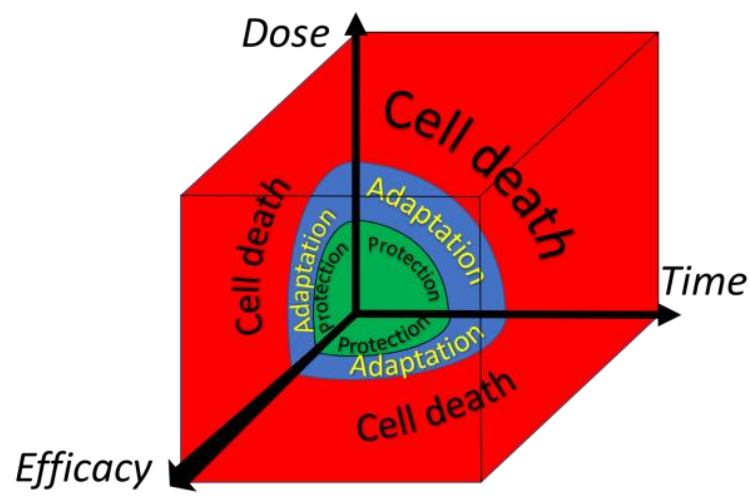

Fig 13. The dependence of the acute adaptive response of the cell to a toxic compound on the dose of the compound, on the efficacy of the compound and on time. Adapted from Sthijns et al.[74]

Adaptation due to switching on redox sensitive master switches takes several hours. This type of adaptation is exemplified in paragraph 3.2 with the transcriptions factor Nrf2 and GAPDH, that act as a protective switch, and an emergency, suicide switch, respectively. As also discussed in that paragraph, redox modulators can be used to turn on these switches in cells. Longer periods of deranged energy can result in remodeling of organs. In the long run, 
adaptation can be imprinted on the epigenetic and genomic level. Also, these types of modulation can be affected by redox modulators. The different types of adaptation discussed do not only differ in their time of onset, also their duration and impact are different, as schematically depicted in figure 14. Apparently, in modulating an adaptive response, beside the type of the deranged energy flow as well as the dose and the 'efficacy' of the redox modulator, also time and timing of the intervention should be considered.

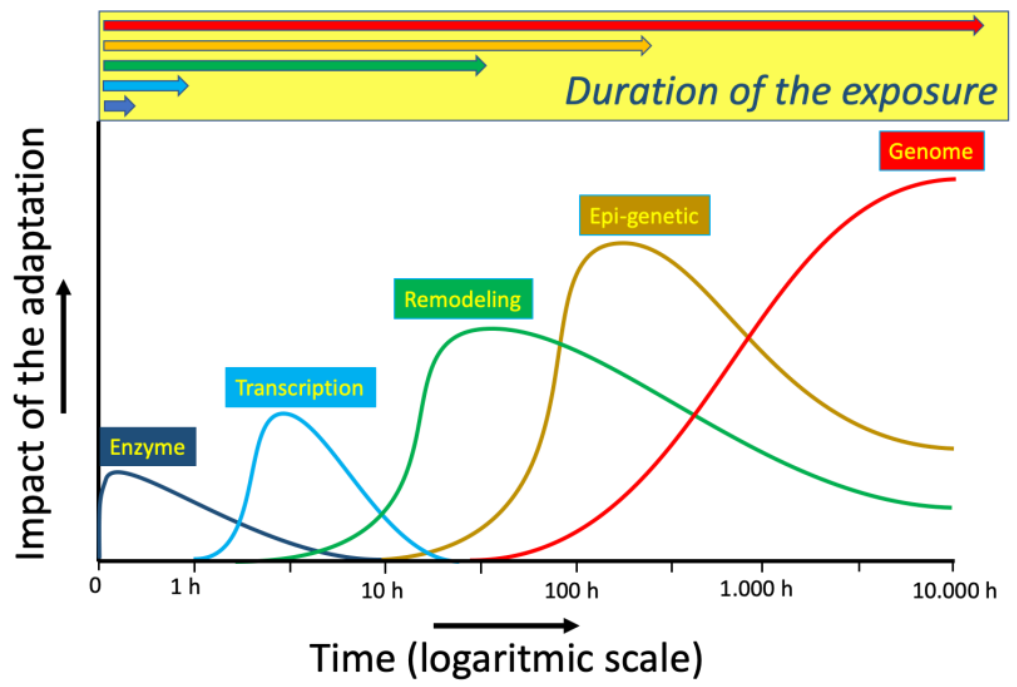

Fig 14. The difference in impact, and in the time of onset and duration of several types of adaptation of a cell based on to the molecular mechanism of the adaptation. Direct modification of the activity of an enzyme by the exposure is an acute adaptive response of cells. In adaptation due to the activation of the transcription of DNA, there is a lag time in the production of the protective proteins. Remodeling of an organ is a more drastic form of adaptation that takes relatively long and can persist for a relatively long period. Epi-genetic adaptations and especially modification of the genome can have a large impact as it can influence the whole population. Adaptation of the level of the genome forms the basis for evolution, which can be seen as an adaptation driven by long lasting environmental changes according to the principle of 'survival of the fittest'. In this paradigm, the genome is in the end the 'information-store' of the adaption to a persistent change, provided that the organism survives the change. The short time types of adaptation provide the time for the adaptation of the genome to take place. Intriguingly, the genome also stores the information of the other types of adaptation. Adapted from Sthijns et al[74].

\subsection{Specific question that need further attention}

During our research we have come up with several questions that we would like to answer. These are:

- The high rates of radical scavenging of some compounds that seems to exceed the diffusion rate constant. This was addressed paragraph 2.3 with the hydroxyl radical scavenging of monoHER

- Explain why a relatively low concentration of flavonoid is able to protect against an excess of ROS. In cell experiments, $40 \mathrm{nM}$ of monoHER was able to protect against $200 \mu \mathrm{M} \mathrm{H}_{2} \mathrm{O}_{2}$.

- Examine how redox modulators 'modulate' the energy on a molecular level (the 'efficacy' of redox modulators). In this thesis an attempt to understand this for quercetin is presented. 
- Establish a stimulus-effect relationship for redox modulators. We still do not know how to choose the appropriate redox modulator for a specific disease.

- Further establish how the redox modulators fit into molecules of the recipient complex like a piece of mosaic finds its place in a pattern.

\subsection{Forgotten perspectives: Back to the future, connection with traditional types of medicine}

To find answers for questions we are face with, we might look back to find strategies that were used in the past to (re)discover the answer. For example, we need to extend our knowledge on how various redox modulators will have different effects in the network. For this interaction, we might learn from one of the fundaments of traditional Chinese medicine, namely the dynamic interaction between herbs. The idea is that carefully selected herbs interact, according to the rule of 'Jun-Chen-Zuo-Shi' (Fig. 15). Translated into Western terminology, the Emperor (Jun) herb has the compounds with the highest efficacy, the Minister (Chen) herb increases the efficacy of these bioactive compounds and reduces their side effect, the Adjuvant (Zuo) herb improves the bioaccessibility, and finally the Messenger (Shi) herb affect the pharmacokinetics resulting in targeting. All these interaction strategies that date back to the beginning of our era, have recently been re-invented for making the effect of Western drugs more specific. Examining the 'Jun-Chen-Zuo-Shi' principle in basic pharmacological experiments, such as the response of the combinations in isolated organs or on receptor binding, gives unexpected, contra-intuitive results that opens avenues for further research[75].

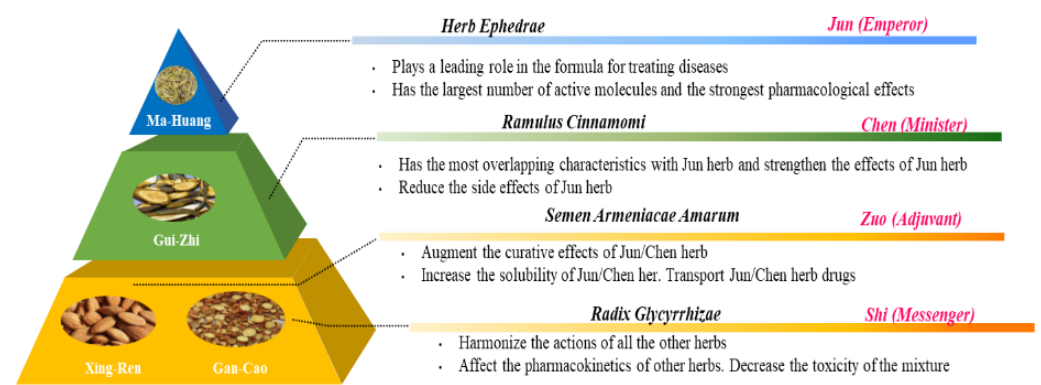

Fig 15. Diagram of the combination principle of Traditional Chinese Medicine formula, adapted from Yao et al[76] and Ming et al[61].

This shows that to connect Western medicine with traditional types of medicine, we should not concentrate on differences but try to find similarities, and skillfully use Occam's razor. The common denominators in all types of medicine shows us were we can find answers. Another common denominator is seen when we look from an energy perspective (Fig 16). In Western medicine as well as Eastern medicine, opposing forces provide the energy that flows through networks in an organism, which fuels life. In this concept, health is the ability of an organism to maintain the balance between these opposing forces, i.e. homeostasis (West) and harmony (East), which creates resilience. Moreover, strategies used to treat diseases are strikingly alike. Redox modulating compounds and TCM are added to increase or strengthen connections in the network to finally adjust the flow of energy and regain its balance. So, the 
energy perspective provides a basis to integrate Eastern and Western medicine. Here also additional research is needed to connect both worlds.

Nevertheless, we have to be careful in taking over answers, without knowing the right perspective. This can be illustrated using TCM in the West. Western medicine is 'optimized' to achieve and big therapeutic effect to cure the disease as quickly as possible Therefore, in the West only the most effective Emperor herb is used, or even the isolated, most active ingredient in this herb. This however gives rise to side effects in the Western world that can be quite severe. To fully appreciate its benefits, and to use its full potential, TCM should be used as developed over centuries in China. In line with the new definition of health, TCM is 'optimized' to increase our ability to adapt and to regain 'harmony', which has a much more long-term perspective compared to short-term perspective generally used for in the West[77].

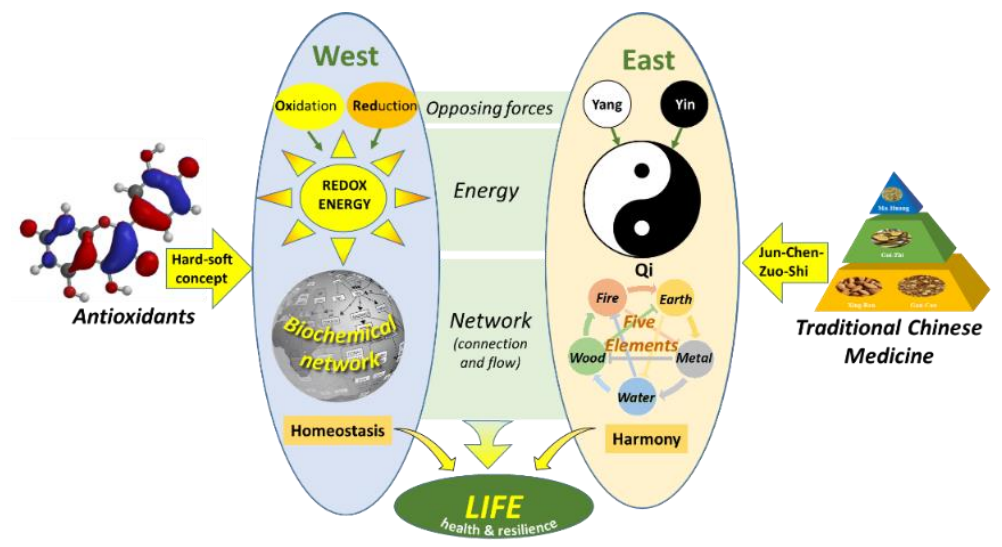

Figure 16. The connection of Western medicine and Eastern medicine from energy perspective. In both worlds, opposing forces generate the energy that flows through networks, which fuels life. Antioxidants interact with other molecules based on the hard-soft-acid-base concept which can be used to regain homeostasis. In TCM, different herbs are combined based on the rule of "Jun-Chen-Zuo-Shi" to restore the energy of Qi in the network to regain harmony, taken from Ming et al[61].

Another opportunity is to study other forms of energy, e.g. light. An interesting finding is that TCM "corrects" the light transmitted by the body [78]. This cannot be explained with the Western reductionistic approach, yet. A solution might be found in the physiological effect of ultra-weak bioluminescence[79]. Although the molecular mechanism is not well understood, this effect might not only affect the health of an individual, but also the integration and synchronization of members in group, or even in society. Interestingly, after absorbing the energy of a photon, the redox modulation activity of a flavonoid will drastically change. The impact on health of 'excited' flavonoids is also 'terra incognita'.

There are numerous other mysterious "forces" in Eastern medicine and other types of traditional medicine that lack a "Western scientific basis", and therefore are left unused. We would like to end with, what we consider, one of the most mysterious forces in the environmental-physiological interaction reported. During and after a war, the shortfall of men caused by war seems to be instantaneously compensated by an increased percentage of boys among newborns $[80,81]$. Despite the enigmatic nature of this force that even eclipses that of vitamin E, its universal message is crystal clear: 'Make love, not war'. 


\section{Acknowledgment}

This manuscript is part of the $\mathrm{PhD}$ project of Z.L., who was the main contributor to the present manuscript. All other authors also had an essential contribution to this manuscript. Their order is trivial and is therefore alphabetical. The ideas pursued in the manuscript were generated in previous research by others, and by former and present members of our research group on redox modulation who inspired each other. The present manuscript is the concerted action of many, and results or parts of the theses of Guido Haenen, Gerreke Biewenga, Chantal Heijnen, Agnes Boots, Mariken Arts, Nuria Mateo Ansón, Hilde Jacobs, Mohamed Moalin, Kristien Lemmens, Erik Ruijters, Mireille Sthijns and Ming Zhang were used. All authors have read and agreed to the present version of the manuscript. 


\section{References}

1. $\quad$ Cadenas, E.; Sies, H., The lag phase. Free Radical Research 1998, 28, (6), 601-609.

2. Kovacic, P.; Pozos, R. S.; Somanathan, R.; Shangari, N.; O'Brien, P. J., Mechanism of mitochondrial uncouplers, inhibitors, and toxins: focus on electron transfer, free radicals, and structure-activity relationships. Current Medicinal Chemistry 2005, 12, (22), 2601-2623.

3. Poyton, R. O.; Ball, K. A.; Castello, P. R., Mitochondrial generation of free radicals and hypoxic signaling. Trends in Endocrinology and Metabolism 2009, 20, (7), 332-340.

4. Biswas, S.; Das, R.; Banerjee, E. R., Role of free radicals in human inflammatory diseases. AIMS Biophysics 2017, 4, (4), 596.

5. Ray, P. D.; Huang, B.-W.; Tsuji, Y., Reactive oxygen species (ROS) homeostasis and redox regulation in cellular signaling. Cellular Signalling 2012, 24, (5), 981-990.

6. Benzie, I. F., Evolution of antioxidant defence mechanisms. European journal of nutrition 2000, 39, (2), 53-61.

7. Bast, A.; Haenen, G. R., The toxicity of antioxidants and their metabolites. Environmental toxicology and pharmacology 2002, 11, (3-4), 251-258.

8. Ariëns, E. J., Molecular Pharmacology V3: The Model of Action of Biology Active Compounds. Elsevier: 2012; Vol. 3.

9. Mateo Anson, N.; Aura, A. M.; Selinheimo, E.; Mattila, I.; Poutanen, K.; van den Berg, R.; Havenaar, R.; Bast, A.; Haenen, G. R., Bioprocessing of wheat bran in whole wheat bread increases the bioavailability of phenolic acids in men and exerts antiinflammatory effects ex vivo. The Journal of nutrition 2011, 141, (1), 137-143.

10. Day, A. J.; DuPont, M. S.; Ridley, S.; Rhodes, M.; Rhodes, M. J.; Morgan, M. R.; Williamson, G., Deglycosylation of flavonoid and isoflavonoid glycosides by human small intestine and liver $\beta$ glucosidase activity. FEBS letters 1998, 436, (1), 71-75.

11. Day, A. J.; Cañada, F. J.; Díaz, J. C.; Kroon, P. A.; Mclauchlan, R.; Faulds, C. B.; Plumb, G. W.; Morgan, M. R.; Williamson, G., Dietary flavonoid and isoflavone glycosides are hydrolysed by the lactase site of lactase phlorizin hydrolase. FEBS letters 2000, 468, (2-3), 166-170.

12. Németh, K.; Plumb, G. W.; Berrin, J.-G.; Juge, N.; Jacob, R.; Naim, H. Y.; Williamson, G.; Swallow, D. M.; Kroon, P. A., Deglycosylation by small intestinal epithelial cell $\beta$-glucosidases is a critical step in the absorption and metabolism of dietary flavonoid glycosides in humans. European journal of nutrition 2003, 42, (1), 29-42.

13. Moalin, M., Quercetin and its methylated metabolites: the chemical basis of activity. Maastricht University: 2014.

14. Shimoi, K.; Okada, H.; Furugori, M.; Goda, T.; Takase, S.; Suzuki, M.; Hara, Y.; Yamamoto, H.; Kinae, N., Intestinal absorption of luteolin and luteolin 7-O- $\beta$-glucoside in rats and humans. FEBS letters 1998, 438, (3), 220-224.

15. Spencer, J. P.; Chowrimootoo, G.; Choudhury, R.; Debnam, E. S.; Srai, S. K.; Rice-Evans, C., The small intestine can both absorb and glucuronidate luminal flavonoids. FEBS letters 1999, 458, (2), 224-230.

16. Kuhnle, G.; Spencer, J. P.; Schroeter, H.; Shenoy, B.; Debnam, E. S.; Srai, S. K. S.; Rice-Evans, C.; Hahn, U., Epicatechin and catechin are O-methylated and glucuronidated in the small intestine. Biochemical and biophysical research communications 2000, 277, (2), 507-512.

17. Donovan, J. L.; Crespy, V.; Manach, C.; Morand, C.; Besson, C.; Scalbert, A.; Rémésy, C., Catechin is metabolized by both the small intestine and liver of rats. The Journal of nutrition 2001, 131, (6), 17531757.

18. Oliveira, E.; Watson, D.; Grant, M., Metabolism of quercetin and kaempferol by rat hepatocytes and the identification of flavonoid glycosides in human plasma. Xenobiotica 2002, 32, (4), 279-287.

19. Mojarrabi, B.; Mackenzie, P. I., Characterization of two UDP glucuronosyltransferases that are predominantly expressed in human colon. Biochemical and biophysical research communications 1998, 247, (3), 704-709.

20. Strassburg, C. P.; Nguyen, N.; Manns, M. P.; Tukey, R. H., Polymorphic Expression of the UDPGlucuronosyltransferaseUGT1A Gene Locus in Human Gastric Epithelium. Molecular Pharmacology 1998, 54, (4), 647-654.

21. Cheng, Z.; Radominska-Pandya, A.; Tephly, T. R., Studies on the substrate specificity of human intestinal UDP-glucuronosyltransferases 1A8 and 1A10. Drug Metabolism and Disposition 1999, 27, (10), 1165-1170.

22. Crespy, V.; Morand, C.; Manach, C.; Besson, C.; Demigne, C.; Remesy, C., Part of quercetin absorbed in the small intestine is conjugated and further secreted in the intestinal lumen. American Journal of Physiology-Gastrointestinal and Liver Physiology 1999, 277, (1), G120-G126. 
23. Gregus, Z.; Klaassen, C., Enterohepatic circulation of toxicants. In Elsevier, Amsterdam: 1986; Vol. 57.

24. Kay, C. D., Aspects of anthocyanin absorption, metabolism and pharmacokinetics in humans. Nutrition research reviews 2006, 19, (1), 137-146.

25. Shimoi, K.; Nakayama, T., Glucuronidase deconjugation in inflammation. Methods in enzymology 2005, 400, 263-272.

26. Williamson, G.; Day, A.; Plumb, G.; Couteau, D., Human metabolic pathways of dietary flavonoids and cinnamates. Biochemical Society Transactions 2000, 28, (2), 16-22.

27. Schwenk, M., Mucosal biotransformation. Toxicologic pathology 1988, 16, (2), 138-146.

28. Piskula, M. K.; Terao, J., Accumulation of (-)-epicatechin metabolites in rat plasma after oral administration and distribution of conjugation enzymes in rat tissues. The Journal of nutrition 1998, 128, (7), 1172-1178.

29. Lemmens, K. J.; Vrolijk, M. F.; Bouwman, F. G.; Van der Vijgh, W. J.; Bast, A.; Haenen, G. R., The minor structural difference between the antioxidants quercetin and 4'O-methylquercetin has a major impact on their selective thiol toxicity. International journal of molecular sciences 2014, 15, (5), 74757484.

30. Dutton, G., Glucuronidation of drugs and other compounds. CRC press: 2019.

31. BOULTON, D. W.; WALlE, U. K.; WALLE, T., Fate of the flavonoid quercetin in human cell lines: chemical instability and metabolism. Journal of pharmacy and pharmacology 1999, 51, (3), 353-359.

32. Schneider, H.; Schwiertz, A.; Collins, M. D.; Blaut, M., Anaerobic transformation of quercetin-3glucoside by bacteria from the human intestinal tract. Archives of microbiology 1999, 171, (2), 81-91.

33. Skibola, C. F.; Smith, M. T., Potential health impacts of excessive flavonoid intake. Free radical biology and medicine 2000, 29, (3-4), 375-383.

34. Manach, C.; Williamson, G.; Morand, C.; Scalbert, A.; Rémésy, C., Bioavailability and bioefficacy of polyphenols in humans. I. Review of 97 bioavailability studies. The American journal of clinical nutrition 2005, 81, (1), 230S-242S.

35. Das, N.; Sothy, S., Studies on flavonoid metabolism. Biliary and urinary excretion of metabolites of $(+)-$ [U-14C] catechin. Biochemical Journal 1971, 125, (2), 417-423.

36. Hackett, A. M., The metabolism of flavonoid compounds in mammals. Progress in clinical and biological research 1986, 213, 177.

37. Shaw, I.; Griffiths, L., Identification of the major biliary metabolite of (+)-catechin in the rat. Xenobiotica 1980, 10, (12), 905-911.

38. Murakami, A.; Ashida, H.; Terao, J., Multitargeted cancer prevention by quercetin. Cancer letters 2008, $269,(2), 315-325$.

39. Murota, K.; Terao, J., Quercetin appears in the lymph of unanesthetized rats as its phase II metabolites after administered into the stomach. FEBS letters 2005, 579, (24), 5343-5346.

40. Li, Z.; Knetsch, M., Antibacterial strategies for wound dressing: preventing infection and stimulating healing. Current pharmaceutical design 2018, 24, (8), 936-951.

41. Kenakin, T., Principles: receptor theory in pharmacology. Trends in pharmacological sciences 2004, 25 , (4), 186-192.

42. Stephenson, R., A modification of receptor theory. British journal of pharmacology and chemotherapy 1956, 11, (4), 379.

43. Haenen, G. R. M. M., Thiols in oxidative stress: some implications for catecholamine toxicity. 1989.

44. Haenen, G. R.; Veerman, M.; Bast, A., Reduction of $\beta$-adrenoceptor function by oxidative stress in the heart. Free radical biology and medicine 1990, 9, (4), 279-288.

45. Ruijters, E. J.; Haenen, G. R.; Weseler, A. R.; Bast, A., The cocoa flavanol (-)-epicatechin protects the cortisol response. Pharmacological Research 2014, 79, 28-33.

46. Bermingham, E. N.; Hesketh, J. E.; Sinclair, B. R.; Koolaard, J. P.; Roy, N. C., Selenium-enriched foods are more effective at increasing glutathione peroxidase (GPx) activity compared with selenomethionine: A meta-analysis. Nutrients 2014, 6, (10), 4002-4031.

47. Nagao, A.; Seki, M.; Kobayashi, H., Inhibition of xanthine oxidase by flavonoids. Bioscience, biotechnology, and biochemistry 1999, 63, (10), 1787-1790.

48. Lemmens, K. J.; van de Wier, B.; Vaes, N.; Ghosh, M.; van Zandvoort, M. A.; van der Vijgh, W. J.; Bast, A.; Haenen, G. R., The flavonoid 7-mono-O-( $\beta$-hydroxyethyl)-rutoside is able to protect endothelial cells by a direct antioxidant effect. Toxicology in vitro 2014, 28, (4), 538-543.

49. Costentin, C.; Evans, D. H.; Robert, M.; Savéant, J.-M.; Singh, P. S., Electrochemical approach to concerted proton and electron transfers. Reduction of the water- superoxide ion complex. Journal of the American Chemical Society 2005, 127, (36), 12490-12491.

50. Warren, J. J.; Tronic, T. A.; Mayer, J. M., Thermochemistry of proton-coupled electron transfer reagents and its implications. Chemical Reviews 2010, 110, (12), 6961-7001. 
51. Marino, T.; Galano, A.; Russo, N., Radical scavenging ability of gallic acid toward $\mathrm{OH}$ and $\mathrm{OOH}$ radicals. Reaction mechanism and rate constants from the density functional theory. The Journal of Physical Chemistry B 2014, 118, (35), 10380-10389.

52. EFSA Panel on Dietetic Products, N.; Allergies, Scientific Opinion on the substantiation of health claims related to polyphenols in olive and protection of LDL particles from oxidative damage (ID 1333, 1638, 1639, 1696, 2865), maintenance of normal blood HDL cholesterol concentrations (ID 1639), maintenance of normal blood pressure (ID 3781), "anti-inflammatory properties"(ID 1882), "contributes to the upper respiratory tract health"(ID 3468), "can help to maintain a normal function of gastrointestinal tract"(3779), and "contributes to body defences against external agents"(ID 3467) pursuant to Article 13 (1) of Regulation (EC) No 1924/2006. EFSA journal 2011, 9, (4), 2033.

53. Rietjens, S. J.; Bast, A.; Haenen, G. R., New insights into controversies on the antioxidant potential of the olive oil antioxidant hydroxytyrosol. Journal of agricultural and food chemistry 2007, 55, (18), 76097614.

54. Biewenga, G. P.; Veening-Griffioen, D.; Nicastia, A.; Haenen, G.; Bast, A., Effects of dihydrolipoic acid on peptide methionine sulfoxide reductase. Implications for antioxidant drugs. Arzneimittel-Forschung 1998, 48, (2), 144-148.

55. Geraets, L.; Moonen, H. J.; Brauers, K.; Wouters, E. F.; Bast, A.; Hageman, G. J., Dietary flavones and flavonoles are inhibitors of poly (ADP-ribose) polymerase-1 in pulmonary epithelial cells. The Journal of nutrition 2007, 137, (10), 2190-2195.

56. Nafisi, S.; Hashemi, M.; Rajabi, M.; Tajmir-Riahi, H. A., DNA adducts with antioxidant flavonoids: morin, apigenin, and naringin. DNA and cell biology 2008, 27, (8), 433-442.

57. Pósfai, É.; Bánhidy, F.; Czeizel, A. E., Teratogenic effect of hydroxyethylrutoside, a flavonoid derivate drug-a population-based case-control study. The Journal of Maternal-Fetal \& Neonatal Medicine 2014, 27, (11), 1093-1098.

58. Vanhees, K.; Godschalk, R. W.; Sanders, A.; van Doorn, S. B. v. W.; van Schooten, F. J., Maternal quercetin intake during pregnancy results in an adapted iron homeostasis at adulthood. Toxicology 2011, 290, (2-3), 350-358.

59. Vanhees, K.; de Bock, L.; Godschalk, R. W.; van Schooten, F. J.; van Waalwijk van Doorn-Khosrovani, S. B., Prenatal exposure to flavonoids: implication for cancer risk. Toxicological sciences 2011, 120, (1), 59-67.

60. Bast, A.; Haenen, G. R., Ten misconceptions about antioxidants. Trends in pharmacological sciences 2013, 34, (8), 430-436.

61. Zhang, M.; Moalin, M.; Vervoort, L.; Li, Z. W.; Wu, W. B.; Haenen, G., Connecting Western and Eastern medicine from an energy perspective. International journal of molecular sciences 2019, 20, (6), 1512.

62. Zhang, M.; Vervoort, L.; Moalin, M.; Mommers, A.; Douny, C.; den Hartog, G. J.; Haenen, G. R., The chemical reactivity of (-)-epicatechin quinone mainly resides in its B-ring. Free radical biology and medicine 2018, 124, 31-39.

63. Lo, S. C.; Li, X.; Henzl, M. T.; Beamer, L. J.; Hannink, M., Structure of the Keap1: Nrf2 interface provides mechanistic insight into Nrf2 signaling. The EMBO journal 2006, 25, (15), 3605-3617.

64. Hara, M. R.; Agrawal, N.; Kim, S. F.; Cascio, M. B.; Fujimuro, M.; Ozeki, Y.; Takahashi, M.; Cheah, J. H.; Tankou, S. K.; Hester, L. D., S-nitrosylated GAPDH initiates apoptotic cell death by nuclear translocation following Siah1 binding. Nature cell biology 2005, 7, (7), 665-674.

65. Sen, N.; Hara, M. R.; Kornberg, M. D.; Cascio, M. B.; Bae, B.-I.; Shahani, N.; Thomas, B.; Dawson, T. M.; Dawson, V. L.; Snyder, S. H., Nitric oxide-induced nuclear GAPDH activates p300/CBP and mediates apoptosis. Nature cell biology 2008, 10, (7), 866-873.

66. Zhang, J.-Y.; Zhang, F.; Hong, C.-Q.; Giuliano, A. E.; Cui, X.-J.; Zhou, G.-J.; Zhang, G.-J.; Cui, Y.-K., Critical protein GAPDH and its regulatory mechanisms in cancer cells. Cancer biology \& medicine 2015, 12, (1), 10.

67. Sirover, M. A., Pleiotropic effects of moonlighting glyceraldehyde-3-phosphate dehydrogenase (GAPDH) in cancer progression, invasiveness, and metastases. Cancer and Metastasis Reviews 2018, 37 , (4), 665-676.

68. Russell, G.; Veal, D.; Hancock, J. T., Is glyceraldehyde-3-phosphate dehydrogenase a central redox mediator? Reactive Oxygen Species 2020, 9, (26), 48-69-48-69.

69. Van De Wier, B.; Koek, G. H.; Bast, A.; Haenen, G. R., The potential of flavonoids in the treatment of non-alcoholic fatty liver disease. Critical reviews in food science and nutrition 2017, 57, (4), 834-855.

70. Haslam, E., Polyphenol-protein interactions. Biochemical Journal 1974, 139, (1), 285-288.

71. Murray, N. J.; Williamson, M. P.; Lilley, T. H.; Haslam, E., Study of the interaction between salivary proline-rich proteins and a polyphenol by 1H-NMR spectroscopy. European journal of biochemistry 1994, 219, (3), 923-935. 
72. Brown, A. C.; Fraser, T. R., On the connection between chemical constitution and physiological action; with special reference to the physiological action of the salts of the ammonium bases derived from strychnia, brucia, thebaia, codeia, morphia, and nicotia. Journal of anatomy and physiology 1868, 2, (2), 224.

73. Heijnen, C. G.; Haenen, G. R.; Vekemans, J. A.; Bast, A., Peroxynitrite scavenging of flavonoids: structure activity relationship. Environmental toxicology and pharmacology 2001, 10, (4), 199-206.

74. Sthijns, M. M.; Weseler, A. R.; Bast, A.; Haenen, G. R., Time in redox adaptation processes: from evolution to hormesis. International journal of molecular sciences 2016, 17, (10), 1649.

75. Zhang, M.; Vrolijk, M.; Haenen, G. R., The Screening of Anticholinergic Accumulation by Traditional Chinese Medicine. International journal of molecular sciences 2018, 19, (1), 18.

76. Yao, Y.; Zhang, X.; Wang, Z.; Zheng, C.; Li, P.; Huang, C.; Tao, W.; Xiao, W.; Wang, Y.; Huang, L., Deciphering the combination principles of Traditional Chinese Medicine from a systems pharmacology perspective based on Ma-huang Decoction. Journal of ethnopharmacology 2013, 150, (2), 619-638.

77. Zhang, M.; Schiffers, P.; Janssen, G.; Vrolijk, M.; Vangrieken, P.; Haenen, G. R., The cardiovascular side effects of Ma Huang due to its use in isolation in the Western world. European Journal of Integrative Medicine 2018, 18, 18-22.

78. Rosch, P. J., Bioelectromagnetic and subtle energy medicine. Annals of the New York Academy of Sciences 2009, 1172, (1), 297-311.

79. Van Wijk, R.; Schamhart, D., Regulatory aspects of low intensity photon emission. Experientia 1988, 44, (7), 586-593.

80. Bromen, K.; Jöckel, K.-H., Change in male proportion among newborn infants. The Lancet 1997, 349, (9054), 804-805.

81. Bethmann, D.; Kvasnicka, M., War, marriage markets, and the sex ratio at birth. The Scandinavian Journal of Economics 2014, 116, (3), 859-877. 


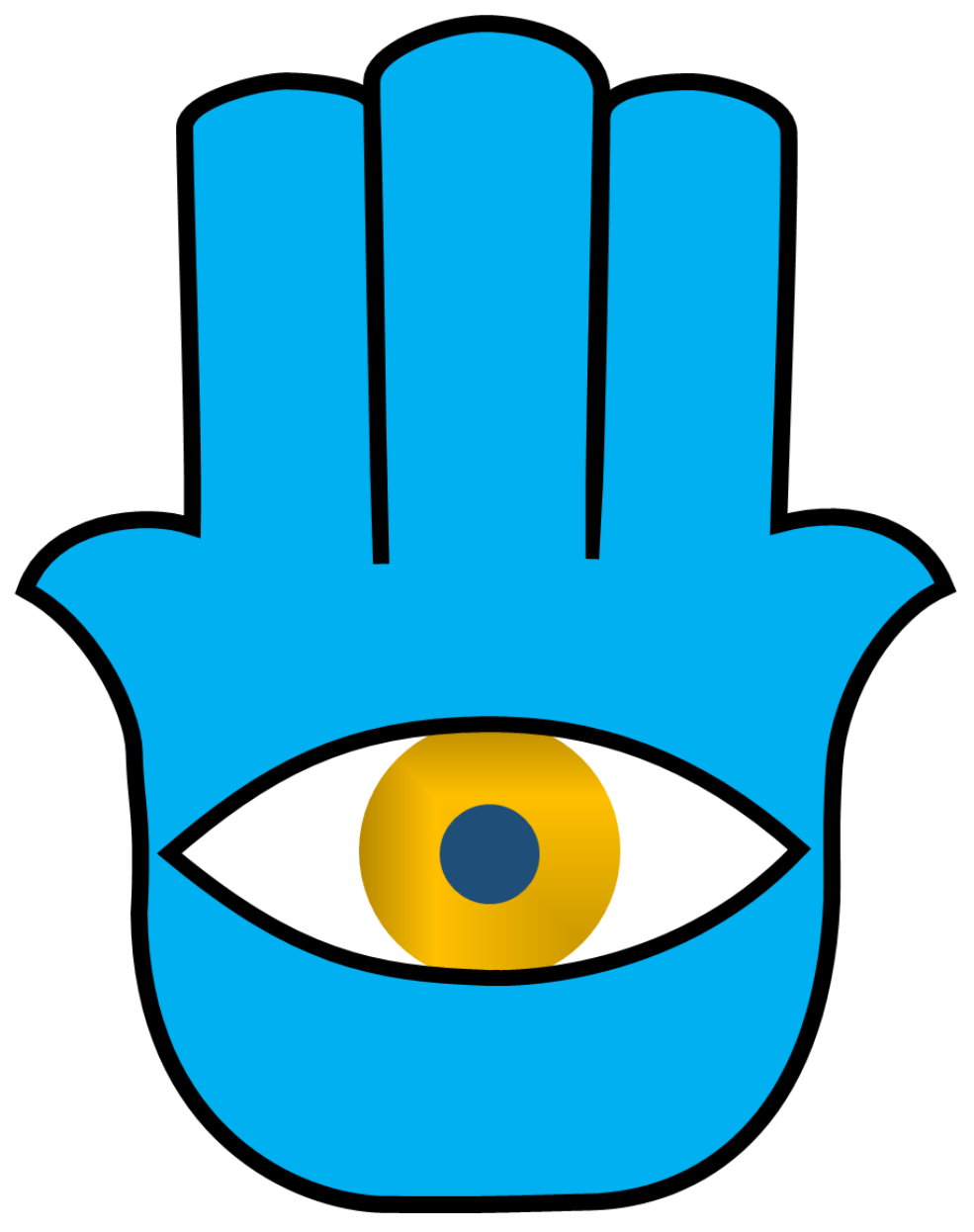




\section{Chapter 2}

\section{Antibacterial strategies for wound dressing: preventing infection and stimulating healing}

\section{Zhengwen $\mathrm{Li}^{* *}$ and Menno Knetsch ${ }^{1,2}$}

${ }^{1}$ Aachen Maastricht Institute for Biobased Materials, Maastricht University, Maastricht, The Netherlands

${ }^{2}$ Biobased Materials, Faculty of Humanities and Sciences, Maastricht University, Maastricht, The Netherlands

Current pharmaceutical design, 2018, 24(8): 936-951. 


\begin{abstract}
Wound management is an important and increasing global issue. Infection of a wound can cause a delay in wound healing and pain, but also more serious complications like tissue necrosis or even sepsis, which can lead to loss of tissue, limbs or life. Antibacterial agents have been introduced into wound infection care. In this review, we provide an insight into the current antibacterial strategies of wound dressings, including wound infection process, antibacterial agents, and controlled drug release system. We also emphasize the development of intelligent wound dressing and introduce a promising research direction.
\end{abstract}

Keywords: Antibacterial strategies; antibacterial drugs; drug delivery system; infection; intelligent dressing; wound dressing 


\section{Introduction}

Wound healing is a complex process, generally going through five major stages including hemostasis, inflammation, proliferation, migration, and remodeling [1]. The inter-related biological and molecular processes among these events are easily influenced by multiple systemic and local factors. Stress, obesity, nutrition, age, gender, and immunosuppressants are typical systemic factors while local factors include blood supply and wound infection. Microbial wound infection can cause tissue damage, matrix remodeling, degradation of collagen fibers, and frequently leads to a non-healing, chronic wound [2,3]. Wound dressings have long been used to provide protection, absorption of exudates, and stimulation of wound healing. Addition of antibacterial agents into wound dressing is the main way to control bacterial wound infection.

This review discusses how bacteria affect the wound healing, currently used antibacterial drugs and their mechanism. We also discuss the drug delivery system to explain treatment methods in the wound dressing.

\section{Bacteria and wound infection}

The skin is considered the largest organ of human body. It is composed of three layers, epidermis, dermis, and hypodermis [4]. Generally, epidermis, which is made of dead cells and keratin, is waterproof and able to protect against the bacterial infection. The dermis is mainly composed of collagen fibers and elastic fibers, mainly for structure, mechanical properties, and support. The hypodermis is mostly made of fat cells and is responsible for energy support. Once the skin is injured, it loses its barrier function of protection. Open wounds provide a moist, warm, nutritious place that is perfect for colonization and growth of bacteria [5].

The process of infection and replication of bacteria is defined as four main stages (Fig 1), contamination, colonization, local infection and invasive infection [6]. Contamination and colonization can be defined as the presence of replicating bacteria adherent to wound that start to multiply. However, colonization by microbes is not considered to inhibit healing. The local infection has been described as the complex stage between the presence of several species of bacteria in the wound and the initiation of the immune response from the host. The invasive infection of a wound by bacteria leads to a series of systemic and local host responses, among which are inflammation and wound healing. 

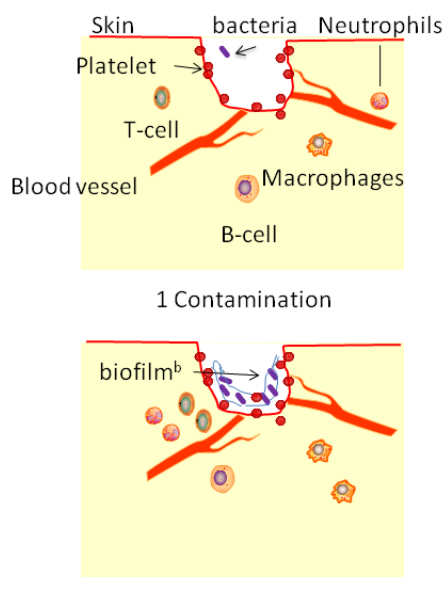

3 Local infection

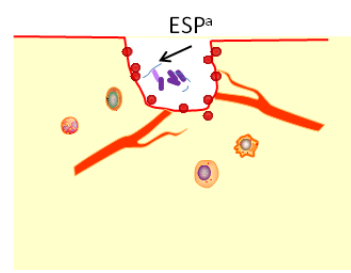

2 Colonization

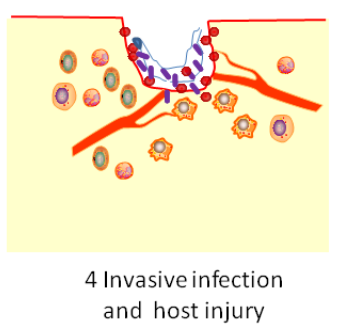

Fig 1. Process of bacterial infection of open wounds (a: ESP: extracellular polysaccharide; b: biofilm: not all infections will form a biofilm)

Herein, we listed some bacterial species that are commonly found in wounds and their mechanism for delay of wound healing (Table 1). Normally, bacteria and endotoxins can lead to a non-healing wound by cell damage. Staphylococcus aureus is one of the aerobic or facultative anaerobic bacteria that can be detected in diabetic foot ulcer infection. An exotoxin secreted by Staphylococcus aureus can cause platelet damage and hemolysis. Moreover, Panton-Valentine leucocidin (PVL) can destroy white blood cells and macrophages thus resulting in immune injury. Inflammatory factors such as interleukin-1 $\beta$, nitric oxide, tumor necrosis factor- $\alpha$ can be over-released after exposure to lipopolysaccharide (LPS) from Escherichia coli, which will prolong the inflammatory phase. Moreover, the delay of healing depends on the bacterial species as well as the location of the wound site. Staphylococcus aureus could induce the senescence phenotype of fibroblasts while Pseudomonas aeruginosa reduced the capability of antigen to active the macrophages by the action of $\mathrm{N}$-(3-oxododecanoyl)-1-homoserine lactone and pseudomonas quinolone signal $[7,8]$. Because the bacteria-induced mechanisms that enhance infection and cause delayed healing differ extensively, it is clear that different antibacterial strategies are required. 
Table 1. Bacterial species in wound and characteristics

Bacterial
genus/species Characteristics

\begin{tabular}{ll}
\hline & $\begin{array}{l}\text { G+, Aerobic or facultative anaerobic } \\
\text { Surgical wound infection, soft tissue infection bite infection, } \\
\text { burn infection, diabetic foot ulcer infection, leg ulcer } \\
\text { infection, bedsore infection } \\
\text { aureus }\end{array}$ \\
& $\begin{array}{l}\text { Hemolysis cause platelet damage, destruction of lysosomes; } \\
\text { Panton-Valentine leukocidin(PVL) can damage white blood } \\
\text { cells and macrophages }\end{array}$ \\
& \\
Gscherichia & $\begin{array}{l}\text { Surgical wound infection, soft tissue infection, burn infection, } \\
\text { diabetic foot ulcer infection }\end{array}$ \\
& $\begin{array}{l}\text { LPS-induced inflammatory factors over-release (interleukin- } \\
\text { 1 }\end{array}$
\end{tabular}

G-, Obligate aerobe

Pseudomonas

Aeruginosa

Surgical wound infection, burn infection, diabetic foot ulcer infection, bedsore infection

ExoA can block protein synthesis; Extracellular enzyme S can destroy the cytoskeleton

G+, Facultative anaerobic

Surgical wound infection, burn infection, diabetic foot ulcer

Enterococcus infection

Cyl-induced cell membrane rupture; GelE can directly or indirectly enzymatic hydrolysis of collagen or tissue proteins

G-, Facultative anaerobic

Proteus $\quad$ Soft tissue infection

mirabilis

Protease can enzymatic hydrolysis IgA and IgG thus leading inhibition of immune defense system. Hemolysin can be inserted into cell membrane, resulting in cell damage

$\mathrm{G}+$, Anaerobic

Peptostreptoco ccus

Soft tissue infection, burn infection, diabetic foot ulcer infection, leg ulcer infection, bedsore infection

Tissue damage induced by hyaluronidase, collagenase and protease 


\author{
G-, Obligate anaerobic \\ Burn infection, diabetic foot ulcer infection, bedsore \\ Bacteroidaceae \\ infection, bite infection \\ LPS, hyaluronidase, neuraminidase, metalloproteinases cause \\ cell damage.
}

$\mathrm{G}+$, Anaerobic

Clostridium Soft tissue infection

Lecithinase can cause degradation of blood cell and

endothelial cells

\section{Biofilms}

Biofilm is another factor that delays the wound healing. Biofilms are complex communities of aggregated bacteria embedded in a self-secreted extracellular polysaccharide matrix. In this matrix, a variety of major biological macromolecules such as protein, polysaccharide, DNA, RNA, fat etc. are present. It has been suggested that biofilms are involved in up to $80 \%$ of all infection $[9,10]$ and evidence of the presence of biofilm in the chronic wound has been systematically summarized by Malone [11]. The formation of biofilms on the wound sites is induced by the bacterial quorum sensing system. This system gets activated once bacteria are faced with uncomfortable conditions like nutrient deficiency, elevated osmotic pressure, lower $\mathrm{pH}$ value, or the use of antibacterial agents. The extracellular signal controls the group behavior of bacteria through expression and activation of specific genes to protect themselves from host immune response. Moreover, this excellent environment facilitates gene transfer leading increased risk of appearance of multiple drug resistance bacteria. However, the mechanism by which a biofilm delays the wound healing has not been fully understood yet. In several experiments, Robert et al.[12], examined the ability of $P$. aeruginosa and $S$. aureus to disrupt the healing processes of cell proliferation and migration on the keratinocytes from the human in vitro. In this research, they found that the biofilm from $S$. aureus inhibited migration of cells basically by the functions of enzymes. Alpha hemolysin, a highly cytotoxic compound is very potent in lysing erythrocytes and possesses dermo-necrotic and neurotoxic activities that delay wound healing. The exogenous fructose-biphosphate aldolase from conditioned biofilms of $S$. aureus may participate in the destruction or alteration of the formation and regulation of actin based lamellipodia, which are important structures for cell migration. Exogenous lactate dehydrogenase effectively converts lactate into pyruvate. The former one stimulates the production of growth factors such as VEGF19 and TGF $\beta 20$, hence in this way, the conversion of pyruvate to exogenous lactate indirectly delays healing. Another protein identified by the authors was epidermal cell differentiation inhibitor protein, which inhibits the migration of keratinocytes by ADPribosylation of the Rho-GTPase family. Others reported that extracellular polysaccharide can limit the chemotaxis and secretion of neutrophils that are the first line of cellular defense 
against bacteria by the production of proteinases and reactive oxygen species [13]. The extracellular polysaccharide can also induce the senescence phenotype of fibroblasts resulting in a hard reconstruction of wound scars[7]. Finally, physical properties of the extracellular polysaccharide as barrier leading to a bad oxygen permeability can slow down patient's cell growth but may be conducive to anaerobic bacterial growth in deep wound infection $[14,15]$.

\section{Wound dressing and Antibacterial strategies}

The wound dressing (Fig 2), are medical items that are designed to temporarily replace the damaged skin and cover the wound, thus providing protection, absorption of exudate and stimulation of wound healing $[16,17]$. Nowadays a wide range of materials from natural products such as cotton, gauze, cellulose, alginate to synthetic polymers polyvinylalcohol, polyethylene oxide, and polyurethane, are being applied for wound dressings $[18,19]$. The classification of dressings can be difficult, and no uniform standard exists. In some view, they are being categorized as passive, interactive and bioactive dressings depending on their behavior when placed on a wound [20]. Passive dressings which are ordinary dressings made of cotton, gauze, merely absorb exudates passively and provide a limited protective coverage for the wound. The interactive dressings are permeable to water and air thus creating an ideal environment for healing, additionally, these dressings, such as foam or hydrocolloids form a gel barrier when in contact with exudates on the wound thus preventing the invasion of environment bacteria and minimizing possibilities of cross-infection. Bioactive dressings, also known as occlusive functional dressings, are formed with double or multi-layer structure. The outer layer is usually made of high molecular weight polymers and functional as the dense barrier, mimicking the epidermis. Furthermore, metal antimicrobial substances like silver, zinc oxide can be electroplated on polymers of the outer layer to enhance the antibacterial ability. The inner layer is mainly constructed from chitosan, alginate, polylactic acid, hyaluronic acid etc., which possess biological compatibility, larger absorption volume of exudates and better breathability. Meanwhile, antibacterial agents, cytokines, growth factors are also incorporated into these dressings to inhibit the bacterial growth and accelerate wound healing processes. 


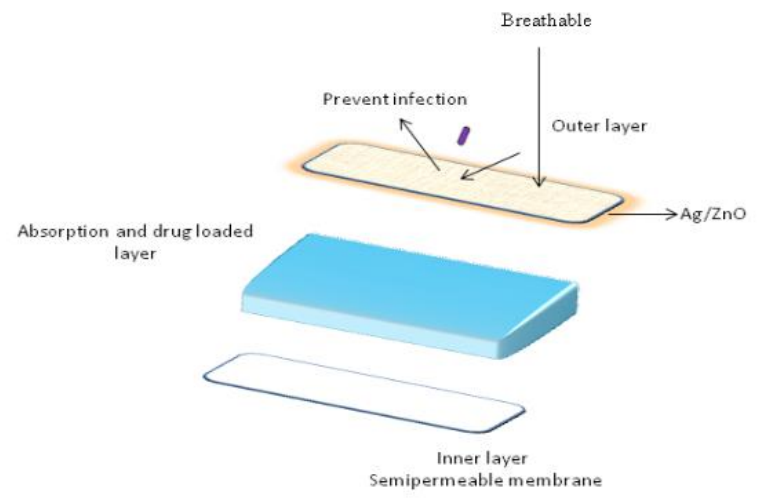

Fig 2. Current dressings design

In this review, we classified wound dressing into fibers, hydrogels, foam, and film basically according to their physical form to get a better insight into their composition in relation to antibacterial agents used as well as the drug release systems that will be discussed later.

\section{Current antibacterial agents in wound dressings}

\section{Inorganic antibacteiral agents}

The inorganic antibacterial agents in wound dressings are silver, copper, and zinc, their ions and compounds that contain these metals. Another kind is photocatalytic antibacterial agents, such as silica, titanium dioxide, tungsten trioxide.

Silver is the most widely used inorganic antibacterial agent in wound dressings, with broad spectrum activity [21]. Metallic silver contacts with the wound exudates and then releases the silver ions. By reacting with the sulfhydryl or amino groups, silver ions interfere with cytochrome complexes of the respiratory chain, causing respiratory defects. It also induces bacterial cell membrane enzyme deactivation, thereby damaging the cell membrane, resulting in cell lysis. Another mechanism reported for silver ions is inhibition of transcription and reproduction of DNA, eventually leading cell death [22]. Silver chloride, silver nitrate, silver sulfadiazine, silver zirconium compounds are common antibacterial forms in wound dressings [23, 24]. Furthermore, silver nanoparticles with a diameter of 1-100nm, have more stable physical, chemical properties and stronger surface activity than conventional silver. Additionally, nano-silver can continuously release silver ions to achieve the purpose of longterm antibacterial effect. However, in recent years, studies have shown that bacteria have begun to develop resistance to silver ions. At the same time, most of the silver compounds 
do not dissolve in water and easily accumulate in the body, causing metal poisoning that might challenge the use of silver [25].

Copper can enhance the activity of skin growth factors, stimulate the skin to generate new capillaries [26]. The use of copper dressings can speed up the wound healing rate and prevent bacterial infection. The mechanism of copper has been described as the interaction of copper with $-\mathrm{SH}$ groups and affinity towards amines and carboxyl groups [27], causing permeation of bacterial cells, blocking metabolism [27, 28]. Another review was written by Joseph Lemire et al. introduced that copper can simulate the production of reactive oxygen species (ROS) and depletion of antioxidants by catalyzing Fenton chemistry in vitro [29]. Zinc is another inorganic agent, commonly used in antibacterial dressings [30, 31]. Nano-zinc oxide has a strong killing activity on Escherichia coli and Staphylococcus aureus. It shows higher inhibition activities on gram-positive than on gram-negative bacteria. The bacteriostatic mechanism of nano-zinc is similar to silver, mainly through the penetration of the cell membrane, binding with the enzymes of electron transport chain to achieve inhibition of bacteria. Some researchers pointed out that zinc ions can bind to the bacteria while because the bacterial surface is full of negative charge, and also binds stronger than silver ions because of more positive charge. After binding, the damage of the bacterial surface occurs, leading to death. Nano-oxide particles such as nano-silver oxide, nano-zinc oxide, possess a strong oxidative activity and can induce the generation of reactive oxygen species, which is also an important mechanism for bacterial inhibition [32].

Silica, titanium dioxide, tungsten trioxide and other photocatalytic antibacterial agents can produce active oxygen species from the air or water under the influence of light and then break down the bacterial cell wall, leading bacteria death [33, 34]. Usually, these agents are used as carrier or layer for other antibacterial agents, mainly silver [35]. In some cases, they are applied for the protection for antibacterial protein [36]. However, their usage is limited for wound dressing because of dependency on light.

\section{Natural agents}

The natural products used in antimicrobial dressings are mainly active components of potential antibacterial extracts from plants such as hemp, rhubarb, aloe etc.. Antimicrobial peptides of insects, chitin and its deacetylated product chitosan can be extracted from insect shells or cell wall of fungi and are also developed for wound care.

\section{Plants}

Plants have long been considered an interesting source of antibacterial and antibacterial agents because of their numerous biologically active compounds. Research on plant-derived antibacterial agents happens all over the world, especially in China, India, South Africa, Denmark, etc.. Many different compounds have been shown to have antibacterial properties and some have been used in the wound dressing. Tina et al. [37] reviewed 22 plants as herbal medicines in wound healing, including Achillea, Angelica Sinensis, Centella Asiatica, Aloe vera etc.. Especially, Aloe vera, is one of the most highly developed herb plants in treating wounds, and many studies of its application have been presented [38-40]. The inhibition activity against bacteria is partly from acemannan, the main polysaccharide from Aloe vera gel, and this component is also attributed to stimulating macrophage activity [41, 42]. 
Natural active compounds like berberine [43], curcumin [44], allicin [45], emodin [46], and quercetin [47] are also introduced into wound dressings as antibacterial agents (Fig 3), occasionally incorporated in combination with silver or antibiotic drugs.<smiles>COc1ccc2cc3[n+](cc2c1OC)CCc1cc2c(cc1-3)OCO2</smiles>

Chemical Formula: $\mathrm{C}_{20} \mathrm{H}_{18} \mathrm{NO}_{4}^{+}$

1 Berberine<smiles>COc1cc(/C=C/C(=O)/C=C(O)/C=C/c2ccc(O)c(OC)c2)ccc1O</smiles>

Chemical Formula: $\mathrm{C}_{21} \mathrm{H}_{20} \mathrm{O}_{6}$

3 Curcumin

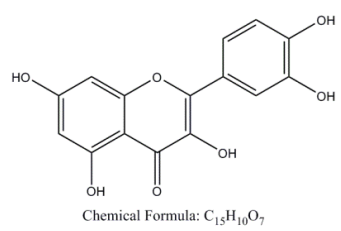

5 Quercetin

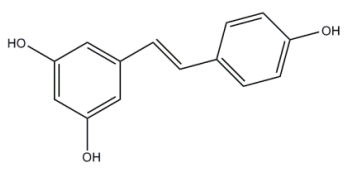

Chemical Formula: $\mathrm{C}_{14} \mathrm{H}_{12} \mathrm{O}_{3}$

6 Resveratrol

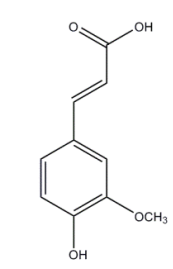

8 Ferulic acid
Chemical Formula: $\mathrm{C}_{10} \mathrm{H}_{10} \mathrm{O}_{4}$

$$
\mathrm{H}_{12} \mathrm{O}_{3}
$$
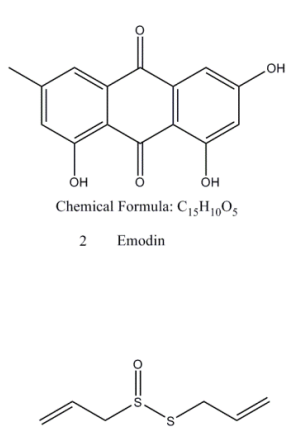

Chemical Formula: $\mathrm{C}_{6} \mathrm{H}_{10} \mathrm{OS}_{2}$

4 Allicin

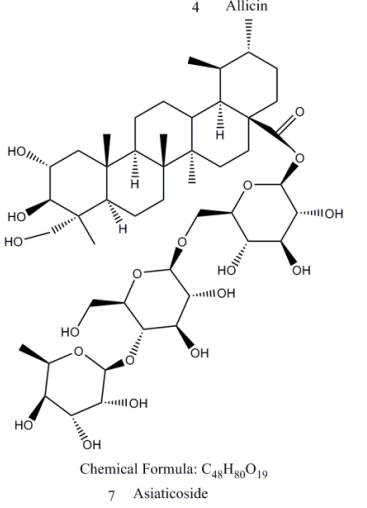

7 Asiaticoside

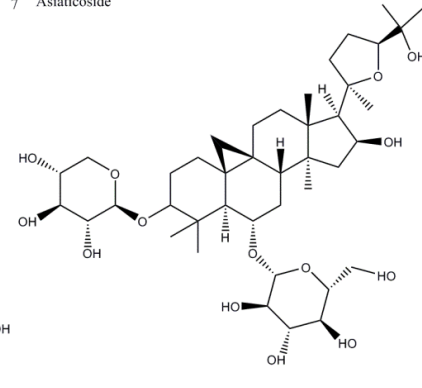

Chemical Formula: $\mathrm{C}_{41} \mathrm{H}_{68} \mathrm{O}_{14}$

10 Astragaloside IV

Fig 3. Natural bioactive ingredients in wound dressing (1-5, antibacterial agents; $6-10$, stimulating healing process)

Another lager part of plant extract prepared and used for application in wound dressings are essential oils, easily obtained from flowers, seeds, leaves, fruits, and roots. Generally, the essential oils come from tea tree, clove, geranium, lavender, thyme, lemon grass, laurel orange, cinnamon, etc. (Table 2) [48-50]. Moreover, some plant fibers such as stinging nettles [51], hemp [52], bamboo [53] are employed as scaffold and effective absorbent for exudates as slipcover, while also delivering bioactive compounds to the wound. 
Table 2 Essential Oil in wound dressing

\begin{tabular}{|c|c|c|c|c|c|}
\hline Polymers & Antibacterial peptide/Resource & Formation & Technology & Bacteria & Ref \\
\hline Sodium alginate & $\begin{array}{l}\text { Elicriso italic, chamomile blue, cinnamon, } \\
\text { lavender, tea tree, peppermint, eucalyptus, } \\
\text { lemongrass and lemon oils }\end{array}$ & Film & $\begin{array}{l}\text { Mixed with alginate solution, } \\
\text { then at room temperature until } \\
\text { films were dried }\end{array}$ & E.coli & [54] \\
\hline Cellulose acetate & Cinnamon, lemongrass, peppermint oils & Fibrous & $\begin{array}{l}\text { Mixed with cellulose acetate, } \\
\text { then electrospun }\end{array}$ & E.coli & [55] \\
\hline $\begin{array}{l}\text { Chitosan/Poly(ethylene } \\
\text { oxide) }\end{array}$ & Cinnamaldehyde & Nanofibers & $\begin{array}{l}\text { Mixed with solution, then } \\
\text { electrospun }\end{array}$ & $\begin{array}{l}\text { E.coli, } \\
\text { P. aeruginosa }\end{array}$ & [56] \\
\hline
\end{tabular}


Cinnamon essential oil

Nanofilm

\section{Co-precipitation method into \\ $\beta$-cyclodextrin, then}

E.coli,

electrospinning in fibers film

The microemulsions of oil

mixed with alginate solution,

In suit
hydrogels then a spray-by-spray

hydrogels

crosslinking method to generate

hydrogels

Fibers 


\section{Gelatin}

Gelatin

Agar, Sodium alginate
Zataria multiflora essential oil

Ferula assa-foetida Essential oil

Film
Mixed with gelatin solution,

then at room temperature until

films were dried

Formulated in $1.5 \%$

hydroxypropyl cellulose
S. aureus,

B. Subtilis

E. coli,

P. aeroginosa

S. aureus, E. coli

Photobacterium

Mixed with agar or sodium

alginate solution to form upper

phosphoreum,

Salmonella

choleraesuis,

Pseudomonas

oven at $45^{\circ} \mathrm{C}$ for $12 \mathrm{~h}$

fluorescens,

L.monocytogenes 


\section{Honey}

Over centuries, honey has been used for the treatment of the chronic wound and was reported to offer a broad antibacterial activity including Gram-positive and negative bacteria [64]. One of its antibacterial mechanisms attributes to the extraordinary high sugar content (elevated fructose, glucose, maltose, and sucrose) induced cumulative action. Lower $\mathrm{pH}$ values caused by an organic acid such as citric acid, malic acid, lactic acid, benzoic acid, gluconic acid etc., may be responsible for bacterial death [65]. Alternatively, some flavonoids such as quercetin, luteolin, apiqenin were reported to enhance the antibacterial activity towards certain bacteria [66], whilst, enzymes from bees or plants like defensin, lysozyme, glucose oxidase play an important role in the degradation of components of bacteria. Besides antibacterial activities, honey also accelerates inflammation phase by regulating the synthesis and secretion of tumor necrosis factor, interleukin- $1 \beta$, and interleukin- 6 . These cell factors activate macrophages which can synthesize several types of growth factors to stimulate the growth of capillaries (angiogenesis), collagen and fiber synthesis [67, 68]. However, different kinds of honeys from diverse areas contain various components that come from the local kinds of plants and bees. The most popular honey for wound healing and in wound dressings is Manuka [69, 70].

\section{Insect and animal-derived compounds}

\section{Lysozyme}

Lysozyme called $\mathrm{N}$-acetylcitaminase hydrolase specifically works on the $\beta-1,4$ bond existing between the $\mathrm{N}$-acetyl muramic acid and $\mathrm{N}$-acetylglucosamine in the peptide polysaccharide molecule and thus destroying the bacterial cell wall. In several studies, lysozyme was incorporated into antibacterial dressings [71, 72]. For example, Abouhmad et al. [73] demonstrated that T4 lysozyme fused with Cellulose Binding Module in gauze wound dressings had activity against Gram-positive and Gram-negative bacteria but lost its inhibition ability of Gram-positive after heat denaturation. In other words, lysozyme can be used as the replacement for traditional antibiotics in wound healing.

\section{Antibacterial peptides}

Antibacterial peptides (Table 3), are a kind of polypeptide named by their efficient antibacterial activity against both Gram-negative and positive bacteria. Some of these peptides also possess strong inhibition towards fungi and even tumor cells. Antibacterial peptides are widely reported from plants, insects, fish, amphibian, and mammals [74]. The mechanism of these agents, at present, is generally believed to cause leakage of cell content triggered by the formation of the transmembrane channel. Moreover, antibacterial peptides from humans including defensins and cathelicidins play an important part in skin healing. Regardless of their significant bactericidal effect, human defensins are also involved in the promotion of humoral and cellular immunity, stimulation the mitosis of epithelial cells and fibroblasts, growth of blood vessels and synthesis of collagen. Cathelicidins stimulate the proliferation and migration of cells as well as release of cytokines. What's more, they can inactive the endotoxin of Gram-negative bacteria thus avoiding the emergence of bacteremia [75]. So, these peptides have great potential for future strategies in wound healing. However, one drawback is these peptides are unstable when exposed to an outer environment which 
allows for only limited use of the incorporation in hydrogels or degradable skin substitutes [76]. 
Table 3. Antimicrobial peptide in wound dressing

\begin{tabular}{|c|c|c|c|c|c|c|}
\hline Polymers & $\begin{array}{c}\text { Antibacterial } \\
\text { peptide/Resource }\end{array}$ & Formation & Technology & Bacteria & Others & Ref \\
\hline $\begin{array}{l}\text { Poly (ethylene } \\
\text { glycol) maleate } \\
\text { cirate/ } \\
\text { Poly } \\
\text { (ethylene glycol) } \\
\text { diacrylate }\end{array}$ & $\begin{array}{l}\text { CHRG01(Human beta } \\
\text { defensin3)/ABO- } \\
\text { CHRG01(Aminobutyri } \\
\text { c acid-)/ } \\
\text { Temporin-A(Rana } \\
\text { temporaria, European } \\
\text { red frog)/Ala5-Tritrp7 } \\
\text { (Cathelicidin) }\end{array}$ & Hydrogel & $\begin{array}{l}\text { Radical } \\
\text { polymerization/ } \\
\text { Antimicrobial peptide } \\
\text { conjugated PEGMC } \\
\text { via the } \\
\text { carbodiimide coupling } \\
\text { technique }\end{array}$ & S. aureus & $\begin{array}{l}\text { More collagen deposition and a } \\
\text { higher amount of myofibroblast } \\
\text { formation }\end{array}$ & [77] \\
\hline Silk fibroin & $\begin{array}{l}\text { Motif (Cys-KR12) } \\
\text { (human cathelicidin } \\
\text { peptide (LL37) ) }\end{array}$ & $\begin{array}{l}\text { Nanofiber } \\
\text { membrane }\end{array}$ & $\begin{array}{l}\text { Immobilized by } \\
\text { ethylcarbodiimide } \\
\text { hydrochloride and N- } \\
\text { hydroxysuccinimide / } \\
\text { thiol-maleimide click } \\
\text { chemistry immobilized }\end{array}$ & $\begin{array}{l}\text { S.aureus, } \\
\text { S.epidermidis, E.coli, } \\
\text { and P. aeruginosa }\end{array}$ & $\begin{array}{l}\text { Proliferation of keratinocytes and } \\
\text { fibroblasts,suppressed the LPS- } \\
\text { induced TNF- } \alpha \text { expression of } \\
\text { monocytes }\end{array}$ & [78] \\
\hline Carbomers & $\begin{array}{l}\text { LLKKK18(Analogs of } \\
\text { LL37) }\end{array}$ & $\begin{array}{l}\text { Carbopol }{ }^{\circledR} \\
\text { hydrogel }\end{array}$ & $\begin{array}{l}\text { Conjugated with } \\
\text { dextrin,then } \\
\text { incorporated into a } \\
\text { Carbopol }{ }^{\circledR}\end{array}$ & & $\begin{array}{l}\text { Decreased neutrophil and } \\
\text { macrophage infiltration and } \\
\text { pro-inflammatory cytokines } \\
\text { levels, stimulated angiogenesis }\end{array}$ & [79] \\
\hline
\end{tabular}




\begin{tabular}{|c|c|c|c|c|c|c|}
\hline $\begin{array}{l}\text { Polypropylene } \\
\text { oxide/Ethylene } \\
\text { oxide }\end{array}$ & $\begin{array}{l}\text { KSL-W antimicrobial } \\
\text { peptide (analog of } \\
\text { KSL peptide) }\end{array}$ & Gel & $\begin{array}{l}\text { Mixed with gel } \\
\text { solution }\end{array}$ & $\begin{array}{l}\text { S. epidermidis, } \\
\text { Vancomycin-resistant } \\
\text { Enterococci, } \\
\text { K.pneumoniae, } \\
\text { P. aeruginosa, } \\
\text { A. baumannii, } \\
\text { Methicillin-resistant } \\
\text { Staphylococcus } \\
\text { aureus, } \\
\text { Coagulase-negative } \\
\text { Staphylococci }\end{array}$ & & [80] \\
\hline Hyaluronic acid & $\begin{array}{l}\text { Nisin Z(from } \\
\text { Streptococcus lactis) }\end{array}$ & Hydrogels & $\begin{array}{l}\text { Grafted onto HA } \\
\text { through by amide } \\
\text { bonds }\end{array}$ & $\begin{array}{l}\text { S. epidermis, S. aureus } \\
\text { and P.aeruginosa }\end{array}$ & Anti-biofilm & [81] \\
\hline $\begin{array}{l}\text { Chitosan/ } \\
\text { Polyanion (alginic } \\
\text { acid sodium } \\
\text { salt)/Cotton } \\
\text { gauzes }\end{array}$ & $\begin{array}{l}\text { hBD-1( } \beta \text {-Defensin-1, } \\
\text { human)/ } \\
\text { Dermaseptin(Phyllome } \\
\text { dusa } \\
\text { genus of frogs)/Cys- } \\
\text { LC-LL-37(LL- } \\
\text { 37)/Magainin 1 } \\
\text { (African clawed } \\
\text { frog-Xenopus laevis) }\end{array}$ & Film & $\begin{array}{l}\text { Film immersed in a } \\
\text { solution of AMPs }\end{array}$ & $\begin{array}{l}\text { S. aureus and } \\
\text { Klebsiella pneumonia }\end{array}$ & $\begin{array}{l}\text { Non-cytotoxic to normal human } \\
\text { dermal fibroblasts at the } \\
\text { concentrations tested. }\end{array}$ & [82] \\
\hline
\end{tabular}


Poly(1-lactic acid)-Pluronic L35-poly(1-lactic acid)

AP-57 (human)

In situ gel

AP-57 was emulsified

with the organic-phase

consisting of PLLA-

L35-PLLA

HHC10 (H-

KRWWKWIRW- Hydrogel

NH2)

glycol)

PXL150(synthesized)

Gel

cellulose

CM11((WKLFKKILK

Alginate

Formulated in $1.5 \%$

cellulose

Peptide was photopolymerization

S. aureus,

S. epidermidis,

E. coli
Increasing collagen deposition

and promoting angiogenesis

[83]

A wide tolerance inside chain and

backbone orientations with

respect to their antibacterial

properties and selectivity

hydroxypropyl

S. aureus

incorporated in the Methicillin-resistant

hydrogel matrices by Staphylococcus aureus

in-situ loading 


\section{Antibiotics and others}

There is no doubt that the main-stream antibiotics play an important role in the treatment of chronic wounds [87]. However, with the emerging of multi-resistance bacteria, for example, methicillin resistant Staphylococcus aureus (MRSA), the use of antibiotics is more cautious in clinical practices. Currently, ceftazidime hydrate, gentamicin sulfate, erythromycin, metronidazole, ofloxacin, silver sulfadiazine etc., are being used in the treatment of chronic wounds [88]. Some low molecular organic antibacterial agents mainly are quaternary ammonium salts, biguanides, phenols, pyridines, and their metal derivatives, are also a part of drugs treating the infection. These organic compounds can bind (passively) with or "be attached to" (actively)polymers to generate high molecular organics by homopolymerization, copolymerization, or grafting technologies [89].

\section{Anti-biofilm agents}

Biofilm, as we discussed earlier in this review, can provide the protection of bacteria and delay the wound healing process. A number of antibiotic have been proposed against biofilm, roxithromycin, fleroxacin, for instance [90, 91] Some studies also demonstrated that transition metal gallium and iodine can reduce the generation of biofilm without tissue damage $[92,93]$. Others reported that lactoferrin could weaken the matrixes by decomposing the extracellular polysaccharides. More recently, Orr et al. [94] found an enzyme named oligoribonuclease which could clean the 'signal switch molecular', cyclic-di-GMP of bacteria, thereby stopping the production of biofilm, may potential used for wound infection.

\section{Graphene and Chitosan}

Graphene is currently thinnest, strongest thermal conductivity nano-material that is known. Shaobin Liu et al. [95] tested antibacterial activity toward Escherichia coli of four types of grapheme-based materials namely graphite, graphite oxide, graphene oxide, and reduced graphene oxide. They found that graphite oxide possessed the highest antibacterial capability. They proposed that the antimicrobial mechanism was due to membrane stress caused by direct contact with sharp nanosheets and superoxide anion-independent oxidation. Zengjie Fan et al. [96] incorporated graphene in a hydrogel dressing combined in a composite with silver and found a strong antibacterial performance and wound-healing ability. Furthermore, graphene has been used as a support to disperse and stabilize various nanomaterials and to construct drug delivery platforms [97].

Chitosan and its derivatives draw much attention by researchers worldwide. It is not only used as the scaffold of dressings due to their biocompatibility and low toxicity but can also act as an antibacterial polymer [98]. The mechanism is not fully explained yet, but it is postulated that the interaction of positive charges brought by protonated amino groups with the negative charge of the bacterial surface contributes strongly to bacterial cell death. Alternatively, chitosan with the molecular weight below $5 \mathrm{kDa}$ could penetrate the bacterial membrane and impede the function of DNA or intracellular proteins. Moreover, high molecular weight chitosan and cross linked polymers form a dense network on the membrane that leads to warped bacteria and blocking of the transportation of nutrition into bacteria [99]. 


\section{The use of drug combinations}

The combination usage of drugs provides a broader antibacterial spectrum, stronger inhibition or killing activity, reduces the chance of emergence of drug resistant bacteria and lowers the risk of toxic side effect by decreasing the individual dose [100-103].

At present, the silver combination with other antibacterial agents may be the widest used approaches to manage wound healing in both clinical practice and lab tests. Lu et al. [104] prepared microporous $\mathrm{Ag} / \mathrm{ZnO}$ nanocomposites into chitosan in view of their antibacterial activities against drug-resistant and drug-sensitive pathogenic bacteria and tested for antibacterial activity. The results demonstrated that the chitosan- $\mathrm{Ag} / \mathrm{ZnO}$ dressings showed obviously antibacterial activities towards drug-sensitive E. coli, $S$. aureus and $P$. aeruginosa using different $\mathrm{Ag} / \mathrm{ZnO}$ content and inhibition toward drug-resistant MRSA when using the high content. Moreover, the dressings also enhanced the wound healing process by stimulating re-epithelialization and collagen deposition. Herein, similar to many other studies $[77,105,106]$, chitosan was used as the scaffold more than as an antimicrobial agent, however, its activity against bacteria still contributed. Graphene and TiO2 are mostly employed as fibers or layers combined with incorporated silver or nano-silver for wound dressing applications [97, 107]. Some anti-biofilm agents like lactoferrin/xylitol have also been used in combination with silver-based wound dressings which provided a more effective approach toward the reduction of biofilm [108].

The combination of the active component of plants with antibiotics has been attempted as the solution for wound infection [109]. In this study, PVA/PEO/CMC/Aloe vera and $\mathrm{PVA} / \mathrm{PEO} / \mathrm{CMC} / \mathrm{curcumin}$ dressings were developed with nonwoven polyester fabric as the support layer and tetracycline hydrochloride as antibiotic drug. The dressings exhibited the ideal irregular, three dimensionally interconnected pores across the matrix for drug loading, drug release and antimicrobial activity against $E$. coli and $S$. aureus.

Antibacterial agents combined with anti-inflammatory drugs also have been reported. Streptomycin and diclofenac were loaded into polyethylene oxide and carrageenan based solvent cast films which could be employed for preventing and treating chronic wound infection and relieving pain and swelling during inflammatory phase [110]. In a related study, a combination of diclofenac sodium, lidocaine hydrochloride, benzalkonium chloride was added into or on the nanofibrous electrospun poly(L-lactide). These drug loaded fibers may be used for chronic wound treatment because of slower drug-release, possibly attributed to an ionic interaction between the diclofenac sodium with lidocaine hydrochloride [111].

Growth factors (such as vascular endothelial growth factor, platelet-derived growth factor, basic fibroblast growth factor and endothelial growth factor etc.) have already been introduced to antibacterial agents (piperacillin-tazobactam, chlorhexidine) or polymers (collagen, hyaluronic acid, chitosan etc.) to generate a suitable environment for accelerating the recovery of wound [112-114]. Xie et al. designed a chitosan/poly(ethylene oxide) material loaded with vascular endothelial growth factor and platelet-delivered factor-BB. Wound area for 2:1 chitosan/poly(ethylene oxide) samples with growth factors is significantly smaller than Hydrofera Blue ${ }^{\circledR}$ (a multi-layer wound dressing which contains gentian violet and methylene Blue compatible for the use of growth factors) as reported in 
their experiments at week 1 and 2. The performance of sectioned tissue samples suggests a quicker collagen deposition and earlier remodeling of tissues compared with commercial Hydrofera Blue ${ }^{\circledR}$ wound dressing [115].

\section{Controlled drug delivery in dressings}

The special multi-layer structure of wound dressings and the characteristics of the polymers have long been considered to provide a perfect means of delivering drugs to wound site in a consistent and sustained way to enable and support chronic wound care. Importantly, a controllable release of drugs in wounds offers safe treatment by avoiding cytotoxicity caused by sudden elevated released dose in regular dressings. Additionally, the lesser requirement for frequent dressings change would be another advantage. It can reduce health care costs and burden to the patient.

\section{From fibers}

Antibacterial agents wrapped in degradable micro- or nano-spheres like gelatin, chitosan and polylactic, or uniformly dispersed into the porous materials/coatings such as titanium dioxide, calcium carbonate, calcium phosphate etc, will be slowly released from such carriers into wound sites once contacted with water or exudates. In this case, polymer fibers made of polyvinyl alcohol, polyvinylpyrrolidone, polyurethane etc., in dressings exhibit wonderful features as drug carriers including high drug-loading content, good biocompatibility, and more stable drug release efficiency. Although the natural fibers such as cotton, gauze, and tulle are still the main plant materials used nowadays for commercially available dressings that are beneficial in clinical wound management, the development now has already focused on synthetic materials.

The drug release system in non-biodegradable fibers can be simply described as contactrelease or contact-invasion-release (Fig 4). In a study with incorporated hydrophilic antibiotic drug cefoxitin sodium on electrospun poly(lactide-co-glycolide)-based nanofibrous scaffolds revealed a sustained release of the drug [116]. Drugs were first mixed with the polymer solution then formed into nanofibers by electrospinning technology and could maintain more drugs and prolong the release time [117]. However, agents loaded by adsorption or chemical bonding like these into or on the surface of fibers, usually have a maximum dosage and release rate in the first few hours after contacting the exudates.

Nanofiber tube like carbon nanotubes, chitosan nanotubes, $\mathrm{TiO} 2$ nanotubes etc., have been applied as a promising solution without burst release compared with regular fibers in many studies [118-121]. A core/shell structure also has been described to enhance the release ability. Ma et al. $[122,123]$ prepared silver nanoparticles decorated $\mathrm{SiO} 2$ nanofiber as core covered by mesoporous $\mathrm{SiO} 2$ nanofiber, which provided high flexibility and huge specific surface area with better exudates absorption and long-term antibacterial effect for potential usage of wound healing. 


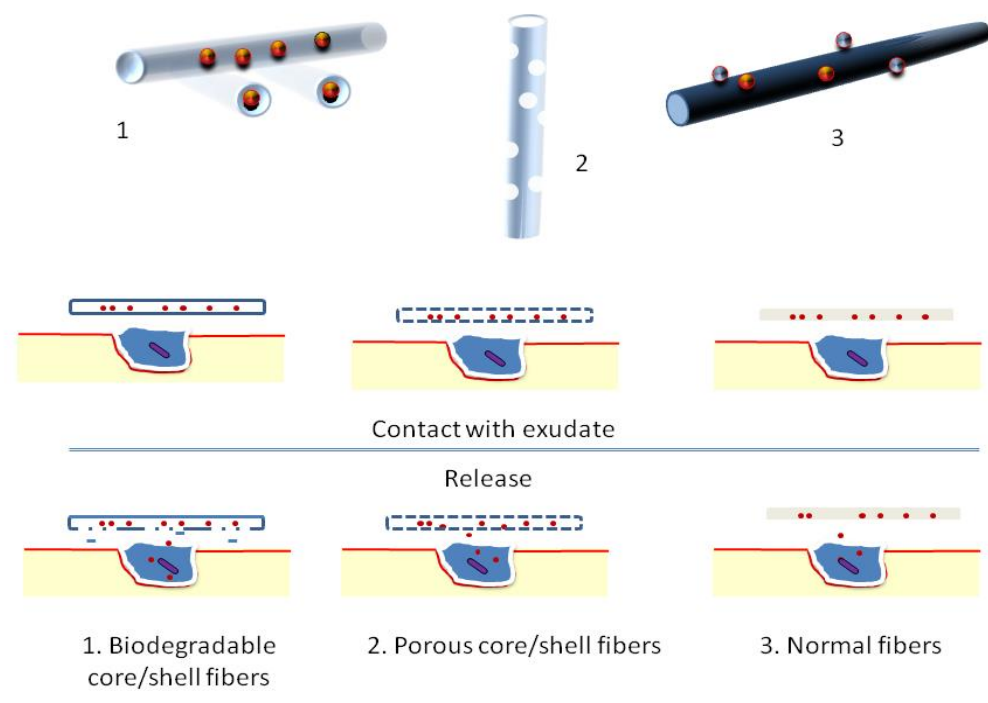

Fig 4. Drug release from fibers. 1) drugs loaded inside of fiber and released with fiber degradation. 2) drugs loaded inside of fibers and released through pores. 3) drugs loaded on the surface of fiber by chemical bonding or adsorption.

\section{From Foam}

Foam is a porous dressing which shows high water (exudates) absorption ability and are mostly made of polyurethane, but also other materials like chitosan, sodium carboxymethyl cellulose, alginate polylactic acid, polyvinyl alcohol have been employed. Antibacterial agents were loaded into the dressings by physical or chemical methods (Fig $\mathbf{5 A}$ ). Once the exudates with bacteria get absorbed from chronic wound site into the holes of foam dressing, the antibacterial agent will be immediately and continuous released from the matrix to inhibit the growth or killing bacteria and would slowly penetrate the area around the wound site. The benefits of these dressings are that the open pore structure gives a high moisture-vapor transmission rate and good breathability. Furthermore, much of its antibacterial agents displayed their action and activities inside the pore structure instead of direct contact with cells in the wound, which minimizes negative effects on wound healing and the risk of systemic cytotoxicity to the human body. 

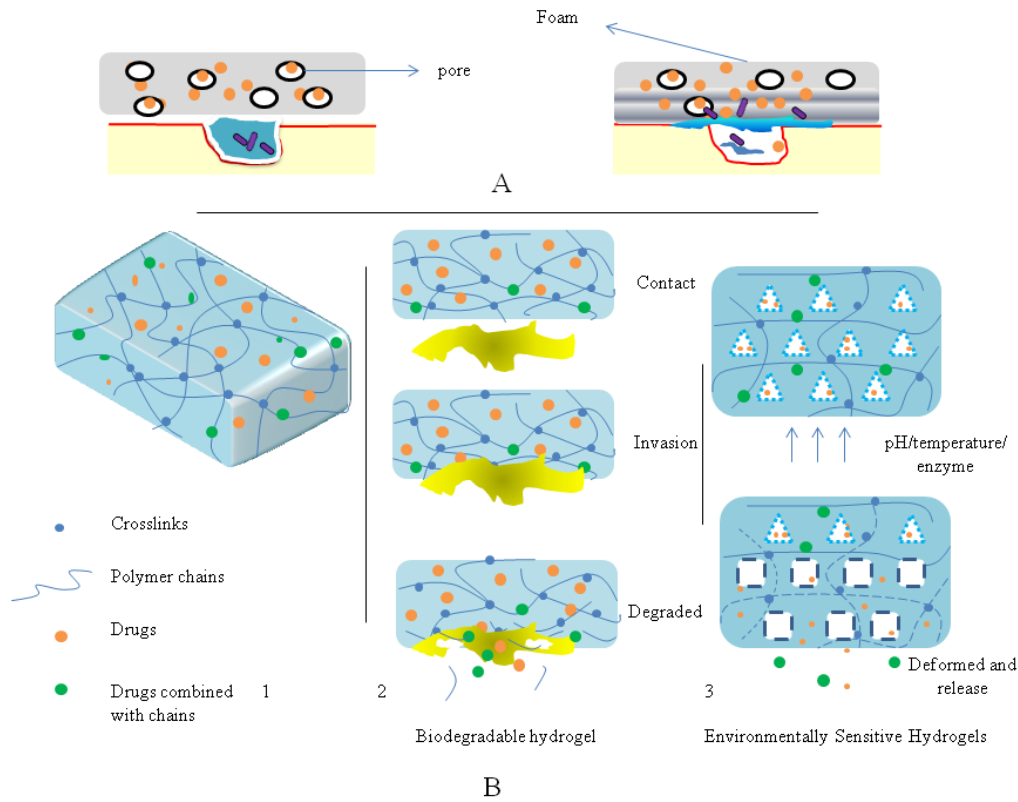

Fig 5. A) Drugs release from foams (contact-invasion-formation of gel-diffusion). B1) The schematic diagram of hydrogel (drugs dispersed inside or combined with polymer chains). B2) Biodegradable hydrogel. B3) Environmentally sensitive hydrogels (polymer network change with environmental factors change. Pores become larger and allow for drug release).

\section{From Hydrogel}

Hydrogel is primarily made from natural polymers such as collagen, gelatin, cellulose, chitosan and its derivatives. Synthetic polymeric like polyvinyl alcohol, polyethylene oxide, poly(lactic acid), polyvinyl-pyrrolidine are also used as swellable absorbent dressings. These polymers usually work as the network to achieve better mechanical properties, water maintenance, drug loading and delivery properties to stimulate wound healing.

Drugs released from the pores of crosslinked polymeric network or dissociation from polymer molecules depends on the hydration of polymer by exudates. In past decade, smart hydrogels were developed that can show phase transformation of cross-linked structure upon the change of environmental parameters like $\mathrm{pH}$, temperature, light, electricity or upon addition of specific compounds These hydrogel dressings allow for the inducible release of incorporated antibacterial drugs (Fig 5B) [124-126]. In these hydrogels, diffusion of antibacterial agents can be induced. In addition, delayed release can be obtained from wound sites by extrusion due to shrinking or swelling of hydrogels. However, only a few studies about the release of antibacterial agents in environment-responsive hydrogels and their potential usage have been described [127, 128]. Lin et al. [129] manufactured the thermosensitive hydrogel made of polyurethane (PU)/ $N$-isopropyl acrylamide and acrylic acid, as carrier of FGF-2, and found the release rate was slower at $37^{\circ} \mathrm{C}$ than at $25^{\circ} \mathrm{C}$. This was caused by the formation of dense structure of hydrogel at $37^{\circ} \mathrm{C}$. Moreover, this dressing was easier to strip off, suggesting a promising and effective controlled release material for 
wound management. In another study, a non-toxic, biocompatible, $\mathrm{pH}$-sensitive hydrogel made of chitosan/gelatin/polyvinyl alcohol hydrogels was produced. The swelling ratios of hydrogels were increased in acid conditions and decreased when $\mathrm{pH}$ values were above 6.0, which could present more space for the potential release of drugs into exudates and wound site, showing $\mathrm{pH}$-controlled drug delivery ability [130].

Nanocellulose pre-treated by carboxymethylation and periodate oxidation was also employed for $\mathrm{pH}$-sensitive hydrogels, which had a higher swelling degree in neutral and alkaline conditions than in an acid environment, suggesting an intelligent release of antibacterial components [131]. Liu et al. [132] studied an injectable acrylate hyperbranched polyphosphoramidate/ thiolated hyaluronan hybrid hydrogel. Dithiothreitol was added as the trigger to accelerate the collapse of gel thus controlling the release of bovine serum albumin. Although this material has encouraging properties, its use for wound dressings remains unclear. G. Tronci et al. [133] presented a metalloproteinase-9 protease-sensitive atelocollagen hydrogels made of 4-Vinylbenzylation/ type I atelocollagen. It is considered as useful drug delivery system in a diabetic wound care, because this collagen system can be equipped with multiple, customisable antibacterial agents and is degradable when in contact with matrix metalloprotein-9 (MMP-9).

\section{From biodegradable dressings}

Biodegradable materials have gained considerable attention in the application of wound dressings to reduce the additional trauma to the newly formed tissues caused by surgically removing used dressings and as the biocompatible scaffold for the growth of new cells. Recently, most of the efforts have been directed to the development of biodegradable hydrogel for the care of chronic wounds. Such other kind of dressings is preferably made from fibers or foam, mainly because of their potential in situ gelling which provides ease of application for complete wound closure. Moreover, it's perfect hydrophilicity maintains a moisture environment which could support the re-epithelialization. However, in degradable dressings, the drug delivery rate depends on the polymer degradation characteristics and the triggers such as water, enzymes or other substances.

Generally, degradable biopolymers are derived from natural polymers like bacterial cellulose alginate, chitosan, hyaluronic acid, collagen, fibrin and polyhydroxy alkanoate, or synthetic product such as poly(lactic acid), polycaprolactone, poly(L-lysine citramide), poly(ortho esters), polydioxanone and their derivatives. Loaded drugs in the matrix of hydrogel or fibers will be automatically released with the bulk degradation or surface erosion of polymers into the wound sites (Fig 4). Poly(lactic acid) and their copolymers probably are the most widely used synthetic degradable polymers in the construction of wound dressings. Mahsa and coworkers [134] produced and evaluated new degradable poly(lactic acid) nanofibers loaded with highly porous silver microparticles or silver nanoparticles as antibacterial agents. The release ability of this carrier has been tested under deionized water at $37^{\circ} \mathrm{C}$ and $5 \% \mathrm{CO}_{2}$ for one week. Results turned out a better gradually release ratio from micro-silver than that of nano-silver which indicated a steady antibacterial activity and less toxicity. In 2015, Xie et al. [135] applied poly(ethylene glycol) maleate citrate with poly(ethylene glycol) diacrylate for wound healing with the conjugation of antibacterial peptides CHRG01, ABU-CHRG01, Temporin-A, and Ala5-Tritrp7, prepared by free radical 
polymerization. The biocompatibility of hydrogel and its hydrolysis products were studied on human dermal fibroblasts and showed no cytotoxicity under $6.67 \mathrm{mg} / \mathrm{mL}$, which suggested a wide potential use.

Chitosan, alginates, cellulose are probably the most common natural materials used for degradable dressings applications because of a wide range of sources, biocompatible, mature cross-link technology that have been reviewed [136, 137].

Hyaluronic acid (HA) is a naturally occurring linear polysaccharide with a high molecular weight, consisting of 2 -acetam-ide-2-deoxy- $\beta$-D-glucose and $\beta$-D-glucuronic. It has attracted much attention from researchers because its rapid biodegradation ability in the human body from where it originates [138]. It is usually combined with other biopolymers as the scaffold because of its weak mechanical properties when applied alone [139-142]. Moses et al.[143] showed the safety and efficacy of a pure HA dressing without additional substances in the treatment of diabetic foot ulcer. Next, to delivery of antibacterial agents [81, 142], porous hyaluronic acid was also employed as the vehicle of nonviral DNA or growth factor to promote granulation tissue formation [144, 145].

Interestingly, some bacterial polyesters, poly( $\beta$-hydroxy butyrate) or poly( $\beta$-hydroxy valerates) are promising materials as drug delivery carriers, especially for anti-biofilm drugs, because these polymers are synthesized by microorganisms as their carbon store and are produced in limiting conditions of various nutritional elements [146]. Once bacteria reuse their stock, the agents could be easily released and absorbed with the process of biodegradation of extracellular polymers: the biofilm. However, despite increasing knowledge on the synthetic routes and degradation characteristics of these polyesters, their application on wound dressings is not extensively studied and needs further development [147-150].

\section{Intelligent dressings: from bacterial detection to treatment}

Due to the development of micro-sensing technology, nanotechnology and the new discoveries of innovative materials, wound dressings will become more and more intelligent $[151,152]$.

However, the difficulty is how to define the 'intelligent wound dressing'. Lin et al. immobilized sulfamethoxazole into poly( $\mathrm{N}$-isopropylacrylamide) micro-gel beads for wound dressing applications [153]. Poly(N-isopropylacrylamide) exhibited thermos-sensitive critical property thus it can automatically release the antibacterial agents into the wound at a certain temperature. Although this dressing can react along with the changes of the wound, it can't give any real-time visually information about wound status. It might be 'smart' but not 'intelligent' enough. The main characteristic of 'intelligent wound dressings' is that it can provide readable output information about the status of wound sites timely through the detection of sensors or indicators. In 1989, Eric Flam applied temperature sensor into wound dressing for monitoring the presence of infection without the need for removal of dressing [154]. This might be the first prototype of 'intelligent wound dressing'. Then, wireless sensor had been employed to reach a more effective detection capability. For example, Sridhar and Takahata fabricated passive wireless sensor into dressing to track the $\mathrm{pH}$ and moisture level of wound [155]. It is known that the treatment with antibiotics is risky and not recommended before the critical colonization (local infection) phase really emerged. However, the accurate 
detection of the critical colonization threshold without changing the wound dressing is not well developed yet. Furthermore, biofilm formation is considered as the main factor responsible for the wound transition into a prolonged chronic wound state. In other words, biofilm formation can be employed as the indicator of local infection where clinical intervention becomes necessary. For these reasons, Thet et al. [156] developed a novel wound dressing that was made of a hydrated agarose film. Fluorescent dye (5,6-carboxyfluoresecin) containing vesicles, made of phospholipid, cholesterol, and polydiacetylene polymer lipid, in the hydrogel matrix could switch on fluorescence when in contact with the population-density regulated cytotoxic virulence factors generated by pathogenic biofilm. By detecting early infection of Staphylococcus aureus, Escherichia coli like this, a timely dosing program can be developed.

Moreover, different sensor devices can collect data of humidity, $\mathrm{pH}$, oxygen, microenvironment pressure, virulence factors, enzyme activity or quantity fluctuation of host cells, even smell in wound and transfer the data through wireless communication to phone or computer, giving comprehensive information to physician before changing the dressings. In this way, a more personalized wound management can be achieved, potentially accelerating the healing process [157-159]. Research has pointed out that chronic wound with a high bacteria amount generally have a $\mathrm{pH}$ level above 7.6 [160], while, a lower $\mathrm{pH}$ value can benefit the wound healing process by reducing the bacterial proliferation. For this reason, Petar et al. [161] presented a pH sensitive smart bandage for the detection of wound status. In their study, vinylsulfonyl derivatives coupled with hydroxyl groups of cellulose acted as $\mathrm{pH}$ indicator. The reversible dynamic color changes from yellow to purple in going from acidic to basic were monitored by a miniaturized optoelectronic probe device made by a wide viewing angle $\left(120^{\circ} \mathrm{C}\right)$ surface mount LED with the photodiode. A large amount of monitor data could be stored by $1 \mathrm{MB}$ memory adequately and readout was performed by phone using radio-frequency identification system. This probe system provided temporal insight into wound healing process without invasion or exposure (wound dressing change) which could reduce the complaints fromthe patient.

That moisture of wound surroundings can be helpful for healing has been accepted by the majority of researchers and has also been proven by clinical research. And commercial moisture monitoring products have been appeared on the market already, for example, 'woundsense ${ }^{\mathrm{TM}}$, , a production of Ohmedics Ltd. In this device, the sensor measures the impedance value of disposable silver chloride electrodes powered up by moisture meter and a hand-held monitoring device employed for information collection [162]. Through monitoring, the physician can provide moisture supplements whenever needed. Another study monitored the uric acid concentration in wound exudate, which is supposed to have a high association with wound severity and can be enzymatic hydrolyzed by bacteria from infected wounds [163, 164]. In their work [157], Prussian blue modified carbon electrodes can selectively reduce the peroxide concentration of hydrogen peroxide generated by the enzyme catalyzed the oxidation of uric acid. Status data of infection can be readable on the smart phone or computer using near-field communication.

Although this information can be helpful for wound management for precise and timely drug usage, there is still a need for wound dressing changes. So, some more advanced steps have been made by researchers. In 2015, Lin et al. [165] designed a new smart wound dressing which is able to sense the temperatures of various locations on the skin and then 
delivering and maintaining a sustained release of drugs to the wound by combining stretchable conductors, functional chips, drug-delivery channels and reservoirs into hydrogel matrices. In their design, when the temperature at certain location goes above $35^{\circ} \mathrm{C}$, the wireless temperature sensors produce signals. Then a drug solution is prepared and manually delivered into reservoirs where drugs can be released into hydrogel matrix through the nondiffusive channel. The advantage of this dressing is injecting or replacing drugs according to information of temperature without wound dressing changes. However, sensors in these dressings are usually applied alone. Different functional sensors integrated with each other in the same dressings have not been designed yet.

Interestingly, Mostafalu et al. [158] explored a platform with the drugs loaded into thermoresponsive microparticles encapsulated inside a hydrogel. A small incorporated heater is controlled by microcontrollers. Once needed, the program on phone or computer can send instructions to microcontrollers via wireless and then activate the heater. The thermoresponsive microparticles start release action of drugs into the wound. A similar study has been made by Sare Bagherifard et al. [166] using growth factors loaded for a smart and controllable delivery. These dressings contained a 'drug pool' and automatically switch on or off the drug release system controlled by the computer. However, the limits in these designs are lack of sensor devices of wound status.

Soon, smart dressings should combine 'drug pools' with diverse wound status sensors (Fig 6). The data such as $\mathrm{pH}$, oxygen, glucose, enzymes in wound sites provide comprehensive information can be presented on the computer's/phone's screen for the physician. For example (Fig 6, 1-3), once the sensor is activated by the fluctuation of virulence factors, the data will be collected and sent to a smart phone. The phone will analyze data with historical statistics both from patient and Epidemiology and then provide monitoring results to the physician. After careful diagnosis, physician will send back a therapy instruction to the information center through the phone. Then the heater will be activated, and the antibiotics or growth factors will be accurately released from the pool into the drug delivery tunnel and finally reached to the wound. With the healing process ongoing, this release action of drugs can be stopped or replaced by other more suitable drugs. In this way, a better treatment experience would become available to the patient. 


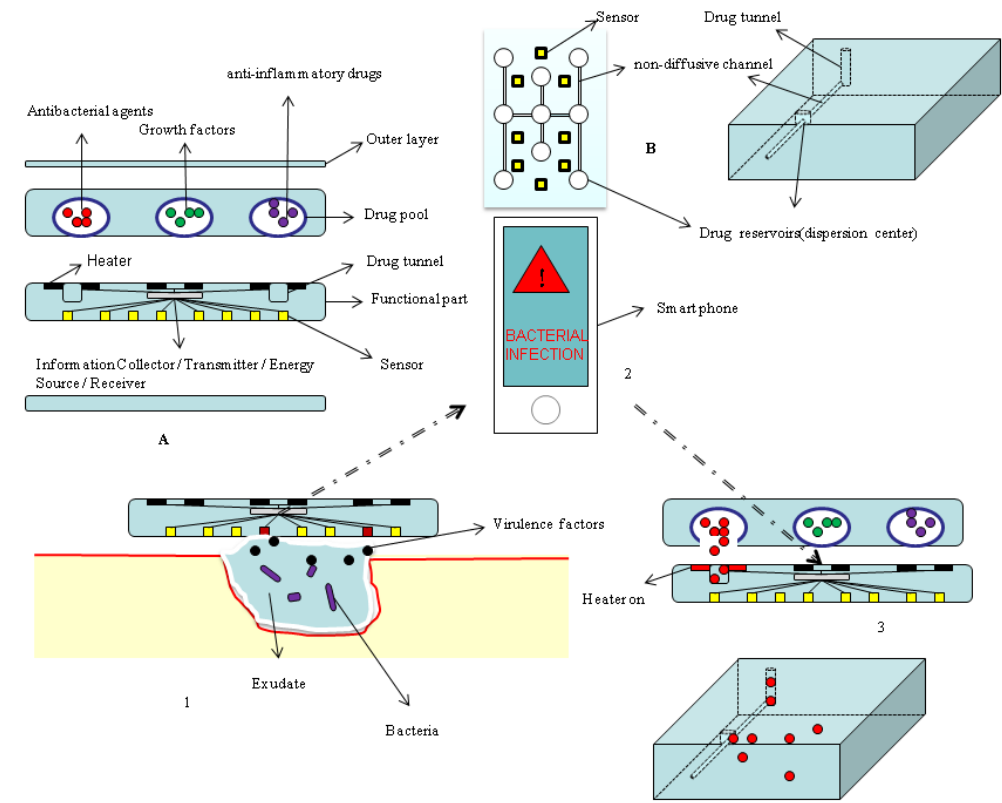

Fig 6. Schematic diagram of the smart wound dressing. A) Multilayer wound dressing: from top to bottom: outer layer, replaceable temperature sensitive layer with drug pool, functional part contains the sensor, heater, information Centre and drug delivery tunnel, non-stick layer. B) Drug delivery system: drug released from the pool into drug tunnel and diffusion at drug reservoirs in order to have a homogeneous sustained release. 1-3) An example of how this system works.

However, disadvantages are also obvious in these smart dressings that currently are too expensive and have higher manufacturing requirements which limit their spread and application for larger numbers of patients.

\section{Limits of this review}

First, it should be noticed that the wound infection mechanisms have not been completely understood yet. The delay of healing depends on the bacterial species as well as the location of the wound site. The reason of the location of wound affecting the healing mainly is caused by the inconsistent distribution of bacterial species on human skin. Additionally, the supplement of blood flow, nutrition, and oxygen are not same in different sites, thus leading to a complex secretion of virulence even in the lifespan of one specific bacteria species. Consequently, infection mechanism will be even more confusing and unpredictable in wound situation where a mixture of bacterial species occurs. For this reason, the understanding of affirmatory mechanism still has a long way to go.In recent years, the silver dressings occupied the majority share in dressings market and were wildly used in the treatment of diabetic foot ulcer infection, leg ulcer infection, bedsore infection management as effective antibacterial agent [23]. However, the evidence of the emerging of silver-resistant bacteria had been reported in clinic practices [167, 168], and cytotoxicity of silver dressings on diabetic fibroblasts has also been recognized [169]. Although its mechanisms are not clear, 
its appearances showed a requirement for new drug's development. Natural products from plant, insects, animals will have to be employed as alternatives.

In fact, there are far more types of wound dressings than mentioned in this review. In early years, bioactive molecules or antibacterial agents in form of solutions, creams, and ointment were used for wound care, mainly in acute wounds. However, when these dressings accumulate more and more exudates during the healing process, they slowly become mobile and another disadvantage is bad breathability [20], so they are replaced by solid dressings like fibers, foam for chronic wound care.

Additionally, tissue engineered skin substitutes are considered useful advanced new generation dressings for the application on severe skin damage where a lot of dermis lost [170]. The substitutes work as scaffolds for tissue engineered substrates by providing space for cell growth. Collagen and hyaluronic acid are the most popular polymers employed for acellular scaffold because of their excellent biocompatibility, biodegradable properties, and non-toxicity of their degradation products as we mentioned before. Cells containing matrices is the another type of materials used as tissue engineered skin substitutes which are made of native dermis with the cell component removed and the dermal structure preserved [171]. The potential use for drug delivery has been reviewed [172, 173], however, the antigen carried with exogenous cells may affect wound healing and the high cost would limit or slow their adoption in clinical practice.

\section{Conclusion}

In this review, we have considered the process of wound healing, bacterial infection and its mechanism in delaying the healing process. The current drugs and their combination used in wound dressings also have been discussed. Drug release systems of wound dressings also have been reviewed. Another important part is smart wound dressings that may be a promising alternative soon.

However, so far, there is no perfect dressing for wound care. The main challenges remain the large variation of exudates, bacterial infection, moisture environment, and stable but unpredictable microenvironment. The steps to develop bioactive and effective mixtures of antibacterial agents, growth factors, immune factor, moisture in multi-layers has been taken to meet an effective, shortened, safe healing process. However, most of these advanced dressings are still under development, not exceeding laboratory studies yet, and their performance in clinical practice still needs to be tested. 


\section{References}

1. Kirsner, R. S.; Eaglstein, W., The wound healing process. Dermatologic clinics 1993, 11, (4), 629-640.

2. Robson, M. C., Wound infection: a failure of wound healing caused by an imbalance of bacteria. Surgical Clinics of North America 1997, 77, (3), 637-650.

3. Dow, G.; Browne, A.; Sibbald, R., Infection in chronic wounds: controversies in diagnosis and treatment. Ostomy/wound management 1999, 45, (8), 23-7, 29-40; quiz 41-2.

4. Larrabee, W. F., A finite element model of skin deformation. I. Biomechanics of skin and soft tissue: A review. The Laryngoscope 1986, 96, (4), 399-405.

5. $\quad$ Cutting, K. F.; White, R., Defined and refined: criteria for identifying wound infection revisited. $\mathrm{Br} J$ Community Nurs 2004, 9, (3), S6-15.

6. Edwards, R.; Harding, K. G., Bacteria and wound healing. Current opinion in infectious diseases 2004, 17, (2), 91-96.

7. Archer, N.; Mazaitis, M.; Costerton, J.; Leid, J.; Powers, M.; Shirtliff, M., Staphylococcus aureus biofilms: properties, regulation, and roles in human disease. Virulence 2: 445-459. In 2011.

8. Skindersoe, M. E.; Zeuthen, L. H.; Brix, S.; Fink, L. N.; Lazenby, J.; Whittall, C.; Williams, P.; Diggle, S. P.; Froekiaer, H.; Cooley, M., Pseudomonas aeruginosa quorum-sensing signal molecules interfere with dendritic cell-induced T-cell proliferation. FEMS Immunology \& Medical Microbiology 2009, 55, (3), 335-345.

9. Percival, S. L.; Cutting, K. F., Biofilms: possible strategies for suppression in chronic wounds. Nursing Standard 2009, 23, (32), 64-72.

10. Metcalf, D. G.; Bowler, P. G., Biofilm delays wound healing: A review of the evidence. Burns \& trauma 2013, 1, (1), 5 .

11. Malone, M.; Bjarnsholt, T.; McBain, A. J.; James, G. A.; Stoodley, P.; Leaper, D.; Tachi, M.; Schultz, G.; Swanson, T.; Wolcott, R. D., The prevalence of biofilms in chronic wounds: a systematic review and meta-analysis of published data. Journal of Wound Care 2017, 26, (1), 20-25.

12. Marano, R. J.; Wallace, H. J.; Wijeratne, D.; Fear, M. W.; San Wong, H.; O'Handley, R., Secreted biofilm factors adversely affect cellular wound healing responses in vitro. Scientific reports 2015, 5, 13296.

13. Thomson, C. H., Biofilms: do they affect wound healing? International wound journal 2011, 8, (1), 6367.

14. Burmølle, M.; Ren, D.; Bjarnsholt, T.; Sørensen, S. J., Interactions in multispecies biofilms: do they actually matter? Trends in microbiology 2014, 22, (2), 84-91.

15. Hurlow, J.; Couch, K.; Laforet, K.; Bolton, L.; Metcalf, D.; Bowler, P., Clinical biofilms: a challenging frontier in wound care. Advances in wound care 2015, 4, (5), 295-301.

16. Queen, D.; Evans, J.; Gaylor, J.; Courtney, J.; Reid, W., Burn wound dressings—a review. Burns 1987, 13, (3), 218-228.

17. Chaby, G.; Senet, P.; Vaneau, M.; Martel, P.; Guillaume, J.-C.; Meaume, S.; Téot, L.; Debure, C.; Dompmartin, A.; Bachelet, H., Dressings for acute and chronic wounds: a systematic review. Archives of dermatology 2007, 143, (10), 1297-1304.

18. Hanna, J. R.; Giacopelli, J. A., A review of wound healing and wound dressing products. The Journal of Foot and Ankle Surgery 1997, 36, (1), 2-14.

19. Murphy, P. S.; Evans, G. R., Advances in wound healing: a review of current wound healing products. Plastic surgery international 2012, 2012.

20. Boateng, J. S.; Matthews, K. H.; Stevens, H. N.; Eccleston, G. M., Wound healing dressings and drug delivery systems: a review. Journal of pharmaceutical sciences 2008, 97, (8), 2892-2923.

21. Leaper, D. J., Silver dressings: their role in wound management. International wound journal 2006, 3 , (4), 282-294.

22. Aziz, Z.; Abu, S.; Chong, N., A systematic review of silver-containing dressings and topical silver agents (used with dressings) for burn wounds. Burns 2012, 38, (3), 307-318.

23. Tiwari, V. K.; Nanda, D., Silver Dressings Revisited. An open access official publication of Society for Wound Care and Research 2013, 24.

24. Mooney, E. K.; Lippitt, C.; Friedman, J.; Committee, P. S. E. F. D., Silver dressings. Plastic and reconstructive surgery 2006, 117, (2), 666-669.

25. Percival, S.; Bowler, P.; Russell, D., Bacterial resistance to silver in wound care. Journal of hospital infection 2005, 60, (1), 1-7.

26. Borkow, G.; Gabbay, J.; Dardik, R.; Eidelman, A. I.; Lavie, Y.; Grunfeld, Y.; Ikher, S.; Huszar, M.; Zatcoff, R. C.; Marikovsky, M., Molecular mechanisms of enhanced wound healing by copper oxideimpregnated dressings. Wound repair and regeneration 2010, 18, (2), 266-275. 
27. Ingle, A. P.; Duran, N.; Rai, M., Bioactivity, mechanism of action, and cytotoxicity of copper-based nanoparticles: a review. Applied microbiology and biotechnology 2014, 98, (3), 1001-1009.

28. Applerot, G.; Lellouche, J.; Lipovsky, A.; Nitzan, Y.; Lubart, R.; Gedanken, A.; Banin, E., Understanding the antibacterial mechanism of $\mathrm{CuO}$ nanoparticles: revealing the route of induced oxidative stress. Small 2012, 8, (21), 3326-3337.

29. Lemire, J. A.; Harrison, J. J.; Turner, R. J., Antimicrobial activity of metals: mechanisms, molecular targets and applications. Nature Reviews Microbiology 2013, 11, (6), 371-384.

30. Lansdown, A. B.; Mirastschijski, U.; Stubbs, N.; Scanlon, E.; Ågren, M. S., Zinc in wound healing: theoretical, experimental, and clinical aspects. Wound repair and regeneration 2007, 15, (1), 2-16.

31. Ågren, M. S. M. S., Zinc and Wound Healing. In Encyclopedia of Metalloproteins, Springer: 2013; pp 2392-2396.

32. Sirelkhatim, A.; Mahmud, S.; Seeni, A.; Kaus, N. H. M.; Ann, L. C.; Bakhori, S. K. M.; Hasan, H.; Mohamad, D., Review on zinc oxide nanoparticles: antibacterial activity and toxicity mechanism. NanoMicro Letters 2015, 7, (3), 219-242.

33. Naves, L.; Almeida, L., Wound Healing Dressing and Some Composites Such as Zeolite, TiO2, Chitosan and PLGA: A Review. World Academy of Science, Engineering and Technology, International Journal of Medical, Health, Biomedical, Bioengineering and Pharmaceutical Engineering 2015, 9, (3), 242-246.

34. Haugen, H.; Lyngstadaas, S., Antibacterial effects of titanium dioxide in wounds. Wound Healing Biomaterials-Volume 2: Functional Biomaterials 2016, 439.

35. Bui, V. K. H.; Park, D.; Lee, Y.-C., Chitosan Combined with ZnO, TiO2 and Ag Nanoparticles for Antimicrobial Wound Healing Applications: A Mini Review of the Research Trends. Polymers 2017, 9, (1), 21.

36. Dickerson, M. B.; Knight, C. L.; Gupta, M. K.; Luckarift, H. R.; Drummy, L. F.; Jespersen, M. L.; Johnson, G. R.; Naik, R. R., Hybrid fibers containing protein-templated nanomaterials and biologically active components as antibacterial materials. Materials Science and Engineering: $C$ 2011, 31, (8), 17481758.

37. Maver, T.; Maver, U.; Stana Kleinschek, K.; Smrke, D. M.; Kreft, S., A review of herbal medicines in wound healing. International journal of dermatology 2015, 54, (7), 740-751.

38. Garcia-Orue, I.; Gainza, G.; Gutierrez, F. B.; Aguirre, J. J.; Evora, C.; Pedraz, J. L.; Hernandez, R. M.; Delgado, A.; Igartua, M., Novel nanofibrous dressings containing rhEGF and Aloe vera for wound healing applications. International Journal of Pharmaceutics 2016.

39. Shahzad, M. N.; Ahmed, N., Effectiveness of Aloe vera gel compared with $1 \%$ silver sulphadiazine cream as burn wound dressing in second degree burns. J Pak Med Assoc 2013, 63, (2), 225-30.

40. Dat, A. D.; Poon, F.; Pham, K. B.; Doust, J., Aloe vera for treating acute and chronic wounds. Sao Paulo Medical Journal 2014, 132, (6), 382-382.

41. Djeraba, A.; Quere, P., In vivo macrophage activation in chickens with Acemannan, a complex carbohydrate extracted from Aloe vera. International journal of immunopharmacology 2000, 22, (5), 365-372.

42. Minjares-Fuentes, J. R.; Femenia, A., Effect of Processing on the Bioactive Polysaccharides and Phenolic Compounds from Aloe vera (Aloe barbadensis Miller). Dietary Fibre Functionality in Food and Nutraceuticals: From Plant to Gut 2016, 263.

43. Bao, J.; Yang, B.; Sun, Y.; Zu, Y.; Deng, Y., A berberine-loaded electrospun poly-( $\varepsilon$-caprolactone) nanofibrous membrane with hemostatic potential and antimicrobial property for wound dressing. Journal of biomedical nanotechnology 2013, 9, (7), 1173-1180.

44. Tummalapalli, M.; Berthet, M.; Verrier, B.; Deopura, B.; Alam, M.; Gupta, B., Composite wound dressings of pectin and gelatin with aloe vera and curcumin as bioactive agents. International journal of biological macromolecules 2016, 82, 104-113.

45. Mirzaei, F.; Salouti, M.; Shapouri, R., Effect of allicin and silver nanoparticles on skin infections due to staphylococcus aureus in mouse model. ZUMS Journal 2015, 23, (97), 94-102.

46. Panichpakdee, J.; Pavasant, P.; Supaphol, P.; Sangsanoh, P.; Chankoa, R.; Kreua-ongarjnukool, N.; Thumsing, S.; Suwantong, O.; Pankongadisak, P.; Deachathai, S., Electrospun cellulose acetate fiber mats containing emodin with potential for use as wound dressing. Month 2014, 43, (1).

47. Vedakumari, W. S.; Ayaz, N.; Karthick, A. S.; Senthil, R.; Sastry, T. P., Quercetin impregnated chitosanfibrin composite scaffolds as potential wound dressing materials-Fabrication, characterization and in vivo analysis. European Journal of Pharmaceutical Sciences 2017, 97, 106-112.

48. Low, W. L.; Kenward, K.; Britland, S. T.; Amin, M. C.; Martin, C., Essential oils and metal ions as alternative antimicrobial agents: a focus on tea tree oil and silver. International wound journal 2016.

49. Maycock, P.; Mackereth, P. A.; Mehrez, A.; Stringer, J., MALODOUR The Potential Use of Essential Oils. Aromatherapy, Massage and Relaxation in Cancer Care: An Integrative Resource for Practitioners 2016, 130. 
50. Stea, S.; Beraudi, A.; De Pasquale, D., Essential oils for complementary treatment of surgical patients: state of the art. Evidence-Based Complementary and Alternative Medicine 2014, 2014.

51. Daunton, C.; Kothari, S.; Smith, L.; Steele, D., A history of materials and practices for wound management. Wound Practice \& Research: Journal of the Australian Wound Management Association 2012, 20, (4), 174.

52. Khan, B. A.; Warner, P.; Wang, H., Antibacterial properties of hemp and other natural fibre plants: a review. BioResources 2014, 9, (2), 3642-3659.

53. ZHUANG, X.; LI, X.; ZHANG, H.; YAN, X., Development of chitin/bamboo pulp fibre interweaving medical wound dressing. Shanghai Textile Science \& Technology 2014, 8, 016.

54. Liakos, I.; Rizzello, L.; Scurr, D. J.; Pompa, P. P.; Bayer, I. S.; Athanassiou, A., All-natural composite wound dressing films of essential oils encapsulated in sodium alginate with antimicrobial properties. International Journal of Pharmaceutics 2014, 463, (2), 137-145.

55. Liakos, I.; Rizzello, L.; Hajiali, H.; Brunetti, V.; Carzino, R.; Pompa, P.; Athanassiou, A.; Mele, E., Fibrous wound dressings encapsulating essential oils as natural antimicrobial agents. Journal of Materials Chemistry B 2015, 3, (8), 1583-1589.

56. Rieger, K. A.; Schiffman, J. D., Electrospinning an essential oil: Cinnamaldehyde enhances the antimicrobial efficacy of chitosan/poly (ethylene oxide) nanofibers. Carbohydrate polymers 2014, 113, 561-568.

57. Rădulescu, M.; Andronescu, E.; Holban, A. M.; Vasile, B. S.; Iordache, F.; Mogoantă, L.; Mogoșanu, G. D.; Grumezescu, A. M.; Georgescu, M.; Chifiriuc, M. C., Antimicrobial Nanostructured Bioactive Coating Based on Fe3O4 and Patchouli Oil for Wound Dressing. Metals 2016, 6, (5), 103.

58. Wen, P.; Zhu, D.-H.; Feng, K.; Liu, F.-J.; Lou, W.-Y.; Li, N.; Zong, M.-H.; Wu, H., Fabrication of electrospun polylactic acid nanofilm incorporating cinnamon essential oil/ $\beta$-cyclodextrin inclusion complex for antimicrobial packaging. Food chemistry 2016, 196, 996-1004.

59. Catanzano, O.; Straccia, M.; Miro, A.; Ungaro, F.; Romano, I.; Mazzarella, G.; Santagata, G.; Quaglia, F.; Laurienzo, P.; Malinconico, M., Spray-by-spray in situ cross-linking alginate hydrogels delivering a tea tree oil microemulsion. European Journal of Pharmaceutical Sciences 2015, 66, 20-28.

60. Khajavi, R.; Abbasipour, M.; Barzi, M. G.; Rashidi, A.; Rahimi, M. K.; Mirzababa, H. H., Eucalyptus Essential Oil-Doped Alginate Fibers as a Potent Antibacterial Wound Dressing. Advances in Polymer Technology 2014, 33, (2).

61. Kavoosi, G.; Rahmatollahi, A.; Dadfar, S. M. M.; Purfard, A. M., Effects of essential oil on the water binding capacity, physico-mechanical properties, antioxidant and antibacterial activity of gelatin films. LWT-Food Science and Technology 2014, 57, (2), 556-561.

62. Kavoosi, G.; Shakiba, A.; Ghorbani, M.; Dadfar, S. M. M.; Purfard, A. M., Antioxidant, antibacterial, water binding capacity and mechanical behavior of gelatin-ferula oil film as a wound dressing material. Galen Medical Journal 2015, 4, (2), 103-14.

63. Arancibia, M.; Giménez, B.; Lopez-Caballero, M.; Gomez-Guillen, M.; Montero, P., Release of cinnamon essential oil from polysaccharide bilayer films and its use for microbial growth inhibition in chilled shrimps. LWT-Food Science and Technology 2014, 59, (2), 989-995.

64. Molan, P. C.; Rhodes, T., Honey: a biologic wound dressing. 2015.

65. Aggad, H.; Guemour, D., Honey antibacterial activity. Med Aromat Plants 2014, 3, (152), $2167-$ 0412.1000152.

66. Viuda-Martos, M.; Ruiz-Navajas, Y.; Fernández-López, J.; Pérez-Álvarez, J., Functional properties of honey, propolis, and royal jelly. Journal of food science 2008, 73, (9).

67. Majtan, J., Honey: an immunomodulator in wound healing. Wound Repair and Regeneration 2014, 22 , (2), 187-192.

68. McLoone, P.; Warnock, M.; Fyfe, L., Honey: an immunomodulatory agent for disorders of the skin. Food and Agricultural Immunology 2016, 27, (3), 338-349.

69. Alvarez-Suarez, J. M.; Giampieri, F.; Cordero, M.; Gasparrini, M.; Forbes-Hernández, T. Y.; Mazzoni, L.; Afrin, S.; Beltrán-Ayala, P.; González-Paramás, A. M.; Santos-Buelga, C., Activation of AMPK/Nrf2 signalling by Manuka honey protects human dermal fibroblasts against oxidative damage by improving antioxidant response and mitochondrial function promoting wound healing. Journal of Functional Foods 2016, 25, 38-49.

70. Yaghoobi, R.; Kazerouni, A., Evidence for clinical use of honey in wound healing as an anti-bacterial, anti-inflammatory anti-oxidant and anti-viral agent: a review. Jundishapur journal of natural pharmaceutical products 2013, 8, (3), 100-104.

71. Öhlknecht, C.; Tegl, G.; Beer, B.; Sygmund, C.; Ludwig, R.; Guebitz, G. M., Cellobiose dehydrogenase and chitosan-based lysozyme responsive materials for antimicrobial wound treatment. Biotechnology and Bioengineering 2017, 114, (2), 416-422. 
72. Tonglairoum, P.; Ngawhirunpat, T.; Rojanarata, T.; Opanasopit, P., Lysozyme-immobilized electrospun PAMA/PVA and PSSA-MA/PVA ion-exchange nanofiber for wound healing. Pharmaceutical development and technology 2015, 20, (8), 976-983.

73. Abouhmad, A.; Mamo, G.; Dishisha, T.; Amin, M.; Hatti-Kaul, R., T4 lysozyme fused with cellulosebinding module for antimicrobial cellulosic wound dressing materials. Journal of applied microbiology 2016, 121, (1), 115-125.

74. Steckbeck, J. D.; Deslouches, B.; Montelaro, R. C., Antimicrobial peptides: new drugs for bad bugs? In Taylor \& Francis: 2014.

75. Wang, G., Human antimicrobial peptides and proteins. Pharmaceuticals 2014, 7, (5), 545-594.

76. Yi, H.-Y.; Chowdhury, M.; Huang, Y.-D.; Yu, X.-Q., Insect antimicrobial peptides and their applications. Applied microbiology and biotechnology 2014, 98, (13), 5807-5822.

77. Abdelgawad, A. M.; Hudson, S. M.; Rojas, O. J., Antimicrobial wound dressing nanofiber mats from multicomponent (chitosan/silver-NPs/polyvinyl alcohol) systems. Carbohydrate polymers 2014, 100, 166-178.

78. Song, D. W.; Kim, S. H.; Kim, H. H.; Lee, K. H.; Ki, C. S.; Park, Y. H., Multi-biofunction of antimicrobial peptide-immobilized silk fibroin nanofiber membrane: Implications for wound healing. Acta biomaterialia 2016, 39, 146-155.

79. Silva, J. P.; Dhall, S.; Garcia, M.; Chan, A.; Costa, C.; Gama, M.; Martins-Green, M., Improved burn wound healing by the antimicrobial peptide LLKKK18 released from conjugates with dextrin embedded in a carbopol gel. Acta biomaterialia 2015, 26, 249-262.

80. Gawande, P. V.; Leung, K. P.; Madhyastha, S., Antibiofilm and antimicrobial efficacy of DispersinB ${ }^{-}$ KSL-W peptide-based wound gel against chronic wound infection associated bacteria. Current microbiology 2014, 68, (5), 635-641.

81. Lequeux, I.; Ducasse, E.; Jouenne, T.; Thebault, P., Addition of antimicrobial properties to hyaluronic acid by grafting of antimicrobial peptide. European Polymer Journal 2014, 51, 182-190.

82. Gomes, A.; Mano, J.; Queiroz, J.; Gouveia, I., Incorporation of antimicrobial peptides on functionalized cotton gauzes for medical applications. Carbohydrate polymers 2015, 127, 451-461.

83. Li, X.; Fan, R.; Tong, A.; Yang, M.; Deng, J.; Zhou, L.; Zhang, X.; Guo, G., In situ gel-forming AP-57 peptide delivery system for cutaneous wound healing. International journal of pharmaceutics 2015, 495 , (1), 560-571.

84. Cleophas, R. T.; Riool, M.; Quarles van Ufford, H. C.; Zaat, S. A.; Kruijtzer, J. A.; Liskamp, R. M., Convenient preparation of bactericidal hydrogels by covalent attachment of stabilized antimicrobial peptides using thiol-ene click chemistry. ACS Macro Letters 2014, 3, (5), 477-480.

85. Håkansson, J.; Björn, C.; Lindgren, K.; Sjöström, E.; Sjöstrand, V.; Mahlapuu, M., Efficacy of the novel topical antimicrobial agent PXL150 in a mouse model of surgical site infections. Antimicrobial agents and chemotherapy 2014, 58, (5), 2982-2984.

86. Babavalian, H.; Latifi, A. M.; Shokrgozar, M. A.; Bonakdar, S.; Mohammadi, S.; Moghaddam, M. M., Analysis of Healing Effect of Alginate Sulfate Hydrogel Dressing Containing Antimicrobial Peptide on Wound Infection Caused by Methicillin-Resistant Staphylococcus aureus. Jundishapur journal of microbiology 2015, 8, (9).

87. Ramasubbu, D. A.; Smith, V.; Hayden, F.; Cronin, P., Systemic antibiotics for treating malignant wounds. The Cochrane Library 2015.

88. Saco, M.; Howe, N.; Nathoo, R.; Cherpelis, B., Topical antibiotic prophylaxis for prevention of surgical wound infections from dermatologic procedures: a systematic review and meta-analysis. Journal of Dermatological Treatment 2015, 26, (2), 151-158.

89. Thoma, L. M.; Boles, B. R.; Kuroda, K., Cationic methacrylate polymers as topical antimicrobial agents against Staphylococcus aureus nasal colonization. Biomacromolecules 2014, 15, (8), 2933-2943.

90. Korber, D.; James, G.; Costerton, J., Evaluation of fleroxacin activity against established Pseudomonas fluorescens biofilms. Applied and environmental microbiology 1994, 60, (5), 1663-1669.

91. Yamasaki, O.; Akiyama, H.; Toi, Y.; Arata, J., A combination of roxithromycin and imipenem as an antimicrobial strategy against biofilms formed by Staphylococcus aureus. Journal of Antimicrobial Chemotherapy 2001, 48, (4), 573-577.

92. Kaneko, Y.; Thoendel, M.; Olakanmi, O.; Britigan, B. E.; Singh, P. K., The transition metal gallium disrupts Pseudomonas aeruginosa iron metabolism and has antimicrobial and antibiofilm activity. The Journal of clinical investigation 2007, 117, (4), 877-888.

93. Tam, A.; Shemesh, M.; Wormser, U.; Sintov, A.; Steinberg, D., Effect of different iodine formulations on the expression and activity of Streptococcus mutans glucosyltransferase and fructosyltransferase in biofilm and planktonic environments. Journal of Antimicrobial Chemotherapy 2006, 57, (5), 865-871.

94. Orr, M. W.; Donaldson, G. P.; Severin, G. B.; Wang, J.; Sintim, H. O.; Waters, C. M.; Lee, V. T., Oligoribonuclease is the primary degradative enzyme for $\mathrm{pGpG}$ in Pseudomonas aeruginosa that is 
required for cyclic-di-GMP turnover. Proceedings of the National Academy of Sciences 2015, 112, (36), E5048-E5057.

95. Liu, S.; Zeng, T. H.; Hofmann, M.; Burcombe, E.; Wei, J.; Jiang, R.; Kong, J.; Chen, Y., Antibacterial activity of graphite, graphite oxide, graphene oxide, and reduced graphene oxide: membrane and oxidative stress. ACS nano 2011, 5, (9), 6971-6980.

96. Fan, Z.; Liu, B.; Wang, J.; Zhang, S.; Lin, Q.; Gong, P.; Ma, L.; Yang, S., A novel wound dressing based on Ag/graphene polymer hydrogel: effectively kill bacteria and accelerate wound healing. Advanced Functional Materials 2014, 24, (25), 3933-3943.

97. Ji, H.; Sun, H.; Qu, X., Antibacterial applications of graphene-based nanomaterials: Recent achievements and challenges. Advanced drug delivery reviews 2016, 105, 176-189.

98. Paul, W.; Sharma, C. P., Chitosan and alginate wound dressings: a short review. Trends Biomater Artif Organs 2004, 18, (1), 18-23.

99. Kong, M.; Chen, X. G.; Xing, K.; Park, H. J., Antimicrobial properties of chitosan and mode of action: a state of the art review. International journal of food microbiology 2010, 144, (1), 51-63.

100. Walsh, C., Antibiotics: actions, origins, resistance. 2003.

101. Ferrante, S.; Guerrero, S.; Alzamora, S. M., Combined use of ultrasound and natural antimicrobials to inactivate Listeria monocytogenes in orange juice. Journal of Food Protection 2007, 70, (8), 1850-1856.

102. Palaniappan, K.; Holley, R. A., Use of natural antimicrobials to increase antibiotic susceptibility of drug resistant bacteria. International journal of food microbiology 2010, 140, (2), 164-168.

103. Pillai, S. K.; Moellering, R.; Eliopoulos, G. M., Antimicrobial combinations. Antibiotics in laboratory medicine 2005, 5, 365-440.

104. Lu Z, Gao J, He Q, et al. Enhanced antibacterial and wound healing activities of microporous chitosan$\mathrm{Ag} / \mathrm{ZnO}$ composite dressing[J]. Carbohydrate Polymers, 2017, 156: 460-469.

105. Petkova, P.; Francesko, A.; Fernandes, M. M.; Mendoza, E.; Perelshtein, I.; Gedanken, A.; Tzanov, T., Sonochemical coating of textiles with hybrid $\mathrm{ZnO} /$ chitosan antimicrobial nanoparticles. ACS applied materials \& interfaces 2014, 6, (2), 1164-1172.

106. Ong, S.-Y.; Wu, J.; Moochhala, S. M.; Tan, M.-H.; Lu, J., Development of a chitosan-based wound dressing with improved hemostatic and antimicrobial properties. Biomaterials 2008, 29, (32), 4323-4332.

107. Liu, Y.; Wang, X.; Yang, F.; Yang, X., Excellent antimicrobial properties of mesoporous anatase TiO 2 and $\mathrm{Ag} / \mathrm{TiO} 2$ composite films. Microporous and Mesoporous Materials 2008, 114, (1), 431-439.

108. Ammons M C B, Ward L S, James G A. Anti-biofilm efficacy of a lactoferrin/xylitol wound hydrogel used in combination with silver wound dressings[J]. International wound journal, 2011, 8(3): 268-273.

109. Gupta, B.; Agarwal, R.; Alam, M. S., Antimicrobial and release study of drug loaded PVA/PEO/CMC wound dressings. Journal of Materials Science: Materials in Medicine 2014, 25, (6), 1613-1622.

110. Pawar, H.; Tetteh, J.; Boateng, J., Polyox and carrageenan based composite films dressings containing antimicrobial and anti-inflammatory drugs for effective wound healing. International Journal of Pharmaceutics 2013, 441, (1-2), 181-191.

111. Toncheva, A.; Paneva, D.; Manolova, N.; Rashkov, I., Electrospun poly (L-lactide) membranes containing a single drug or multiple drug system for antimicrobial wound dressings. Macromolecular research 2011, 19, (12), 1310-1319.

112. Pulat, M.; Kahraman, A. S.; Tan, N.; Gümüşderelioğlu, M., Sequential antibiotic and growth factor releasing chitosan-PAAm semi-IPN hydrogel as a novel wound dressing. Journal of Biomaterials Science, Polymer Edition 2013, 24, (7), 807-819.

113. Jiang, B.; Zhang, G.; Brey, E. M., Dual delivery of chlorhexidine and platelet-derived growth factor-BB for enhanced wound healing and infection control. Acta biomaterialia 2013, 9, (2), 4976-4984.

114. Lai, H.-J.; Kuan, C.-H.; Wu, H.-C.; Tsai, J.-C.; Chen, T.-M.; Hsieh, D.-J.; Wang, T.-W., Tailored design of electrospun composite nanofibers with staged release of multiple angiogenic growth factors for chronic wound healing. Acta biomaterialia 2014, 10, (10), 4156-4166.

115. Xie, Z.; Paras, C. B.; Weng, H.; Punnakitikashem, P.; Su, L.-C.; Vu, K.; Tang, L.; Yang, J.; Nguyen, K. T., Dual growth factor releasing multi-functional nanofibers for wound healing. Acta biomaterialia 2013, 9, (12), 9351-9359.

116. Kim, K.; Luu, Y. K.; Chang, C.; Fang, D.; Hsiao, B. S.; Chu, B.; Hadjiargyrou, M., Incorporation and controlled release of a hydrophilic antibiotic using poly (lactide-co-glycolide)-based electrospun nanofibrous scaffolds. Journal of Controlled Release 2004, 98, (1), 47-56.

117. Hong, K. H., Preparation and properties of electrospun poly (vinyl alcohol)/silver fiber web as wound dressings. Polymer Engineering \& Science 2007, 47, (1), 43-49.

118. Huang, Z. M.; He, C. L.; Yang, A.; Zhang, Y.; Han, X. J.; Yin, J.; Wu, Q., Encapsulating drugs in biodegradable ultrafine fibers through co-axial electrospinning. Journal of Biomedical Materials Research Part A 2006, 77, (1), 169-179. 
119. Matsuda, A.; Kagata, G.; Kino, R.; Tanaka, J., Preparation of chitosan nanofiber tube by electrospinning. Journal of nanoscience and nanotechnology 2007, 7, (3), 852-855.

120. Simmons, T. J.; Lee, S.-H.; Park, T.-J.; Hashim, D.; Ajayan, P.; Linhardt, R., Antiseptic single wall carbon nanotube bandages. Carbon 2009, 47, (6), 1561-1564.

121. Archana, D.; Singh, B. K.; Dutta, J.; Dutta, P., In vivo evaluation of chitosan-PVP-titanium dioxide nanocomposite as wound dressing material. Carbohydrate polymers 2013, 95, (1), 530-539.

122. Ma, Z.; Ji, H.; Teng, Y.; Dong, G.; Tan, D.; Guan, M.; Zhou, J.; Xie, J.; Qiu, J.; Zhang, M., Engineering and optimisation of medically multi-functional mesoporous $\mathrm{SiO} 2$ fibers as effective wound dressing material. Journal of Materials Chemistry 2011, 21, (26), 9595-9602.

123. Ma, Z.; Ji, H.; Tan, D.; Dong, G.; Teng, Y.; Zhou, J.; Guan, M.; Qiu, J.; Zhang, M., Large-scale preparation of strawberry-like, AgNP-doped $\mathrm{SiO} 2$ microspheres using the electrospraying method. Nanotechnology 2011, 22, (30), 305307.

124. Garg, T.; Singh, S.; Goyal, A. K., Stimuli-sensitive hydrogels: an excellent carrier for drug and cell delivery. Critical Reviews ${ }^{\mathrm{TM}}$ in Therapeutic Drug Carrier Systems 2013, 30, (5).

125. Caló, E.; Khutoryanskiy, V. V., Biomedical applications of hydrogels: A review of patents and commercial products. European Polymer Journal 2015, 65, 252-267.

126. Dargaville, T. R.; Farrugia, B. L.; Broadbent, J. A.; Pace, S.; Upton, Z.; Voelcker, N. H., Sensors and imaging for wound healing: a review. Biosensors and Bioelectronics 2013, 41, 30-42.

127. Yin, Y.; Lang, C.; Jiao, S.; Liu, J., Environment Responsive Hydrogels. Gels Handbook: Fundamentals, Properties and Applications (In 3 Volumes) Volume 1: Fundamentals of HydrogelsVolume 2: Applications of Hydrogels in Regenerative MedicineVolume 3: Application of Hydrogels in Drug Delivery and Biosensing 2016, 251.

128. Pachuau, L., Recent developments in novel drug delivery systems for wound healing. Expert opinion on drug delivery 2015, 12, (12), 1895-1909.

129. Lin, Y.-J.; Lee, G.-H.; Chou, C.-W.; Chen, Y.-P.; Wu, T.-H.; Lin, H.-R., Stimulation of wound healing by PU/hydrogel composites containing fibroblast growth factor-2. Journal of Materials Chemistry B 2015, 3, (9), 1931-1941.

130. Fan, L.; Yang, H.; Yang, J.; Peng, M.; Hu, J., Preparation and characterization of chitosan/gelatin/PVA hydrogel for wound dressings. Carbohydrate polymers 2016, 146, 427-434.

131. Chinga-Carrasco, G.; Syverud, K., Pretreatment-dependent surface chemistry of wood nanocellulose for pH-sensitive hydrogels. Journal of biomaterials applications 2014, 29, (3), 423-432.

132. Liu, Y.; Zhang, F.; Ru, Y., Hyperbranched phosphoramidate-hyaluronan hybrid: A reduction-sensitive injectable hydrogel for controlled protein release. Carbohydrate polymers 2015, 117, 304-311.

133. Tronci, G.; Yin, J.; Holmes, R. A.; Liang, H.; Russell, S. J.; Wood, D. J., Protease-sensitive atelocollagen hydrogels promote healing in a diabetic wound model. Journal of Materials Chemistry B 2016, 4, (45), 7249-7258.

134. Mohiti-Asli, M.; Pourdeyhimi, B.; Loboa, E. G., Skin tissue engineering for the infected wound site: biodegradable PLA nanofibers and a novel approach for silver ion release evaluated in a 3D coculture system of keratinocytes and Staphylococcus aureus. Tissue Engineering Part C: Methods 2014, 20, (10), 790-797.

135. Xie, Z.; Aphale, N. V.; Kadapure, T. D.; Wadajkar, A. S.; Orr, S.; Gyawali, D.; Qian, G.; Nguyen, K. T.; Yang, J., Design of antimicrobial peptides conjugated biodegradable citric acid derived hydrogels for wound healing. Journal of Biomedical Materials Research Part A 2015, 103, (12), 3907-3918.

136. Harkins, A. L.; Duri, S.; Kloth, L. C.; Tran, C. D., Chitosan-cellulose composite for wound dressing material. Part 2. Antimicrobial activity, blood absorption ability, and biocompatibility. Journal of Biomedical Materials Research Part B: Applied Biomaterials 2014, 102, (6), 1199-1206.

137. Dumville, J. C.; Keogh, S. J.; Liu, Z.; Stubbs, N.; Walker, R. M.; Fortnam, M., Alginate dressings for treating pressure ulcers. Sao Paulo Medical Journal 2015, 133, (5), 455-455.

138. Shimizu, N.; Ishida, D.; Yamamoto, A.; Kuroyanagi, M.; Kuroyanagi, Y., Development of a functional wound dressing composed of hyaluronic acid spongy sheet containing bioactive components: evaluation of wound healing potential in animal tests. Journal of Biomaterials Science, Polymer Edition 2014, 25 , (12), 1278-1291.

139. Gladman, J. M.; Griffiths, B., Wound dressing material. In Google Patents: 2016.

140. Roehrs, H.; Stocco, J. G.; Pott, F.; Blanc, G.; Crozeta, K.; Meier, M. J.; Dias, F. A., Dressings and topical agents containing hyaluronic acid for chronic wound healing. The Cochrane Library 2016.

141. Zhou, Z.; Chen, J.; Peng, C.; Huang, T.; Zhou, H.; Ou, B.; Chen, J.; Liu, Q.; He, S.; Cao, D., Fabrication and physical properties of gelatin/sodium alginate/hyaluronic acid composite wound dressing hydrogel. Journal of Macromolecular Science, Part A 2014, 51, (4), 318-325. 
142. Anisha, B.; Biswas, R.; Chennazhi, K.; Jayakumar, R., Chitosan-hyaluronic acid/nano silver composite sponges for drug resistant bacteria infected diabetic wounds. International journal of biological macromolecules 2013, 62, 310-320.

143. Lee, M.; Han, S. H.; Choi, W. J.; Chung, K. H.; Lee, J. W., Hyaluronic acid dressing (Healoderm) in the treatment of diabetic foot ulcer: A prospective, randomized, placebo-controlled, single-center study. Wound Repair and Regeneration 2016, 24, (3), 581-588.

144. Tokatlian, T.; Cam, C.; Segura, T., Porous hyaluronic acid hydrogels for localized nonviral DNA delivery in a diabetic wound healing model. Advanced healthcare materials 2015, 4, (7), 1084-1091.

145. Su, Z.; Ma, H.; Wu, Z.; Zeng, H.; Li, Z.; Wang, Y.; Liu, G.; Xu, B.; Lin, Y.; Zhang, P., Enhancement of skin wound healing with decellularized scaffolds loaded with hyaluronic acid and epidermal growth factor. Materials Science and Engineering: C 2014, 44, 440-448.

146. Wani, S.; Shaikh, S.; Sayyed, R., Microbial Biopolymers in Biomedical Field. MOJ Cell Sci Rep 2016, 3, (3), 00055.

147. Ke, Y.; Zhang, X.; Ramakrishna, S.; He, L.; Wu, G., Synthetic routes to degradable copolymers deriving from the biosynthesized polyhydroxyalkanoates: A mini review. Express Polymer Letters 2016, 10, (1).

148. Mekala, M.; Rajendran, R.; Maheshwari, S. U.; Suganya, K., Comparative studies on poly- $\beta$ hydroxybutyrate (PHB) with gelatin and PHB with starch as a finished fabric. International Journal of Environmental Sciences 2014, 4, (5), 754-765.

149. Kundu, P.; Nandy, A.; Mukherjee, A.; Pramanik, N., Polyhydroxyalkanoates: Microbial Synthesis and Applications. 2014.

150. Abhilash, M.; Thomas, D., Biopolymers for Biocomposites and Chemical Sensor Applications. Biopolymer Composites in Electronics 2016, 405.

151. Tan, L.; Hu, J.; Huang, H.; Han, J.; Hu, H., Study of multi-functional electrospun composite nanofibrous mats for smart wound healing. International journal of biological macromolecules 2015, 79, 469-476.

152. Gokarneshan, N.; Rachel, D. A.; Rajendran, V.; Lavanya, B.; Ghoshal, A., Smart Textile Wound Dressings. In Emerging Research Trends in Medical Textiles, Springer: 2015; pp 27-38.

153. Lin, S.-Y.; Chen, K.-S.; Run-Chu, L., Design and evaluation of drug-loaded wound dressing having thermoresponsive, adhesive, absorptive and easy peeling properties. Biomaterials 2001, 22, (22), 29993004.

154. Flam, E., Method of monitoring the condition of the skin or wound. In Google Patents: 1993.

155. Sridhar, V.; Takahata, K., A hydrogel-based passive wireless sensor using a flex-circuit inductive transducer. Sensors and Actuators A: Physical 2009, 155, (1), 58-65.

156. Thet, N.; Alves, D.; Bean, J.; Booth, S.; Nzakizwanayo, J.; Young, A.; Jones, B.; Jenkins, A. T. A., Prototype development of the intelligent hydrogel wound dressing and its efficacy in the detection of model pathogenic wound biofilms. ACS applied materials \& interfaces 2015, 8, (24), 14909-14919.

157. Kassal, P.; Kim, J.; Kumar, R.; de Araujo, W. R.; Steinberg, I. M.; Steinberg, M. D.; Wang, J., Smart bandage with wireless connectivity for uric acid biosensing as an indicator of wound status. Electrochemistry Communications 2015, 56, 6-10.

158. Mostafalu, P.; Amugothu, S.; Tamayol, A.; Bagherifard, S.; Akbari, M.; Dokmeci, M. R.; Khademhosseini, A.; Sonkusale, S. In Smart flexible wound dressing with wireless drug delivery, Biomedical Circuits and Systems Conference (BioCAS), 2015 IEEE, 2015; IEEE: 2015; pp 1-4.

159. McLister, A.; McHugh, J.; Cundell, J.; Davis, J., New Developments in Smart Bandage Technologies for Wound Diagnostics. Advanced Materials 2016.

160. Gethin, G. T.; Cowman, S.; Conroy, R. M., The impact of Manuka honey dressings on the surface $\mathrm{pH}$ of chronic wounds. International wound journal 2008, 5, (2), 185-194.

161. Kassal, P.; Zubak, M.; Scheipl, G.; Mohr, G. J.; Steinberg, M. D.; Steinberg, I. M., Smart bandage with wireless connectivity for optical monitoring of pH. Sensors and Actuators B: Chemical 2017, 246, 455460.

162. McColl, D.; MacDougall, M.; Watret, L.; Connolly, P., Monitoring moisture without disturbing the wound dressing. Wounds UK 2009, 5, (3), 2-6.

163. Fernandez, M. L.; Upton, Z.; Edwards, H.; Finlayson, K.; Shooter, G. K., Elevated uric acid correlates with wound severity. International wound journal 2012, 9, (2), 139-149.

164. Sharp, D.; Davis, J., Integrated urate sensors for detecting wound infection. Electrochemistry Communications 2008, 10, (5), 709-713.

165. Lin, S.; Yuk, H.; Zhang, T.; Parada, G. A.; Koo, H.; Yu, C.; Zhao, X., Stretchable hydrogel electronics and devices. Advanced Materials 2015.

166. Bagherifard, S.; Tamayol, A.; Mostafalu, P.; Akbari, M.; Comotto, M.; Annabi, N.; Ghaderi, M.; Sonkusale, S.; Dokmeci, M. R.; Khademhosseini, A., Dermal patch with integrated flexible heater for on demand drug delivery. Advanced healthcare materials 2016, 5, (1), 175-184. 
167. Finley, P. J.; Austin, C.; Mitchell, A.; Zank, S.; Norton, R.; Durham, P., Evidence of emergent silverresistance in clinical bacteria: a major implication for wound care and the use of silver-dressings: finley SAWC poster. Wound Healing Southern Africa 2015, 8, (2), 37-39.

168. Percival, S. L.; Woods, E.; Nutekpor, M.; Bowler, P.; Radford, A.; Cochrane, C., Prevalence of silver resistance in bacteria isolated from diabetic foot ulcers and efficacy of silver-containing wound dressings. Ostomy/wound management 2008, 54, (3), 30-40.

169. Zou, S. B.; Yoon, W. Y.; Han, S. K.; Jeong, S. H.; Cui, Z. J.; Kim, W. K., Cytotoxicity of silver dressings on diabetic fibroblasts. International wound journal 2013, 10, (3), 306-312.

170. Boateng, J.; Catanzano, O., Advanced therapeutic dressings for effective wound healing-a review. Journal of pharmaceutical sciences 2015, 104, (11), 3653-3680.

171. Ramos-e-Silva, M.; de Castro, M. C. R., New dressings, including tissue-engineered living skin. Clinics in dermatology 2002, 20, (6), 715-723.

172. Augustine, R.; Kalarikkal, N.; Thomas, S., Advancement of wound care from grafts to bioengineered smart skin substitutes. Progress in Biomaterials 2014, 3, (2-4), 103-113.

173. Sridhar, R.; Lakshminarayanan, R.; Madhaiyan, K.; Barathi, V. A.; Lim, K. H. C.; Ramakrishna, S., Electrosprayed nanoparticles and electrospun nanofibers based on natural materials: applications in tissue regeneration, drug delivery and pharmaceuticals. Chemical Society Reviews 2015, 44, (3), 790-814. 
(2)

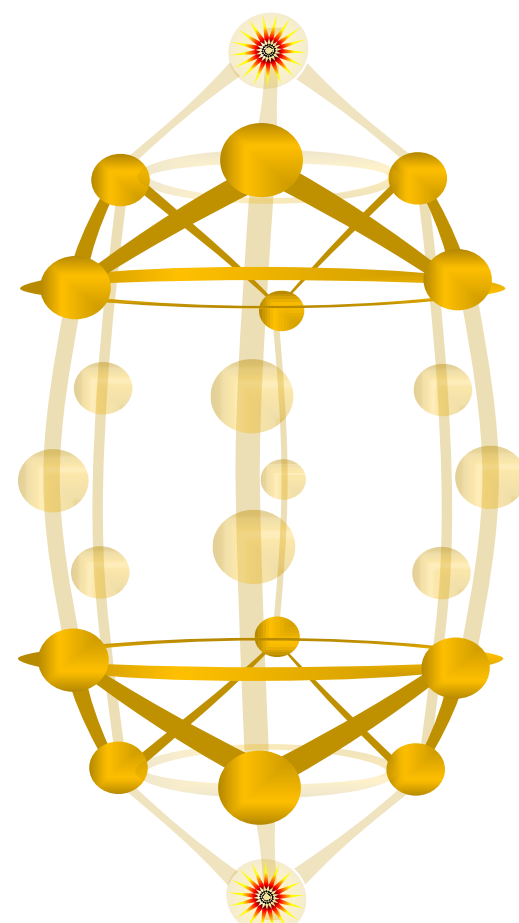

(2)

(2)

说

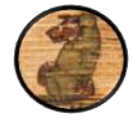




\section{Chapter 3}

\section{Delocalization of the Unpaired Electron in the Quercetin Radical: Comparison of Experimental ESR Data with DFT Calculations}

Zhengwen Li ${ }^{1}$, Mohamed Moalin ${ }^{1,2}$, Ming Zhang ${ }^{1}$, Lily Vervoort ${ }^{1}$, Alex Mommers ${ }^{1}$ and Guido R.M.M. Haenen ${ }^{1}$

1 Department of Pharmacology and Toxicology, Faculty of Health, Medicine and Life Sciences, Maastricht University, P.O. Box 616, 6200 MD Maastricht, The Netherlands; maxamed.moalin@gmail.com (M.M.); z.ming@maastrichtuniversity.nl (M.Z.); 1.vervoort@maastrichtuniversity.nl (L.V.); a.mommers@ maastrichtuniversity.nl (A.M.)

2 Research Centre Material Sciences, Zuyd University of Applied Sciences, 6419 DJ Heerlen, The Netherlands 


\begin{abstract}
In the antioxidant activity of quercetin $(\mathrm{Q})$, stabilization of the energy in the quercetin radical (Q') by delocalization of the unpaired electron (UE) in $\mathrm{Q}^{*}$ is pivotal. The aim of this study is to further examine the delocalization of the UE in $Q^{*}$, and to elucidate the importance of the functional groups of $\mathrm{Q}$ for the stabilization of the UE by combining experimentally obtained spin resonance spectroscopy (ESR) measurements with theoretical density functional theory (DFT) calculations. The ESR spectrum and DFT calculation of $\mathrm{Q}^{\bullet}$ and structurally related radicals both suggest that the UE of $\mathrm{Q}^{*}$ is mostly delocalized in the $\mathrm{B}$ ring and partly on the AC ring. The negatively charged oxygen groups in the B ring $\left(3^{\prime}\right.$ and $\left.4^{\prime}\right)$ of $\mathrm{Q}^{*}$ have an electron-donating effect that attract and stabilize the UE in the B ring. Radicals structurally related to $\mathrm{Q}^{*}$ indicate that the negatively charged oxygen at $4^{\prime}$ has more of an effect on concentrating the UE in ring B than the negatively charged oxygen at 3 '. The DFT calculation showed that an $\mathrm{OH}$ group at the 3-position of the $\mathrm{AC}$ ring is essential for concentrating the radical on the $\mathrm{C} 2-\mathrm{C} 3$ double bond. All these effects help to explain how the high energy of the UE is captured and a stable $\mathrm{Q}^{*}$ is generated, which is pivotal in the antioxidant activity of Q.
\end{abstract}

Keywords: quercetin radical; ESR; unpaired electron; DFT calculation 


\section{Introduction}

In all life forms, opposing forces provide the energy that flows through networks in an organism, which fuels life [1]. In this concept, health is the ability of an organism to maintain the balance between these opposing forces, which creates resilience. The major source of energy in our body is provided by the redox reactions of glycolysis, lipid oxidation, and the citric acid cycle. In a healthy body, the redox energy is high and kept within very strict limits, known as homeostasis [2, 3].

Within this concept, the treatment of diseases should focus on adjusting the deranged flow of energy. The deranged energy flow is manifested by the formation of highly reactive oxygen species (ROS) [4]. In the most reactive ROS, the hydroxyl radical, all the energy of its unpaired electron (UE) is located on a single atom (i.e., oxygen). The highly concentrated energy explains why the hydroxyl radical is "hard" and very reactive. It is the most reactive molecule formed in our body. The hydroxyl radical reacts quickly with virtually any molecule it encounters. This will inflict damage to our body and further derange the energy flow. Antioxidants such as quercetin $(\mathrm{Q})$ are hard electron donors that react quickly with ROS that are hard electron acceptors. By accepting electrons, ROS are converted into relatively unreactive compounds, which do not damage the cell. For example, by accepting an electron, the hydroxyl radical is converted into the hydroxyl anion that, after protonation, becomes water $[1,5,6]$. In the protection against ROS, Q takes over the energy of the ROS and channels this energy in the antioxidant network of the body [7]. When $Q$ takes over the energy, it is firstly oxidized to a quercetin radical (Q*). To protect, it is essential that the energy of the $\mathrm{UE}$ of in $\mathrm{Q}^{*}$ is safely stored in the molecule. It is generally accepted that this is due to the delocalization of the UE in the extensive $\pi$-system of $\mathrm{Q}^{*}$. Despite its pivotal role in the antioxidant activity of Q, research on the exact delocalization of the UE in $\mathrm{Q}^{*}$ is rare and not conclusive [6,8-10]. This prompted us to elaborate on this by combing experimentally obtained spin resonance spectroscopy (ESR) results with theoretical quantum calculation of the delocalization of the UE in $\mathrm{Q}^{*}$, while also examining some structurally closely related radicals, and comparing our results to previously reported data.

In the ESR experiments, a magnetic field is generated, and the para-magnetic protons in the neighborhood of the UE will give rise to different peaks in the ESR spectrum of an organic radical such as $\mathrm{Q}^{\circ}$. In this way, the ESR spectrum gives information about the delocalization of the UE in the molecule [11]. A disadvantage of the ESR technique is that, of Qं, only the spin populations on atoms with protons are obtained. Information about atoms or bonds without a proton nearby (such as oxygen, $\pi$-bond conjugated of the aromatic ring) is not obtained, while these ESR silent groups are critical in the delocalization of the UE of Q: Quantum calculations were used to complete the missing part and to verify the experimental ESR results.

\section{Results}

In order to resolve the delocalization of the UE in Q*, the ESR spectrum of Q ${ }^{\circ}$ and that of several structurally related radicals were recorded and analyzed. Density functional theory (DFT) was used for the electronic properties of the compounds. To generate reliable spin population and spin density results of a compound, its three-dimensional (3D) structure has to be accurate. Therefore, the geometry of the radicals in the water phase was determined 
first. Considering the high $\mathrm{pH}$ in the experiments, the fully deprotonated form of the radicals was used. Finally, the ESR data were combined with the DFT calculations.

\subsection{ESR Spectrums}

\subsubsection{Hydroquinone and Catechol Radicals}

To unravel the complicated ESR spectrum of Q*, the ESR spectra of the hydroquinone and catechol radicals were examined first (Fig 1).

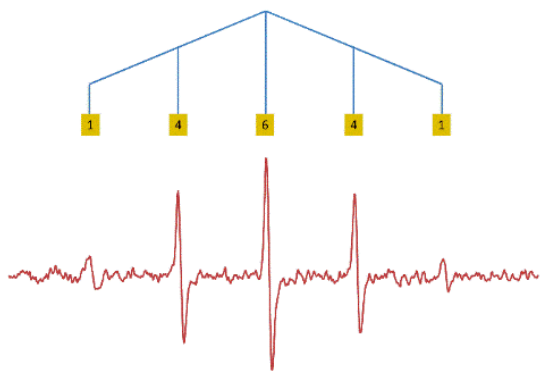

Hydroquinone radical

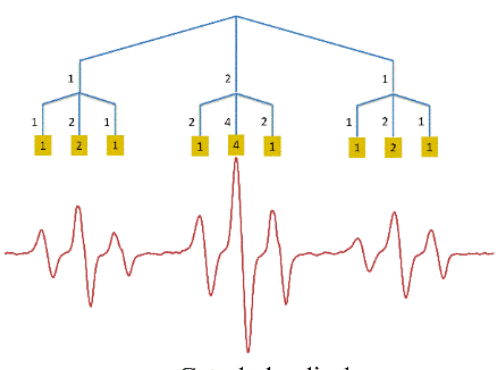

Catechol radical

Fig 1. Experimentally obtained spin resonance spectroscopy (ESR) spectra of the hydroquinone radical and the catechol radical with the protons causing the splitting of the signal. The relative intensities of the peaks are given in yellow squares.

Autoxidation of hydroquinone gave a typical quintet [12]. Following Pascal's triangle, the observed quintet can be explained by the interaction of the UE with four equivalent protons. The hydroquinone radical has four protons that are bound to $\mathrm{C} 2, \mathrm{C} 3, \mathrm{C} 5$, and C6. The equivalence of these protons is ascertained by the symmetry of the molecule. Their hyperfine coupling constant was found to be $2.337 \mathrm{G}$.

The ESR spectrum of the catechol radical shows a triplet split into a smaller triplet (Fig 1). The symmetry of the catechol molecule shows that the protons on C3 and C6 are equivalent, and, because of the neighboring electronegative oxygen atom, the small triplet signals with hyperfine coupling of $0.8405 \mathrm{G}$ were assigned to the effect of these protons. The larger triplet with hyperfine coupling of $3.549 \mathrm{G}$ can be assigned to the other two equivalent protons on C4 and C5.

\subsubsection{Myricetin, Kaempferol, and Quercetin Radicals}

Autoxidation of myricetin (M) led to a distinct triplet ESR signal, indicating the presence of two equivalent protons, with a hyperfine coupling of $1.007 \mathrm{G}$. The structure of the fully deprotonated myricetin radical $\left(\mathrm{M}^{*}\right)$ shows that four protons may affect the ESR signal, namely, those on $\mathrm{C} 6, \mathrm{C} 8, \mathrm{C} 2$ ', and $\mathrm{C}^{\prime}$. Due to the location of a negatively charged oxygen at the 5-position, the protons on $\mathrm{C} 6$ and $\mathrm{C} 8$ in the $\mathrm{A}$ ring are not equivalent and, therefore, would not lead to the observed triplet. Based on the symmetry of the B ring of $\mathrm{M}^{\circ}$, it is most likely that the two equivalent protons that are responsible for the triplet signal are on $\mathrm{C}^{2}$ and $\mathrm{C6}^{\prime}$ in the B ring (Fig 2). 

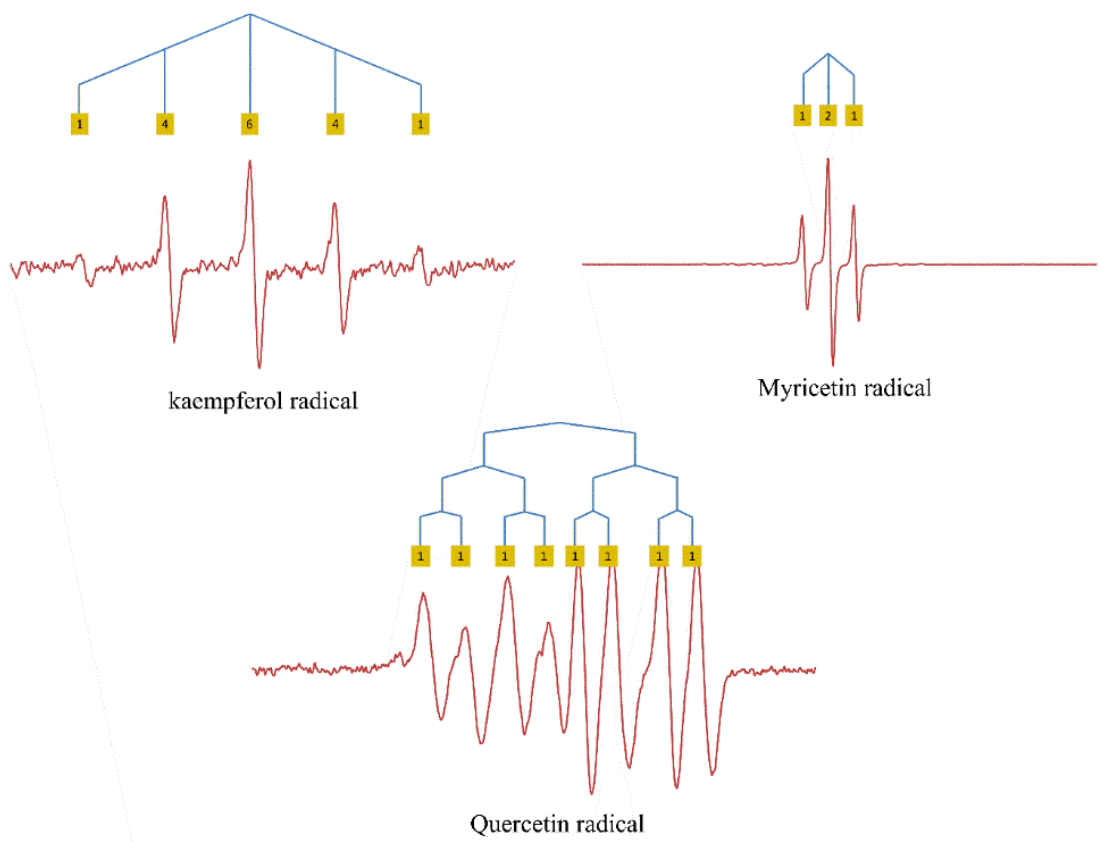

Fig 2. ESR spectra of flavonol radicals with the protons causing hyperfine couplings indicated. The relative intensities of peaks are given in yellow squares.

The ESR spectrum of the kaempferol radical $\left(\mathrm{K}^{*}\right)$ is a quintet with a hyperfine coupling of $2.522 \mathrm{G}$. The quintet obtained is equal to that of the hydroquinone radical, although the intensity of the ESR signal obtained of $\mathrm{K}^{*}$ is much lower. At first, it was thought that the quintet was caused by the interaction of the $\mathrm{UE}$ with four protons on $\mathrm{C}^{\prime}, \mathrm{C}^{\prime}, \mathrm{C}^{\prime}$ ' and $\mathrm{C}^{\prime}$ ' in the $\mathrm{B}$ ring. This is further addressed in the discussion.

The ESR spectrum of $\mathrm{Q}^{*}$ is a doublet, doublet, doublet with hyperfine couplings of 3.184, 1.480 , and $0.652 \mathrm{G}$ (Fig 2). This spectrum suggests that there are three different protons with one higher, one medium, and one smaller interaction intensity. Because the three protons are not equal, it is more difficult to assign these protons. The protons on $\mathrm{C} 6$ or $\mathrm{C} 8$ on the A ring with two negatively charged oxygens on C5 and C7 might interact with the UE. However, considering the results of $\mathrm{K}^{\cdot}$ and $\mathrm{M}^{*}$ where the protons in the $\mathrm{B}$ ring are thought to have the main effect on the ESR signal, the simplest explanation for $\mathrm{Q}^{*}$ is that the three protons on the $\mathrm{B}$ ring are responsible for the doublets, with the proton on $\mathrm{C}^{\prime}$ causing the largest doublet (similar to the catechol radical), the proton on $\mathrm{C} 2{ }^{\prime}$ causing the intermediate doublet, and the proton on $\mathrm{C} 5^{\prime}$ causing the smallest doublet.

\subsubsection{Methylated Quercetin Radicals}

The three methylated quercetin compounds were synthesized to investigate the influence of the negatively charged oxygen on the delocalization of UE. 
Autoxidation of 3MQ gives an ESR signal composed of a large doublet split into a smaller triplet, with hyperfine couplings of $2.884 \mathrm{G}$ and of $0.9385 \mathrm{G}$, respectively (Fig 3). The triplet signals might be due to the two protons on $\mathrm{C}^{\prime}$ ' and $\mathrm{C} 5^{\prime}$ in the $\mathrm{B}$ ring, as these two protons are roughly in the same environment. The proton on $\mathrm{C}^{\prime}$ might cause the large doublet signals (similar to catechol radical).
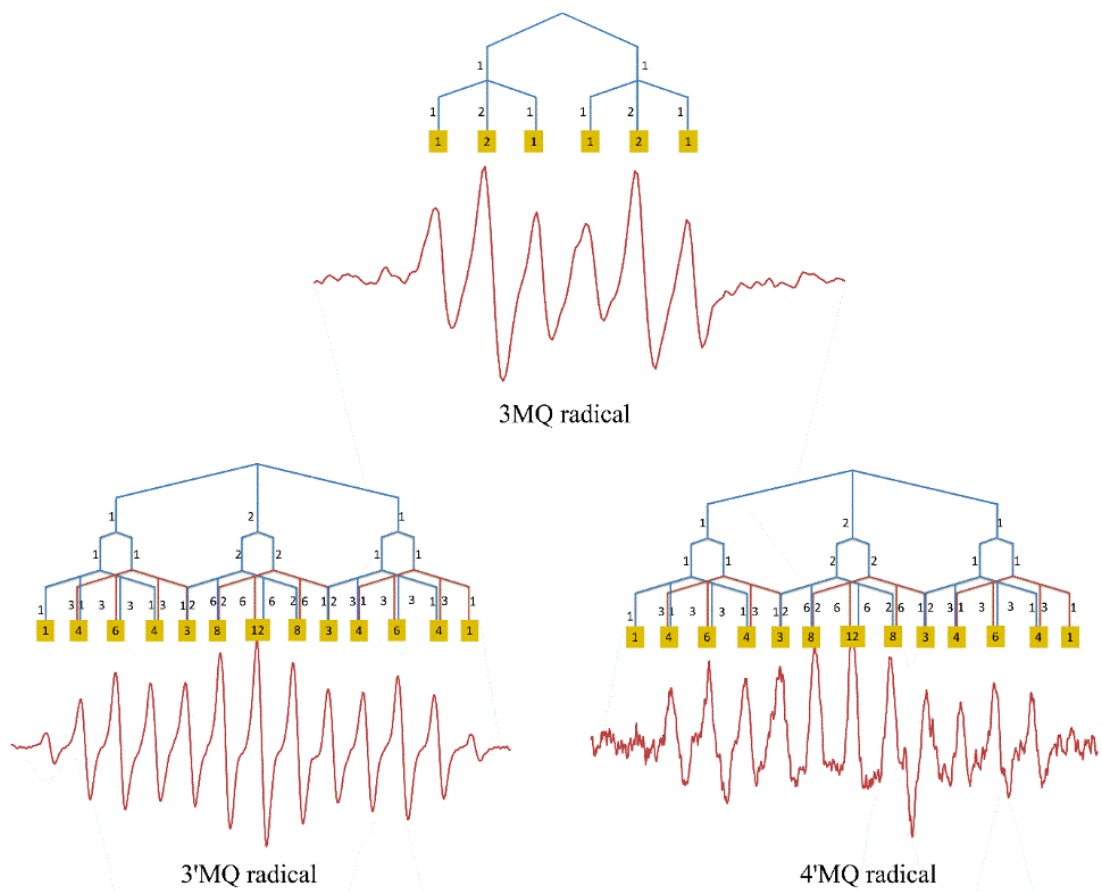

Fig 3. ESR spectra of the radical of the $O$-methylated derivatives of Q, with the protons causing hyperfine couplings indicated. The relative intensities of peaks are given in yellow squares.

The ESR spectra of 3'MQ' and 4'MQ' are much more complex compared with the spectrum of $3 \mathrm{MQ}^{\circ}$, indicating that the protons on the methoxy group in the $\mathrm{B}$ ring affect the delocalization of the UE. The ESR spectrum of $3^{\prime} \mathrm{MQ}^{\prime}$, as well as that of $4^{\prime} \mathrm{MQ}^{\circ}$, is a triplet, a doublet, and a quartet. Their hyperfine couplings are $2.835,0.760$, and $0.684 \mathrm{G}$ in $3^{\prime} \mathrm{MQ}$;, and $2.811,0.7355$, and $0.7355 \mathrm{G}^{\text {in }} 4^{\prime} \mathrm{MQ} \mathrm{MQ}^{*}$ (Fig 3). $O$-methylation of the $3^{\prime} \mathrm{OH}$ group or of the $4^{\prime} \mathrm{OH}$ group changes the electronic environment of the protons in the $\mathrm{B}$ ring, which makes assigning the hyperfine couplings of $3^{\prime} \mathrm{MQ}^{*}$ or $4^{\prime} \mathrm{MQ}^{*}$ to a proton challenging. In order to solve this, we employed DFT calculation.

\subsection{Structure}

An accurate $3 \mathrm{D}$ structure of $\mathrm{Q}^{*}$ is important for the calculation of its spin population. We firstly optimized the structure of $\mathrm{Q}$ at M062X/6-311G $(\mathrm{d}, \mathrm{p})$ level. The result of the optimization shows that the dihedral angle $\left(\mathrm{C} 3-\mathrm{C} 2-\mathrm{C}^{\prime}-\mathrm{C} 2^{\prime}\right)$ formed between the $\mathrm{B}$ and $\mathrm{C}$ ring is $6.89^{\circ}$. This is close to the X-ray experimental data of $8.0^{\circ}$, indicating that the optimization at this level is accurate. Due to the high $\mathrm{pH}$ used in the ESR experiment, the 
optimization of Q was carried out on its fully deprotonated form. The optimization shows that the dihedral angle $\left(\mathrm{C} 3-\mathrm{C} 2-\mathrm{C}^{\prime}-\mathrm{C} 2^{\prime}\right)$ of $\mathrm{Q}^{\circ}$ is $0.072^{\circ}$ which means that the molecule is practically planar. The bond length of $\mathrm{C} 2-\mathrm{Cl}^{\prime}$ is also reduced from $1.46 \AA$ in $\mathrm{Q}$ to $1.44 \AA$ in $\mathrm{Q}^{*}$. The planar configuration of $\mathrm{Q}^{*}$ and the relatively short bond length in $\mathrm{Q}^{*}$ indicate that the $\mathrm{C} 2-\mathrm{C} 1$ ' single bond between both rings is transformed into a "semi-double bond", which points toward delocalization of the UE over the B ring and the $\mathrm{C}$ ring (Fig 4).

$\mathrm{K}^{\circ}$ and $\mathrm{M}^{*}$ were also found to be practically planar, with dihedral angles of $0.02^{\circ}$ and $3.58^{\circ}$, respectively. The dihedral angles of $3 \mathrm{MQ}^{\circ}, 3^{\prime} \mathrm{MQ}$, and $4^{\prime} \mathrm{MQ} \mathrm{Q}^{\circ}$ are $24.08^{\circ}, 2.19^{\circ}$, and $11.81^{\circ}$, respectively. The relatively high dihedral angle of $3 \mathrm{MQ}^{\circ}$ probably involves a steric effect of the methoxy group at the 3-position within the B ring. More detailed structural characteristics of investigated compounds are given in the Supplementary Materials (Supplementary Figure S1).
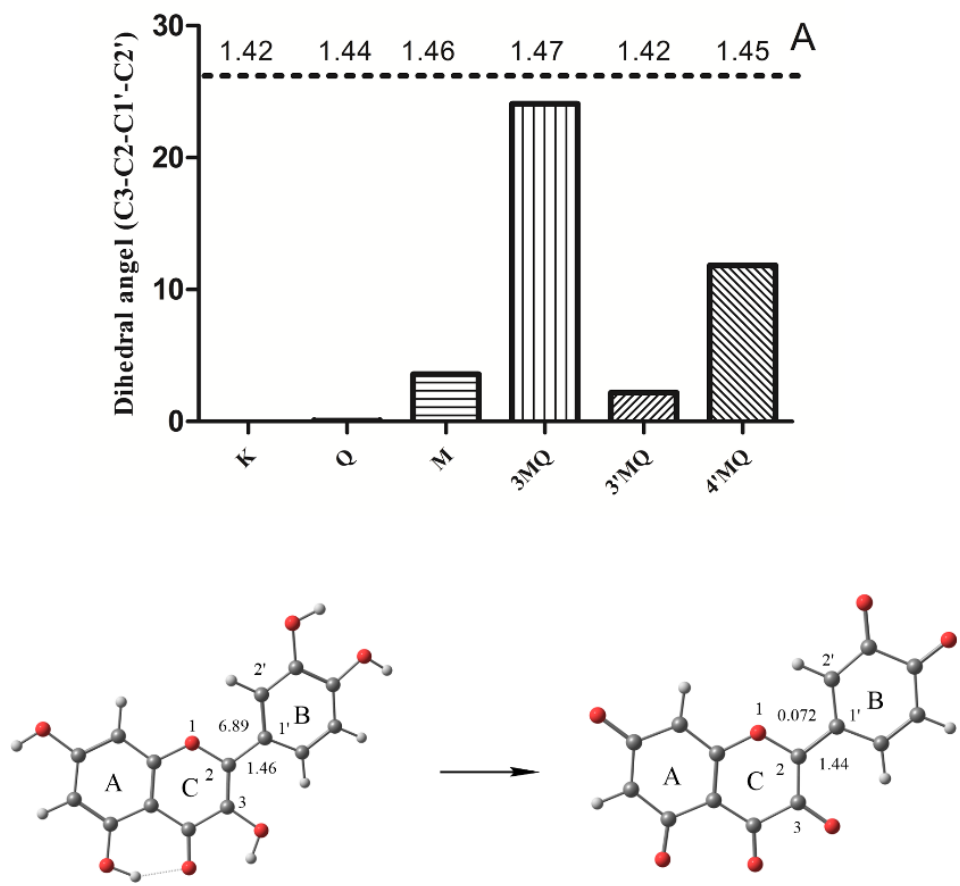

Fig 4. The dihedral angle $\left(\mathrm{C} 3-\mathrm{C} 2-\mathrm{C} 1^{\prime}-\mathrm{C} 2^{\prime}\right)$ of tested compounds and the optimized structure of $\mathrm{Q}$ and fully deprotonated $\mathrm{Q}^{*}$ in the water phase. The dihedral angle $\left(\mathrm{C} 3-\mathrm{C} 2-\mathrm{C}^{\prime}-\mathrm{C} 2^{\prime}\right)$ of $0.072^{\circ}$ indicates that $\mathrm{Q}^{\circ}$ is planar; A: bond length. 


\subsection{Spin Density Map and Spin Population}

For radicals, the distributions of the alpha electron density and beta electron density are different. The spin density maps of the distribution of the UE of all tested compounds are given in Fig. 5.

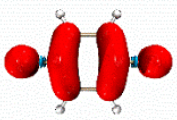

Hydroquinone

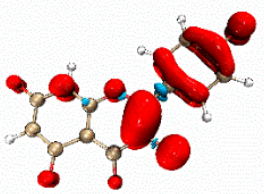

Kaempferol radical

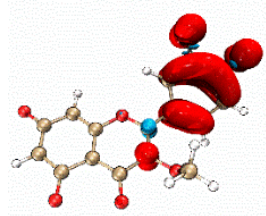

3MQ radical

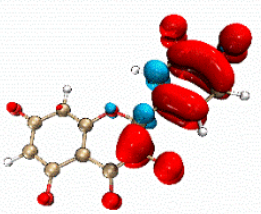

Q radical

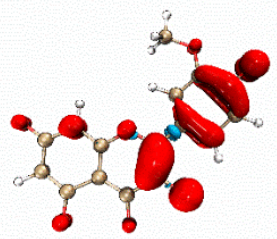

3'MQ radical

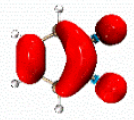

Catcchol radical

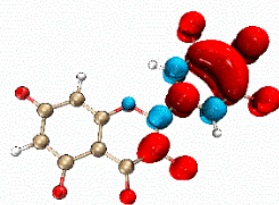

Myricetin radical

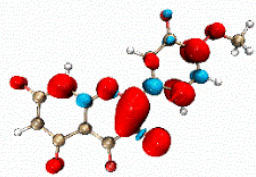

4'MQ radical

Fig 5. The spin density map of the deprotonated radicals in water. The red color represents the alpha electron and the blue color represents the beta electron.

The spin density map of the hydroquinone radical shows that its UE is delocalized over the whole molecule and concentrated on the oxygen atoms and the carbon bound to the oxygen. The UE of the catechol radical is primarily delocalized around its two adjacent oxygen atoms and the carbon atoms they are bound to. The two equivalent neighboring carbons also have a high UE delocalization. The two other carbons have a lower UE delocalization. The spin density maps of both the hydroquinone radical and the catechol radical confirm the interpretation of their ESR signal given above.

The spin density map of $\mathrm{K}^{\bullet}$ shows that its UE is concentrated on $\mathrm{C} 2$ and $\mathrm{C} 3$, and partly on its $\mathrm{B}$ ring. In $\mathrm{Q}^{*}$, the $\mathrm{UE}$ is less concentrated on the $\mathrm{C} 2$ and $\mathrm{C} 3$ positions and resides more in the $\mathrm{B}$ ring, compared to the UE of $\mathrm{K}^{*}$. The difference of $\mathrm{M}^{\cdot}$ with $\mathrm{K}^{\cdot}$ (i.e., less on the $\mathrm{C} 2$ and $\mathrm{C} 3$ and more in ring $\mathrm{B}$ ) is even more pronounced than the difference of $\mathrm{Q}^{\bullet}$ with $\mathrm{K}^{\bullet}$. This indicates that the negatively charged oxygen in ring B greatly attracts and stabilizes the UE. Another important finding is that methylation of the 3-OH as in $3 \mathrm{MQ}$, drastically reduces the delocalization of UE over the $\mathrm{C} 2-\mathrm{C} 3$ double bond. The methylated group also prevents the planar arrangement of the $\mathrm{B}$ ring and $\mathrm{C}$ ring, which limits the delocalization over both rings and causes the UE to concentrate in only one ring, which appeared to be the B ring. This is 
also in line with the relatively high length of the $\mathrm{C} 2-\mathrm{C}^{\prime}$ ' bond, i.e., the connection of the $\mathrm{B}$ ring with the $\mathrm{C}$ ring, in $3 \mathrm{MQ}^{\circ}$ compared to $\mathrm{Q}^{*}$.

Comparing the spin density map of $4^{\prime} \mathrm{MQ}^{*}$ to that of $\mathrm{Q}^{*}$ shows that methylation of the $4^{\prime} \mathrm{OH}$ of $\mathrm{Q}^{\circ}$ greatly neutralizes the ability of the negatively charged oxygen in ring $\mathrm{B}$ to attract and stabilize the UE in the B ring, and concentrates the UE on the $\mathrm{C} 2-\mathrm{C} 3$ double bond in the $\mathrm{C}$ ring. Comparing the spin density map of $3^{\prime} \mathrm{MQ}^{*}$ and $4^{\prime} \mathrm{MQ}^{*}$ to that of $\mathrm{Q}^{*}$ shows that methylation of the $3^{\prime} \mathrm{OH}$ has less of an effect than methylation of the $4^{\prime} \mathrm{OH}$. This means that, of the negatively charged oxygens in ring B that greatly stabilize the UE, the negatively charged oxygen at the $4^{\prime}$ position has the greatest effect. Interestingly, the spin density map of $3^{\prime} \mathrm{MQ} Q^{*}$ closely resembles that of $\mathrm{K}^{*}$, which misses the $3^{\prime} \mathrm{OH}$ group, indicating that methylation of the $\mathrm{OH}$ group (which prevents deprotonation and converts the $\mathrm{OH}$ group into a negatively charged oxygen) neutralizes the effect of the $3^{\prime} \mathrm{OH}$ group on the delocalization of the UE.

\subsection{Combining the ESR Data with the DFT Calculation}

By calculating the spin population on the atoms using the splitting constants according to Becke method, the experimental results obtained with the ESR measurements and the DFT calculation were compared. The protons which generate the ESR signal were assigned by (i) ranking the values of the spin density calculation of each proton bound carbon of a specific radical, and (ii) pairing the rank of the calculated spin density to the rank of the value of the hyperfine splitting constant found in the ESR spectrum of that radical (Fig 6).

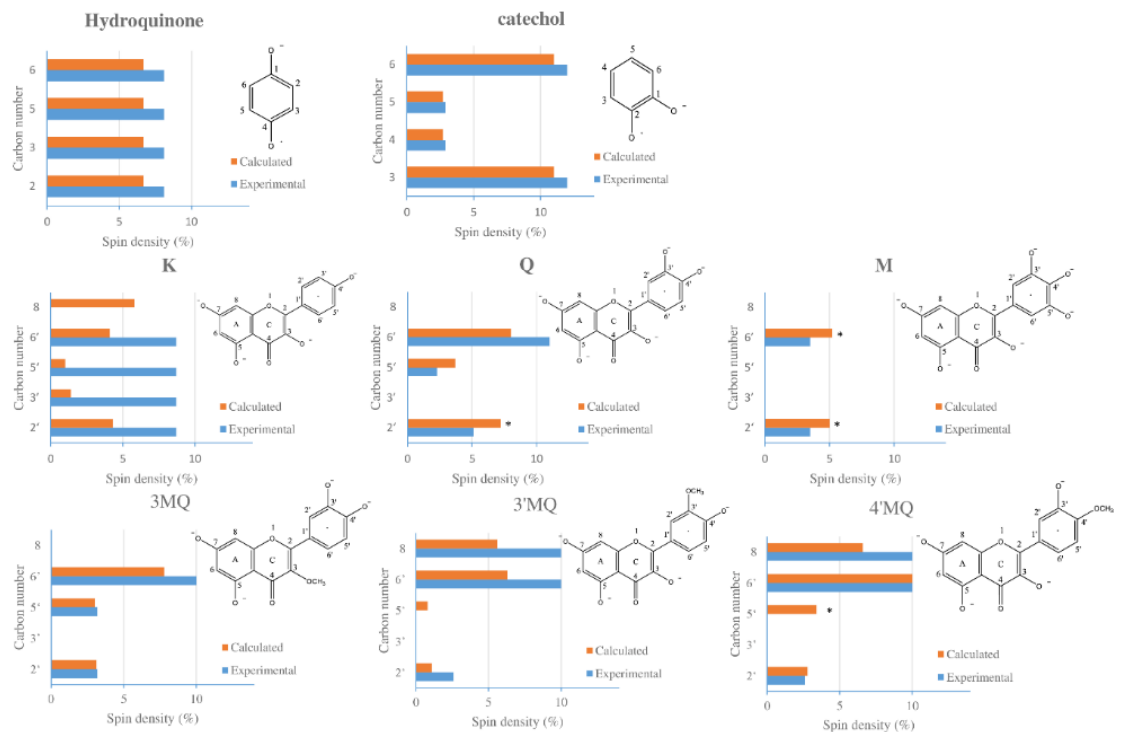

Fig 6. The experimental and calculated spin populations of proton-bound carbons of tested compounds. * representing $\beta$ electrons (the values of the $\beta$ electron are negative; for a better comparison, we used absolute values in the picture above, noting that the calculated spin populations are in percentages. This also applies to the whole text when talking about calculated data). 
Although $\mathrm{Q}^{\bullet}$ possesses five protons, the experimental ESR results and calculation both indicate that only three of them significantly affect the ESR spectrum. The calculation shows that the spin density of the UE at the C6 and C8 position is too low to affect the ESR signal. Our results suggest that the $\mathrm{UE}^{-} \mathrm{Q}^{*}$ is delocalized on the $\mathrm{B}$ ring, as well as on the $\mathrm{C}$ ring. The calculation by the Beck method shows that the absolute spin populations at $\mathrm{C}^{\prime}, \mathrm{C}^{\prime}$, and $\mathrm{C6}^{\prime}$ are $7.2,3.7$, and 8.0, respectively, indicating that the spin densities calculated using the hyperfine couplings of $5.1,2.3$, and 11 can be assigned to $\mathrm{C} 2^{\prime}, \mathrm{C}^{\prime}$, and $\mathrm{C} 6^{\prime}$ in the $\mathrm{B}$ ring, respectively. The similarity of the value of the experimentally determined spin densities with the spin densities obtained using the DFT calculation supports the accuracy of the DFT calculation.

The absolute spin population of all four proton-connected carbons of the hydroquinone radical is 6.7 , and an experimentally obtained spin density of 8.1 can be assigned to each of them. The geometry of the molecule confirms that these four protons and the carbon atoms they are bound to are equal. The two adjacent negatively charged oxygens of catechol make the C3 and C6 less attractive for UE than C4 and C5. The calculated delocalization for the $\mathrm{UE}$ at these sites is $2.7,2.7,11$, and 11 , respectively, which corresponds to the experimental spin densities of 2.9, 2.9, 12, and 12 .

$\mathrm{M}^{*}$ contains four protons: two protons on its $\mathrm{A}$ ring and two protons on its $\mathrm{B}$ ring. Calculation shows that the spin density on C6 and C8 of its A ring is relatively low (both 0.2 (Supplementary Figure S1), suggesting that their adjacent protons are unlikely to affect the ESR spectrum. Calculation also shows that the protons on $\mathrm{C}^{\prime}$ and $\mathrm{C}^{\prime}{ }^{\prime}$ in the $\mathrm{B}$ ring are practically equivalent, with calculated values of 5.0 and 5.2, respectively. The equivalence of these protons is corroborated by the geometry of the molecule. These equivalent protons produce the triplet in the ESR signal, which has the experimental spin density of 3.5.

The calculation of 3MQ shows that the proton on C8 in the A ring does not affect the ESR spectrum, which is also the case in $\mathrm{Q}^{\circ}$ and $\mathrm{M}^{*}$. The protons on $\mathrm{C}^{\prime}$ and $\mathrm{C}^{\prime}$ in the $\mathrm{B}$ ring of $3 \mathrm{MQ}^{\bullet}$ are practically equivalent with values of 3.1 and 3.0, respectively, giving the triplet in the ESR spectrum. The calculated spin density on $\mathrm{C6}^{\prime}$ is relatively high, with a value of 7.8 , which gives the doublet.

The spin density maps show that the UEs in Q' and $\mathrm{M}^{*}$ are less "soft" than the UEs in $3^{\prime} \mathrm{MQ}^{\circ}$ and $4^{\prime} \mathrm{MQ} \mathrm{Q}^{\circ}$, as $\mathrm{C} 8$ of the A ring is also favored by the UE in $3^{\prime} \mathrm{MQ}{ }^{\circ}$ and $4^{\prime} \mathrm{MQ}$. The calculated spin densities on $\mathrm{C6}^{\prime}$ and $\mathrm{C} 8$ in $3^{\prime} \mathrm{MQ}^{\circ}$, as well as in $4^{\prime} \mathrm{MQ}^{\circ}$, are higher than any other proton-connected carbon in these molecules; at $\mathrm{C}^{\prime}$, the values are 6.3 and 10 (for $3^{\prime} \mathrm{MQ} \mathbf{Q}^{\circ}$ and $4^{\prime} \mathrm{MQ}$, respectively) and, on $\mathrm{C} 8$, the values are 5.6 and 6.6 (for $3^{\prime} \mathrm{MQ}^{\circ}$ and $4^{\prime} \mathrm{MQ}^{\circ}$, respectively). This also indicates that the protons at $\mathrm{C}^{\prime}$ and $\mathrm{C} 8$ in $3^{\prime} \mathrm{MQ} \mathbf{Q}^{\circ}$, as well as those in 4'MQ', are practically equivalent and, therefore, generate a triplet in their ESR spectrums. The proton on $\mathrm{C}^{\prime}$ ' in $3^{\prime} \mathrm{MQ}{ }^{*}$ and the proton on $\mathrm{C} 2^{\prime}$ in $4^{\prime} \mathrm{MQ}{ }^{\circ}$ in their $\mathrm{B}$ rings generate a doublet. Furthermore, with the three types of methylated quercetin radicals, the calculated spin densities are in line with the experimental spin densities.

The calculation shows that the delocalization of the UE on the proton-connected carbons of the $\mathrm{B}$ ring of $\mathrm{K}^{\circ}$ are 4.3 and 4.1 on $\mathrm{C}^{\prime}$ and $\mathrm{C}^{\prime}$, and 1.3 and on $\mathrm{C}^{\prime}$ and $\mathrm{C}^{\prime}$ ', indicating the presence of two pairs of practically equivalent protons in ring $\mathrm{B}$ (as corroborated by the geometry of the molecule). The $\mathrm{UE}$ of $\mathrm{K}^{\cdot}$ is also highly concentrated on $\mathrm{C} 8$ of its A ring with 
a calculated spin density of 5.8. The calculated spin distribution of the UE of $\mathrm{K}^{\bullet}$ does not correspond to the ESR signal we obtained experimentally via the autoxidation of K. In several other studies $[13,14]$, more complex spectra than the spectrum we obtained were found after the autoxidation of $\mathrm{K}$. This makes analyzing the delocalization of $\mathrm{UE}$ of $\mathrm{K}^{*}$ puzzling. This is further elaborated in the discussion.

\section{Discussion}

The principle of the protective effect of a free radical scavenger antioxidant is that (i) the antioxidant quickly takes over the high energy contained in a reactive free radical, (ii) the energy is stabilized by forming a relatively un-reactive antioxidant radical, and (iii) the energy is safely channeled in the antioxidant network of the cell [10]. Q is one of the most studied free radical scavengers because of its extraordinary high potency and, therefore, we focused on this compound $[7,15]$. In the first step, Q donates an electron to the free radical through hydrogen atom transfer (HAT), sequential proton-loss electron transfer (SET-PT), or single electron transfer followed by proton loss (SPLET), depending on the solvent. In a HAT mechanism, the proton and electron are transferred in the same kinetic process, while in SET-PT or SPLET mechanisms, the electron transfer and proton transfer are two independent kinetic processes; the difference between these two is the sequence of the kinetic processes $[16,17]$. The HAT mechanism is more plausible for scavenging of radicals by Q in acetone and ethanol [18], while, in aqueous solution, the SPLET mechanism is thermodynamically preferred [19]. The formed $\mathrm{Q}^{\bullet}$ is relatively stable due to the delocalization of its UE. Although it is generally accepted that the delocalization is pivotal in the antioxidant activity of Q, the exact delocalization of the UE in Q ${ }^{*}$ is not well determined. The aim of this paper is to further examine the delocalization of the UE in Q', and to elucidate the importance of the $\mathrm{A}, \mathrm{B}$, and $\mathrm{C}$ ring for the stabilization of the radical by combining experimental ESR measurements with theoretical DFT calculations.

The ESR signal of Q ${ }^{*}$ has eight peaks, composed of one large doublet, one medium doublet, and one small doublet. This splitting of the spectrum of $\mathrm{Q}^{-}$is of similar to that reported by Kuwabara et al. [20], who oxidized Q to $\mathrm{Q}^{*}$ in an $\mathrm{Na}_{2} \mathrm{CO}_{3}{ }^{-} / \mathrm{NaHCO}_{3}(0.1 \mathrm{M})$ buffer ( $\left.\mathrm{pH} 10\right)$ under nitrogen atmosphere using the ${ }^{15} \mathrm{~N}$-labeled sodium salt of nitrosodisulfonate. The proton hyperfine coupling constants they obtained were $1.36,0.76$, and 2.56 , assigned to the protons on $\mathrm{C}^{\prime}, \mathrm{C}^{\prime}$, and $\mathrm{C}^{\prime}$ ' in the $\mathrm{B}$ ring, respectively. The previously reported ESR spectrum obtained by autoxidation of $\mathrm{Q}$ in dimethyl sulfoxide (DMSO) $-\mathrm{H}_{2} \mathrm{O}-\mathrm{KOH}$ showed similar hyperfine coupling constants of $1.45,0.70$, and 2.70 that were also assigned to the same protons [12]. These hyperfine coupling constants are in the same range as those we obtained, i.e., 1.480, 0.652, and 3.184. This indicates that $\mathrm{Q}^{\bullet}$ was successfully generated. The small differences in the obtained values probably originate from the difference in the oxidation procedures and solvents used. Assigning the protons appropriately relied on chemical intuition and was sometimes incorrect. For example, in some reports, the lowest hyperfine constant was assigned to the proton on $\mathrm{C}^{\prime}$ ' of $\mathrm{Q}^{*}$. However, our DFT calculation indicates that this has to be the proton on $\mathrm{C} 5^{\prime}$, which is in agreement with the report by Kuwabara et al. [20]. Q at the high $\mathrm{pH}$ we used is fully deprotonated, indicating that Q cannot donate a hydrogen atom, implying SPLET as the dominant mechanism for generating Q*.

Spin population results of $\mathrm{Q}^{\bullet}$ show that delocalization of the UE on $\mathrm{C}^{\prime}$ ', $\mathrm{C}^{\prime}$ ', and $\mathrm{C}^{\prime}$ ' was $7.2,8$, and 3.7, respectively. This is in line with the experimental data obtained using ESR. 
The calculated value at $\mathrm{C}^{\prime}$ ' is a bit higher, and that on $\mathrm{C}^{\prime}$ ' is a bit lower compared with the experimental data. This might partly be attributed to a solvent effect, since the experiments were carried out in a mixed DMSO-water solution while the calculation was in water. Actually, the solvent might not only affect the splitting intensities but also affect the distribution of UE. Calculation shows that, in Q*, with only one deprotonated hydroxyl group in the gas phase, the UE of $\mathrm{Q}^{*}$ is largely localized on the negative charged oxygen [21], while, in a polar solvent, the UE is not concentrated on the negatively charged oxygen [22]. Our calculations also show that the delocalization of the UE in the gas phase differs from that in water (data not shown). The calculation also shows that the total delocalization on the negatively charged oxygen (i.e., on the charged oxygen at the $3^{\prime}-, 4^{\prime}-, 3-, 5-$, and 7-position with a delocalization of $8.7,16.1,8.7,0.7$, and 0.7 , respectively) is only $34.9 \%$. Instead, the $\mathrm{UE}$ of $\mathrm{Q}^{*}$ is mainly delocalized on $\mathrm{C} 2-\mathrm{C} 3$ and on the carbons in the $\mathrm{B}$ ring.

Another interesting finding is that, upon increasing the number of negatively charged oxygens on the $\mathrm{B}$ ring, more of the UE of the flavonoid radical is delocalized on the $\mathrm{B}$ ring. This is as expected as it is generally believed that the oxygen can donate parts of its electrons and, thus, stabilize an UE around it. This explains an enrichment of UE going from $\mathrm{K}^{*}$ to $\mathrm{Q}^{\bullet}$ to $\mathrm{M}^{*}$, which contain respectively one, two, and three deprotonated hydroxyl groups in their $\mathrm{B}$ ring. As a consequence, $\mathrm{Q}^{\bullet}$ and $\mathrm{M}^{*}$ are more likely to donate a second electron compared with $\mathrm{K}^{*}$, which corresponds to the ranking of the antioxidant potency of these three flavonoids $[18,23]$.

The spin density map of $\mathrm{Q}^{\bullet}$ shows that the beta electron delocalizes on $\mathrm{C} 2$ in the $\mathrm{C}$ ring, whereas the alpha electron delocalizes on $\mathrm{C}^{\prime}$ in the $\mathrm{B}$ ring. This suggests an electronic interaction between both carbons on the connection between the $\mathrm{B}$ ring and the $\mathrm{C}$ ring and that, in an alkaline environment, a semi-double bond is formed between these two rings. Moreover, (i) the reduction in the dihedral angle between the $\mathrm{B}$ ring and the $\mathrm{C}$ ring, from $6.89^{\circ}$ of $\mathrm{Q}$ to $0.14^{\circ}$ of fully deprotonated $\mathrm{Q}^{*}$, and (ii) the reduction of the $\mathrm{C} 2-\mathrm{C} 1^{\prime}$ bond length from $1.46 \AA$ to $1.44 \AA$ are both consistent with the formation of the semi-double bond between the $\mathrm{B}$ ring and the $\mathrm{A}$ ring, and with the UE electron being delocalized not only in the $\mathrm{B}$ ring, but also in the $\mathrm{AC}$ ring of $\mathrm{Q}^{*}$.

Comparing the spin density maps of 3MQ` with $\mathrm{Q}^{\bullet}, 3^{\prime} \mathrm{MQ}^{*}$, and $4^{\prime} \mathrm{MQ} \mathrm{Q}^{\bullet}$ indicates that the negatively charged oxygen at the 3 -position in ring $C$ plays a pivotal role in the distribution of UE. Once the 3-OH group is $O$-methylated, the UE is mainly localized on the B ring. This involves a steric effect of the methyl group, which forces the B ring out of the plane of the AC ring, preventing the delocalization of the UE over both rings since their $\pi$-systems are not well connected. Another important reason is that $O$-methylation of the $3-\mathrm{OH}$ group prevents it from deprotonation, whereby no negatively charged oxygen is formed and no "spare electron" is available to stabilize the UE at that position.

Comparing the spin maps of the methylated Q derivatives also indicates that the $4^{\prime} \mathrm{OH}$ group is more critical for the attraction and delocalization of $\mathrm{UE}$ in the $\mathrm{B}$ ring than the $3^{\prime} \mathrm{OH}$ group. Previous experiments revealed that the antioxidant potency (2,2'-azino-bis(3ethylbenzothiazoline-6-sulfonic acid) (ABTS) scavenging ability) of $4^{\prime}$ methylated Q derivatives is less than that of $3^{\prime}$ methylated Q derivatives [24]. This confirms that a higher concentration of the UE in the $\mathrm{B}$ ring is associated with a higher antioxidant activity. 
The interpretation of the ESR spectrum of $\mathrm{K}^{*}$ is challenging because the experimental data do not correspond to the calculated data. The ESR spectrum obtained after incubating $\mathrm{K}$ at a high pH is similar with to that of Kuhnle et al. [12] and Pirker et al. [13] and consists of a quintet. Our first interpretation was that the quintet might be caused by the interaction of the $\mathrm{UE}$ with four equivalent protons on $\mathrm{C}^{\prime}, \mathrm{C}^{\prime}, \mathrm{C}^{\prime}$, and $\mathrm{C}^{\prime}$ in the $\mathrm{B}$ ring. However, the DFT calculation of $\mathrm{K}^{\cdot}$ shows that the spin populations of these carbons on the $\mathrm{B}$ ring are not equal. Moreover, the DFT calculation also shows that the $\mathrm{C} 8$ of $\mathrm{K}^{*}$ causes a significantly higher hyperfine splitting in the ESR spectrum than the protons in the B ring, because C8 has a spin population with a relatively high value of 5.8. The simulated ESR spectrum based on our DFT calculation (Supplementary Figure S2) resembles the ESR spectrum found experimentally by Pirker et al. [13] after incubating $\mathrm{K}$ in an alkaline solution under an argon atmosphere for 5 min. Pirker et al. [13] and van Acker et al. [14] hypothesized that, in an alkaline solution, part of $\mathrm{K}$ decomposes, leading to the rapid formation of hydroquinone, and that the quintet ESR signal is that of the hydroquinone radical and not of $\mathrm{K}^{\circ}$. As our results also show, the ESR spectra we obtained with $\mathrm{K}$ and hydroquinone are similar. Analysis of a solution of $\mathrm{K}$ incubated for $5 \mathrm{~min}$ at high $\mathrm{pH}$, similar to the incubation of $\mathrm{K}$ in the ESR experiment, confirmed the formation of hydroquinone (Supplementary Figure S3), substantiating the explanation that the ESR signal with $\mathrm{K}$ was derived from the hydroquinone radical.

The intensity of the ESR spectrum we obtained via the autoxidation of $\mathrm{K}$ is weaker than that of hydroquinone, which can be explained by the relatively low amount of hydroquinone formed from $\mathrm{K}$ during the relatively short time between preparing the reaction mixture and recording the ESR spectrum (Supplementary Figure S3). Moreover, the difference between our simulated ESR spectrum of $\mathrm{K}^{\bullet}$ and the ESR spectrum of $\mathrm{K}^{\bullet}$ experimentally found by Pirker et al. [13] might be due to formation of some hydroquinone radicals in their incubation. For a better comparison, the simulated spectrums of other tested compounds were drawn (Supplementary Figure S4).

This spin distribution of $\mathrm{K}^{*}$ obtained with the DFT calculation is consistent with the spin distributions of the other compounds discussed in the present study for which the experimental data did correspond with the calculated data. $\mathrm{K}$ has fewer $\mathrm{OH}$ groups its $\mathrm{B}$ ring compared to $\mathrm{Q}$ and $\mathrm{M}$, which explains why relatively less of the $\mathrm{UE}$ in $\mathrm{K}^{\bullet}$ is attracted to its $\mathrm{B}$ ring, while more resides in its AC ring. This is consistent with the result that the dihedral angle of $\mathrm{K}^{*}$ is even smaller than that of $\mathrm{Q}^{*}$ and $\mathrm{M}^{*}$, and that the bond length of $\mathrm{C} 2-\mathrm{C}^{\prime}$ is the shortest among these three compounds with a length of 1.42 . This is also consistent with the result that the $\mathrm{HOMO}(\mathrm{SOMO})-\mathrm{LUMO}$ gap of $\mathrm{K} \bullet$ is the highest comparing with $\mathrm{Q} \bullet$ and $\mathrm{M} \bullet$, indicated that the $\mathrm{K} \bullet$ is less reactive and might be more stable (Supplementary Figure S5).

In addition to the tested compounds, we also tried to record the ESR spectrum of galangin, a compound that has the same AC ring as $\mathrm{K}, \mathrm{M}$, and Q, but with no hydroxyl group in its $\mathrm{B}$ ring. We failed to generate an ESR spectrum with galangin under the same experimental conditions we used for the other compounds (data not shown). Galangin is a potent free radical scavenging antioxidant, and we expected that a galangin radical would have been formed under the conditions we used. A possible explanation for failing to detect a galangin radical is that the half-life of the galangin radical is even shorter than that of $\mathrm{K}^{*}$; thus, so the galangin radical is degraded before it can be detected in our experiments. This would be in line with our conclusion that hydroxyl groups in ring B play a key role in stabilizing the UE, 
as galangin lacks a hydroxyl group in the B ring. The different behavior of galangin would also corroborate the presence of two antioxidant pharmacophore moieties in flavonols as suggested previously, namely, the $\mathrm{AC}$ ring and the $\mathrm{B}$ ring [25], which seem to have different properties. We hypothesize that, in the antioxidant activity of Q, the AC ring pharmacophore in Q donates an electron to a radical, and, as indicated in the present study, the UE of the formed $\mathrm{Q}^{*}$ is safely stored the B ring pharmacophore.

\section{Materials and Methods}

\subsection{Chemicals}

Quercetin $2 \mathrm{H}_{2} \mathrm{O}$ was purchased from Acros Organics (Geel, Belgium) and used as received. Hydroquinone, kaempferol, and myricetin were obtained from Fluka ( Buchs, Switzerland). Catechol was purchased from Janssen Chimica (Beerse, Belgium). All chemicals were at least of $95 \%$ purity. The methylated derivatives of quercetin were synthesized as described previously [24]. The structures of the tested compounds are given in Fig 7.<smiles>Oc1ccc(O)cc1</smiles>

Hydroquinone<smiles>Oc1ccccc1O</smiles>

Catechol<smiles>[R8]c1cc(-c2oc3cc(O)cc(O)c3c(=O)c2[R])cc([R8])c1[R1]</smiles>

Quercetin: $\mathrm{R}_{3}=\mathrm{R}_{3}{ }^{\prime}=\mathrm{R}_{4}{ }^{\prime}=\mathrm{OH}, \mathrm{R}_{5}{ }^{\prime}=\mathrm{H} \quad$ Myricetin: $\mathrm{R}_{3}=\mathrm{R}_{3^{\prime}}=\mathrm{R}_{4}{ }^{\prime}=\mathrm{R}_{5}{ }^{\prime}=\mathrm{OH} \quad$ Kaempferol: $\mathrm{R}_{3}=\mathrm{R}_{4}{ }^{\prime}=\mathrm{OH}, \mathrm{R}_{3}{ }^{\prime}=\mathrm{R}_{5}{ }^{\prime}=\mathrm{H}$ 3MQ: $\mathrm{R}_{3}=\mathrm{OCH}_{3}, \mathrm{R}_{3}{ }^{\prime}=\mathrm{R}_{4}{ }^{\prime}=\mathrm{OII}, \mathrm{R}_{5}^{\prime}=\mathrm{II} \quad \mathbf{3}^{\prime} \mathrm{MQ}: \mathrm{R}_{3}=\mathrm{R}_{4}^{\prime}=\mathrm{OII}, \mathrm{R}_{3}^{\prime}=\mathrm{OCH}_{3}, \mathrm{R}_{5}^{\prime}=\mathrm{II} \quad \mathbf{4}^{\prime} \mathrm{MQ}: \mathrm{R}_{3}=\mathrm{R}_{3}^{\prime}=\mathrm{OII}, \mathrm{R}_{4}^{\prime}=\mathrm{OCI}_{3}, \mathrm{R}_{5}^{\prime}=\mathrm{II}$

Fig 7. The structures of the tested compounds.

\subsection{Autoxidation and ESR Procedures}

Autoxidation was performed as described by Pirker et al. [13]. Briefly, the compounds were dissolved in DMSO to a concentration of $1-5 \mathrm{mM}$. Then, $650 \mu \mathrm{L}$ of the DMSO solution was added into an ESR flat cell, and $250 \mu \mathrm{L}$ of a $0.1-1 \mathrm{M}$ sodium hydroxide solution was added. The flat cell was immediately placed in the ESR spectrometer (Bruker BioSpin, Rheinstetten, Germany). The recordings were at $10 \mathrm{kHz}$ of modulation frequency and $1 \mathrm{G}$ of 
amplitude on a Bruker ESP300 ESR spectrometer. The microwave frequency was set at 9.79 $\mathrm{GHz}$, with a power of $20 \mathrm{~mW}$. Magnetic field sweep widths were in the range 0.9-2.0 mT, depending on the spectral widths. A modulation amplitude of $0.01 \mathrm{mT}$ was used for most measurements. The spectra given are the sum of 10 successive scans of the same sample that were all recorded in $5 \mathrm{~min}$. The spin populations $(\rho \pi)$ of the proton-bound carbon atoms were calculated by O'Connell's equation, $\mathrm{a}=29 * \rho \pi$, from the hyperfine couplings obtained [26].

\subsection{Calculation Details}

The equilibrium geometries of all compounds (radical forms) were fully optimized with Gaussian 09 package [27] using the DFT method at the M062X [28]/6-311G (d,p) [29] level. In order to calculate the spin populations of investigated compounds, their energies were obtained at the PWPB95 [30]/ma-def2-TZVPP [31] level by orca [32], whereas Grimme's DFT-D3 dispersion correction was also employed [33]. The solvent effects on the tested compounds were taken into account by application of implemented Solvation Model Density (SMD, Water) method [34].

The spin density maps were generated with the help of Multiwfn [35] and VMD [36]. Multiwfn was also applied for the calculation of spin population with Becke methods.

\subsection{Statistics}

All ESR experiments were performed at least in triplicate. Data are expressed as means \pm SD or as a typical example.

\section{Conclusions}

In conclusion, our experimental ESR measurements and theoretical DFT calculations appear to give similar results that are in line with previous reports, which makes the outcome trustworthy. The UE of $\mathrm{Q}^{\bullet}$ is mostly delocalized in the $\mathrm{B}$ ring and partly on the AC ring. The negatively charged oxygen group at the $4^{\prime}$ position and, to a lesser extent, the negatively charged oxygen group at the $3^{\prime}$ position have an electron-donating effect that stabilizes the electron-deficient $\pi$ system in the $\mathrm{B}$ ring. In addition, an $\mathrm{OH}$ group at the 3-position of the $\mathrm{AC}$ ring is essential for concentrating the radical on the $\mathrm{C} 2-\mathrm{C} 3$ double bond. The delocalization in the $\mathrm{C} 2-\mathrm{C} 3$ double bound, especially in the $\mathrm{B}$ ring, stabilizes the UE in $\mathrm{Q}^{*}$ such that the energy it contains is relatively safely stored. 


\section{References}

1. Zhang, M.; Moalin, M.; Vervoort, L.; Li, Z. W.; Wu, W. B.; Haenen, G., Connecting Western and Eastern medicine from an energy perspective. International Journal of Molecular Sciences 2019, 20, (6), 1512.

2. Sthijns, M.; Weseler, A.; Bast, A.; Haenen, G., Time in redox adaptation processes: from evolution to hormesis. International Journal of Molecular Sciences 2016, 17, (10), 1649.

3. Jung, D.-W.; Kim, W.-H.; Seo, S.; Oh, E.; Yim, S.-H.; Ha, H.-H.; Chang, Y.-T.; Williams, D. R., Chemical targeting of GAPDH moonlighting function in cancer cells reveals its role in tubulin regulation. Chemistry \& Biology 2014, 21, (11), 1533-1545.

4. Schieber, M.; Chandel, N. S., ROS function in redox signaling and oxidative stress. Current Biology 2014, 24, (10), R453-R462.

5. Pearson, R. G., Hard and soft acids and bases. Journal of the American Chemical Society 1963, 85, (22), 3533-3539.

6. Moalin, M.; van Strijdonck, G. P.; Bast, A.; Haenen, G. R., Competition between ascorbate and glutathione for the oxidized form of methylated quercetin metabolites and analogues: tamarixetin, 4' Omethylquercetin, has the lowest thiol reactivity. Journal of agricultural and food chemistry 2012, 60, (36), 9292-9297.

7. Drummond, N. J.; Davies, N. O.; Lovett, J. E.; Miller, M. R.; Cook, G.; Becker, T.; Becker, C. G.; McPhail, D. B.; Kunath, T., A synthetic cell permeable antioxidant protects neurons against acute oxidative stress. Scientific Reports 2017, 7, (1), 1-12.

8. Zhang, M.; Vervoort, L.; Moalin, M.; Mommers, A.; Douny, C.; den Hartog, G. J.; Haenen, G. R., The chemical reactivity of (-)-epicatechin quinone mainly resides in its B-ring. Free radical biology and medicine 2018, 124, 31-39.

9. Boots, A. W.; Kubben, N.; Haenen, G. R.; Bast, A., Oxidized quercetin reacts with thiols rather than with ascorbate: implication for quercetin supplementation. Biochemical and biophysical research communications 2003, 308, (3), 560-565.

10. Bast, A.; Haenen, G. R.; Doelman, C. J., Oxidants and antioxidants: state of the art. The American journal of medicine 1991, 91, (3), S2-S13.

11. Villamena, F. A.; Zweier, J. L., Detection of reactive oxygen and nitrogen species by EPR spin trapping. Antioxidants and Redox Signaling 2004, 6, (3), 619-629.

12. Kuhnle, J.; Windle, J.; Waiss, A., Electron paramagnetic resonance spectra of flavonoid anion-radicals. Journal of the Chemical Society B: Physical Organic 1969, 613-616.

13. Pirker, K. F.; Stolze, K.; Pirker, K. F.; Stolze, K.; Reichenauer, T. G.; Pirker, K. F.; Stolze, K.; Reichenauer, T. G.; Nohl, H.; Pirker, K. F., Are the biological properties of kaempferol determined by its oxidation products? Free Radical Research 2006, 40, (5), 513-521.

14. van Acker, S. A.; de Groot, M. J.; van den Berg, D.-J.; Tromp, M. N.; Donné-Op den Kelder, G.; van der Vijgh, W. J.; Bast, A., A quantum chemical explanation of the antioxidant activity of flavonoids. Chemical Research in Toxicology 1996, 9, (8), 1305-1312.

15. Bast, A.; Haenen, G. R., Ten misconceptions about antioxidants. Trends in Pharmacological Sciences 2013, 34, (8), 430-436.

16. Huang, D.; Ou, B.; Prior, R. L., The chemistry behind antioxidant capacity assays. Journal of agricultural and food chemistry 2005, 53, (6), 1841-1856.

17. Litwinienko, G.; Ingold, K., Abnormal solvent effects on hydrogen atom abstraction. 2. Resolution of the curcumin antioxidant controversy. The role of sequential proton loss electron transfer. The Journal of organic chemistry 2004, 69, (18), 5888-5896.

18. Chen, X.; Deng, Z.; Zhang, C.; Zheng, S.; Pan, Y.; Wang, H.; Li, H., Is antioxidant activity of flavonoids mainly through the hydrogen-atom transfer mechanism? Food Research International 2018.

19. Marković, Z.; Amić, D.; Milenković, D.; Dimitrić-Marković, J. M.; Marković, S., Examination of the chemical behavior of the quercetin radical cation towards some bases. Physical Chemistry Chemical Physics 2013, 15, (19), 7370-7378.

20. Kuwabara, K.; Sakurai, Y.; Sanuki, H.; Morimoto, C.; Li, Y.; Miyake, Y.; Kanaori, K.; Tajima, K., Application of a Stopped-Flow EPR Method for the Detection of Short-Lived Flavonoid Semiquinone Radicals Produced by Oxidation Using 15 N-Labeled Nitrosodisulfonate Radical (Fremy's Salt). Applied Magnetic Resonance 2018, 49, (8), 911-924.

21. Zheng, Y.-Z.; Deng, G.; Liang, Q.; Chen, D.-F.; Guo, R.; Lai, R.-C., Antioxidant activity of quercetin and its glucosides from propolis: A theoretical study. Scientific Reports 2017, 7, (1), 7543.

22. Heřmánková, E.; Zatloukalová, M.; Biler, M.; Sokolová, R.; Bancířová, M.; Tzakos, A. G.; Křen, V.; Kuzma, M.; Trouillas, P.; Vacek, J., Redox properties of individual quercetin moieties. Free Radical Biology and Medicine 2019, 143, 240-251. 
23. Krych-Madej, J.; Stawowska, K.; Gebicka, L., Oxidation of flavonoids by hypochlorous acid: reaction kinetics and antioxidant activity studies. Free Radical Research 2016, 50, (8), 898-908.

24. Moalin, M.; Van Strijdonck, G. P.; Beckers, M.; Hagemen, G. J.; Borm, P. J.; Bast, A.; Haenen, G. R., A planar conformation and the hydroxyl groups in the $\mathrm{B}$ and $\mathrm{C}$ rings play a pivotal role in the antioxidant capacity of quercetin and quercetin derivatives. Molecules 2011, 16, (11), 9636-9650.

25. Heijnen, C. G.; Haenen, G. R.; Vekemans, J. A.; Bast, A., Peroxynitrite scavenging of flavonoids: structure activity relationship. Environmental Toxicology and Pharmacology 2001, 10, (4), 199-206.

26. Weil, J. A.; Bolton, J. R.; Wertz, J. E.; Nugent, J. A., Electron paramagnetic resonance: elementary theory and practical applications. Wiley New York: 1994.

27. Frisch, M. J.; Trucks, G. W.; Schlegel, H. B.; Scuseria, G. E.; Robb, M. A.; Cheeseman, J. R.; Scalmani, G.; Barone, V.; Mennucci, B.; Petersson, G. e., Gaussian 09 Revision D. 01. 2014.

28. Zhao, Y.; Truhlar, D. G., The M06 suite of density functionals for main group thermochemistry, thermochemical kinetics, noncovalent interactions, excited states, and transition elements: two new functionals and systematic testing of four M06-class functionals and 12 other functionals. Theoretical Chemistry Accounts 2008, 120, (1-3), 215-241.

29. Krishnan, R.; Binkley, J. S.; Seeger, R.; Pople, J. A., Self-consistent molecular orbital methods. XX. A basis set for correlated wave functions. The Journal of chemical physics 1980, 72, (1), 650-654.

30. Goerigk, L.; Grimme, S., Efficient and Accurate Double-Hybrid-Meta-GGA Density Functionals Evaluation with the Extended GMTKN30 Database for General Main Group Thermochemistry, Kinetics, and Noncovalent Interactions. Journal of Chemical Theory and Computation 2010, 7, (2), 291-309.

31. Weigend, F.; Ahlrichs, R., Balanced basis sets of split valence, triple zeta valence and quadruple zeta valence quality for $\mathrm{H}$ to $\mathrm{Rn}$ : Design and assessment of accuracy. Physical Chemistry Chemical Physics 2005, 7, (18), 3297-3305.

32. Neese, F., The ORCA program system. Wiley Interdisciplinary Reviews: Computational Molecular Science 2012, 2, (1), 73-78.

33. Grimme, S.; Ehrlich, S.; Goerigk, L., Effect of the damping function in dispersion corrected density functional theory. Journal of Computational Chemistry 2011, 32, (7), 1456-1465.

34. Marenich, A. V.; Cramer, C. J.; Truhlar, D. G., Universal solvation model based on solute electron density and on a continuum model of the solvent defined by the bulk dielectric constant and atomic surface tensions. The Journal of Physical Chemistry B 2009, 113, (18), 6378-6396.

35. Lu, T.; Chen, F., Multiwfn: a multifunctional wavefunction analyzer. Journal of Computational Chemistry 2012, 33, (5), 580-592.

36. Humphrey, W.; Dalke, A.; Schulten, K., VMD: visual molecular dynamics. Journal of molecular graphics 1996, 14, (1), 33-38. 


\section{Supplementary Materials}
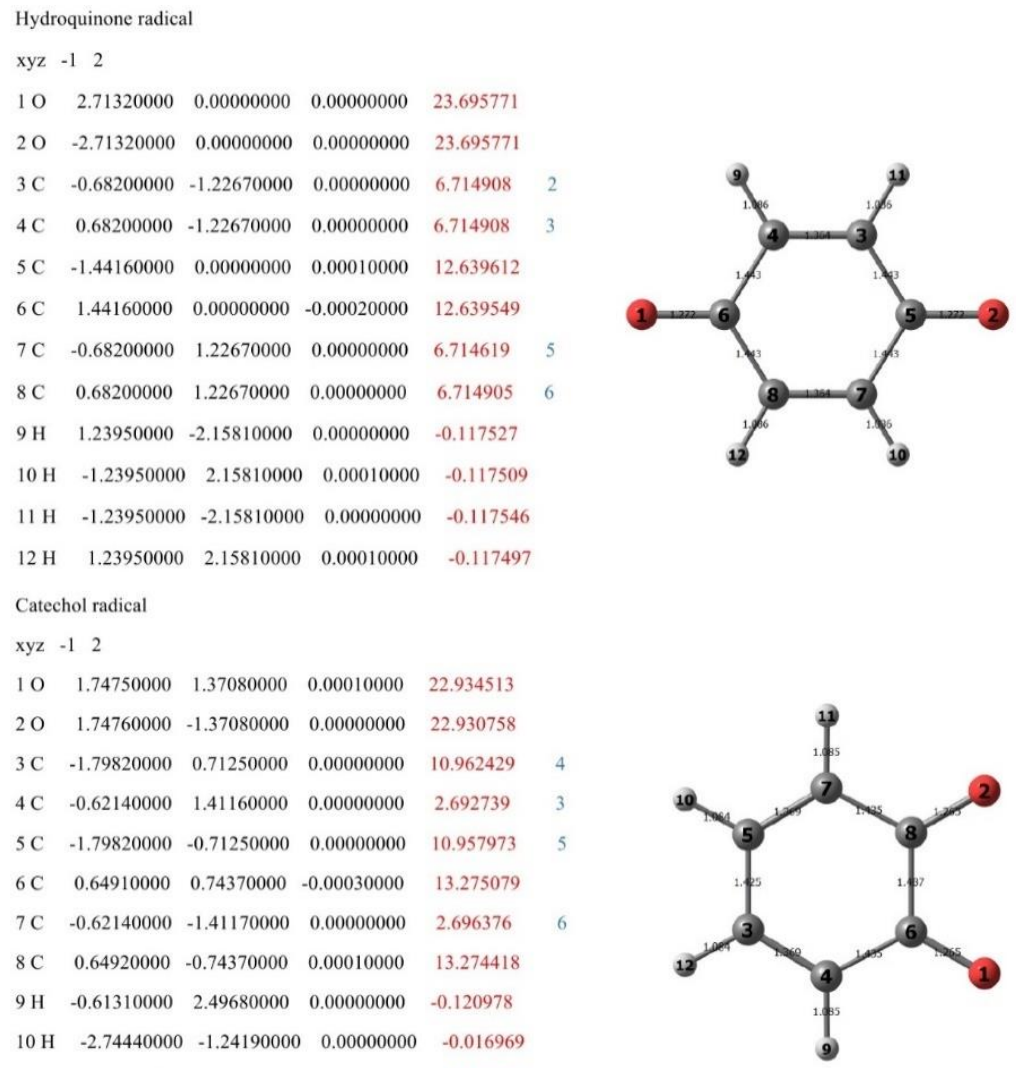


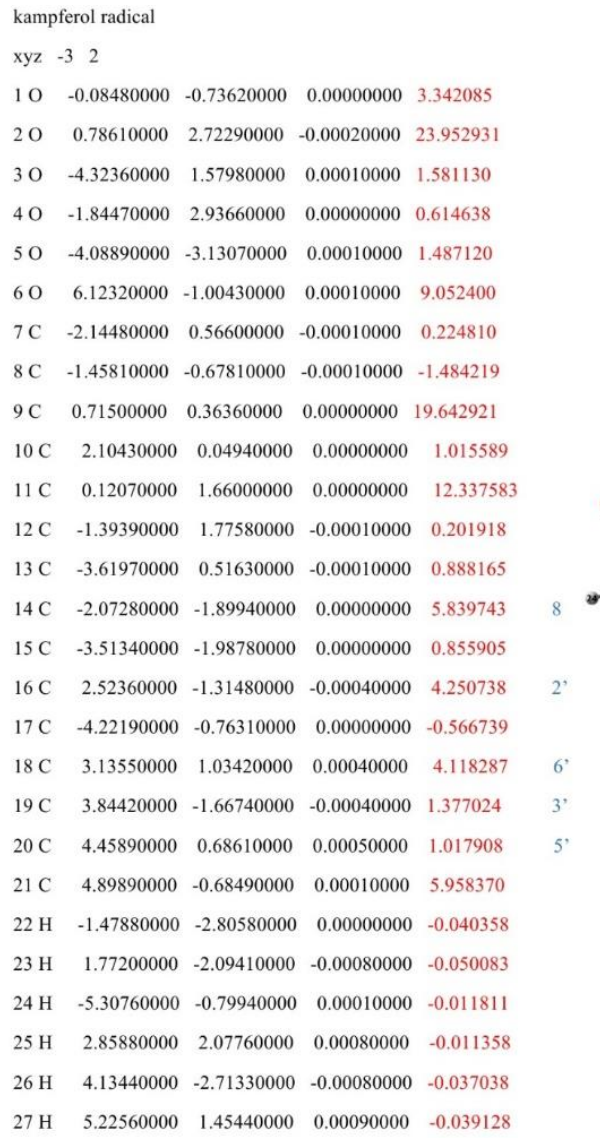




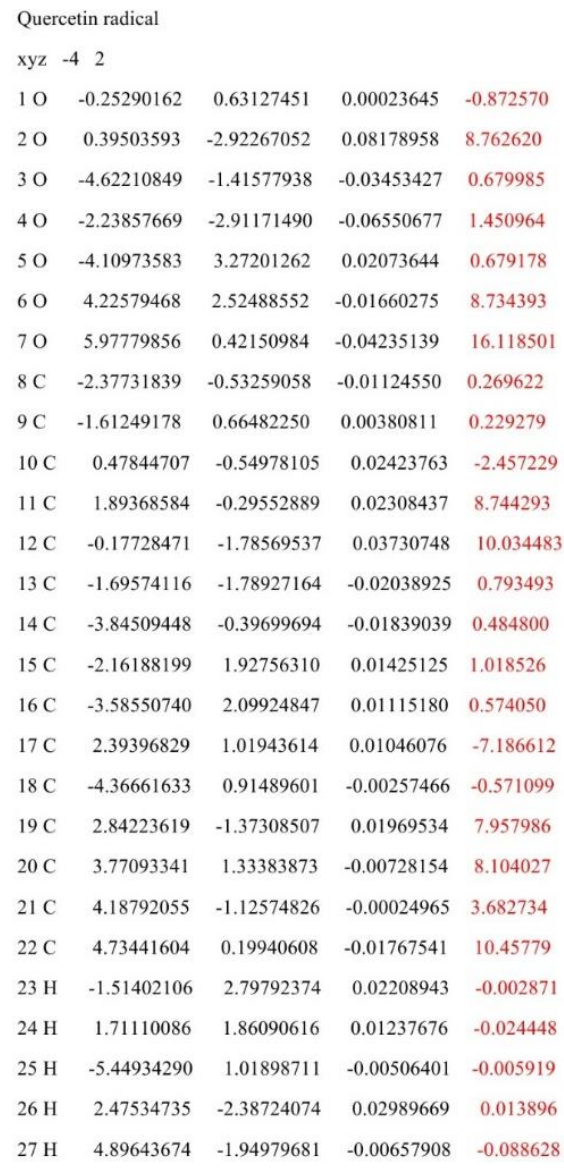




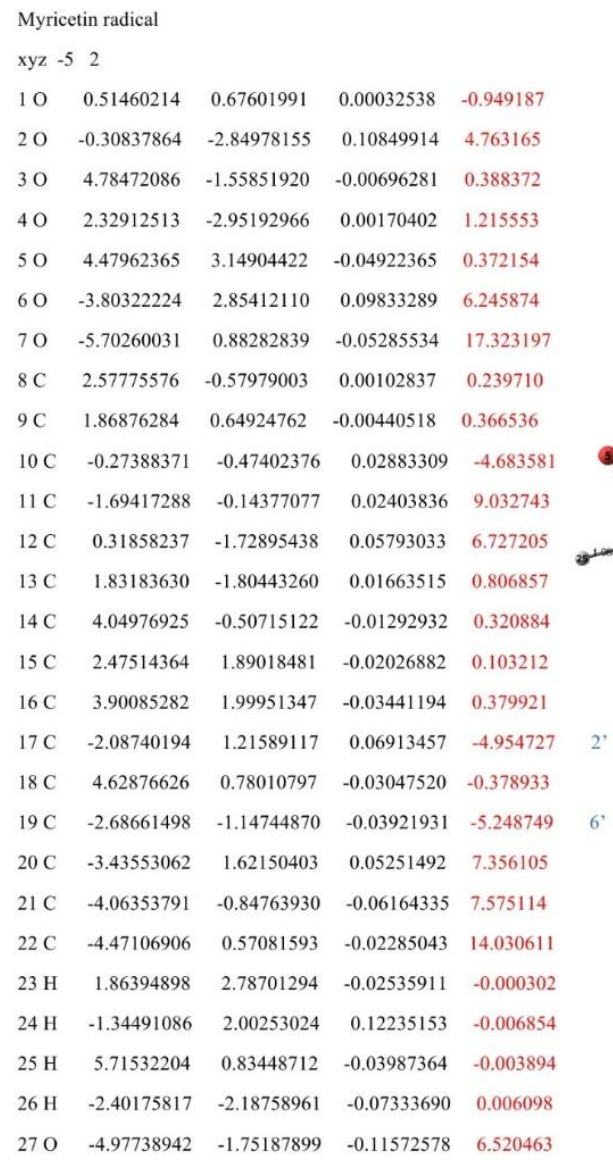




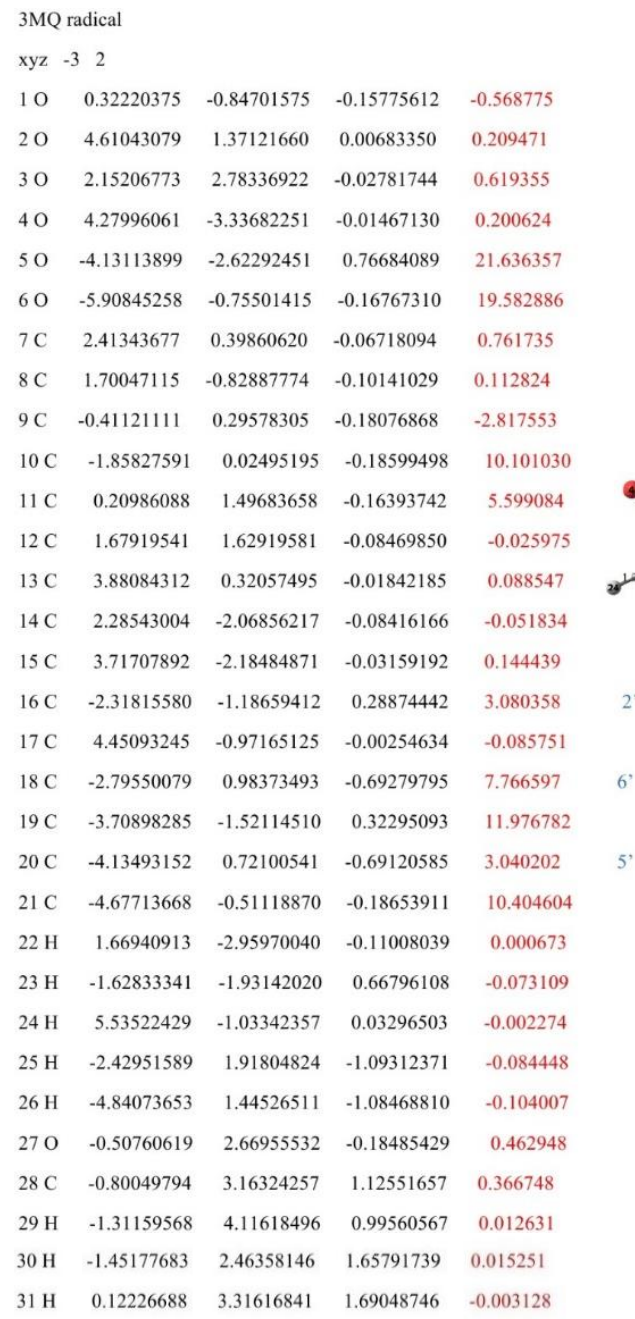




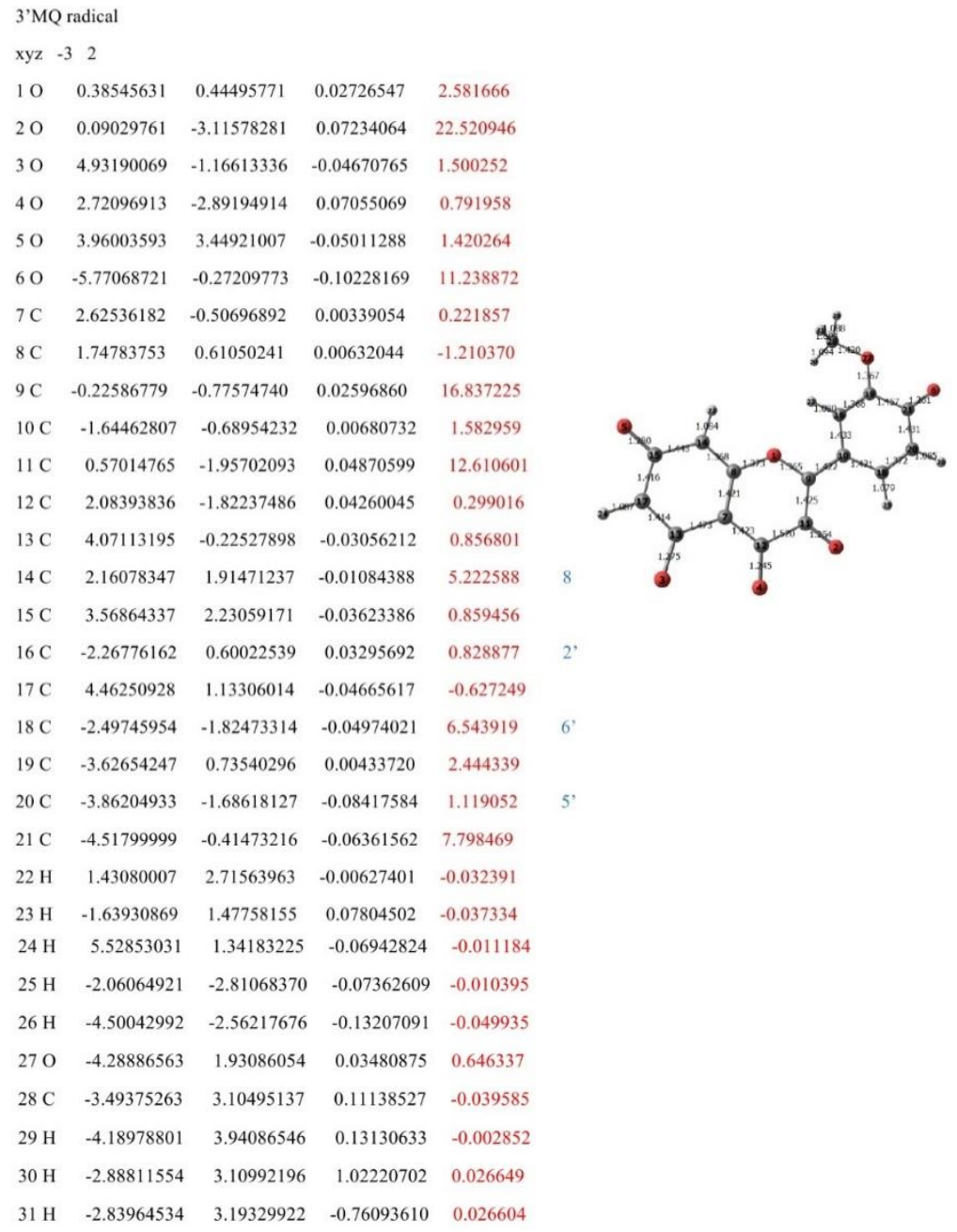




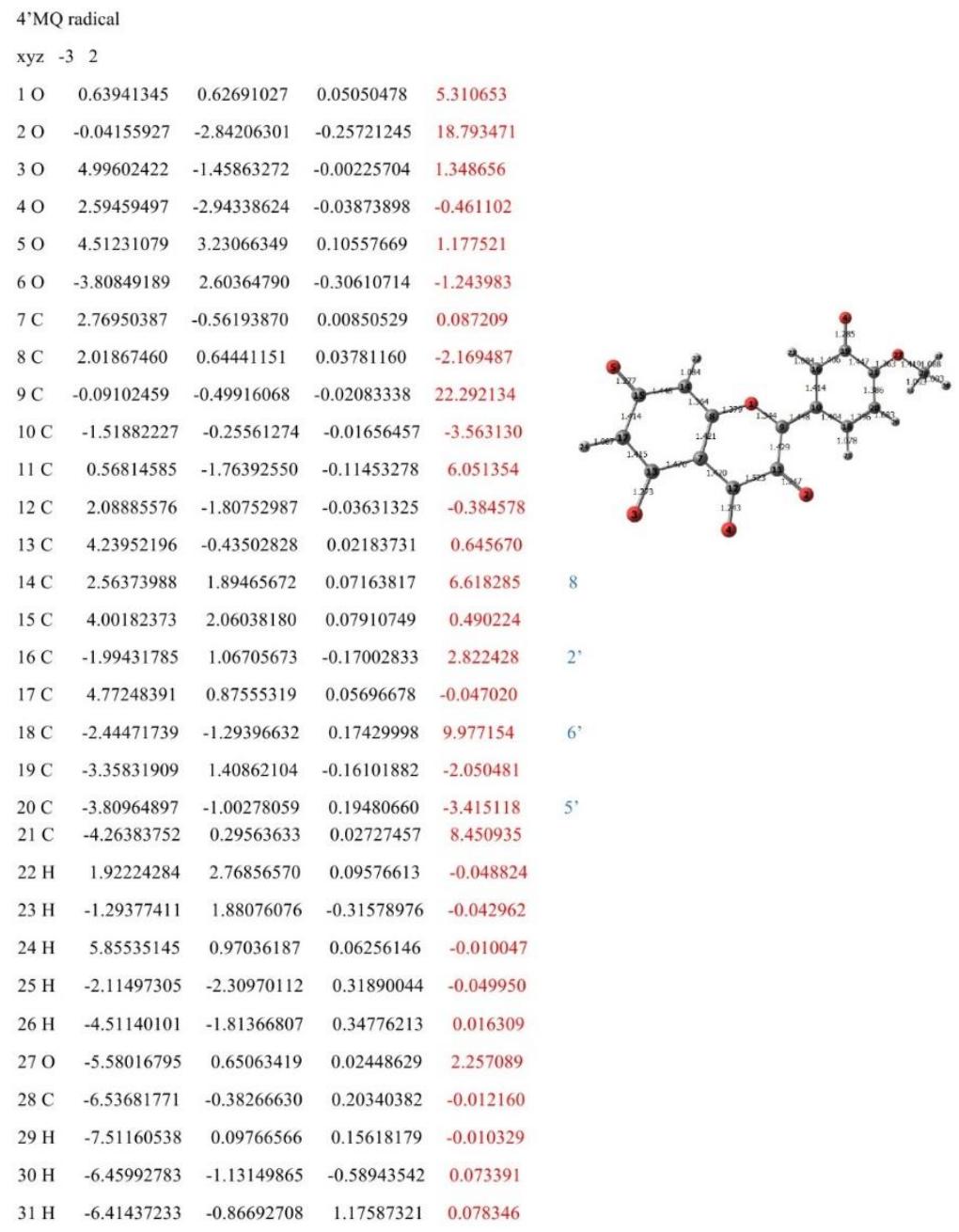

Figure S1. The optimized structure of the test compounds (fully deprotonated radical). The xyz coordinate of the atoms of each molecule (from the second to the fourth column), the spin population in percentage (numbers in red, the fifth column) and the bond lengths given in the depicted molecule ( $\AA$ ). Note that the number here is not the same as that of manuscript, the number in blue (the sixth line) represents the number of the carbon used in manuscript and depicted in Figure 1. 


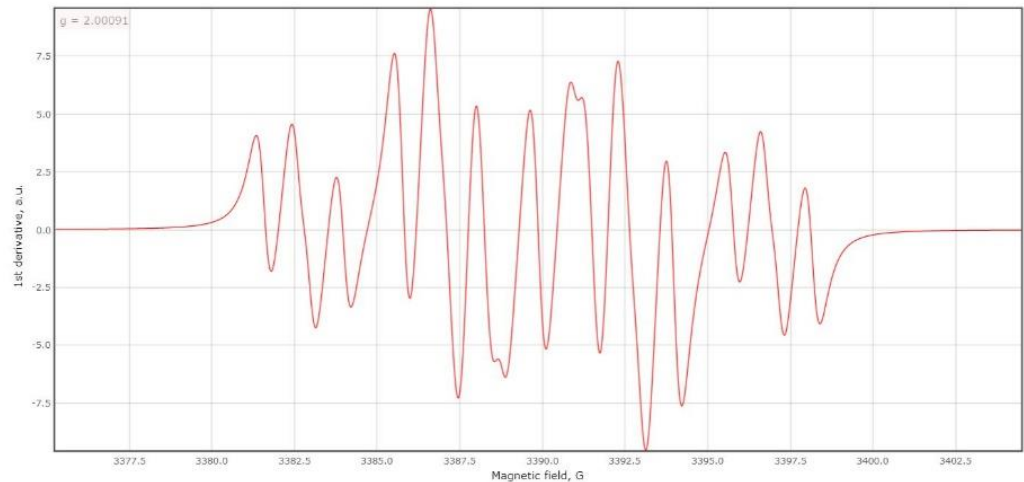

Figure S2. Simulated ESR spectrum of the kaempferol radical using our calculated spin densities. The simulated ESR spectrum is similar as the experimental ESR spectrum of the kaempferol radical Pirker et al. [1]. reported. The simulation was made using epr simulator (http://www.eprsimulator.org/ isotropic.html) with the splitting constants of 4.3, 1.3, 1.0, 4.1, and 5.8, respectively. 


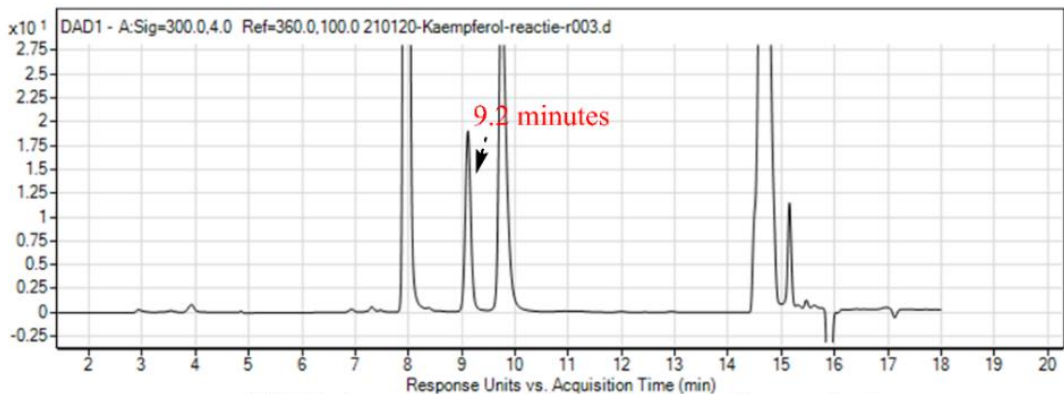

HPLC chromatogram of kaempferol reaction products

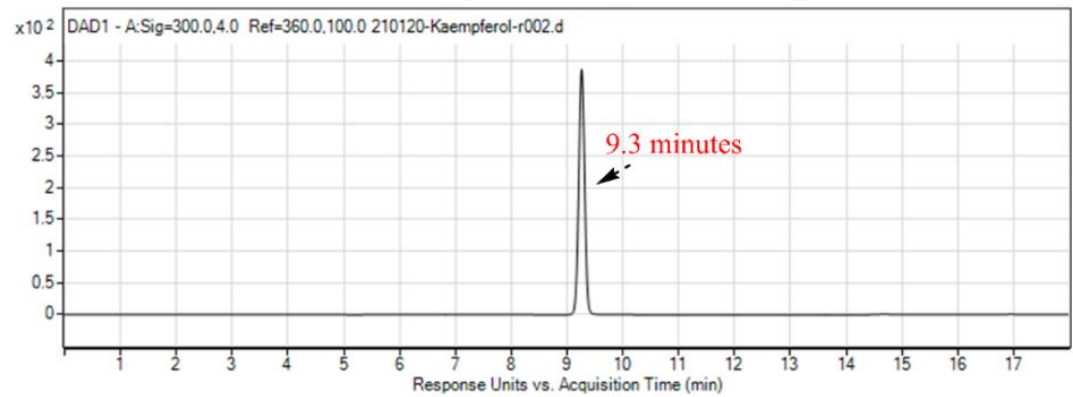

HPLC chromatography of Standard Hydroquinone

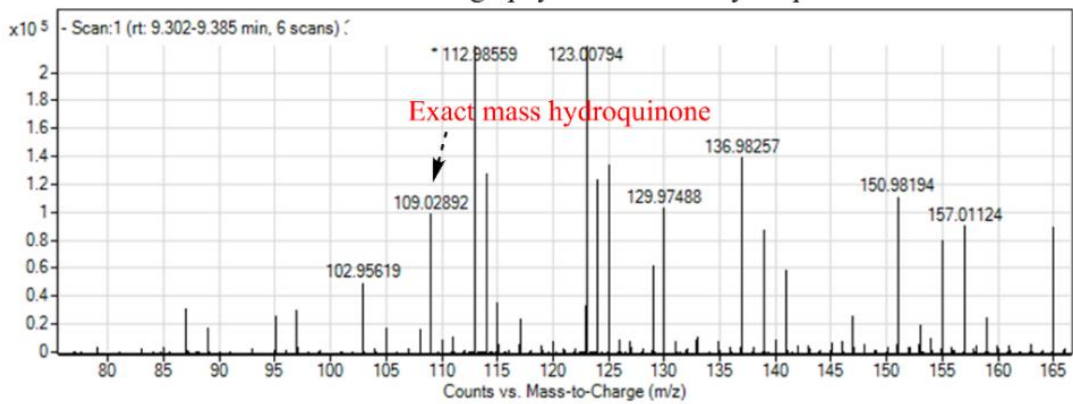

MS of kaempferol reaction products between RT 9.302 and 9.385 minutes

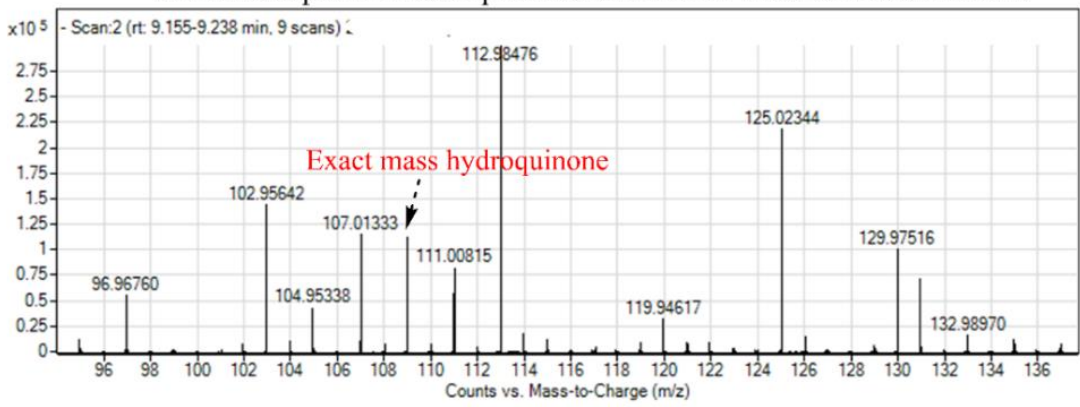

MS of Standard hydroquinone between RT 9.155 and 9.238 minutes

Figure S3. HPLC/MS analysis of a solution of kaempferol incubated for $5 \mathrm{~min}$ at high $\mathrm{pH}$, similar to the incubation of kaempferol in the ESR experiment as described in the material and method section of our manuscript. Panel A is the HPLC chromatogram of the Kaempferol solution after the $5 \mathrm{~min}$ incubation. In panel B is the HPLC chromatogram of a freshly prepared $2.5 \mathrm{mM}$ hydroquinone solution in a $0.1 \%$ formic acid $(85 \%)$ acetonitril (15\%) 
mixture. The exact mass of the peak at $9.2 \mathrm{~min}$ in the kaempferol chromatogram had the same exact mass as the peak of the hydroquinone standard, confirming the formation of hydroquinone out of kaempferol during the incubation. The small difference in retention time incubation between the hydroquinone peak in the chromatogram of the kaempferol incubation and the chromatogram of the hydroquinone reference is probably due to the difference in the composition of solvent of the kaempferol incubation and that of the hydroquinone standard. The formation of hydroquinone in the kaempferol incubation, substantiates the explanation that the ESR signal with kaempferol was derived from the hydroquinone radical.

The conditions of the HPLC analysis are:

The column used for the separation was an Apollo C18 $(150 \times 4.6 \mathrm{~mm}, 5 \mu \mathrm{m})$ from Grace. The mobile phase was $0.1 \%$ formic acid (solvent A) and acetonitrile (solvent B). The linear gradient elution conditions were: start with $95 \%$ solvent A ; from $95 \%$ to $85 \%$ of solvent A in $2 \mathrm{~min}$; from $85 \%$ to $78 \%$ of solvent A in $7 \mathrm{~min}$; from $78 \%$ to $50 \%$ of solvent A in $1 \mathrm{~min}$; from $50 \%$ to $10 \%$ of solvent $\mathrm{A}$ in $2 \mathrm{~min}$ and this condition was held for $6 \mathrm{~min}$; and from $10 \%$ to $95 \%$ of solvent $\mathrm{A}$ in 1 min which was maintained for 1 min. The oven temperature was set at $25{ }^{\circ} \mathrm{C}$ and the injection volume was $5 \mu \mathrm{L}$. The flow rate was 0.4 $\mathrm{mL} / \mathrm{min}$.

The detection was performed with an Agilent DAD detector (set a $300 \mathrm{~nm}$ ) on an Agilent 6550 iFunnel Accurate-Mass QuadrupoleTime-of-Flight Mass Spectrometer (QTOF MS) through an electrospray interface with Jet Stream technology after separation on a 1290 Infinity UHPLC system (Agilent, Santa Clara, CA, USA). All samples and standards were analysed in negative mode with gas temperature $150{ }^{\circ} \mathrm{C}$, gas flow $20 \mathrm{~L} / \mathrm{min}$, nebulizer $25 \mathrm{psig}$, sheath gas temperature $350^{\circ} \mathrm{C}$, sheath gas flow $12 \mathrm{~L} / \mathrm{min}$, Vcap $3000 \mathrm{~V}$ and nozzle voltage $1000 \mathrm{~V}$. 


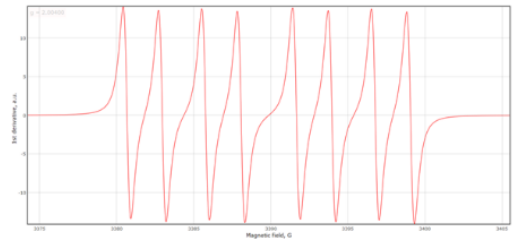

quercetin

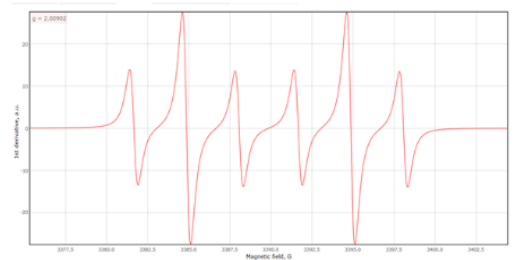

$3 \mathrm{MQ}$

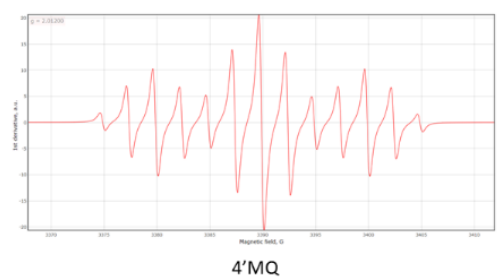

$4^{\prime} \mathrm{MQ}$

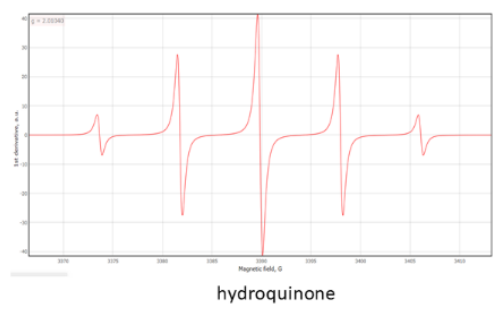

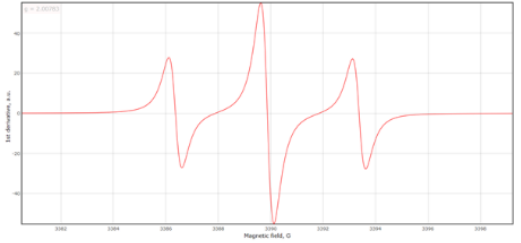

mycricetin

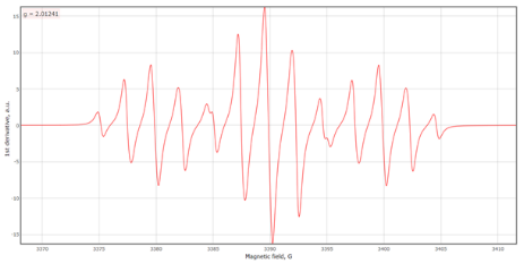

3'MQ

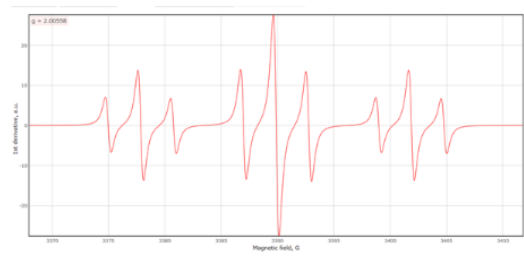

catechol

Figure S4. The simulated ESR spectrum of tested compounds (expect kaempferol) made using EPR simulator (http://www.eprsimulator.org/isotropic.html) with the experimental splitting constants. 


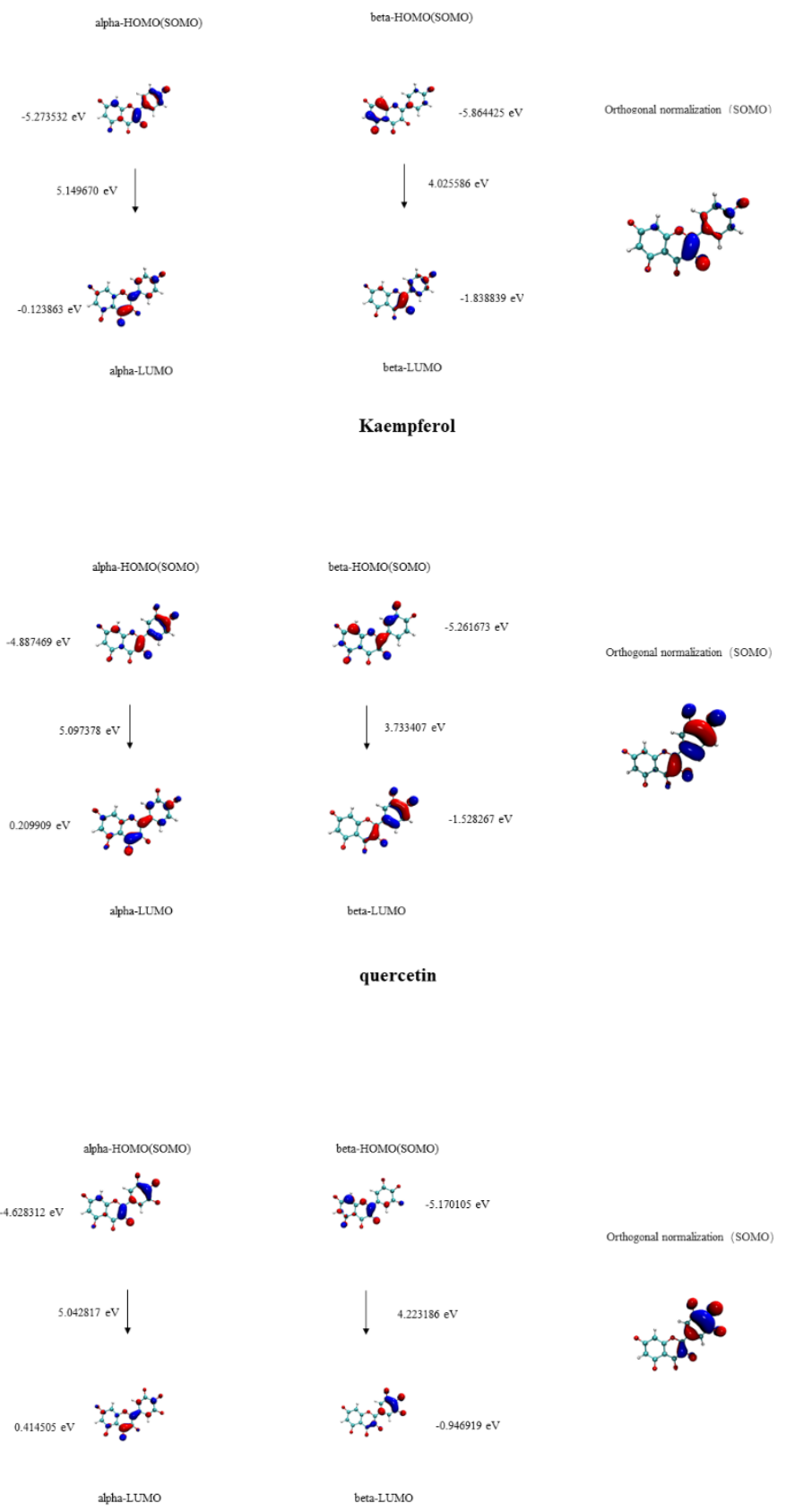

myricetin 

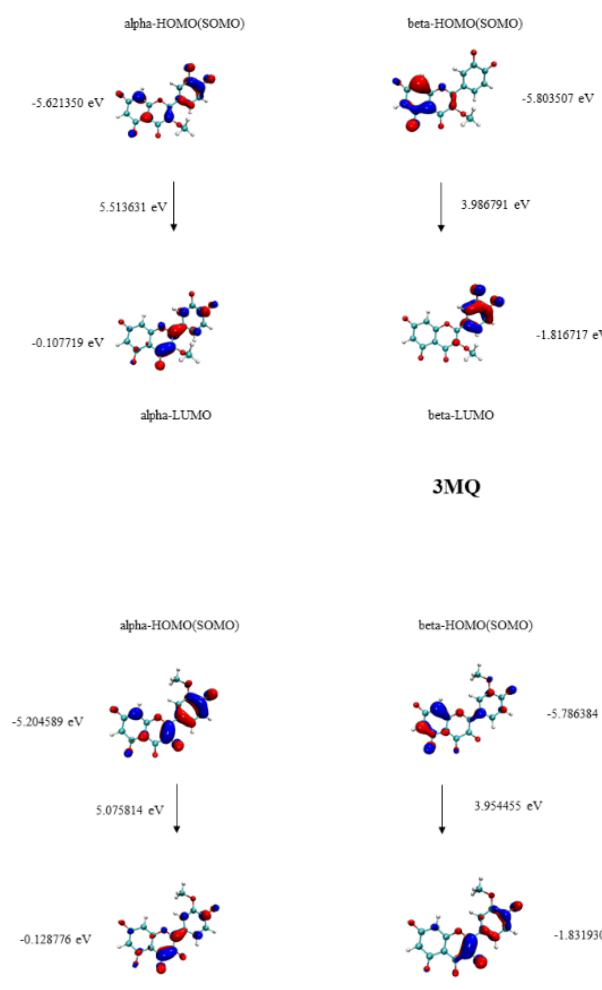

alpha-LUMO

alpha-HOMO(SOMO)

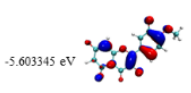

$$
5.350190 \mathrm{eV}
$$

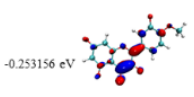

alpha-LUMO
3MQ

beta-HOMO(SOMO)
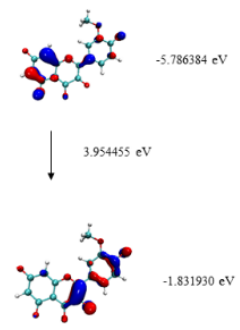

beta-LUMO

3'MQ

beta-HOMO(SOMO)

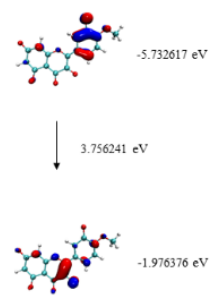

beta-LUMO

4'MQ
Orthogonal normalization (SOMO)

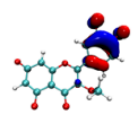

Orthogonal normalization (SOMO

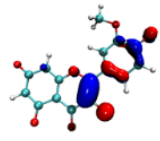

Orthogonal normalization (SOMO)

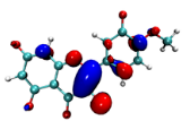




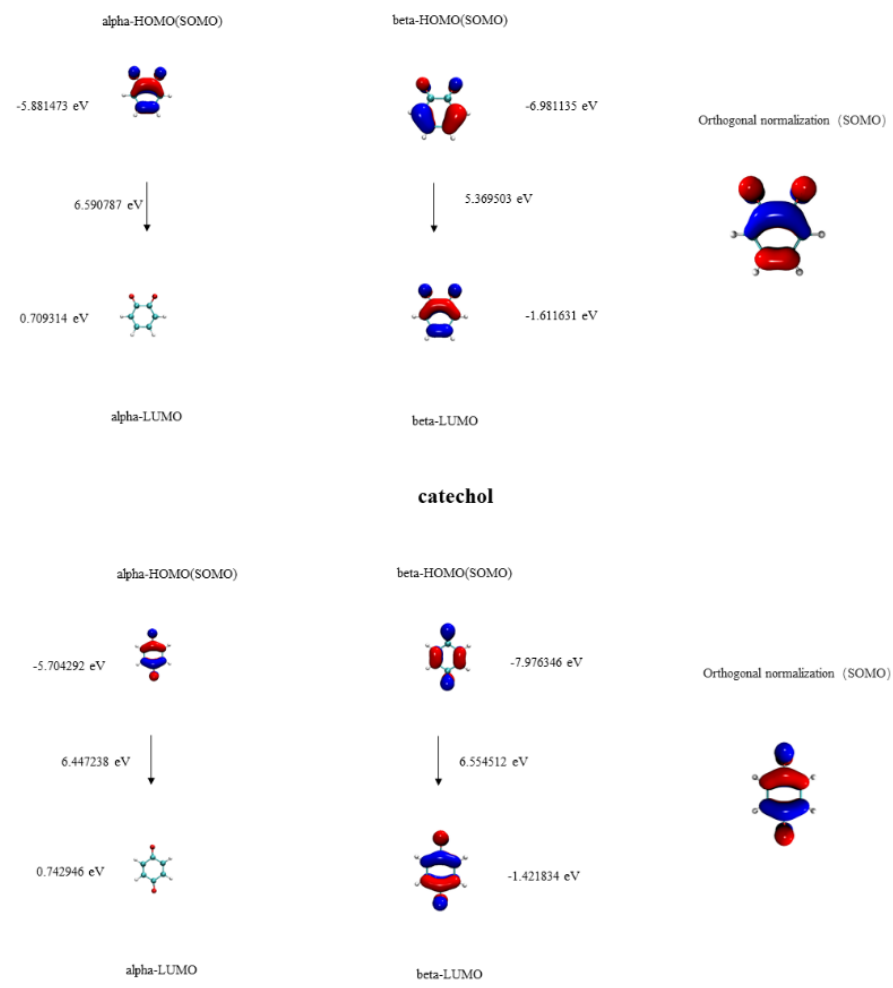

\section{Hydroquinone}

Figure S5. The HOMO (SOMO) and LUMO gap of the tested compounds (in the radical form). The gap between alpha-HOMO (SOMO) and alpha-LUMO of kaempferol radical, quercetin radical and myricetin radical are $5.15,5.10,5.04 \mathrm{eV}$, respectively, which indicates that the kaempferol radical is more stable than the quercetin radical and the myricetin radical. The higher alpha energy gap of 4'MQ radical compared with $3^{\prime} \mathrm{MQ}$ radical indicates the importance of hydroxyl group in $\mathrm{Q}$ at the $4^{\prime}$ position. The default isosurface is 0.05 that's why the alpha-LUMO of catechol radical and hydroquinone radical can't be shown. The SOMO maps of tested compounds after orthogonal normalization are shown on the right. 


\section{Reference}

1. Pirker, K. F.; Stolze, K.; Pirker, K. F.; Stolze, K.; Reichenauer, T. G.; Pirker, K. F.; Stolze, K.;

Reichenauer, T. G.; Nohl, H.; Pirker, K. F., Are the biological properties of kaempferol determined by its oxidation products? Free Radical Research 2006, 40, (5), 513-521. 


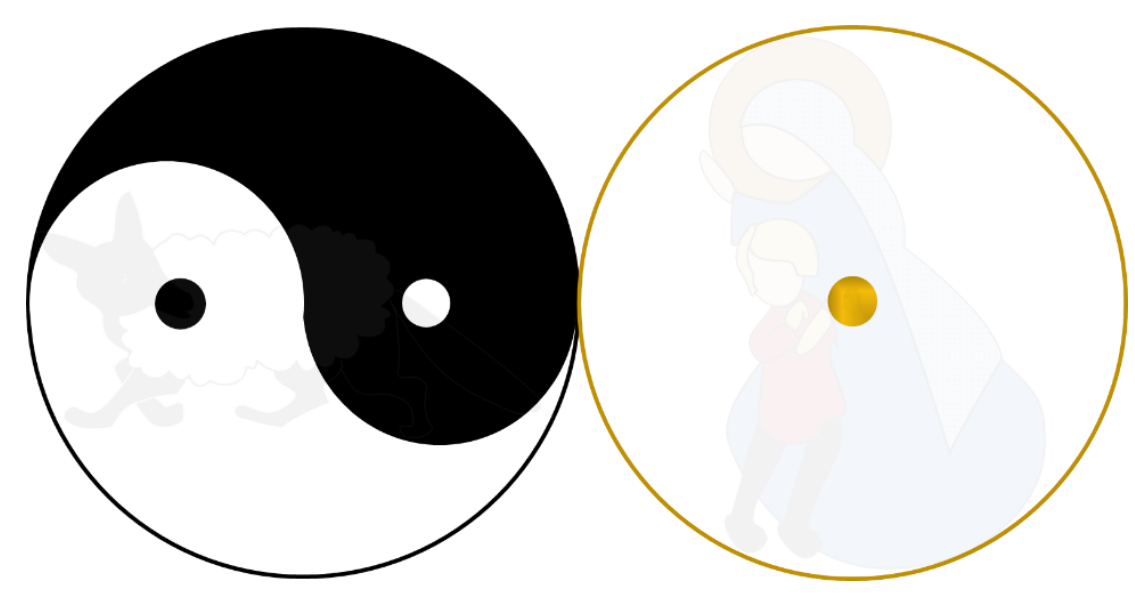





\section{Chapter 4}

\section{The flow of the redox energy in Quercetin during its antioxidant activity in water}

Zhengwen Li ${ }^{1}$, Mohamed Moalin ${ }^{1,2}$, Ming Zhang ${ }^{1}$, Lily Vervoort ${ }^{1}$, Erik Hursel ${ }^{1}$, Alex Mommers ${ }^{1}$ and Guido R.M.M. Haenen ${ }^{1}$

1 Department of Pharmacology and Toxicology, Faculty of Health, Medicine and Life Sciences, Maastricht University, P.O. Box 616, 6200 MD Maastricht, The Netherlands; maxamed.moalin@gmail.com (M.M.); z.ming@maastrichtuniversity.nl (M.Z.); 1.vervoort@maastrichtuniversity.nl (L.V.); a.mommers@maastrichtuniversity.nl (A.M.); hursel.erik@gmail.com (E.H.).

2 Research Centre Material Sciences, Zuyd University of Applied Sciences, 6419 DJ Heerlen, The Netherlands 


\begin{abstract}
Most studies on the antioxidant activity of flavonoids like Quercetin (Q) do not consider that it comprises of a series of sequential reactions. Therefore, the present study examines how the redox energy flows through the molecule during Q's antioxidant activity, by combining experimental data with quantum calculations. It appears that several main pathways are possible. Pivotal are subsequently: deprotonation of the 7-OH group; intramolecular hydrogen transfer from the 3-OH group to the 4-Oxygen atom; electron transfer leading to two conformers of the $\mathrm{Q}$ radical; deprotonation of the $\mathrm{OH}$ groups in the B-ring, leading to three different deprotonated $\mathrm{Q}$ radicals; and finally electron transfer of each deprotonated $\mathrm{Q}$ radical to form the corresponding quercetin quinones. The quinone in which the carbonyl groups are the most separated, has the lowest energy content, and is the most abundant quinone. The pathways are also intertwined. The calculations show that $\mathrm{Q}$ can pick up redox energy at various sites of the molecule which explains Q's ability to scavenge all sorts of reactive oxidizing species. In the described pathways, Q has picked up of e.g. two hydroxyl radicals, can be processed and softened by forming quercetin quinone.
\end{abstract}

Keywords: Flavonoid, Quercetin, Redox modulation, Antioxidant, Molecular mechanism, Electron transfer, Proton transfer. 


\section{Introduction}

In all life forms, opposing forces provide the energy that flows through networks in an organism, which fuels life [1]. The major source of energy in our body is provided by the redox reactions of glycolysis, lipid oxidation and the citric acid cycle [2]. This redox energy flows through biochemical networks and is the driving force of vital cellular reactions. However, a substantial part of the energy flow is uncontrolled and produces reactive oxidizing species that can inflict damage to crucial cellular components such as lipids, proteins and DNA. This plays a central role in numerous patho-physiological processes, from ageing to inflammation $[1,3]$.

Flavonoid antioxidants can neutralize these reactive oxidizing species by donating electrons. By accepting electrons, reactive oxidizing species are converted into relatively unreactive compounds, that do not damage the cell. For example, by accepting an electron of a flavonoid, the hydroxyl radical is converted into the hydroxyl anion that, after protonation, becomes water. Their redox modulating activity has been implicated in the beneficial health effect of flavonoid antioxidants [4-6].

Although the antioxidant activity of flavonoids has been studied for over several decades, the molecular mechanism remains enigmatic. One of the reasons for this is that in addressing their antioxidant activity, all flavonoids are generally put under the same umbrella. Nevertheless, it is known that a minor change in the molecular structure of a flavonoid can drastically change its antioxidant activity [7], indicating that the molecular mechanism of each flavonoid is unique. An 'universal' mechanism for all flavonoids does not exist. Another reason for the enigmatic nature of the antioxidant activity, is that the antioxidant effect of a specific flavonoid comprises of a series of sequential reactions, and each reaction in this series has its specific characteristics [8]. Not separating these reactions will blur the vision on the molecular mechanism.

In the present study we aim to zoom in on the antioxidant activity of one of the most important flavonoids, i.e. quercetin (Q), By combining experimental data with quantum calculations, it is possible to look, the sequential reactions in its antioxidant activity separately. In this way we aim to unveil how the redox energy flows though the molecule during its antioxidant activity.

Most of the studies on the antioxidant mechanism of quercetin only address one electron oxidation, from $\mathrm{Q}$ to the $\mathrm{Q}$ radical ( $\left.\left.\mathrm{Q}^{*}\right)[9,10]\right]$. The oxidation of $\mathrm{Q}$ is however a two-electron process, in which $\mathrm{Q}$ is finally converted into a quinone methide (QQ) [11]. Our previous work also confirmed the formation of QQ in the radical scavenging reactions of Q, although the evidence still is indirect $[12,13]$. So ultimately, the redox energy picked up by $\mathrm{Q}$ flows through the molecule to form QQ. Via QQ the redox energy is processed further in the antioxidant network. In the present manuscript we first examine $Q$ itself; what is the molecular mechanism of the scavenging of radicals by $\mathrm{Q}$. The site at which the electron is donated is also determined. Subsequently, we examined $\mathrm{Q}^{*}$; where its unpaired electron is retained within the molecule. We also addressed the molecular mechanism of the scavenging of radicals by $\mathrm{Q}^{*}$ and at which site $\mathrm{Q}^{\bullet}$ donates an electron. Finally, we focused on the twoelectron oxidation product, i.e. quercetin quinone methide (QQ); how QQ is formed and the energy is stabilized in this molecule. Sharpening the picture will help us to understand the 
molecular mode of action of polyphenols and to see differences between polyphenols, so we will be able to select the appropriate redox modulating compound for a specific redox mediated disorder.

Three theoretical pathways exist for the molecular mechanism of an antioxidant such as Q. These are Hydrogen atom transfer (HAT), single electron transfer followed by proton transfer (SET-PT), and sequential proton loss electron transfer (SPLET). The descriptors characterizing the enthalpy of the first step of each of these three mechanisms are the homolytic bond dissociation enthalpy (BDE) for HAT; the ionization potential (IP) for SETPT; and the proton affinity (PA) for SPLET [14-17]. These reaction enthalpies were calculated as the difference of the calculated enthalpies of the reactant (which is fully protonated $\mathrm{Q}$ ) with that of the products. These products are the $\mathrm{Q}$ radical $\left(\mathrm{Q}^{*}\right)$ and a hydrogen atom $\left(\mathrm{H}^{*}\right)$ for BDE; the protonated $\mathrm{Q}$ radical $\left(\mathrm{Q}^{\cdot+}\right)$ and an electron (e) for IP; deprotonated $\mathrm{Q}$ $\left(\mathrm{Q}^{-}\right)$and a proton $\left(\mathrm{H}^{+}\right)$for $\mathrm{PA}$. The equations are:

$$
\begin{array}{llll}
\mathrm{BDE} & =H\left(\mathrm{Q}^{\circ}\right) & +H\left(\mathrm{H}^{*}\right) & -H(\mathrm{Q}) \\
\mathrm{IP} & =H\left(\mathrm{Q}^{\bullet+}\right) & +H(\mathrm{e}) & -H(\mathrm{Q}) \\
\mathrm{PA} & =H\left(\mathrm{Q}^{-}\right. & +H\left(\mathrm{H}^{+}\right) & -H(\mathrm{Q})
\end{array}
$$

In these equations $H$ represent the enthalpies of the corresponding fragments.

We intent to study the antioxidant activity of $\mathrm{Q}$ in the water phase, and $\mathrm{Q}$ is partly deprotonated at physiological $\mathrm{pH}$. Because deprotonation, and the group that deprotonates, play a pivotal in the antioxidant activity of Q, we also addressed this in our study. We will take the deprotonated conformation of $\mathrm{Q}$ into account. $\mathrm{Q}$ has five phenolic $\mathrm{OHs}$, which have five different $\mathrm{pKa}$ values[18]. The $\mathrm{pKa}$ of $\mathrm{Q}$ has been studied using various methods, but no consistent value was found; namely varying from 6.74 [19]] determined by spectrophotometry, 7.19 [20] by capillary zone electrophoresis and 7.71 [21]/8.21 [22] by potentiometry. There is also no consensus on the pKa of the second acid group of Q, the reported value of this pKa varies from 8.4 to 9.4 [18]. Moreover, there is also no consensus on which group of $\mathrm{Q}$ is the most acidic one.

DFT calculation by Markovic et al. [23], at the M0-52X/6-311+G(d,p) level showed that the proton affinity of the 5, 7, 3', 3, and 4' hydoxyl groups of Q were 26.75, 22.45, 27.71, 25.80 , and $22.21 \mathrm{Kcal} / \mathrm{mol}$, respectively, suggesting that first the 4'-OH is deprotonated, followed by the 7-OH. Calculation at lower basis set of $6-31+\mathrm{G}(\mathrm{d}, \mathrm{p})$ by Vásquez-Espinal et al. [15], revealed that the proton affinity of the 5, 7, 3', 3, and 4' hydoxyl groups of Q were $28.30,23.50,28.59,26.39$, and $23.20 \mathrm{Kcal} / \mathrm{mol}$, respectively. This calculation also suggests that the 4'-OH group is the most acidic one. However, some studies, especially experimental studies, conclude that the 7-OH group is the most acidic group [24, 25]. The most convincing is the ${ }^{13} \mathrm{C} \mathrm{CP} / \mathrm{MAS}$ NMR study performed by Musialik et al. [25]. They found that the ${ }^{13} \mathrm{C}-7$ signal of $\mathrm{Q}$ in $\mathrm{D}_{2} \mathrm{O}$ was the first one that considerably shifted toward higher frequency field by raising the $\mathrm{pH}$, indicating that the $7-\mathrm{OH}$ group is the most acidic one. To solve the inconsistency in the literature, we decided to perform Time-dependent density functional theory (TDDFT) calculations to obtain the UV spectrum of 7-OH deprotonated Q (7DE) and the UV spectrum of 4'-OH deprotonated Q (4'DE). Subsequently, we compared the obtained calculated spectra with experimental UV spectra of a Q solution in water recorded at various $\mathrm{pH}$ values. 
Recently, a quantum chemical computational study by Brovarets et al. [26], on the tautomerization of Q by intramolecular proton transfer, revealed 48 stable conformers ( 24 planar and 24 non-planar) with relative Gibbs free energies within the range of 0.0 to 25.3 $\mathrm{Kcal} / \mathrm{mol}$. This included conformers formed by proton transfer from the $3-\mathrm{OH}$ group to the 4 oxygen atom with a Gibbs free energy change of around $13 \mathrm{Kcal} / \mathrm{mol}$. This proton transfer will affect the antioxidant mechanism of Q. Also, proton transfer from the 5-OH group to the 4 oxygen atom is relevant. Therefore, these two proton transfers will be taken into consideration in our study.

In the literature on the antioxidant activity of Q, the importance of C2-C3 double bond of $\mathrm{Q}$ is frequently emphasized. Therefore, the present study will also address this, in order to sharpen our view on how the redox energy flows through $Q$ during its antioxidant activity.

\section{Results}

\subsection{The molecular mechanism of scavenging of the first radical by $Q$-deprotonation of $Q$}

To determine which mechanism is involved in the scavenging of the first radical by $\mathrm{Q}$, the $\mathrm{O}-\mathrm{H}$ bond dissociation enthalpy (BDE), ionization potential (IP), and proton affinity (PA) of $\mathrm{Q}$ were calculated, to estimate the likelihood of HAT, SET-PT and SPLET, respectively. These reaction enthalpies were calculated as the difference of the calculated enthalpies of the reactant (which was Q) with that of the products. All possible products formed out of Q by the three mechanism are depicted in Fig.1, and the enthalpies of the formation of these products out of Q are shown. Generally, the lower the value of the enthalpy, the more likely it is that the products will be formed.

The IP value of $\mathrm{Q}^{\circ}$ to $\mathrm{Q}^{\bullet}$ is $112.51 \mathrm{Kcal} / \mathrm{mol}$, which is the highest of all three types of calculated enthalpies. This indicates that SET-PT is not an energy favorable pathway for the first radical scavenging.

The calculated BDE values of the $\mathrm{OH}$ groups show that HAT from the 4'-OH group, with an enthalpy of $77.49 \mathrm{Kcal} / \mathrm{mol}$, is preferred over HAT from the other $\mathrm{OH}$ groups. Nevertheless, the BDE of the 4'-OH group is substantial higher than that of the PA values, indicating that HAT is also not favorable from the energy perspective.

The sequence of the calculated PA values of the hydroxyl groups from low to high are: $26.11,26.80,31.20,31.27$ and $31.39 \mathrm{Kcal} / \mathrm{mol}$, for the 4'-OH, 7-OH, 3-OH, 5-OH and 3'$\mathrm{OH}$ group, respectively. 


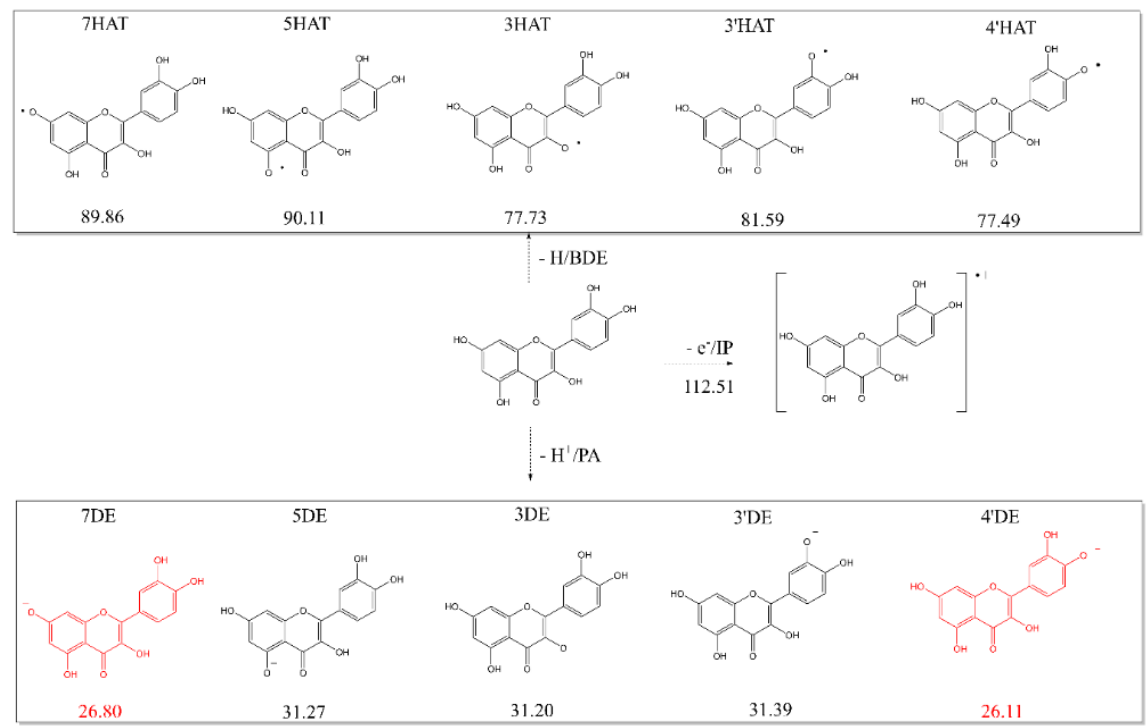

Fig 1. The products formed out of Q by hydrogen atom transfer, electron transfer or proton transfer; and the BDE, IP or PA enthalpies (in Kcal/mol) for the formation of these products. The two products in red are the products formed out of Q by deprotonation (proton transfer) of its 7-OH or 4'-OH group, and the formation of these products appeared to require the lowest reaction enthalpy.

It can be concluded that based on the enthalpies of three descriptors, the deprotonation of $\mathrm{Q}$, represented by the PA values, is preferred in an aqueous solution. This indicates that SPLET is the preferred mechanism and that the first step in the scavenging activity of Q in an aqueous solution is deprotonation of $\mathrm{Q}$.

\subsection{From $Q$ to $Q$ anion - deprotonation of the 7-OH group}

The PA values of the 7-OH and 4'-OH groups are the lowest. The difference of both PA values is only $0.69 \mathrm{Kcal} / \mathrm{mol}$, so it is hard to determine which hydroxyl group is deprotonated first. As outlined in the introduction, in the literature there is also no consensus on the order of deprotonation of the hydroxyl groups of Q. In order to solve this, the UV/Vis spectrum of 7-OH deprotonated Q (7DE) and that of 4'-OH deprotonated Q (4'DE) were calculated. Since tautomerization of 7-OH deprotonated $\mathrm{Q}$ has been proposed, this was also considered. The tautomer in which the proton of the 5-OH group is transferred to the oxygen atom at the 4position appeared to be unstable. Therefore, only the UV/Vis spectrum of the tautomer in which the proton of the 3-OH group is transferred to the 4 oxygen atom (abbreviated as 7DEITPT, in which ITPT stands for Intramolecular Proton Transfer) was calculated. These calculated spectra were compared to change in the spectrum of a solution of Q in water when the $\mathrm{pH}$ increases. (Fig 2). 

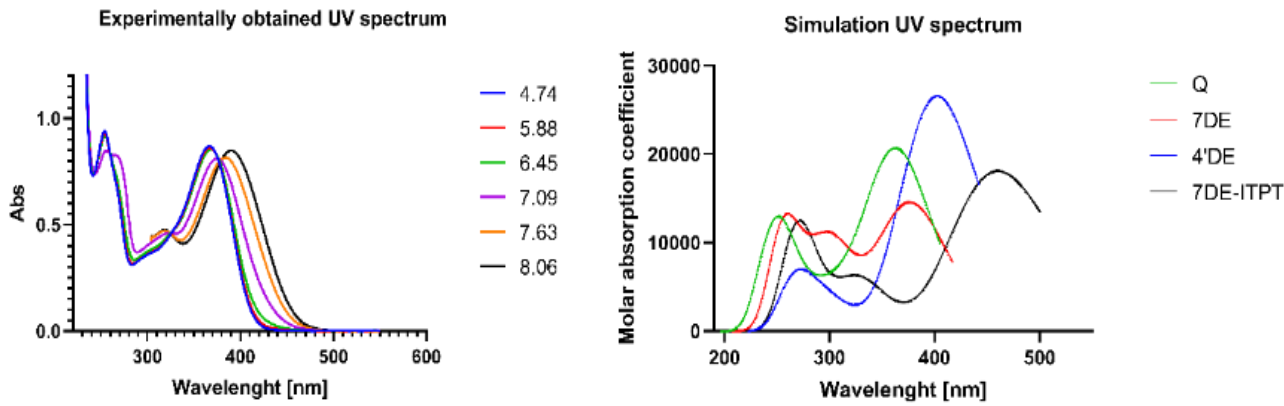

Fig 2. The experimentally obtained UV spectrum of a Q solution $(50 \mu \mathrm{M})$ in a $50 \mathrm{mM}$ phosphate buffer at various $\mathrm{pH}$ values (left panel) and the simulated UV spectra (right panel) of $\mathrm{Q}$ and the three energetically most favorable mono-deprotonated forms of Q. i.e 7-OH deprotonated Q (7DE), 4'-OH deprotonated Q (4'DE) and the tautomer of $7 \mathrm{DE}$ in which the proton of the $3-\mathrm{OH}$ group is transferred to the 4 oxygen atom (7DE-ITPT)

In acidic solutions with a $\mathrm{pH}$ below 5, the spectrum of $\mathrm{Q}$ is independent of the $\mathrm{pH}$ value. This indicates that at these acidic $\mathrm{pH}$ values, practically all $\mathrm{Q}$ is fully protonated. The absorption spectrum of the fully protonated Q only has two peaks, which are at $367 \mathrm{~nm}$ and $255 \mathrm{~nm}$. Raising the $\mathrm{pH}$ above 5, results in the deprotonation of $\mathrm{Q}$ as the absorption spectrum changes. There is a red shift of the Q peak of $367 \mathrm{~nm}$ of about $10 \mathrm{~nm}$ when the $\mathrm{pH}$ goes from 5 to 8 . Also, a new absorption peak appears at around $318 \mathrm{~nm}$ (fig. 2).

The simulation results depicted in Fig. 2 show that fully protonated Q has a peak in the simulated absorption spectrum at $367 \mathrm{~nm}$, which is practically similar with the wavelength of the peak at $377 \mathrm{~nm}$ of the experimental absorption spectrum of fully protonated $\mathrm{Q}$. The calculated spectrum of 7DE has a peak at $376 \mathrm{~nm}$, which is $9 \mathrm{~nm}$ higher as the peak of 367 $\mathrm{nm}$ of the calculated spectrum of fully protonated Q. This fits with the red shift of $10 \mathrm{~nm}$ of the peak of the $\mathrm{Q}$ solution at $367 \mathrm{~nm}$ caused by raising the $\mathrm{pH}$. Moreover, the new peak that appears in the $\mathrm{Q}$ solution at around $318 \mathrm{~nm}$ by raising the $\mathrm{pH}$, nicely coincides with the peak in the calculated spectrum of $7 \mathrm{DE}$ at that wavelength. In addition, the lower calculated height of the peak around $376 \mathrm{~nm}$ in the calculated spectrum of 7DE compared to the height of the peak around $367 \mathrm{~nm}$ in the calculated spectrum of Q, is in accordance with the difference in height of the corresponding peaks in the spectrum of the Q solution observed by raising the pH. 4DE has two peaks at $270 \mathrm{~nm}$ and $400 \mathrm{~nm}$, which does not fit with the in the change in the spectrum of the $\mathrm{Q}$ solution caused by increasing the $\mathrm{pH}$. These observations indicate that the 7-OH group is the most acidic group of $\mathrm{Q}$. Therefore, we consider that deprotonation of the 7-OH group is the first step in the antioxidant activity of $\mathrm{Q}$ in water. 


\subsection{From 7-OH deprotonated $Q$ to $Q$ radical - electron transfer}

According to the SPLET mechanism, the second step in radical scavenging of $\mathrm{Q}$ is the transfer of an electron from 7DE to an oxidizing species. The enthalpy of the electron donation was calculated. The tautomer of 7DE in which the proton of the 3-OH group is transferred to the 4 oxygen atom (7DE-ITPT) was also taken into consideration.

$7 \mathrm{DE}$<smiles></smiles>

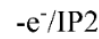

107.22
7DE-ET<smiles>O=C1C=C(O)C2C(=O)C(O)=C(c3ccc(O)c(O)c3)OC2=C1</smiles>

$0.36^{\mathrm{A}}$

13.30 Intramolecular proton transfer ,

7DE-ITPT<smiles></smiles>

$-\mathrm{e}^{-/ I P 3}$

94.61
7DE-ITPT-ET

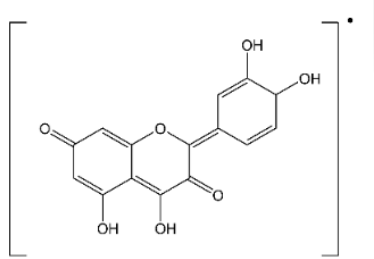

107.91

Fig 3. The two pathways for the electron transfer of 7-OH deprotonated Q (7DE) to a Q radical. The enthalpies requirement $(\mathrm{Kcal} / \mathrm{mol})$ of the reactions are given. The first pathway is a direct electron transfer from 7DE giving 7DE-ET. The second pathway is first an intramolecular proton transfers from 7DE to give 7DE-ITPT, followed by an electron transfer from 7DE-ITPT to give 7DE-ITPT-ET. The enthalpy difference of $0.36 \mathrm{Kcal} / \mathrm{mol}$ between the two conformers of the Q radicals, 7-DE-ET and 7DE-ITPT-ET, is also depicted1.

The enthalpy of the electron transfers of 7DE to the corresponding Q radical (denoted as 7DE-ET, in which ET stands for Electron Transfer) is $107.22 \mathrm{Kcal} / \mathrm{mol}$ (ionization potential 2, abbreviated as IP2). Tautomerization of 7DE and subsequent electron transfer (IP3) of this tautomer (giving the 7DE-ITPT-ET) has a total enthalpy of $107.91 \mathrm{Kcal} / \mathrm{mol}$, which is almost the same as the IP2 pathway. This indicates that both pathways are possible. Although the

1 In the Q molecules, the electrons in the $\pi$ orbitals of all the oxygen atoms are part of a conjugated $\pi$-system. Therefore, a 'deprotonated $\mathrm{OH}$ group' (incorrectly) suggesting that the negative charge (electrons) is exclusively on the $\pi$-orbital of the oxygen atom, is actually equal to an 'oxo group' with the negative charge delocalized in the $\pi$-system. 'Deprotonated OH group' is used in the text when in the reaction discussed, the $\mathrm{OH}$ group referred to, losses its proton. Because we choose to show the carbonyls in the chemical structure of the molecule, and the limitation of the traditional way molecules are depicted, the number and the fixed position of the double bounds in the rings is not accurate. These 'errors' are seen in some of the structures shown in Fig.3,5 and 6. This is the reason we show their 3D structures in the Supplementary SI 4. 
enthalpy gap of 7DE-ET with the 7DE-ITPT-ET is only $0.36 \mathrm{Kcal} / \mathrm{mol}$, their 3D structure greatly differs (Supplementary Table S1). The dihedral angle of C2-C3-C1'-C2' (which reflects the angle of the B-ring with the AC ring) of the 7DE-ET is $27.65^{\circ}$, while that of the 7DE-ITPT-ET is only $3.7^{\circ}$ which indicates that 7DE-ET and 7DE-ITPT-ET do not convert in each other. This means that the pathway is split at 7DE, as 7DE and 7-hDE-ITPT continue to produce different conformers of the Q radical that do not interconvert. Both pathways will be further investigated in the following sections.

\subsection{Electron structure of the two conformers of the $Q$ radical - importance of C2-C3 bond.}

To determine where the electron was lost from the deprotonated forms of $\mathrm{Q}$, electron density difference maps of 7DE as well as 7DE-ITPT with their corresponding radical were generated.

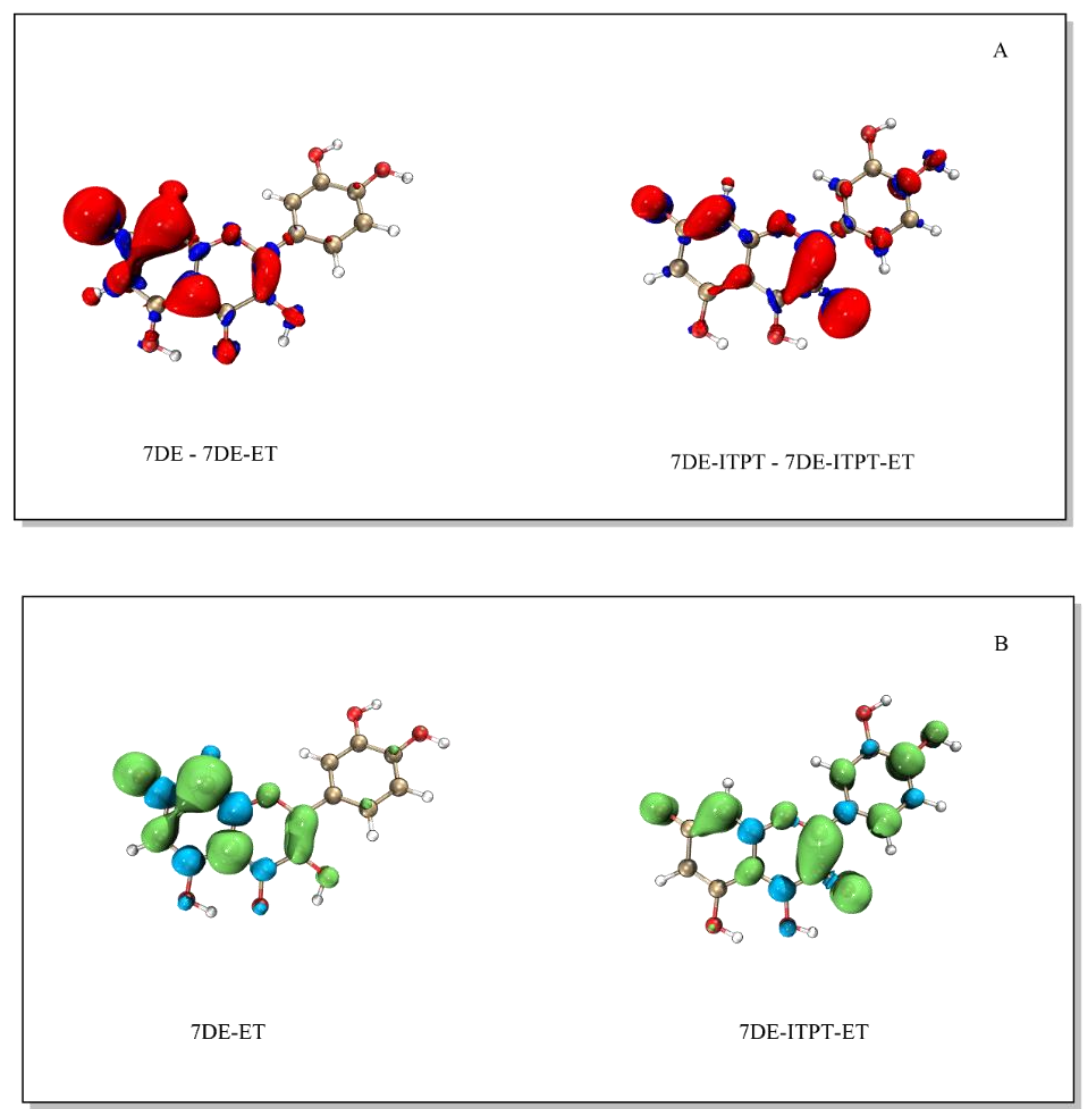

Fig 4. The electron density difference map of 7DE and of 7DE-ITPT with their corresponding radical (panel A), and the spin density of the 7DE-ET and the 7DE-ITPT-ET radical (Panel B). In constructing the electron density difference map, the radical formed immediately after the electron transfer has taken place is used, and the electrons in the radical have not yet relaxed. The difference map shows where the electron is lost. The electron density map of the radicals depicted in panel $\mathrm{B}$ is of the stable radical. 
The electron density difference of 7DE with the 7DE-ET radical shows that by electron transfer most of the electron density is lost on $\mathrm{C} 8, \mathrm{C} 10$ and $\mathrm{O} 7$, and on the $\mathrm{C} 2-\mathrm{C} 3$ bond (Fig. 4). This indicates that the electron was primarily donated at these positions. The electron density difference of 7DE-ITPT with 7DE-ITPT-ET, shows that in 7DE-ITPT the electron was primarily donated at $\mathrm{C} 2-\mathrm{C} 3$ bond and $\mathrm{O} 3$.

The spin density map shows that, after donating one electron, the unpaired electron in 7DE-ET is mostly delocalized on the AC-ring and concentrated on C8, C10 and O7, and the $\mathrm{C} 2-\mathrm{C} 3$ bond. The relatively high dihedral angle of 7DE-ET of $27.65^{\circ}$, as mentioned in section 3.2 , is in line with the observed delocalization of its unpaired electron primarily in the AC ring. Although in 7DE-ITPT-ET, the unpaired electron is concentrated on the C-ring and Bring (especially on the $\mathrm{C} 2-\mathrm{C} 3$ bond), the unpaired electron is delocalized over the whole molecule. The angle in 7DE-ITPT-ET between the AC-ring and B-ring of only $3.7^{\circ}$ indicates that the molecule is virtually planar, which is in line with the observed delocalization of its unpaired electron over the $\pi$ system of the whole molecule.

\subsection{From $Q$ radical to $Q$ radical anion - deprotonation of the 3-OH or 4'-OH group.}

The 7DE-ET radical and 7DE-ITPT-ET radical formed when $\mathrm{Q}$ has scavenged a radical, can scavenge a second oxidizing species. Of the BDE, IP, and PA values of the radicals (Supplementary Figure S1), the PA values are significantly lower than other two, indicating that molecular mechanism of the antioxidant activity of the Q radicals also is a SPLET mechanism. This means that here also the first step is deprotonation. To determine which hydroxyl group is deprotonated first, the PA values of the hydroxyl groups of both conformers of the $\mathrm{Q}$ radical were calculated.

As shown in Fig. 5, the enthalpy needed for deprotonation of the 3-OH or 4'-OH group of the 7DE-ET are the lowest and do not differ much, indicating that one of these groups is the first to be deprotonated. The same goes for the enthalpy needed for deprotonation of the 4$\mathrm{OH}$ or 4'-OH group of 7DE-ITPT-ET.

Therefore, the conclusion can be made that for 7DE-ET as well as 7DE-IPET-ET, the most favorable pathways from an energy perspective are deprotonation of either their $\mathrm{OH}$ group in the C-ring or their 4'-OH group in the B-ring. The products in which the 4'-OH group is deprotonated are denoted by 7DE-ET-4'DE and 7DE-IPET-ET-4'DE. It is noteworthy that the products in which the $\mathrm{OH}$ group in the B-ring is deprotonated, denoted by 7DE-ET-3DE and 7DE-IPET-ET-4DE in Fig. 5, are identical. For sake of clarity, 7DE-ET-3DE is used in this manuscript to denote this conformer in the next step of the antioxidant activity (the second electron transfer), but it should be realized that this conformer can be formed by two pathways. So, in total 3 forms of the Q radical anion need to be considered. 


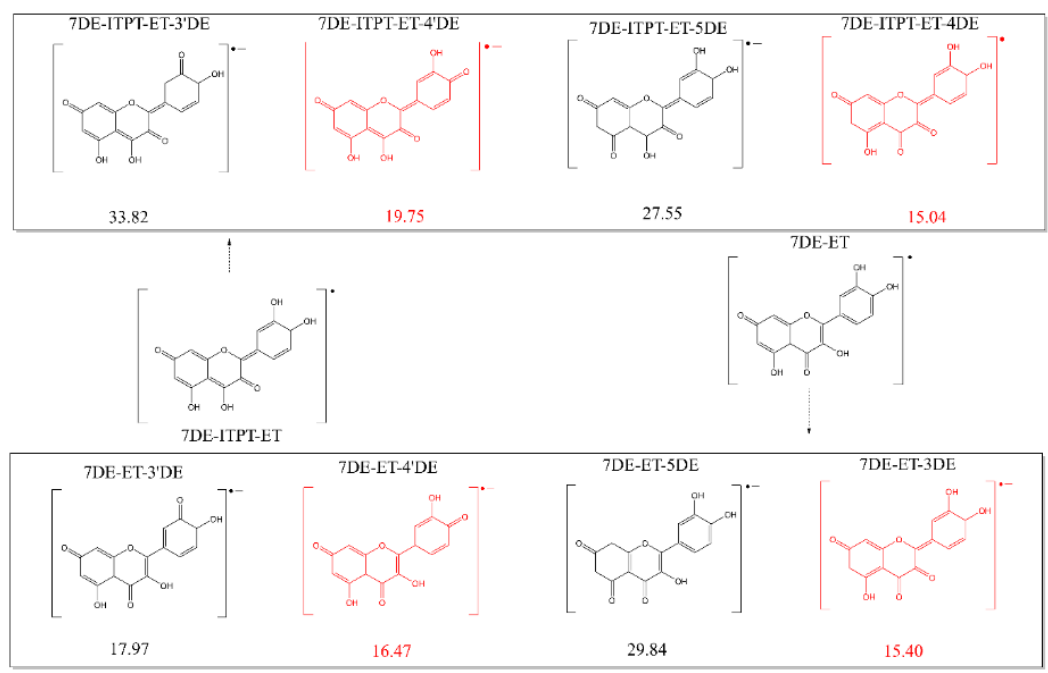

Fig 5. The enthalpy requirement of the deprotonation of the two conformers of the Q radical, 7DE-ET and 7DEITPT-ET. The four products in red are the products formed out of both Q radical conformers by deprotonation (proton transfer) of their 3-OH or 4'-OH group, and the formation of these products appeared to require the lowest reaction enthalpy.

The spin density maps show that the unpaired electron is mostly concentrated on the B ring and the $\mathrm{C} 2-\mathrm{C} 3$ bond of the $\mathrm{Q}$ radical anions. In 7DE-ET-4'DE and the 7DE-ITPT-ET4'DE, the $\mathrm{B}$ ring is favored. This is probably because in these radical anions an $\mathrm{OH}$ group in the B-ring (i.e. the 4'-OH) is deprotonated. In the 7DE-ET-3DE radical, the C2-C3 bond is favored. This is probably due to the oxo group on the $\mathrm{C} 2-\mathrm{C} 3$ bond.

\subsection{From the $Q$ radical anion to $Q$ quinone - electron transfer.}

The next step is that the $\mathrm{Q}$ radical anion donates an electron to the second oxidizing species. In this reaction a $\mathrm{Q}$ quinone/quinone methide (QQ) is formed. 


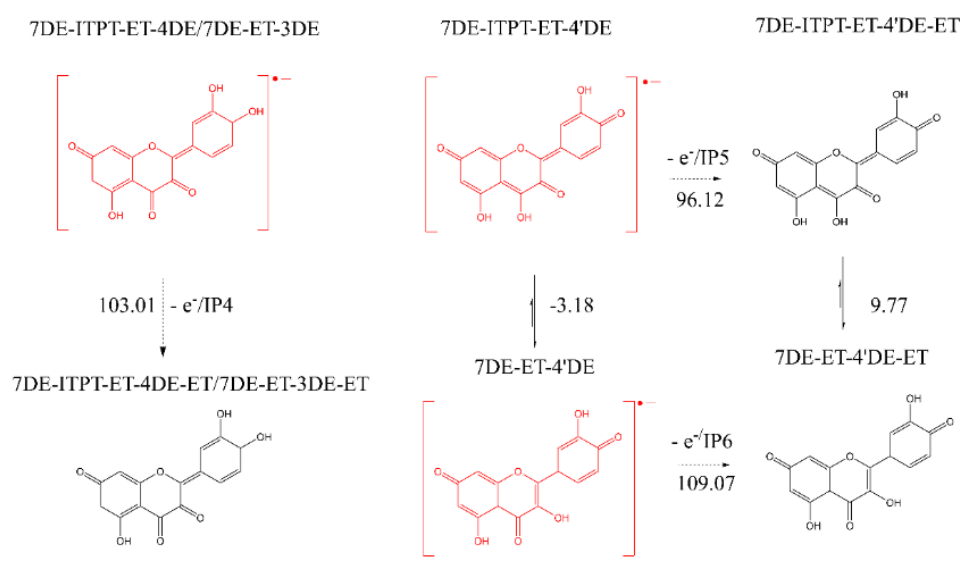

Fig 6. The enthalpy requirement (in $\mathrm{Kcal} / \mathrm{mol}$ ) of the second electron donation from the 3 conformers of the $\mathrm{Q}$ radical to form the corresponding quinone.

It was found that the enthalpy difference between each $Q$ radical anion and its corresponding quinone are comparable and have a value of approximately $100 \mathrm{Kcal} / \mathrm{mol}$ (Fig. $6)$.

The electron density difference maps of the $\mathrm{Q}$ radical anions and their corresponding quinones appear to be very similar to the spin density map of the Q radical anions (Fig. 7).

The electron density difference maps show that the electron is primarily donated at the Bring and the $\mathrm{C} 2-\mathrm{C} 3$ bond of the $\mathrm{Q}$ radical anions. This coincides with the locations at which the spin density in the $\mathrm{Q}$ radical anion is the highest.

The total enthalpies of the three pathways from Q leading to QQ are $259.56 \mathrm{Kcal} / \mathrm{mol}$, $252.53 \mathrm{Kcal} / \mathrm{mol}$, and $250.58 \mathrm{Kcal} / \mathrm{mol}$, for 7DE-ET-4'DE-ET, 7DE-ET-3DE-ET, and 7DEITPT-ET-4'DE-ET quinone, respectively. That these total enthalpy values do not differ much, indicates that all three pathways should be considered for the flow of the redox energy of $Q$ during its antioxidant activity. 

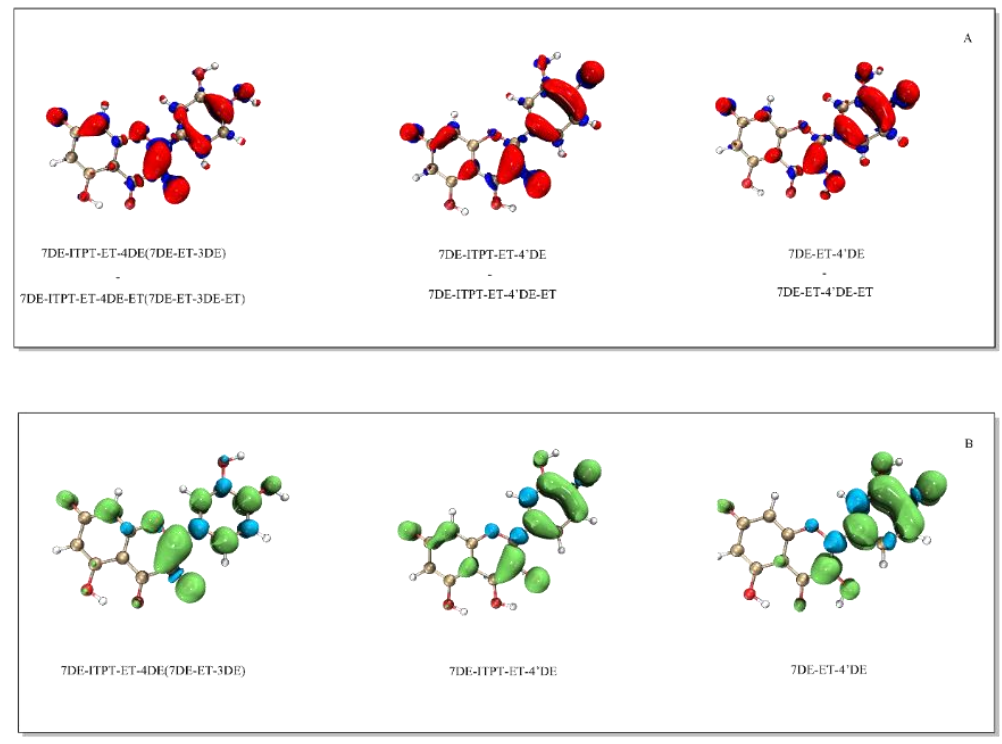

Fig 7. The electron density difference of the three forms of the Q radical with their corresponding quinone (panel A) and the spin density of the three forms of the Q radical (panel B).

The HOMO-LUMO gap (Supplementary Figure S2) of the three quinones are $3.16 \mathrm{eV}$ (7DE-ET-4'DE-ET), 3.77 eV (7DE-ET-3DE-ET) and $4.13 \mathrm{eV}$ (7DE-ITPT-ET-4'DE-ET), respectively. These results indicate that the quinones are reactive and that 7DE-ET-4'DE-ET and -ET-3DE-ET quinone are less stable as 7DE-ITPT-ET-4'DE-ET Quinone. Previously, we tried to detect the formation of QQ during the oxidation of Q using HPLC analysis with UV detection, but this failed. This confirms the limited stability of QQ, probably because QQ reacts quickly with water. The indirect evidence for the formation of QQ is that QQ can be trapped with GSH. 6GS-Q and 8GS-Q are exclusively formed [11]. That only these adducts are formed, is consistent with the formation of 7DE-ET-ITPT-4'DE-ET as the most prominent form of QQ. Using a mass spectrometry, we were able to detect QQ during the oxidation of QQ (Supplementary Figure S3). To our knowledge this is the first time that QQ was directly detected in the oxidation of $\mathrm{Q}$.

It is worth to mention that the dihedral angle of C2-C3-C1'-C2' of 7DE-ET-ITPT-4'DE is $2^{\circ}$ (Supplementary Table S1), indicating that this quinone is virtually flat and that the electrons in the $\pi$ system of the quinone can delocalize over the whole molecule. This indicates the 'soft' nature of QQ. That QQ prefers to react with the 'soft' GSH over the 'hard' ascorbate [27], confirms the soft nature of QQ. 


\section{Discussion}

In its antioxidant activity, Q easily picks up redox energy, that is softened when it flows through the molecule, and finally the redox energy is passed over from the oxidized Q into the antioxidant network. The aim of our study is to find, from an energy perspective, the most favorable pathway for the flow of the redox energy through Q during this activity. Usually only the one electron reaction of Q to form Q* is examined. However, Q donates two electrons in its antioxidant activity [12]. Therefore, it is also examined how $\mathrm{Q}^{*}$ can pick up redox energy, and how the energy flows through Q $\mathrm{Q}^{*}$ to form QQ.

In most theoretical studies on the antioxidant activity of Q, the likelihood of HAT, SETPT and SPLET as the first step is investigated [28, 29]. This has been done by calculating the enthalpy or Gibbs free energy of the first step in the three mechanisms in various solvent using different calculation methods at numerous levels. A consensus seems to arise that the enthalpy for the first step in SPLET, this is PA, is the lowest [9]. We also found that the enthalpy for PA is the lowest, indicating that the deprotonation of $\mathrm{Q}$ is most energy favorable first step. This is in line with the observation that $\mathrm{Q}$ in water at $\mathrm{pH} 2.1$, when it is fully protonated, is a poor antioxidant compared to $\mathrm{Q}$ in water at $\mathrm{pH} 7.4$, when $\mathrm{Q}$ is partially deprotonated [30]. This confirms that deprotonation is the primary first step in the antioxidant activity of $\mathrm{Q}$ in the water.

There is no consensus on which $\mathrm{OH}$ group of $\mathrm{Q}$ is the most acidic. Our calculation agrees with other DFT calculations that the 4'-OH will be the first group of Q to deprotonate. However, the difference between the PA of the 4'-OH group and the 7-OH group is small, and experimental studies indicate that the 7-OH group is the most acidic group[25]. Of our TDDFT simulated UV spectra, the difference between the spectrum of Q and 7DE fitted the best with the change in the spectrum of a $\mathrm{Q}$ solution caused by raising the $\mathrm{pH}$. This confirms the conclusion of the previously reported experimental studies that the 7-OH group is the most acidic.

A shortcoming of the DFT calculation is that a hydrogen bond of the $\mathrm{OH}$ groups of Q with water cannot be reflected or simulated by the SMD model we used, or other solvent models since no real water molecules had been added. The 4'-OH group can form an intramolecular hydrogen bond with the 3'-OH group, which may lead to the enhancement of their stability. The deprotonated 7-OH group cannot form an intramolecular hydrogen bridge. This means that the formation of an intermolecular hydrogen bridge with a water is, from the energy perspective, more relevant for 7DE as for 4'DE. This may explain why based on the calculation, the 4'-OH seems to be the most acidic, while actually - as found in the experimental studies - the 7-OH is the most acidic. Therefore, we considered that deprotonation of the 7-OH group is the first step in the antioxidant activity of Q. The DFT calculation shows that after deprotonation, a tautomer of 7DE can be formed by in which the proton of the 3-OH group is transferred to the 4 oxygen atom (7DE-ITPT) [26]. Therefore, the formation of this tautomer is also considered.

In the SPLET mechanism, the next step after the deprotonation is electron donation. Our electron density difference maps reveal that 7DE as well as its tautomer 7DE-ITPT can 
donate an electron at various sites of the molecule with variable energies, which explains Q's ability to scavenge all sorts of reactive oxidizing species.

The dihedral angle of $\mathrm{C} 2-\mathrm{C} 3-\mathrm{C} 1$ '-C2' (the angle between the $\mathrm{B}$ ring and $\mathrm{AC}$ ring) greatly affects the delocalization of the unpaired electron. In 7DE-ET the dihedral angle is $27.6^{\circ}$, which prevents the delocalization of the unpaired electron from passing through the $\mathrm{C} 2-\mathrm{C} 1$ ' bond and concentrates the unpaired electron on B ring of 7DE-ET. The angle in 7DE-ITPEET is $3.7^{\circ}$, ( Supplementary Table S1)), which indicates that it is almost planar, and that the unpaired electron can delocalize over the whole molecule. The relatively high difference in the dihedral angle also means that the conformers of the Q radical formed out of 7DE and 7DE-ITPT do not interconvert. So, the pathway splits after the deprotonation of Q, and 7DE and 7-DE-ITPT continue to produce a different conformer of the Q radical.

The spin density map of both Q radicals shows that the spin density of the unpaired electron concentrates near the deprotonated $\mathrm{OH}$ and oxo groups, i.e. on $\mathrm{C} 2-\mathrm{C} 3$ bond and $\mathrm{O} 5$ for 7DEITPT-ET and C8 and $\mathrm{O} 7$ for 7DE-ET. The concentration of the unpaired electron near deprotonated $\mathrm{OH}$ groups and oxo groups is also found in the Electron Spin Resonance spectra of $\mathrm{Q}$ and $\mathrm{Q}$ derivatives recorded at high $\mathrm{pH}$ [31]. This can be explained by the electronwithdrawing nature of the deprotonated $\mathrm{OH}$ group and the oxo group [32].

It is known that the oxidation of $\mathrm{Q}$ is a two-electron process, which finally generates QQ [33]. Nevertheless, the antioxidant activity of $Q^{*}$ has not been studied well. The enthalpy of PA of the hydroxyl groups of both Q radicals (Supplementary Figure S1), are significantly lower than that of BDE or IP, indicating that molecular mechanism of the antioxidant activity of $\mathrm{Q}^{\bullet}$ also is SPLET.

Our calculation shows that the enthalpy for deprotonation of the $\mathrm{OH}$ group in the $\mathrm{C}$-ring or the 4'-OH group in the B-ring of both Q radicals are the lowest and do not differ much. Interestingly, deprotonation of the $\mathrm{OH}$ group in the $\mathrm{C}$-ring of both radicals, giving the products denoted as 7DE-ET-3DE in one pathway and as 7DE-ITPT-ET-4DE in the other pathway, appears to generate the same molecule. This indicates that both pathways can come together again. Deprotonation of the 4'-OH generates different molecules. So, beside the mutual pathway, there are two other pathways (Fig. 8). The angle in 7DE-ITPE-ET, 7DEET-3DE, and 7DE-ITPT-ET-4'DE is $3.7^{\circ}, 0.03^{\circ}$, and $0.001^{\circ}$ (Supplementary Table S1), which indicates that these molecules are almost planar and explains that the unpaired electron can delocalize over the whole molecule, which will reduce the reactivity.

The spin density map shows that in 7DE-ET-4'DE and 7DE-ITPT-ET-4'DE, the deprotonated 4'-OH group concentrates the unpaired electron on B ring. Also, this can be explained by the electron-withdrawing nature of this group [31]. Notably, in all radicals of $\mathrm{Q}$, the unpaired electron is for a substantial part concentrated on the C2-C3 bond. Moreover, the sp2 nature of the $\mathrm{C} 2-\mathrm{C} 3$ bond is essential for connecting the $\pi$-system of the AC-ring with that of the B-ring. In addition, the electron density difference maps show that the first electron as well as the second electron is donated for a substantial part from the $\mathrm{C} 2-\mathrm{C} 3$ bond. This all may explain why the importance of the $\mathrm{C} 2-\mathrm{C} 3$ moiety is highlighted in virtually all the reports on the antioxidant activity of Q [33]. 
Although, the enthalpy difference between the three quinones formed is relatively small, their abundancy in the solution might greatly differ and 7DE-ITPT-ET-4'DE-ET is the most abundant one. This is in agreement with previous work [27].

It has to be realized that $\mathrm{Q}$ has the capacity to react with up to 12 radicals in antioxidant capacity assays [34]. This indicates that QQ and oxidation products of QQ also have antioxidant activity. The molecular mechanism of their antioxidant activity is beyond the scope of the present study. Moreover, QQ quickly reacts with GSH and ascorbate in biological systems before QQ is oxidized $[11,12]$. Therefore, the oxidation of QQ and its oxidation products is considered to be less relevant.

\section{Computation details}

The geometry and vibration spectra of $\mathrm{Q}$ and oxidized forms of $\mathrm{Q}$, as well their deprotonated forms, were generated by Gaussian 09 [35] at M062X [36]/6-311+G(d,p) [37] level. Calculation of the enthalpy of the various forms of $\mathrm{Q}$ in gas phase were carried at M062X/def2-TZVP [38] level with a D3 correction [39] by Orca[40]. The solvent effect was included by using the implemented SMD (water) method [41]. Since the solvent model cannot exactly calculate the enthalpy of solvation (H(solvation)), the solvation free energy was estimated using as an Approximate alternative method. For this, the recommended basis set M052X/6-31G* was used. Additionally, $1.89 \mathrm{Kcal} / \mathrm{mol}$ was added to balance the difference of the enthalpy of the molecules in gas phase with that in the water phase. The ZPE correction factor is 0.97 as described by Truhlar [42]. The enthalpy of an electron, hydrogen atom or proton in the gas phase, used in the present manuscript are $0.751 \mathrm{Kcal} / \mathrm{mol}$, $-313.75 \mathrm{Kcal} / \mathrm{mol}$ and $1.48 \mathrm{Kcal} / \mathrm{mol}$, respectively [43]. The solvation enthalpy of an electron, hydrogen atom or proton are $-18.51 \mathrm{Kcal} / \mathrm{mol},-0.955 \mathrm{Kcal} / \mathrm{mol}$ and $-252.365 \mathrm{Kcal} / \mathrm{mol}$, respectively [44]. All enthalpies and free energies were calculated for $298.15^{\circ} \mathrm{K}$. The spin density maps and electron density difference maps were generated by Multiwfn [45] and VMD [46]. The 3D structures of all investigated compounds can be seen in Supplementary Figure S4.

Time-dependent density functional theory (TDDFT) was applied to simulate the UV/VIS spectrum of Q and deprotonated Q. Herein, functional PEB0 at the Def2-tzvp level was used. In order to obtain accurate spectra over a wide wavelength range, in total 10 excited states were taken into consideration[47]. The spectra were generated by Multiwfn by the Gaussian function with the full width at half maximum (FWHM) of $0.67 \mathrm{eV} \mathrm{[30].} \mathrm{The} \mathrm{spectra} \mathrm{of} \mathrm{a} 50$ $\mu \mathrm{M} \mathrm{Q}$ in a $50 \mathrm{mM}$ phosphate buffer at the indicated $\mathrm{pH}$ were recorded on a Cary 50 spectrophotometer. At a $\mathrm{pH}$ above $7.5,1 \mathrm{mM}$ of ascorbate was added to prevent or reverse the oxidation of Q. Due to the absorption of ascorbate below $300 \mathrm{~nm}$, only the absorption spectrum above $300 \mathrm{~nm}$ is given when ascorbate was present. 


\section{Conclusions}

The antioxidant activity of flavonoids has been studied over a long time. At first it was suggested that for all flavonoids this proceeded by the same simple scavenging reaction:

$$
\text { Flavonoid-OH }+\mathrm{R}^{\bullet} \rightarrow \text { Flavonoid-O• }+\mathrm{RH}
$$

This evolved when the antioxidant activity of more flavonoids was tested, and descriptive Structure Activity Relationships were constructed, that also generated a theoretical fundament. Now it is realized that the molecular mechanism of the antioxidant activity of each flavonoid is unique, and the simple scavenging reaction is split up in sequential reactions when the redox energy flows through the molecule.

The present study confirms that SPLET is the mechanism of the antioxidant activity of Q as well as that of $\mathrm{Q}^{*}$. The enthalpy of the second SPLET process of $\mathrm{Q}^{*}(115.87 \mathrm{Kcal} / \mathrm{mol})$ is less than that of the first 'SPLET' process of Q $(134.71 \mathrm{Kcal} / \mathrm{mol})$, suggesting that the second radical scavenging reaction of $Q$ is quicker than the first scavenging, which is in line with the literature. This means that in studying the antioxidant activity of Q, two sequential SPLET mechanism should be considered. Mostly the antioxidant activity of $\mathrm{Q}^{\bullet}$ is not considered, indicating that only half of the antioxidant activity of Q is studied.

In the present study the series of sequential reactions in the antioxidant activity of $\mathrm{Q}$ are separately studied and connected. The calculations show that Q can pick up redox energy at various sites of the molecule, with variable energies. This explains Q's potent scavenging ability of all sorts of reactive oxidizing species. Moreover, it appears that not one, but several pathways are possible for the flow of redox energy through Q. In addition, these pathways are also intertwined. This flexibility of the flow of the redox energy is depicted in the overview Fig. (Fig. 8). There were already some clues that pointed towards the flexibility of the antioxidant activity of Q: Q contains more than one antioxidant "pharmacophore" and both pharmacophores do not work separately but interact $[8,48]$. The flexibility of the flow of the redox energy through the molecule adds to the efficiency and increases the versatility of Q's redox modulating potency. 


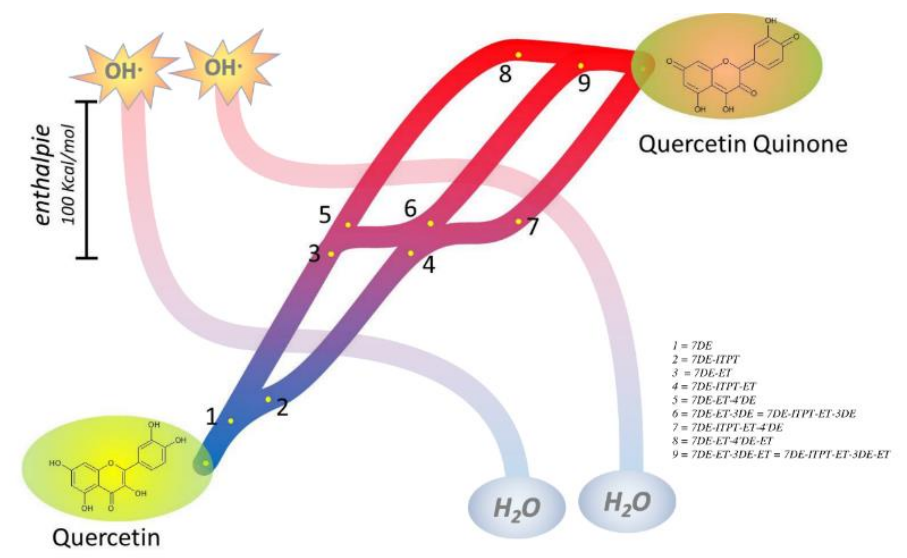

Fig 8. Overview of the main pathways of the flow of the redox energy in Q during its antioxidant activity in water. First $\mathrm{Q}$ is deprotonated at the 7 position to give 7DE (1). Then the pathway spits, due to an intramolecular proton transfer, generating 7DE-ITPT (2). In one pathway, electron transfer coverts 7DE in the Q radical 7DE-ET (3). In 7DE-ET the second deprotonation can take place at the 4' or 3 position, again splitting the pathway, generating 7DEET-4'DE (5) and 7DE-ET-3DE (6), respectively. After the second electron transfer the quinones 7DE-ET-4'DE-ET (8) and 7DE-ET-3DE-ET (9) are formed.

The other pathway starts with the generation of 7DE-ITPT (2). Electron transfer converts 7DE-ITPT in the Q radical 7DE-ITPT-ET (4). The second deprotonation of this Q radical (4) also can take place at two positions. Interestingly, deprotonation of the $\mathrm{Q}$ radical (4) at the 4 position generates a molecule identical to 7DE-ET-3DE (6), and here the pathways come together. The second deprotonation of the Q radical (4) at the 4' position generates a third pathway by the formation of 7DE-ITPT-ET-4'DE (9). After a second electron transfer 7DE-ITPT-ET-4'DE is converted in the quinone 7DE-ITPT-ET-4'DE-ET (Quercetin Quinone).

Of the quinones formed, 7DE-ITPT-ET-4'DE-ET (Quercetin Quinone) has the lowest energy content, and ultimately this appears to be the most abundant quinone in the antioxidant activity of Q. In these pathways, Q can pick up the hard energy of e.g. two hydroxyl radicals, and the hard energy is softened before it is passed on into the antioxidant network. 


\section{References}

1. Zhang, M.; Moalin, M.; Vervoort, L.; Li, Z. W.; Wu, W. B.; Haenen, G., Connecting Western and Eastern medicine from an energy perspective. International Journal of Molecular Sciences 2019, 20, (6), 1512.

2. Sthijns, M.; Weseler, A.; Bast, A.; Haenen, G., Time in redox adaptation processes: from evolution to hormesis. International Journal of Molecular Sciences 2016, 17, (10), 1649.

3. Kurutas, E. B., The importance of antioxidants which play the role in cellular response against oxidative/nitrosative stress: current state. Nutrition Journal 2015, 15, (1), 1-22.

4. Lobo, V.; Patil, A.; Phatak, A.; Chandra, N., Free radicals, antioxidants and functional foods: Impact on human health. Pharmacognosy Reviews 2010, 4, (8), 118.

5. Santos-Sánchez, N. F.; Salas-Coronado, R.; Villanueva-Cañongo, C.; Hernández-Carlos, B., Antioxidant compounds and their antioxidant mechanism. In Antioxidants, IntechOpen: 2019.

6. Bast, A.; Haenen, G. R.; Doelman, C. J., Oxidants and antioxidants: state of the art. The American journal of medicine 1991, 91, (3), S2-S13.

7. Lemmens, K. J.; Herst, P. M.; Housmans, B. A.; Moalin, M.; van der Vijgh, W. J.; Bast, A.; Haenen, G. R., The contribution of the major metabolite 4'-O-methylmonoHER to the antioxidant activity of the flavonoid monoHER. Chemico-biological interactions 2015, 239, 146-152.

8. Heijnen, C. G.; Haenen, G. R.; Minou Oostveen, R.; Stalpers, E. M.; Bast, A., Protection of flavonoids against lipid peroxidation: the structure activity relationship revisited. Free Radical Research 2002, 36 , (5), 575-581.

9. Zheng, Y.-Z.; Deng, G.; Liang, Q.; Chen, D.-F.; Guo, R.; Lai, R.-C., Antioxidant activity of quercetin and its glucosides from propolis: A theoretical study. Scientific Reports 2017, 7, (1), 7543.

10. Justino, G. C.; Vieira, A. J., Antioxidant mechanisms of Quercetin and Myricetin in the gas phase and in solution-a comparison and validation of semi-empirical methods. Journal of Molecular Modeling 2010, $16,(5), 863-876$.

11. Awad, H. M.; Boersma, M. G.; Boeren, S.; van der Woude, H.; van Zanden, J.; van Bladeren, P. J.; Vervoort, J.; Rietjens, I. M., Identification of o-quinone/quinone methide metabolites of quercetin in a cellular in vitro system. FEBS Letters 2002, 520, (1-3), 30-34.

12. Boots, A. W.; Kubben, N.; Haenen, G. R.; Bast, A., Oxidized quercetin reacts with thiols rather than with ascorbate: implication for quercetin supplementation. Biochemical and biophysical research communications 2003, 308, (3), 560-565.

13. Lemmens, K. J.; Vrolijk, M. F.; Bouwman, F. G.; Van der Vijgh, W. J.; Bast, A.; Haenen, G. R., The minor structural difference between the antioxidants quercetin and 4'O-methylquercetin has a major impact on their selective thiol toxicity. International Journal of Molecular Sciences 2014, 15, (5), 7475 7484.

14. Amić, A.; Marković, Z.; Marković, J. M. D.; Stepanić, V.; Lučić, B.; Amić, D., Towards an improved prediction of the free radical scavenging potency of flavonoids: The significance of double PCET mechanisms. Food Chemistry 2014, 152, 578-585.

15. Vásquez-Espinal, A.; Yañez, O.; Osorio, E.; Areche, C.; García-Beltrán, O.; Ruiz, L. M.; Cassels, B. K.; Tiznado, W., Theoretical Study of the Antioxidant Activity of Quercetin Oxidation Products. Frontiers in Chemistry 2019, 7, 818 .

16. Stepanić, V.; Trošelj, K. G.; Lučić, B.; Marković, Z.; Amić, D., Bond dissociation free energy as a general parameter for flavonoid radical scavenging activity. Food Chemistry 2013, 141, (2), 1562-1570.

17. Amić, D.; Stepanić, V.; Lučić, B.; Marković, Z.; Marković, J. M. D., PM6 study of free radical scavenging mechanisms of flavonoids: why does $\mathrm{O}-\mathrm{H}$ bond dissociation enthalpy effectively represent free radical scavenging activity? Journal of Molecular Modeling 2013, 19, (6), 2593-2603.

18. Álvarez-Diduk, R.; Ramírez-Silva, M. T.; Galano, A.; Merkoçi, A., Deprotonation mechanism and acidity constants in aqueous solution of flavonols: a combined experimental and theoretical study. The Journal of Physical Chemistry B 2013, 117, (41), 12347-12359.

19. Jovanovic, S. V.; Steenken, S.; Tosic, M.; Marjanovic, B.; Simic, M. G., Flavonoids as antioxidants. Journal of the American Chemical Society 1994, 116, (11), 4846-4851.

20. Herrero-Martínez, J. M.; Sanmartin, M.; Rosés, M.; Bosch, E.; Ràfols, C., Determination of dissociation constants of flavonoids by capillary electrophoresis. Electrophoresis 2005, 26, (10), 1886-1895.

21. Herrero-Martínez, J. M.; Repollés, C.; Bosch, E.; Rosés, M.; Ràfols, C., Potentiometric determination of aqueous dissociation constants of flavonols sparingly soluble in water. Talanta 2008, 74, (4), 1008-1013.

22. Georgievskii, V., Acidic properties of flavonoid compounds and the choice of solvent for performing potentiometric analysis. Chemistry of Natural Compounds 1980, 16, (2), 136-141.

23. Marković, Z.; Amić, D.; Milenković, D.; Dimitrić-Marković, J. M.; Marković, S., Examination of the chemical behavior of the quercetin radical cation towards some bases. Physical Chemistry Chemical Physics 2013, 15, (19), 7370-7378. 
24. Agrawal, P. K.; Schneider, H.-J., Deprotonation induced 13 C NMR shifts in phenols and flavonoids. Tetrahedron Letters 1983, 24, (2), 177-180.

25. Musialik, M.; Kuzmicz, R.; Pawłowski, T. S.; Litwinienko, G., Acidity of hydroxyl groups: an overlooked influence on antiradical properties of flavonoids. The Journal of organic chemistry 2009, 74, (7), 2699-2709.

26. Brovarets, O. h. O.; Hovorun, D. M., Intramolecular tautomerization of the quercetin molecule due to the proton transfer: QM computational study. PloS One 2019, 14, (11).

27. Moalin, M.; van Strijdonck, G. P.; Bast, A.; Haenen, G. R., Competition between ascorbate and glutathione for the oxidized form of methylated quercetin metabolites and analogues: tamarixetin, 4' Omethylquercetin, has the lowest thiol reactivity. Journal of agricultural and food chemistry 2012, 60, (36), 9292-9297.

28. Urbaniak, A.; Szeląg, M.; Molski, M., Theoretical investigation of stereochemistry and solvent influence on antioxidant activity of ferulic acid. Computational and Theoretical Chemistry 2013, 1012, 33-40.

29. Galano, A.; Álvarez-Diduk, R.; Ramírez-Silva, M. T.; Alarcón-Ángeles, G.; Rojas-Hernández, A., Role of the reacting free radicals on the antioxidant mechanism of curcumin. Chemical Physics 2009, 363, (13), 13-23.

30. Amorati, R.; Baschieri, A.; Cowden, A.; Valgimigli, L., The antioxidant activity of quercetin in water solution. Biomimetics 2017, 2, (3), 9.

31. Li, Z.; Moalin, M.; Zhang, M.; Vervoort, L.; Mommers, A.; Haenen, G. R., Delocalization of the Unpaired Electron in the Quercetin Radical: Comparison of Experimental ESR Data with DFT Calculations. International Journal of Molecular Sciences 2020, 21, (6), 2033.

32. Leopoldini, M.; Marino, T.; Russo, N.; Toscano, M., Density functional computations of the energetic and spectroscopic parameters of quercetin and its radicals in the gas phase and in solvent. Theoretical Chemistry Accounts 2004, 111, (2-6), 210-216.

33. Zare, H. R.; Namazian, M.; Nasirizadeh, N., Electrochemical behavior of quercetin: Experimental and theoretical studies. Journal of electroanalytical chemistry 2005, 584, (2), 77-83.

34. Arts, M. J.; Dallinga, J. S.; Voss, H.-P.; Haenen, G. R.; Bast, A., A new approach to assess the total antioxidant capacity using the TEAC assay. Food Chemistry 2004, 88, (4), 567-570.

35. Frisch, M. J.; Trucks, G. W.; Schlegel, H. B.; Scuseria, G. E.; Robb, M. A.; Cheeseman, J. R.; Scalmani, G.; Barone, V.; Mennucci, B.; Petersson, G. e., Gaussian 09 Revision D. 01. 2014.

36. Zhao, Y.; Truhlar, D. G., The M06 suite of density functionals for main group thermochemistry, thermochemical kinetics, noncovalent interactions, excited states, and transition elements: two new functionals and systematic testing of four M06-class functionals and 12 other functionals. Theoretical Chemistry Accounts 2008, 120, (1-3), 215-241.

37. Krishnan, R.; Binkley, J. S.; Seeger, R.; Pople, J. A., Self-consistent molecular orbital methods. XX. A basis set for correlated wave functions. The Journal of chemical physics 1980, 72, (1), 650-654.

38. Weigend, F.; Ahlrichs, R., Balanced basis sets of split valence, triple zeta valence and quadruple zeta valence quality for H to Rn: Design and assessment of accuracy. Physical Chemistry Chemical Physics 2005, 7, (18), 3297-3305.

39. Grimme, S.; Ehrlich, S.; Goerigk, L., Effect of the damping function in dispersion corrected density functional theory. Journal of Computational Chemistry 2011, 32, (7), 1456-1465.

40. Neese, F., The ORCA program system. Wiley Interdisciplinary Reviews: Computational Molecular Science 2012, 2, (1), 73-78.

41. Marenich, A. V.; Cramer, C. J.; Truhlar, D. G., Universal solvation model based on solute electron density and on a continuum model of the solvent defined by the bulk dielectric constant and atomic surface tensions. The Journal of Physical Chemistry B 2009, 113, (18), 6378-6396.

42. Alecu, I.; Zheng, J.; Zhao, Y.; Truhlar, D. G., Computational thermochemistry: scale factor databases and scale factors for vibrational frequencies obtained from electronic model chemistries. Journal of Chemical Theory and Computation 2010, 6, (9), 2872-2887.

43. Fouegue, A. D. T.; Mama, D. B.; Ghogomu, J. N.; Elie, Y.; Etoh, M.-A., The Substitution Effect on Reaction Enthalpies of Antioxidant Mechanisms of Juglone and Its Derivatives in Gas and Solution Phase: DFT Study. Journal of Chemistry 2018, 2018.

44. Marković, Z.; Tošović, J.; Milenković, D.; Marković, S., Revisiting the solvation enthalpies and free energies of the proton and electron in various solvents. Computational and Theoretical Chemistry 2016, 1077, 11-17.

45. Lu, T.; Chen, F., Multiwfn: a multifunctional wavefunction analyzer. Journal of Computational Chemistry 2012, 33, (5), 580-592.

46. Humphrey, W.; Dalke, A.; Schulten, K., VMD: visual molecular dynamics. Journal of molecular graphics 1996, 14, (1), 33-38.

47. Simulating UV-Vis and ECD spectra using ORCA and Multiwfn. http://sobereva.com/485 
48. Heijnen, C. G.; Haenen, G. R.; Vekemans, J. A.; Bast, A., Peroxynitrite scavenging of flavonoids: structure activity relationship. Environmental Toxicology and Pharmacology 2001, 10, (4), 199-206. 


\section{Supplementary Materials}

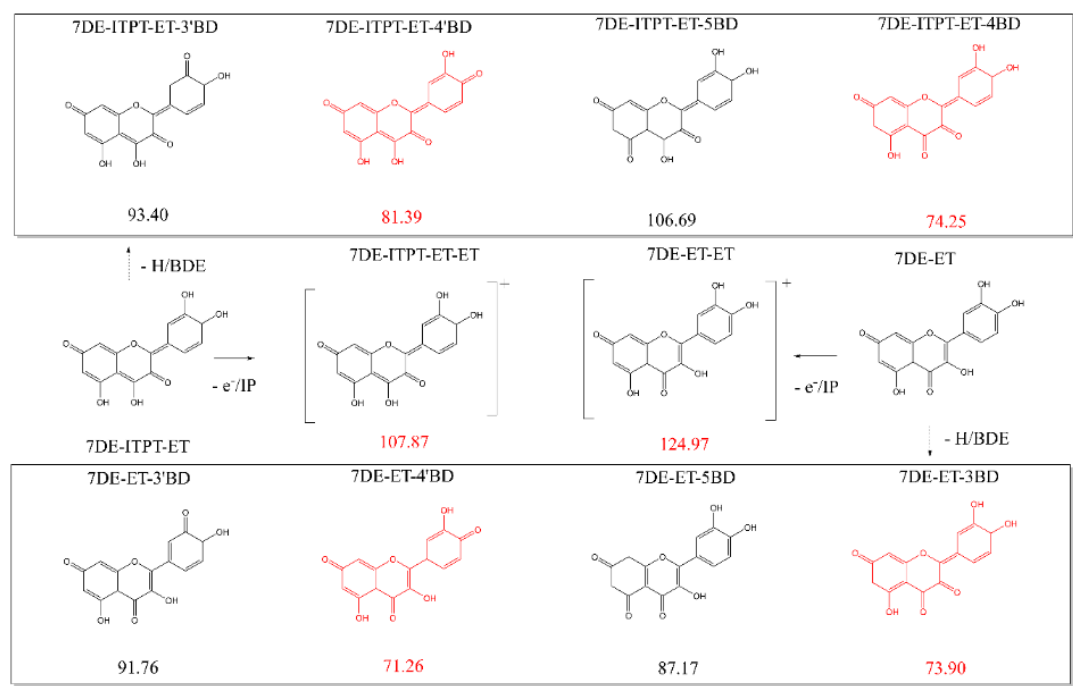

Figure SI 1: The products formed out of 7DE-ITPT-ET radical or 7DE-ET radical by hydrogen atom transfer, electron transfer; and the BDE or IP enthalpies (in Kcal/mol) for the formation of these products. Of the BDE, IP, and PA values (Figure 5) of the radicals, the PA values are significantly lower than other two, indicating that molecular mechanism of the antioxidant activity of the Q radicals also is a SPLET mechanism. 
Table SI 1: The dihedral angle of C2-C3-C1'-C2'(B ring and $\mathrm{C}$ ring) of some compounds

\begin{tabular}{ll}
\hline & \\
Compounds & Angle \\
\hline Quercetin & 28.3 \\
7DE & 29.1 \\
7DE-ET & 27.6 \\
7DE-ITPT & 0.1 \\
7DE-ITPT-ET & 3.7 \\
7DE-ET-3DE/7DE-ITPI-ET-4DE & 0.03 \\
7DE-ET-4'DE & 17.09 \\
7DE-ITPI-ET-4'DE & 0.001 \\
7DE-ET-3DE-ET/7DE-ITPI-ET-4DE-ET & $8.27^{*}$ \\
7DE-ET-4'DE-ET & 3.93 \\
7DE-ITPI-ET-4'DE-ET & 2.03 \\
\hline
\end{tabular}

*: The $\mathrm{C} 3$ and $\mathrm{O} 3$ are not in the planarity with $\mathrm{A}$ ring.

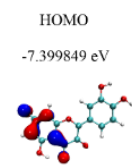

$3.767350 \mathrm{eV}$

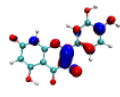

$-3.632499 \mathrm{eV}$

LUMO

7DE-ITPT-ET-4DE-ET /7DE-ET-3DE-ET

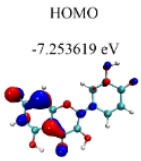

$3.163044 \mathrm{eV}$

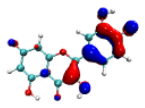

$-4.090575 \mathrm{eV}$

LUMO

7DE-ET-4'DE-ET

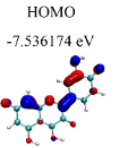

$4.133482 \mathrm{eV}$

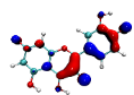

$-3.402691 \mathrm{eV}$

LUMO

7DE-TTPT-ET-4'DE-ET

Figure SI 2: The HOMO-LUMO gap of three selected QQ. The HOMO-LUMO gap of 7DE-ET-4'DE-ET and 7DEITPT-ET-4DE-ET/7DE-ET-3DE-ET are $3.163044 \mathrm{eV}$ and $3.767350 \mathrm{eV}$, reflecting that the 7DE-ET-4'DE-ET and 7DE-ITPT-ET-4DE-ET/7DE-ET-3DE-ET are unstable comparing with 7DE-ITPT-ET-4'DE-ET which the gap is $4.133482 \mathrm{eV}$. 

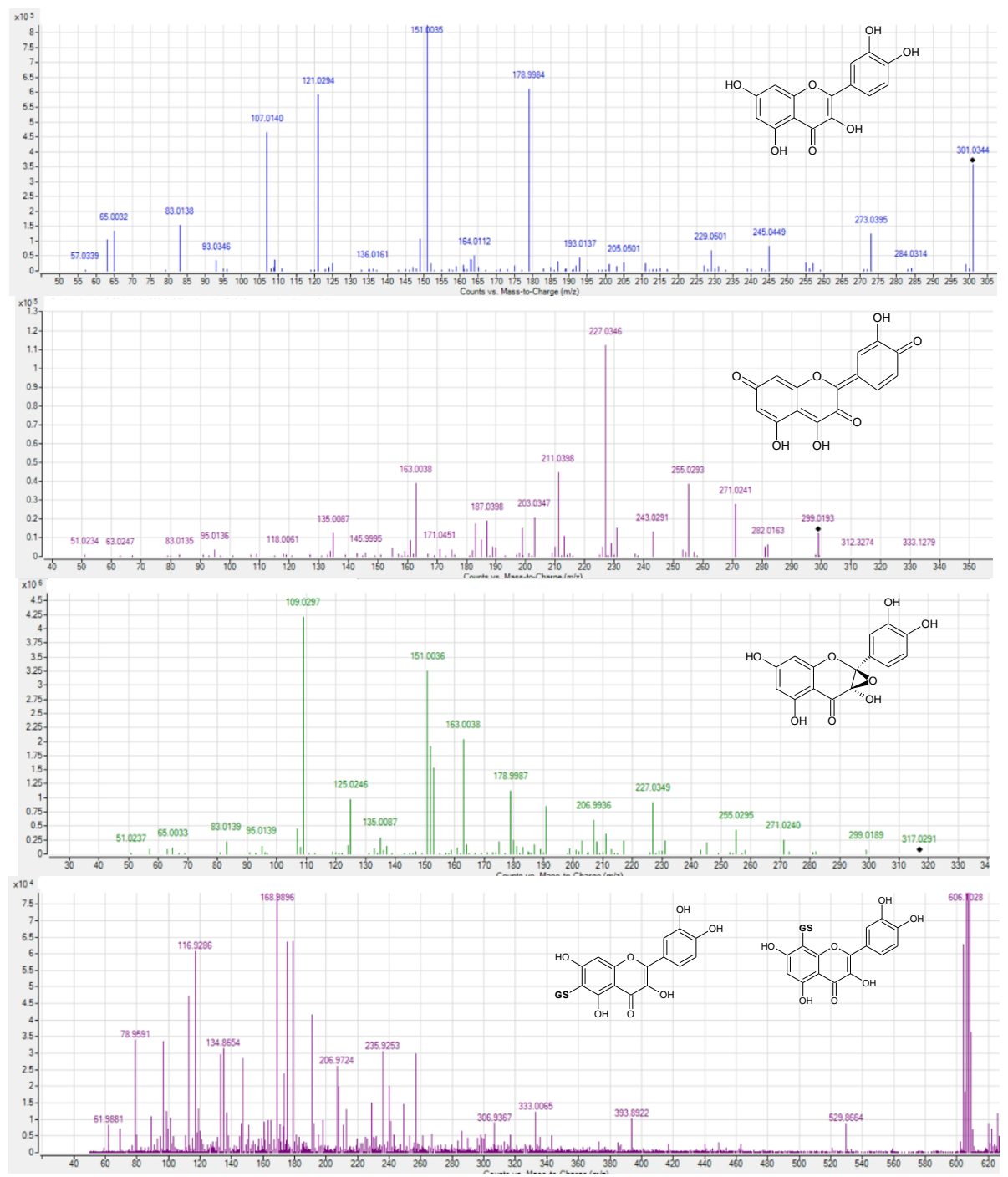

Figure SI 3: LC/MS-MS spectra of quercetin (A), quercetin quinone (B), quercetin-water (C) and quercetin-GSH (D) with their relative proposed fragmentations formed during the oxidation of Q in the absence (A, B, C) or presence (D) of GSH. To get direct evidence for the formation of QQ and other oxidized products of Q during the oxidation of Q, Q was oxidized by tyrosinase. To a $50 \mu \mathrm{M}$ Q solution in a $100 \mathrm{mM}$ ammonium bicarbonate, $\mathrm{pH} 7.4 ., 37^{\circ} \mathrm{C}$, $25 \mathrm{U} / \mathrm{mL}$ tyrosinase was added to start the oxidation, in a procedure described previously[1]. Q yielded fragment ions at $151.0 \mathrm{~m} / \mathrm{z}, 121.0 \mathrm{~m} / \mathrm{z}$ and $180.0 \mathrm{~m} / \mathrm{z}$. The protonated and fragmented ions of QQ are at $227.0 \mathrm{~m} / \mathrm{z}$ and 211.0 $\mathrm{m} / \mathrm{z}$. To our knowledge this is the first time that direct evidence for the formation of QQ is produced. The product of QQ with water has fragments at $198.0 \mathrm{~m} / \mathrm{z}, 151.0 \mathrm{~m} / \mathrm{z}$ and $163.0 \mathrm{~m} / \mathrm{z}$. This confirms that QQ readily reacts with water. In a parallel incubation, $100 \mu \mathrm{M}$ GSH was added to the Q solution before starting the oxidation. The incubation mixtures were analyzed with UHPLC-Q-TOF/MS. In the presence of GSH, the characteristic fragment ions of GSQ are $169.0 \mathrm{~m} / \mathrm{z}$ and $117.0 \mathrm{~m} / \mathrm{z}$ were found. As concluded previously [1], Q is first oxidized to QQ, and subsequently QQ reacts with GSH to form the GS-Q adducts. Until now, this was the only indirect evidence for the formation of QQ during the oxidation of Q. 


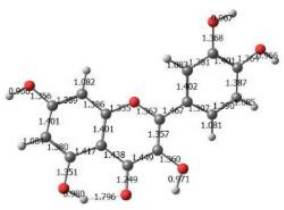

QCT

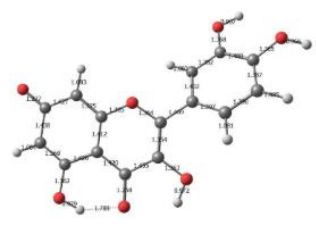

7DE

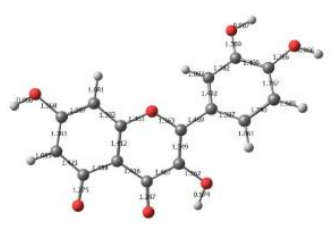

5DE

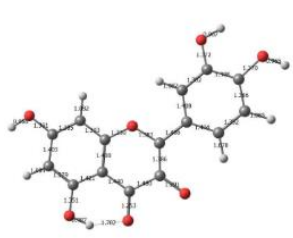

3DE

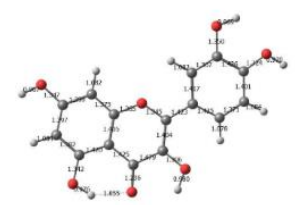

Q Radical

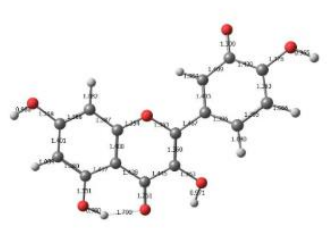

3'DE

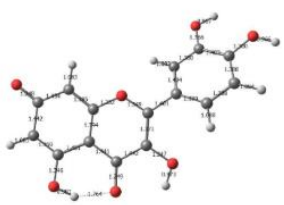

7HAT

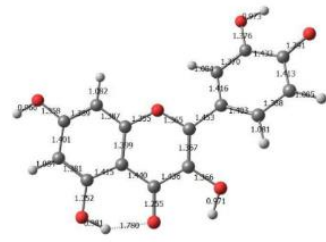

4'DE

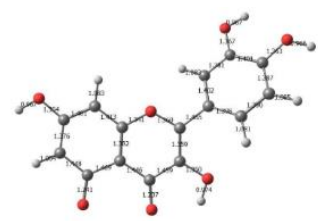

5HAT

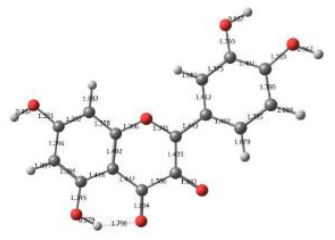

3HAT

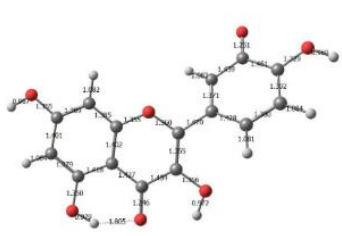

3'HAT

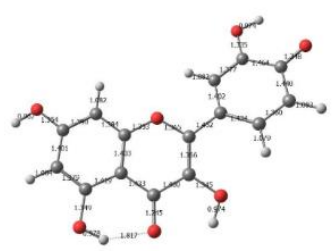

4'HAT 


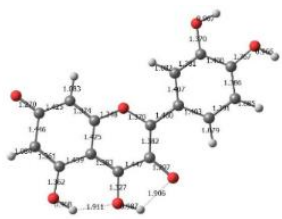

7DE-ITPT

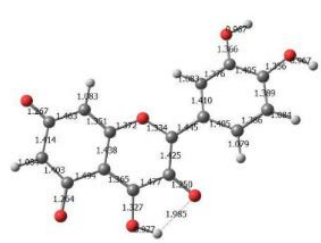

7DE-ITPT-ET-5DE

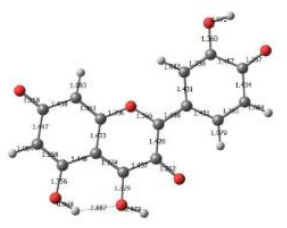

7DE-ITPT-ET-4'DE

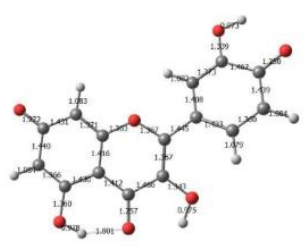

7DE-ET-4'DE

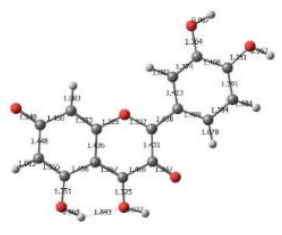

7DE-ITPT-ET

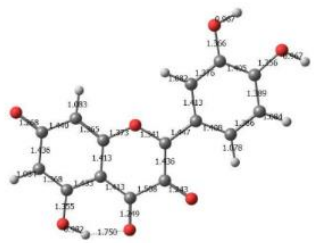

7DE-ITPT-ET-4DE OR 7DE-ET-3DE

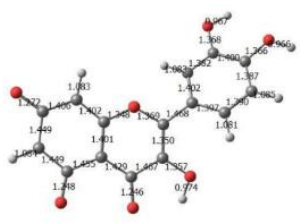

7DE-ET-5DE

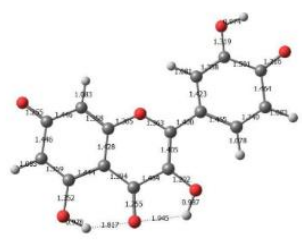

7DE-ET-4'DE-ET1

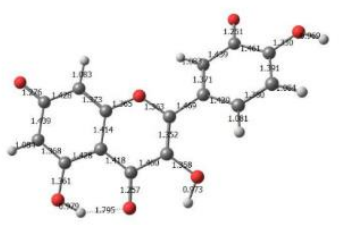

7DE-ET-3'DE

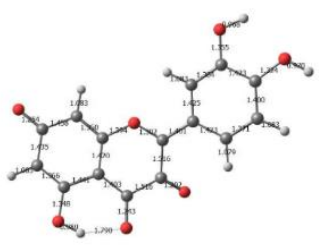

7DE-ITPT-ET-4DE-ETOR 7DE-ET-3DE-ET

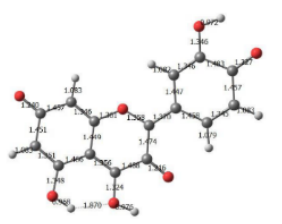

7DE-ITPT-ET-4'DE-ET

Figure SI 4: The structures of compounds investigated in the manuscript. 


\section{References}

1. Boots, A. W.; Kubben, N.; Haenen, G. R.; Bast, A., Oxidized quercetin reacts with thiols rather than with ascorbate: implication for quercetin supplementation. Biochemical and biophysical research communications 2003, 308, (3), 560-565. 



\section{Chapter 5}

\section{The antioxidant activity of 'simple' phenolic compounds towards peroxynitrite, refining the structure activity relationship}

Zhengwen Li ${ }^{1}$, Mohamed Moalin ${ }^{1,2}$, Ming Zhang ${ }^{1}$, Lily Vervoort ${ }^{1}$ and Guido R.M.M. Haenen ${ }^{1}$

1 Department of Pharmacology and Toxicology, Faculty of Health, Medicine and Life Sciences, Maastricht University, P.O. Box 616, 6200 MD Maastricht, The Netherlands

2 Research Centre Material Sciences, Zuyd University of Applied Sciences, 6419 DJ Heerlen, The Netherlands 


\begin{abstract}
The structure activity relationship of the antioxidant activity of a series of 'simple' phenolic compounds was re-examined. Understanding the mechanisms of the antioxidant activity of these 'simple' phenolic compounds will form the fundament to the understanding of the mechanism of more complex phenolic antioxidants, such as quercetin. Ultimately, this will help to unveil the biological profile of these compounds, so we will be able to select the 'right' antioxidant to protect against the uniquely deranged energy flow involved in a specific pathology.
\end{abstract}

The use of the new perspective provided by quantum chemical calculation revealed that even within the group of structurally closely related compounds studied, different molecular mechanisms are involved in the antioxidant activity. Because of a fundamental difference in the activity in the series of compounds, no relationship between the activity and the molecular structure can be made that incorporates all of these compounds. First the compounds that have the same molecular mechanism need to be grouped. Within each group, a SAR might be constructed. As shown in the present study, one of the Fukui Functions, i.e. f-, can be used to classify the type of reaction process, and to determine to what group a compound belongs.

Our study indicates that we need to further investigate the SAR of the simple phenolic compounds, before we can start building a SAR that includes more complex poly-phenolic compounds such as the flavonoids.

Keywords: Antioxidant; phenolic compounds; DFT calculation; f- 


\section{Introduction}

In all organisms, opposing forces create the energy that flows through a network which fuels life[1]. In aerobic organisms, redox energy is the main chemical energy source. However, part of this energy flow is uncontrolled; it gives rise to reactive oxygen and nitrogen species[2-5]. It is widely accepted that a deranged energy flow is pivotal in the etiology of numerous pathologies. Antioxidants can protect against this uncontrolled energy, and thus protect against these pathologies.

An important group of antioxidants is formed by phenolic compounds, such as vitamin $\mathrm{E}$, quercetin and (-)-epicatechin. Despite extensive research, the exact molecular mechanism of their protective effect is still enigmatic. New approaches, such as quantum chemical evaluation of the antioxidant process, open new perspectives that can help to have a more accurate look on the mechanisms, which helps to better understand their activity.

The aim of the present study is to reevaluate the SAR of the peroxynitrite scavenging of phenolic antioxidants from this new perspective. We have chosen a series of relatively simple phenols, that have only one aromatic ring. As reported previously, even within this group there are striking differences between the antioxidant activity of compounds that only have a relatively small difference in chemical structure. One example is the difference in activity of 2,4-dihydroxy acetophenone and 2,6-dihydroxy acetophenone, which is not fully understood. The three theoretical pathways for the molecular mechanism of phenolic antioxidants are hydrogen atom transfer (HAT), single electron transfer followed by proton transfer (SETPT), and sequential proton loss electron transfer (SPLET). The descriptors characterizing the enthalpy of the first step of each of these three mechanisms will be calculated. These are the homolytic bond dissociation enthalpy (BDE) for HAT, the ionization potential (IP) for SET$\mathrm{PT}$, and the proton affinity (PA) for SPLET[6-9].

Understanding the mechanisms of the antioxidant activity of these 'simple' phenolic compounds will form the fundament to the understanding of the mechanism of more complex phenolic antioxidants, such as quercetin. Ultimately, this will help to unveil the biological activity of these compounds, so we will be able to select the 'right' antioxidant to protect against the uniquely deranged energy flow involved a specific pathology.

\section{Results}

Phenolic compounds are potent antioxidants because they efficiently scavenging reactive oxygen and nitrogen species. It is widely accepted that in general the more aromatic hydroxyl groups a phenolic compound has, the better its scavenging activity is. This is also evidenced in our study by the observed increase in activity going from phenol (15), resorcinol (20) to phloroglucinol (24) with respectively 1, 2 and 3 aromatic hydroxyl groups (Table 1 and Table 2). However, compound $\mathbf{2 1}$ with two aromatic hydroxyl groups is less active than compound 16 with only one hydroxyl group. In addition, the compounds 21 and 22 with identical substituents but at a different position, have a big difference in activity. Apparently, not only the number of aromatic hydroxyl groups is important for the activity, it is more complicated. In order to systematically reevaluate the antioxidant activity of phenolic compounds, we have chosen a bottom-up approach; starting with mono-phenolic compounds, followed by diphenolic and tri-phenolic compounds. 


\section{Mono-phenolic compounds}

In our bottom-up approach; we start with the mono-phenolic compounds. Of the monophenolic compounds, the experimental $\mathrm{IC}_{50}$, the calculated enthalpies with different mechanisms, and the VIP under various conditions are presented in Table 1. The experimental $\mathrm{IC}_{50}$ was obtained in a competition assay. It did not discriminate between poor antioxidants with an $\mathrm{IC}_{50}$ above $1000 \mu \mathrm{M}$. Moreover, in competition assays very potent scavengers have similar low $\mathrm{IC}_{50}$ values, since they far outcompete the reference compound, which in the case of peroxynitrite scavenging is 123 rhodamine. Moreover, it should be taken in consideration that the antioxidant activity is determined at a physiological $\mathrm{pH}$ of 7.4 , and at that $\mathrm{pH}$ the $\mathrm{COOH}$ moiety of compounds such as 2-hydroxycinnamic acid, vanillic acid, and ferulic acid, is deprotonated. Thus, the enthalpies of the anion of these compounds is calculated. In the other cases the fully protonated form is used. The pKa listed in table 1 is the $\mathrm{pKa}$ of the most acidic $\mathrm{OH}$ group on the aromatic ring. 
Table 1: Experimental and some theoretical indicators of antioxidative activity of the investigated molecules: BDE, (PA + ETE), and (DIP+PDE) stand for thermodynamic descriptors.

\begin{tabular}{|c|c|c|c|c|c|c|c|c|c|c|c|c|}
\hline \multirow[t]{2}{*}{ Selected Phenolic (1 OH) } & \multirow{2}{*}{$\begin{array}{c}\text { HAT(Kcal/ } \\
\text { mol }) \\
\text { BDE }(\mathrm{H})\end{array}$} & \multicolumn{3}{|c|}{$\operatorname{SPLET}(\mathrm{Kcal} / \mathrm{mol})$} & \multirow[t]{2}{*}{ VIP1 } & \multirow[t]{2}{*}{ VIP2 } & \multirow[t]{2}{*}{ VIP3 } & \multirow[t]{2}{*}{$\mathrm{pKa}$} & \multicolumn{3}{|c|}{ SET-PT(Kcal/mol) } & \multirow[t]{2}{*}{$\mathrm{IC}_{50}(\mu \mathrm{M})$} \\
\hline & & PA & ETE & Total & & & & & DIP4 & PDE & Total & \\
\hline 1 2-Hydroxycinnamic acid & 85.13 & 36.84 & 92.44 & 129.28 & 5.8141 & 5.47 & 4.1067 & 9.6 & 120.21 & 9.07 & 129.28 & 27.7 \\
\hline 2 3-Hydroxycinnamic acid & 88.2 & 38.13 & 94.22 & 132.36 & 5.9181 & 5.63 & 4.1673 & 10.39 & 126.74 & 5.62 & 132.36 & $1000.00 \mathrm{a}$ \\
\hline 3 4-Hydroxycinnamic acid & 83.86 & 36.47 & 91.54 & 128.02 & 5.6788 & 5.33 & 4.0629 & 9.9 & 116.15 & 11.87 & 128.02 & 8.3 \\
\hline 4 2-Hydroxybenzoic acid & 97.52 & 49.85 & 91.82 & 141.68 & 6.0981 & 5.6 & 4.1134 & 13.2 & 111.5 & 30.18 & 141.68 & 1000 \\
\hline 5 3-Hydroxybenzoic acid & 87.41 & 38.97 & 92.36 & 131.33 & 6.0842 & 5.75 & 4.0729 & 9.6 & 122.85 & 8.48 & 131.33 & 1000 \\
\hline 6 4-Hydroxybenzoic acid & 90.94 & 41.76 & 93.32 & 135.09 & 6.1646 & 5.73 & 4.0967 & 9.98 & 123.74 & 11.35 & 135.09 & 1000 \\
\hline 7 2-Methoxyphenol & 82.57 & 38.82 & 87.89 & 126.72 & 5.4869 & 5.49 & 3.9702 & 9.98 & 116.42 & 10.3 & 126.72 & 12.6 \\
\hline 8 3-Methoxyphenol & 88.47 & 37.75 & 94.87 & 132.62 & 5.6566 & 5.66 & 4.1922 & 9.65 & 121.64 & 10.98 & 132.62 & 24.7 \\
\hline 9 4-Methoxyphenol & 80.32 & 39.66 & 84.81 & 124.47 & 5.3084 & 5.3 & 3.8622 & 10.21 & 111.87 & 12.6 & 124.47 & 6.66 \\
\hline 10 Vanillic acid & 82.9 & 37.55 & 89.49 & 127.05 & 5.7847 & 5.41 & 3.9643 & 8.96 & 115.49 & 11.56 & 127.05 & 7.54 \\
\hline 11 Ferulic acid & 85.13 & 38.85 & 90.43 & 129.29 & 5.6617 & 5.19 & 4.0927 & 8.65 & 113.18 & 16.11 & 129.29 & 1.41 \\
\hline 12 Eugenol & 81.2 & 39.22 & 86.13 & 125.35 & 5.4005 & 5.4 & 3.9104 & 9.97 & 114.06 & 11.29 & 125.35 & 4.88 \\
\hline $13 \mathrm{BHT}$ & 77.69 & 41.82 & 80.02 & 121.85 & 5.44 & 5.44 & 3.8386 & 12.5 & 114.91 & 6.94 & 121.85 & 72.4 \\
\hline 14 Tyrosine & 84.46 & 39.48 & 89.12 & 128.61 & 5.6334 & 5.39 & 3.9737 & 10.07 & 108.68 & 19.93 & 128.61 & 162 \\
\hline 15 Phenol & 87.26 & 38 & 93.41 & 131.42 & 5.8463 & 5.84 & 4.1418 & 9.99 & 124.72 & 6.7 & 131.42 & 552 \\
\hline 16 2-Hydroxyacetophenone & 95.04 & 40.67 & 98.52 & 139.19 & 6.033 & 6.03 & 4.5493 & 10.3 & 128 & 11.19 & 139.19 & 1000 \\
\hline $\begin{array}{l}17 \text { 2-Hydroxy-6- } \\
\text { methoxyacetophenone }\end{array}$ & 93.86 & 42.23 & 95.78 & 138.02 & 5.7287 & 5.74 & 4.5053 & 9.79 & 121.8 & 16.22 & 138.02 & 1000 \\
\hline
\end{tabular}

1: vertical ionization potential, represent the energy difference after one electron loss (The structure has not relaxed). 1,2,3 represented the VIP (eV) of fully protonated form, parts of deprotonated forms (for acids), and the SPLET. 4: The diabetic ionization potential enthalpy where the relaxation of the structure has been considered. 
It was found that the $\mathrm{pKa}$ value of the monophenolic compounds is not related to their radical scavenging activity. First of all, the relatively low $\mathrm{pKa}$ of the $\mathrm{COOH}$ group does not result in a potent scavenging activity. For example, 2-hydroxybenzoic acid (4) with a relatively high $\mathrm{pKa}$ of its $\mathrm{COOH}$ group of around 4.5 , is a poor scavenger ( $\mathrm{IC}_{50}$ is over 1000 $\mu \mathrm{M})$. The $\mathrm{pKa}$ of $\mathrm{OH}$ group on the aromatic ring also has a bad correlation with the $\mathrm{IC}_{50}$. For example, the pKa of BHT (13) is 12.5 which is higher than the pKa of phenol (15) of 9.99, while the scavenging activity of BHT (13) is much higher than that of phenol (15) (IC 50 of respectively $72.4 \mu \mathrm{M}$ and $552 \mu \mathrm{M}$ ). This indicates that the pKa is not a good descriptor for the SAR.

The calculations revealed that the total enthalpies requirements of SPLET and SET-PT are equal, and both were higher than the total enthalpies requirements of HAT. The BDE, the descriptor for the HAT mechanism, correlates with the antioxidant activities of several phenolic compounds such as for 2-hydroxycinnamic acid (1) where the BDE value is 85.13 and $\mathrm{IC}_{50}$ is $27.7 \mu \mathrm{M}$, while for 3-hydroxycinnamic acid (2) where the BDE is $88.2 \mu \mathrm{M}$ and with the $\mathrm{IC}_{50}$ of over $1000 \mu \mathrm{M}$. As expected, a lower enthalpy change is correlated with a relatively better radical scavenging activity.

However, the correlation is relatively poor, and the rule that a lower the BDE is reflected by a lower $\mathrm{IC}_{50}$ does not apply for all of the phenolic compounds: This can be exemplified by the BDE of ferulic acid (11) of 85.13 that is higher than that of BHT (13) of 77.69, while the $\mathrm{IC}_{50}$ is $1.41 \mu \mathrm{M}$ and $72.4 \mu \mathrm{M}$, respectively. Apparently, even in our series of simple monophenols, there are exceptions to the rule. This also applies to the SPLET and SET-PT mechanism where the total enthalpy needed for vanillic acid (10) to donate its electron and proton of 127.05 is lower than that of ferulic acid (11) with the value of 129.29 , while the peroxynitrite scavenging ability is of vanilic acid (10) is lower than that of ferulic acid (11).

The most probable explanation for the poor correlation is that even in our series of simple phenolic compounds the scavenging proceeds by different mechanisms. For each mechanism, the SAR will be different. So, to refine the relationship between the structure and the activity, the compounds that have the same mechanisms should be first selected, and within this group the SAR for that specific mechanism can be constructed. We have determined the mechanism by the Fukui function $\mathrm{f}$-. 

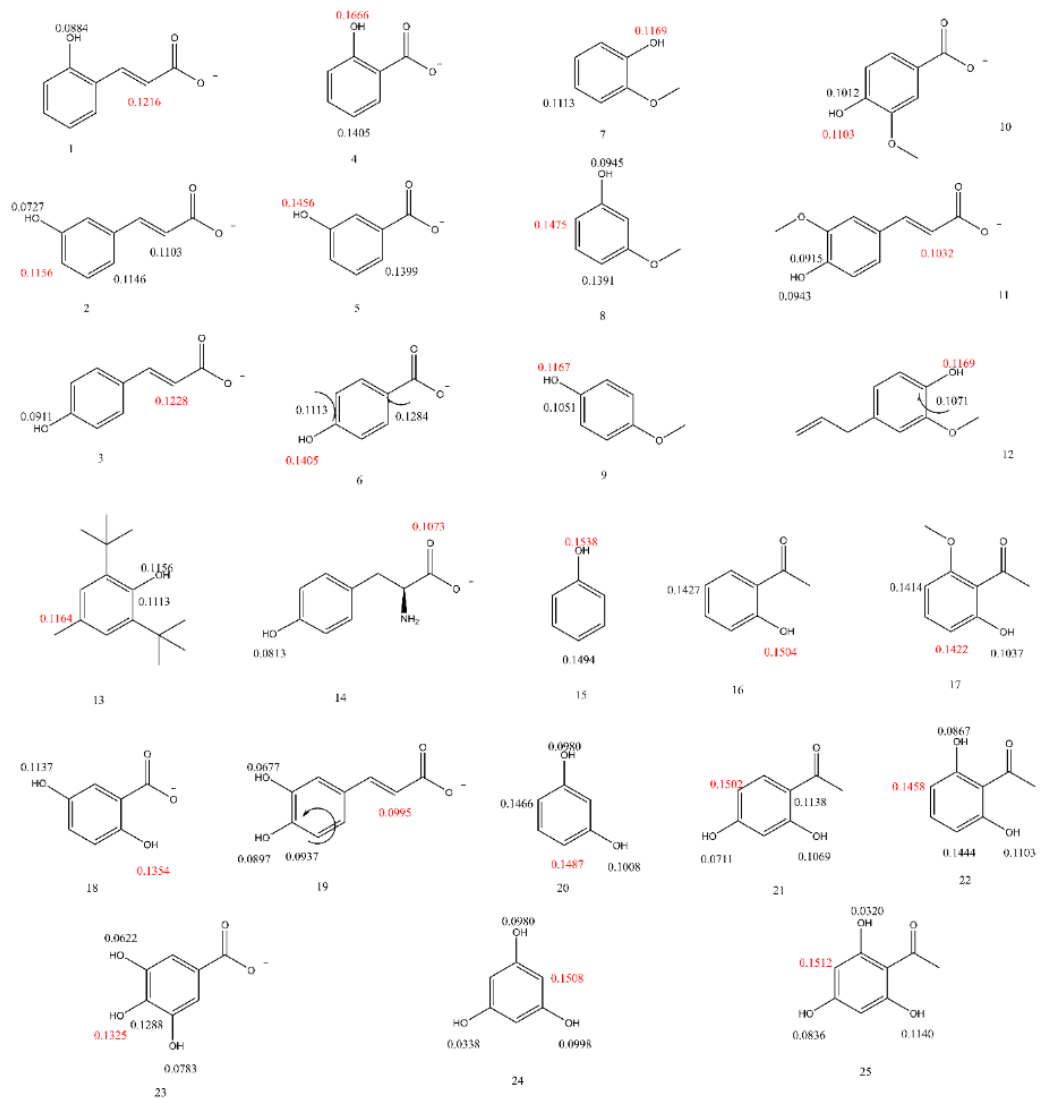

Fig 1. The condensed Fukui function f- of selected phenolic compounds. The highest possibility to lose their electron has been marked in red.

The condensed Fukui function $\mathrm{f}$ - gives the ionization potential of the atoms in a molecule; the higher the f- value of an atom, the higher possibility to lose an electron on that atom. According to the f-, it was found that the location where the electron is released by the monophenolic compounds is diverse. The type and position of substituents apparently significant influence the electron releasing behavior of the atoms. For example, due to the location of the propenoic acid side chain at the meta position, 3-hydroxycinnamic acid (2) most probably donates its electron at the aromatic ring, while location of the same side chain at the ortho or para position makes that electron is most probably donated at the carbon-carbon double bond in the side chain of 2-hydroxycinnamic acid (1) and 4-hydroxycinnamic acid (3). This might also be part of explanation that the peroxynitrite scavenging activity of the meta substituted 3-Hydroxycinnamic acid is less than that of ortho or para substituted hydroxycinnamic acid (1 and 3). The f- reveals that of all the mono-phenolic compounds (1-17), in compounds 4, $5,6,7,9,10,12,15$, and 16 most probably to donate their electrons from the oxygen of the 
aromatic hydroxyl group. These compounds will favor the HAT mechanism. The other compounds will favor a SPLET or SET-PT mechanism.

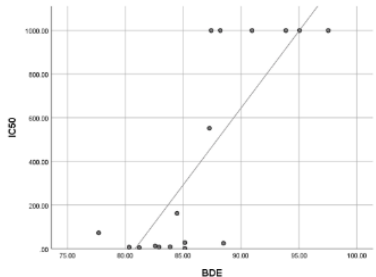

A

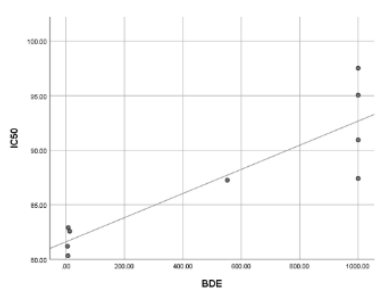

C

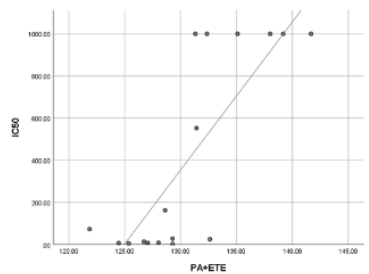

B

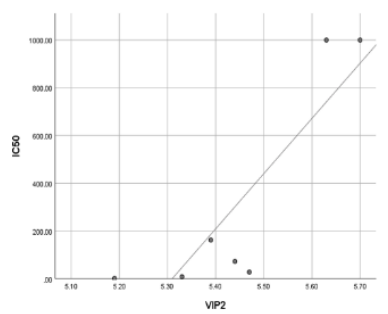

D

Fig 2. The Correlation between the BDE (A) and PA+ETE (DIP+PDE) (B) of all substituted mono-phenolic compounds (1-17) with the $\mathrm{IC}_{50}$ towards the peroxynitrite, and Correlation between the BDE (C) and $\mathrm{VIP}_{2}$ (D) of the selected phenolic compounds based on the $\mathrm{f}$ - with $\mathrm{IC}_{50}$ towards the peroxynitrite, where the correlation are $\mathrm{r}=0.805, \mathrm{P}<0.01 ; \mathrm{r}=0.802, \mathrm{P}<0.001 ; \mathrm{r}=0.889, \mathrm{P}<0,001 ;$ and $\mathrm{r}=0.865, \mathrm{P}<0.012$, respectively.

In the investigated series of compounds, both the BDE correlated with the peroxynitrite scavenging activity of all mono-phenolic compounds, the correlation coefficient is 0.805 (Fig 2A). Only considering the compounds that favor the HAT mechanism significantly increases the correlation of BDE with $\mathrm{IC}_{50}$ to 0.889 (Fig 2C). The correlation of the activity with the BDE for the compounds $(\mathbf{1}, \mathbf{2}, \mathbf{3}, \mathbf{1 1}, \mathbf{1 3}, 14$ and 17) that were excluded was very poor (SI 1A, $\mathrm{r}=0.763, \mathrm{P}<0.046)$. This indicates that even in our series of 'simple' phenolic compounds classification of the compounds according to their mechanism is critical.

Since the ionization potential is dominant in the SET-PT/SPLET processes, we also examined the correlation of IP (DIP and VIP) with IC $_{50}$. It appears that the correlation of $\mathrm{VIP}_{2}$ with $\mathrm{IC}_{50}$ also increased after excluding the compounds that favor the HAT mechanism (compare Fig 2B with Fig 2D). Interesting is that for SET-PT/SPLET, the VIP2 might be a more suitable descriptor than the DIP (SI 1B, $\mathrm{r}=0.732, \mathrm{P}<0.061$ ). The correlation between VIP1(SI 1C) and VIP3 (SI 1D) with the IC $_{50}$ is relatively poor, indicating that these two descriptors are less relevant for the SAR of phenolic compounds. 
Table 2. Experimental and some theoretical indicators of antioxidative activity of investigated molecules

\begin{tabular}{|c|c|c|c|c|c|c|c|c|c|}
\hline Selected Phenolic (2/3 OH) & $\begin{array}{l}\text { HAT }(\mathrm{Kcal} / \mathrm{mol}) \\
\mathrm{BDE}(\mathrm{H})\end{array}$ & \multicolumn{3}{|c|}{ SPLET(Kcal/mol) } & \multicolumn{3}{|c|}{ SET-PT(Kcal/mol) } & $\mathrm{pKa}$ & $\mathrm{IC}_{50}$ \\
\hline 18 Gentistic acid & 78.58 & 41.02 & 81.72 & 122.74 & 103.35 & 19.39 & 122.74 & 10.1 & 1.25 \\
\hline 19 Caffeic acid & 78.51 & 32.05 & 90.62 & 122.67 & 114.43 & 8.24 & 122.67 & 7.6 & 1.13 \\
\hline 20 Resorcinol & 87.56 & 37.4 & 94.32 & 131.72 & 121.56 & 10.16 & 131.72 & 8.6 & 58 \\
\hline 21 2,4-Dihydroxyacetophenone & 92.81 & 32.16 & 104.8 & 136.96 & 127.83 & 9.13 & 136.96 & 7.42 & 1000 \\
\hline 22 2,6-Dihydroxyacetophenone & 85.82 & 32.14 & 97.84 & 129.98 & 121.9 & 8.08 & 129.98 & 7.94 & 7.8 \\
\hline 23 Gallic acid & 76.41 & 32.05 & 88.52 & 120.57 & 116.76 & 3.81 & 120.57 & 8.25 & 1.51 \\
\hline 24 Phloroglucinol & 88.22 & 37.06 & 95.32 & 132.38 & 122.63 & 9.75 & 132.38 & 7.95 & 39 \\
\hline 25 2,4,6-Trihydroxyacetophenone & 88.26 & 31.79 & 100.62 & 132.41 & 124.65 & 7.76 & 132.41 & 8.03 & 5.5 \\
\hline
\end{tabular}




\section{Di-phenolic and tri-phenolic compounds}

As also mentioned above, the presumption that the more aromatic hydroxyl groups result in a better scavenging activity, is not entirely correct. In this respect it is worth to mention that in the series phenol, resorcinol, phloroglucinol, the scavenging activity is not merely related to the number of aromatic hydroxyl groups; it also has to be considered that according to the $\mathrm{f}-$, the scavenging of resorcinol and phloroglucinol proceeds by different mechanisms.

The high pKa of 10.1 of the most acidic aromatic hydroxyl group of the potent peroxynitrite scavenger Gentistic acid (18) indicates that also in compounds with more than 1 aromatic hydroxyl groups the $\mathrm{pKa}$ is a poor descriptor for the activity.

In the series of phenolic compounds with an acetophenone side group $(\mathbf{7}, \mathbf{8 , 9}, \mathbf{1 0}, \mathbf{1 7}, \mathbf{1 8}$, 21 22, 23 and 25) the peroxynitrite scavenging proceeds by different mechanisms. Within this group, the big difference between 2,4-dihydroxyacetophenone (21) and 2,6dihydroxyacetophenone (22) drew our attention. This different $\mathrm{IC}_{50}$ is correlated to the DIP or ET E requirements with the values of 127.83 or 104.8 and 121.9 or 97.84 , respectively.

In addition, we have analyzed the spin density of the radicals of compounds $\mathbf{2 1 , 2 2}$ and $\mathbf{2 5}$. The results are shown in Fig 3.
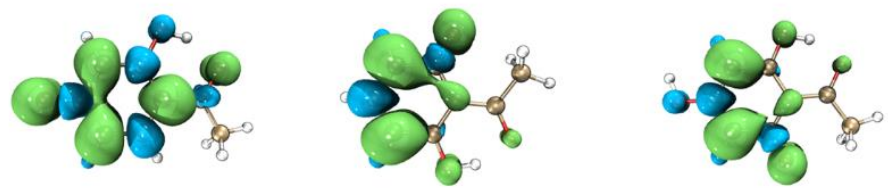

Fig 3. The spin density map shows that the unpaired electron is wildly delocalized in the 2,4-dihydroxyacetophenone (21) radical, while in the 2,6-dihydroxyacetophenone (22) radical and 2,4,6-trihydroxyacetophenone (25) the unpaired electron are concentrated. This suggests that the 2,6-dihydroxyacetophenone (22) and 2,4,6trihydroxyacetophenone (25) more easily donate a second electron, which increases their peroxynitrite scavenging activity.

The spin density map shows that comparing with compound 21, the delocalization of unpaired electron in compound $\mathbf{2 2}$ and compound $\mathbf{2 5}$ is much more concentrated in C8, C9, and O2. The relatively 'hard' delocalization gives these two compounds ( 22 and $\mathbf{2 5}$ ) a highly potential to donate a second electron, while for compound 21, the relatively 'soft' delocalization of unpaired electron leads to a stable radical which results in lower activity.

The pKa of the compounds $\mathbf{2 1 , 2 2}$ and $\mathbf{2 5}$ are 7.42, 7.94 and 8.03, respectively. This means that at a physiological $\mathrm{pH}$ of 7.4 (which is also the $\mathrm{pH}$ of the peroxynitrite scavenging assay) a substantial part of the compound is deprotonated. Therefore, also the deprotonated forms have been evaluated (Fig 4). 


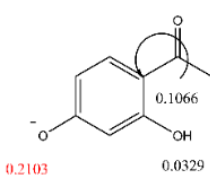

21

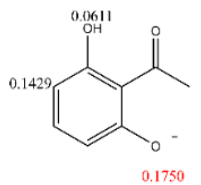

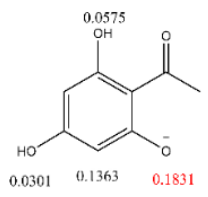

25

Fig 4. The condensed Fukui function f- of the deprotonated form of the compound 21, 22 and 25.

The results show that after deprotonated, the highest condensed $\mathrm{f}$ - on the oxygen of compounds 21, 22, and 25 are $0.2103,0.1750$, and 0.1831 , respectively. The interesting finding is that the location of the highest possibility to lose electrons has been changed from the carbons in the aromatic ring of their fully protonated forms to the deprotonated hydroxyl group of deprotonated forms. This indicts that the fully protonated forms and deprotonated forms scavenge peroxynitrite by different mechanisms. The former ones prefer the HAT and the later ones favor the SPLET mechanism.

\section{Discussion}

In studying the biological activity of compounds, the structure activity relationship (SAR) has gained a pivotal role. Linking the difference in activity to differences in the chemical structure of compounds gives clues for the interaction of the compounds with the biological system they are interacting with. The groups of both the compound and the biological target that are important for the activity can be identified, as well as the type of their interaction, and the consequence of this interaction on e.g. the conformation of the biotarget and the consequence of this. Ultimately, this may lead to the molecular mechanism of the activity of the compounds and an 'understanding' of the activity of the compounds. Moreover, the SAR gives clues for the design of more active compounds than the ones tested.

In fundamental research compounds that do not fit in the relationship are important, as these 'outliers' can be used to refine the SAR, or to 'discover' a new class of compounds with a new mode of action. This approach has been very successful for e.g. the development of drugs that act on a receptor, enzyme or other large biomolecules.

For radical scavenging, redox modulating compounds, the constructing of a SAR is more complex. This is because the 'biologically active compound' they react with is much more 'fluid' than e.g. the receptor of drugs. This means that the paradigm coined for traditional drugs that 'corpora non agit nisi fixata' (compounds do not have an effect unless they are bound) has to be adjusted for radical scavenging, redox modulating compounds. First of all, these compounds redirect energy, which cannot be visualized as done for receptors. Moreover, the intrinsic high energy of redox energy (that is much greater than the energies involved in e.g. receptor binding) makes that the interaction with the redox modulator can take place at several sites of the redox modulator. Finally, the energy present in the 'oxidized' redox modulator can still be relatively high, which might make the biological effect of the 'modulated energy' rather broad and unspecific.

The present explorative study on relatively 'simple' phenolic compounds is intended to provide the fundament to finally refine the SAR of the redox modulation of more complex phenolic compounds such as quercetin. 
The antioxidant activity of phenolic compounds together with quantum chemical descriptors have been extensively studied at diverse levels. Chen et al., investigate the structure-thermodynamics-antioxidant relationships of 20 natural phenolic acids and derivatives at the B3LYP/6-311++G(d,p) levels with experimental data, where they demonstrated that the HAT mechanism is more favorable in the gas phase and dissolved in benzene, and the SPLET mechanism is preferred in water and ethanol based on the correlation results of BDE and IP-PDE descriptors[10]. Not only BDE or IP enthalpy, other descriptor such as eHOMO, Hammett-Brown substituent's constants, Aromaticity indices have been added in SARs. Svetlana et al, found that a three-descriptor QSAR model including Aromaticity indices, intramolecular hydrogen bond and PA+ETE had the best correlation with the vitamin $C$ equivalent antioxidative capacity values in a series of 21 natural or synthetic phenolic compounds[11]. The Hammett Constant often shows a good correlation with the Hydrogen Atom Abstraction rate in para-Substituted Phenols, and where the abstraction rate relates to the BDE [12]. This indicate that Hammett constant is not a universal descriptor since a lot of phenolic compounds may undergoing SPLET mechanisms. In general, the more descriptors the more accurate a SAR model is. Although with Artificial neutral networks good correlations with several descriptors can be obtained, the models lack a solid chemical fundament. In addition, sometime a descriptor is unintentional reused. For example, the eHOMO reflected by VIP according to Koopmans-theorem, should not be used together with IP in the SPLET mechanisms. In these cases, Occam's razor should be skillfully applied, realizing that the simpler explanation is usually the better one.

In our study we examined the three mechanisms for the antioxidant activity of the phenolic compounds. The correlation of $\mathrm{IC}_{50}$ with BDE and PA+ETE (DIP+PDE) are 0.805, and 0.802, respectively, and fit nicely with the presumption that the lower the enthalpy change, the higher the antioxidant activity is [10]. However, the uneven distribution of the data in Table 1 , shows us that the antioxidant activity of the examined mono-phenolic compounds probably does not have the same molecular mechanism.

Three types of Fukui functions, namely f-, f0 and $\mathrm{f}+$ can be used to predict the reaction sites within a molecule; f- predicts the electrophilic attack, f0 predicts the radical attack, and $\mathrm{f}+$ predicts the nucleophilic attack[13]. It should be noted that in $\mathrm{f} 0$ the radical is considered to be amphoteric. It is used in radical adduct reactions, and no electron transfer process between the reactants incorporated. In fact, the correctness of this assumption is questioned, because electrons are always transferred during a radical attack [14]. During the radical scavenging process that we are examining, electron transfer does take place. This also takes place in the HAT or SPLET mechanisms, proposed for scavenging reactions. A study carried out by Sarkar et al.[15], revealed that the group electrophilic frontier electron density is a good descriptor for the radical scavenging mechanism of flavonoids, confirming the importance of the electrophilic properties of the atoms. Based on this finding, we selected the condensed f- to map the electrophilic character of the molecule. The higher value of $f$ - of an atom in the phenolic compound, the higher chance that an electron is donated from that atom.

As illustrated in figure 1, the discrepancy between the BDE and measured peroxynitrite scavenging activity of ferulic acid (11) and BHT (13), can perfectly be explained by their fvalues. Based on it, it can be deduced that ferulic acid (11) and BHT (13) prefer the 
SPLET/SET-PT mechanisms rather than the HAT. In this case, BDE is not appropriate for reflecting the antioxidant process of these two compounds. Also, according to their calculated $\mathrm{VIP}_{2}$, the enthalpy for the peroxynitrite scavenging by ferulic acid (11) is lower than that of BHT (13), which is in line with lower $\mathrm{IC}_{50}$ of ferulic acid (13).

Apparently, ferulic acid (11) and BHT (13) do not scavenge peroxynitrite by the same reaction mechanisms. Taking full deprotonation of the $\mathrm{COOH}$ moiety at $\mathrm{pH} 7.4$ into account (based on its pKa), ferulic acid (11) takes the SPLET pathway while BHT (13) is more likely taken the SET-PT pathway. Based on our results, compound 4, 5, 6 and 10 also follow the SPLHAT pathway, as has been reported previously[16]. In order to reduce the complexity of the calculation, we have ignored the deprotonation and focused on the BDE. This makes sense because deprotonation takes place before the actual radical scavenging, and the deprotonation step makes no part of the actual antioxidant process. However, this does not mean that the deprotonation is not important. In fact, deprotonation greatly affects the radical scavenging activity. For example, at a low $\mathrm{pH}$ where none of the quercetin is deprotonated, quercetin hardly displays antioxidant activity[17]. Moreover, deprotonation is expected to change the reaction process of compounds 21, 22 and 25. According to the f-, the most probable location for electron donation changes from the carbon of the aromatic ring of the fully protonated form, to the oxygen of the deprotonated form (Fig. 1 and Fig. 4). Similarly, the VIP is not combined with deprotonation. That the correlation significantly increased after grouping the compounds based on the classification, confirmed that $\mathrm{f}$ - is suited to identify the reaction mechanisms. However, we have to keep in mind that the improvement of the correlation is partly due to the decreased of the number of data.

It is also worthy to mention that for constructing SARs, VIP is often used. In a study carried out by Mauro Reis et al. on the redox potential of 41 phenolic compounds, a significant correlation with the VIP was reported[18]. In a review by Petko Alov et al., the adiabatic IP was found to give a higher correlation with the antioxidant activities of Vitamin $\mathrm{E}$ and it's analogs, than the VIP[19-21]. In our study, we found that VIP2 more accurately correlates with the antioxidant activity than DIP, which suggests that in a qualitative analysis, the relaxation effect of molecules caused by electron rearrangement might not always be correctly modeled.

As already mentioned, the use of the number of aromatic hydroxyl groups as the main descriptor of the antioxidant activities of phenolic compounds [22] has been rejected. This is evidenced in various studies, e.g. the DFT study presented by Milos Filipovic et al[23], in which the BDE of protocatechuic acid ( with 2 aromatic $\mathrm{OH}$ groups) surpasses that of Syringic acid (with 1 aromatic $\mathrm{OH}$ group), while the vitamin $\mathrm{C}$ equivalent antioxidant capacity of protocatechuic is of higher than that of Syringic acid. Also, the position of the $\mathrm{OH}$ groups matter, which is clearly seen with compound $\mathbf{2 1}$ and $\mathbf{2 2}$. The difference is the para or ortho position of the $\mathrm{OH}$ groups. The antioxidant activities of these two are very different. From the energy perspective, the DIP of compound 21 (127.83) is higher than that of compound 22 (121.9). According to their f-, the fully protonated forms of these two are likely undergoing SET-PT mechanisms. The higher DIP indicates that compound 21 has a higher activation energy in its radical scavenging reaction. Moreover, the delocalization of the unpaired electron radical form is of importance as well. This is because the radical form is often a better scavenger than the parent antioxidant, although this is not often incorporated in evaluating the antioxidant activity. For compounds with two or more hydroxyl groups, the 
more concentrated the unpaired electron, the better the antioxidant activity of the radical form is. This is because a higher electron polarity increases the chance of the radical form of the antioxidant to donate an electron to the (second) radical it scavenges. This had been addressed in our previously manuscript in which we found that for the radical forms of the flavonoids kaempferol, quercetin and myricetin, the more concentrated the unpaired electron in the B ring is, the better the antioxidant activity is[24]. We applied this on compound $\mathbf{2 5}$, and according to its spin density map, the unpaired electron in the radical form of $\mathbf{2 5}$ is of concentrated.

The impact of the intramolecular hydrogen bridges also needs to be addressed. The presence of intramolecular hydrogen bridges in phenolic compounds reduces the antioxidant activity. This can be ascribed to the higher energy requirement of the hydrogen abstraction [25]. This is seen in the present study by comparing compound 7, with a BDE of 82.57 , and compound 9, with a BDE of 80.32. The intramolecular hydrogen bridge enhanced the stability of the compound $\mathbf{7}$, leading a relatively lower antioxidant activity compared to that of compound 9. In addition, it appears that the strength of an intramolecular hydrogen bridge, which depends on the electrostatic effects of the hydrogen binding acceptor, should also be considered. For compound 4, the hydrogen bridge acceptor is the $\mathrm{COO}^{-}$group. The electrons in this group are more concentrated compared to that of $\mathrm{OCH}_{3}$ hydrogen bridge acceptor group of compound 7. This difference is involved in the lower antioxidant activity of compound 4 compared to that of compound 7.

The examples given above indicate that in order to explain the antioxidant activity of 'simple' phenolic compounds, other descriptors might have to be added to the ones we used, leading to relatively complex regression equation [23]. The more complex the equation, the less understandable it becomes, and the elegance of the SAR is lost. Past experiences learn that then Occam's razor should be skillfully applied. One of the solutions might be the use of Non-Linear Modelling [26].

\section{Computation details}

The geometry and vibration spectra of selected phenolic compounds were generated by Gaussian 09[27] at B3LYP[28]/6-31G*[29], Calculation of the enthalpy of the various forms of phenolic compounds were carried at M06-2X[30]/def2-TZVP[31] level with a D3 correction[32] by Orca[33]. The solvent effect was included by using the implemented SMD (water) method[34] both in Gaussian 09 and Orca. The enthalpy of an electron, hydrogen atom or proton in the gas phase, used in the present manuscript are $0.751 \mathrm{Kcal} / \mathrm{mol},-313.75$ $\mathrm{Kcal} / \mathrm{mol}$ and $1.48 \mathrm{Kcal} / \mathrm{mol}$, respectively[35]. The solvation enthalpy of an electron, hydrogen atom or proton are $-18.51 \mathrm{Kcal} / \mathrm{mol},-0.955 \mathrm{Kcal} / \mathrm{mol}$ and $-252.365 \mathrm{Kcal} / \mathrm{mol}$, respectively[36]. All enthalpies and free energies were calculated for $298.15^{\circ} \mathrm{K}$. The VIP and condensed Fukui function f- were calculated by Multiwfn[37]. The spin density map was also generated by Multiwfn with the help of VMD[38]. The pKa of selected phenolic compounds were collected from database developed by NanKai University and Tsinghua University (http://ibond.chem.tsinghua.edu.cn/pka/). The data analysis has been carried by SPSS (SPSS, Inc., Chicago, IL, USA). 


\section{Conclusion.}

Even in the series of simple, structurally closely related phenolic antioxidants, the antioxidant mechanism does not proceed via the same molecular mechanism. Because a fundamental difference in the activity in the series of compounds, no relationship between the activity and the molecular structure can be made that incorporates all of these compounds. First the compounds that have the same molecular mechanism need to be grouped. Within each group, a SAR might be constructed. As shown in the present study, the f- can be used classify the type of reaction process, and to determine to what group a compound belongs.

Our study indicates that we need to further investigate the SAR of the simple phenolic compounds, before we can start building a SAR that includes more complex poly-phenolic compounds such as the flavonoids. Beside the grouping of compounds with the similar molecular mechanism as presented in the present study, another part of the solution might be the use of Non-Linear Modelling[23], but the fundament will always be the use of plain common sense and understand what you are doing. 


\section{References}

1. Zhang, M.; Moalin, M.; Vervoort, L.; Li, Z. W.; Wu, W. B.; Haenen, G., Connecting Western and Eastern medicine from an energy perspective. International Journal of Molecular Sciences 2019, 20, (6), 1512.

2. $\quad$ Cadenas, E.; Sies, H., The lag phase. Free Radical Research 1998, 28, (6), 601-609.

3. Kovacic, P.; Pozos, R. S.; Somanathan, R.; Shangari, N.; O'Brien, P. J., Mechanism of mitochondrial uncouplers, inhibitors, and toxins: focus on electron transfer, free radicals, and structure-activity relationships. Current Medicinal Chemistry 2005, 12, (22), 2601-2623.

4. Poyton, R. O.; Ball, K. A.; Castello, P. R., Mitochondrial generation of free radicals and hypoxic signaling. Trends in Endocrinology and Metabolism 2009, 20, (7), 332-340.

5. Ray, P. D.; Huang, B.-W.; Tsuji, Y., Reactive oxygen species (ROS) homeostasis and redox regulation in cellular signaling. Cellular Signalling 2012, 24, (5), 981-990.

6. Amić, A.; Marković, Z.; Marković, J. M. D.; Stepanić, V.; Lučić, B.; Amić, D., Towards an improved prediction of the free radical scavenging potency of flavonoids: The significance of double PCET mechanisms. Food Chemistry 2014, 152, 578-585.

7. Vásquez-Espinal, A.; Yañez, O.; Osorio, E.; Areche, C.; García-Beltrán, O.; Ruiz, L. M.; Cassels, B. K.; Tiznado, W., Theoretical Study of the Antioxidant Activity of Quercetin Oxidation Products. Frontiers in Chemistry 2019, 7, 818.

8. Stepanić, V.; Trošelj, K. G.; Lučić, B.; Marković, Z.; Amić, D., Bond dissociation free energy as a general parameter for flavonoid radical scavenging activity. Food Chemistry 2013, 141, (2), 1562-1570.

9. Amić, D.; Stepanić, V.; Lučić, B.; Marković, Z.; Marković, J. M. D., PM6 study of free radical scavenging mechanisms of flavonoids: why does $\mathrm{O}-\mathrm{H}$ bond dissociation enthalpy effectively represent free radical scavenging activity? Journal of Molecular Modeling 2013, 19, (6), 2593-2603.

10. Chen, Y.; Xiao, H.; Zheng, J.; Liang, G., Structure-thermodynamics-antioxidant activity relationships of selected natural phenolic acids and derivatives: An experimental and theoretical evaluation. PloS One 2015, 10, (3), e0121276.

11. Jeremić, S.; Radenković, S.; Filipović, M.; Antić, M.; Amić, A.; Marković, Z., Importance of hydrogen bonding and aromaticity indices in QSAR modeling of the antioxidative capacity of selected (poly) phenolic antioxidants. Journal of Molecular Graphics and Modelling 2017, 72, 240-245.

12. Yoshida, T.; Hirozumi, K.; Harada, M.; Hitaoka, S.; Chuman, H., Density Functional Theory Study of Hydrogen Atom Abstraction from a Series of para-Substituted Phenols: Why is the Hammett $\sigma p^{+}$ Constant Able to Represent Radical Reaction Rates? The Journal of organic chemistry 2011, 76, (11), 4564-4570.

13. Fuentealba, P.; Pérez, P.; Contreras, R., On the condensed Fukui function. The Journal of chemical physics 2000, 113, (7), 2544-2551.

14. Chandra, A. K.; Nguyen, M. T., Use of DFT-based reactivity descriptors for rationalizing radical addition reactions: applicability and difficulties. Faraday Discussions 2007, 135, 191-201.

15. Sarkar, A.; Middya, T. R.; Jana, A. D., A QSAR study of radical scavenging antioxidant activity of a series of flavonoids using DFT based quantum chemical descriptors-the importance of group frontier electron density. Journal of Molecular Modeling 2012, 18, (6), 2621-2631.

16. Medina, M. E.; Galano, A.; Alvarez-Idaboy, J. R., Theoretical study on the peroxyl radicals scavenging activity of esculetin and its regeneration in aqueous solution. Physical Chemistry Chemical Physics 2014, 16, (3), 1197-1207.

17. Amorati, R.; Baschieri, A.; Cowden, A.; Valgimigli, L., The antioxidant activity of quercetin in water solution. Biomimetics 2017, 2, (3), 9.

18. Reis, M.; Lobato, B.; Lameira, J.; Santos, A. S.; Alves, C. N., A theoretical study of phenolic compounds with antioxidant properties. European Journal of Medicinal Chemistry 2007, 42, (4), 440-446.

19. Migliavacca, E.; Carrupt, P. A.; Testa, B., Theoretical parameters to characterize antioxidants. Part 1. The case of vitamin E and analogs. Helvetica Chimica Acta 1997, 80, (5), 1613-1626.

20. Van Acker, S. A.; Koymans, L. M.; Bast, A., Molecular pharmacology of vitamin E: structural aspects of antioxidant activity. Free Radical Biology and Medicine 1993, 15, (3), 311-328.

21. Alov, P.; Tsakovska, I.; Pajeva, I., Computational studies of free radical-scavenging properties of phenolic compounds. Current Topics in Medicinal Chemistry 2015, 15, (2), 85-104.

22. Lien, E. J.; Ren, S.; Bui, H.-H.; Wang, R., Quantitative structure-activity relationship analysis of phenolic antioxidants. Free Radical Biology and Medicine 1999, 26, (3-4), 285-294.

23. Filipović, M.; Marković, Z.; Đorović, J.; Marković, J. D.; Lučić, B.; Amić, D., QSAR of the free radical scavenging potency of selected hydroxybenzoic acids and simple phenolics. Comptes Rendus Chimie 2015, 18, (5), 492-498. 
24. Li, Z.; Moalin, M.; Zhang, M.; Vervoort, L.; Mommers, A.; Haenen, G. R., Delocalization of the Unpaired Electron in the Quercetin Radical: Comparison of Experimental ESR Data with DFT Calculations. International Journal of Molecular Sciences 2020, 21, (6), 2033.

25. Amorati, R.; Lucarini, M.; Mugnaini, V.; Pedulli, G. F., Antioxidant activity of o-bisphenols: The role of intramolecular hydrogen bonding. The Journal of organic chemistry 2003, 68, (13), 5198-5204.

26. Žuvela, P.; David, J.; Yang, X.; Huang, D.; Wong, M. W., Non-Linear Quantitative Structure-Activity Relationships Modelling, Mechanistic Study and In-Silico Design of Flavonoids as Potent Antioxidants. International Journal of Molecular Sciences 2019, 20, (9), 2328.

27. Frisch, M. J.; Trucks, G. W.; Schlegel, H. B.; Scuseria, G. E.; Robb, M. A.; Cheeseman, J. R.; Scalmani, G.; Barone, V.; Mennucci, B.; Petersson, G. e., Gaussian 09 Revision D. 01. 2014.

28. Stephens, P. J.; Devlin, F.; Chabalowski, C.; Frisch, M. J., Ab initio calculation of vibrational absorption and circular dichroism spectra using density functional force fields. The Journal of physical chemistry 1994, 98, (45), 11623-11627.

29. Rassolov, V. A.; Pople, J. A.; Ratner, M. A.; Windus, T. L., 6-31G* basis set for atoms K through Zn. The Journal of chemical physics 1998, 109, (4), 1223-1229.

30. Zhao, Y.; Truhlar, D. G., The M06 suite of density functionals for main group thermochemistry, thermochemical kinetics, noncovalent interactions, excited states, and transition elements: two new functionals and systematic testing of four M06-class functionals and 12 other functionals. Theoretical Chemistry Accounts 2008, 120, (1-3), 215-241.

31. Weigend, F.; Ahlrichs, R., Balanced basis sets of split valence, triple zeta valence and quadruple zeta valence quality for $\mathrm{H}$ to Rn: Design and assessment of accuracy. Physical Chemistry Chemical Physics 2005, 7, (18), 3297-3305.

32. Grimme, S.; Ehrlich, S.; Goerigk, L., Effect of the damping function in dispersion corrected density functional theory. Journal of Computational Chemistry 2011, 32, (7), 1456-1465.

33. Neese, F., The ORCA program system. Wiley Interdisciplinary Reviews: Computational Molecular Science 2012, 2, (1), 73-78.

34. Marenich, A. V.; Cramer, C. J.; Truhlar, D. G., Universal solvation model based on solute electron density and on a continuum model of the solvent defined by the bulk dielectric constant and atomic surface tensions. The Journal of Physical Chemistry B 2009, 113, (18), 6378-6396.

35. Fouegue, A. D. T.; Mama, D. B.; Ghogomu, J. N.; Elie, Y.; Etoh, M.-A., The Substitution Effect on Reaction Enthalpies of Antioxidant Mechanisms of Juglone and Its Derivatives in Gas and Solution Phase: DFT Study. Journal of Chemistry 2018, 2018.

36. Marković, Z.; Tošović, J.; Milenković, D.; Marković, S., Revisiting the solvation enthalpies and free energies of the proton and electron in various solvents. Computational and Theoretical Chemistry 2016, 1077, 11-17.

37. Lu, T.; Chen, F., Multiwfn: a multifunctional wavefunction analyzer. Journal of Computational Chemistry 2012, 33, (5), 580-592.

38. Humphrey, W.; Dalke, A.; Schulten, K., VMD: visual molecular dynamics. Journal of molecular graphics 1996, 14, (1), 33-38. 


\section{Supplementary Materials}
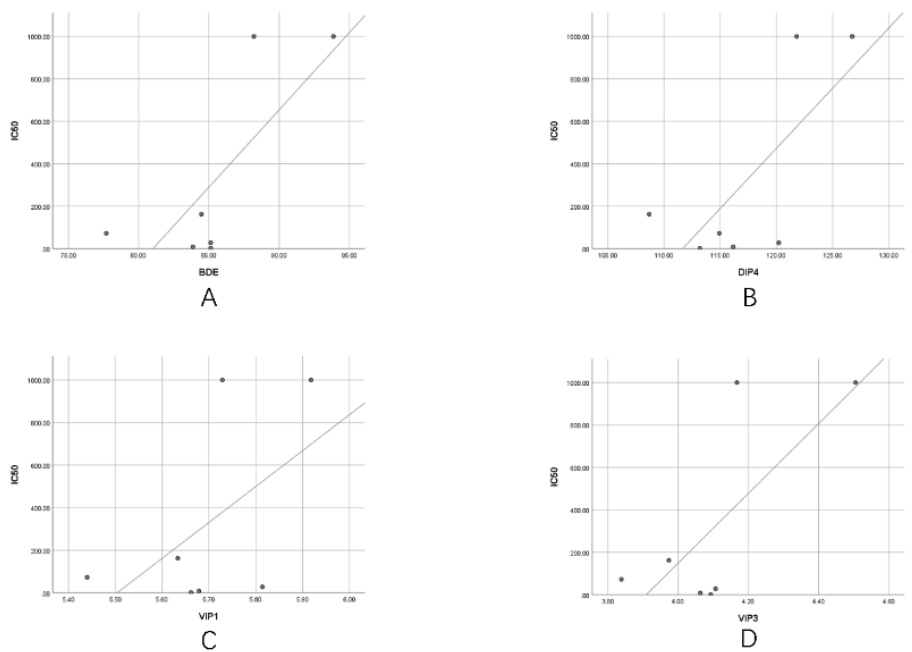

SI Figure 1, The Correlation between the BDE (A), DIP (B), $\operatorname{VIP}_{1}(\mathrm{C})$ and $\operatorname{VIP}_{2}$ (D) for the compounds (1, 2, 3, 11, 13,14 and 17) with the $\mathrm{IC}_{50}$ towards the peroxynitrite, where the correlation are $\mathrm{r}=0.763, \mathrm{P}<0.046(\mathrm{~A}) ; \mathrm{r}=0.732$, $\mathrm{P}<0.061(\mathrm{~B}) ; \mathrm{r}=0.545, \mathrm{P}<0.205$ (C) and $\mathrm{r}=0.728, \mathrm{P}<0.064$ (D), respectively. 
Chapter 6

General discussion and summary 


\section{General discussion and summary}

Redox energy is essential for life, as it fuels all our biochemical processes. Most of the redox energy is safely channeled in the biochemical networks, but for some unknown reason, part of the oxidizing energy flow is uncontrolled. This deranged energy can, seemingly quite randomly, damage our cells. This oxidative damage is involved in all kinds of diseases, and ultimately, when too much oxidative damage has accumulated, death is our inevitable destiny. In a healthy body the oxidizing and reducing forces are - to a large extend - balanced and generate a reasonably controlled energy flow in which the accumulation of oxidative damage is kept within limits, and we can enjoy a healthy life for, on average, 80 years. Intriguingly, the deranged energy also has a good side; e.g. it also triggers the healing process.

In Chapter 1, we outlined and extensively discussed how flavonoids might be used to modulate and redirect deranged redox energy. Our hypothesis is that flavonoids can modulate the redox energy in such a way that its 'destructive' power is mitigated, while its 'healing' power is retained or even raised. The fundament for this is found in the hard-soft acid base concept. 'Hard' and therefore rather indiscriminative damaging energy is generated by the formation of reactive oxidizing species as a byproduct in e.g. the oxidative phosphorylation that generates ATP. Flavonoids are very efficient in capturing this hard energy, and after capturing flavonoids convert the hard energy into relatively 'soft' energy. The hypothesis is that by making the energy softer, protective redox switches are more efficiently switched on.

A very practical problem is that the bioavailability of flavonoids is relatively poor. They are extensively metabolized, and only relatively low concentrations of the 'free' flavonoid aglycon have been detected in blood after oral administration. As outlined in chapter 1, the entero-hepatic cycle of flavonoids and the local de-glucuronidation of flavonoid metabolites may direct the flavonoid to the sites where they have to display their redox modulating activity. An alternative is intravenous administration that has been practiced with the flavonoid monoHER in which relatively high concentrations can be reached. A simple way to effectively direct a bioactive flavonoid to its site of action is to locally administer the compound, e.g. in wound dressings. In this way systemic toxicity is prevented, and the therapy is expected to be more effective. Newly developed wound dressings contain a mixture of anti-inflammatory and antibacterial agents (e.g. flavonoids), growth factors, immune factors, moisture in a multi-layer. The main complications are the large variation in exudates, bacterial infection, moisture, and the unpredictable microenvironment. As outlined in Chapter 2, most of the advanced dressings are still under development, and their performance in clinical practice still needs to be tested.

Regarding the distribution of flavonoids over the body, an interesting finding is found after intravenous administration of the flavonoid monoHER in mice. MonoHER or a metabolite of monoHER appear to be still present in arterial endothelial cells and muscle cell long after all the monoHER has been cleared from the blood[1]. This local retention of monoHER especially at this site calls for further research.

Although many studies are devoted to the free radical scavenging and redox modulation by flavonoids, the molecular mechanism still remains enigmatic and only slowly evolves. In Chapter 3, we examined how the redox energy is stored in the quercetin radical ( $\left.\mathrm{Q}^{*}\right)$. The ESR spectrum and DFT calculation of $\mathrm{Q}^{*}$ and structurally related radicals both suggest that 
the $\mathrm{UE}$ of $\mathrm{Q}^{\bullet}$ is mostly delocalized in the $\mathrm{B}$ ring and partly on the $\mathrm{AC}$ ring. The negatively charged oxygen groups in the $\mathrm{B}$ ring $\left(3^{\prime}\right.$ and $\left.4^{\prime}\right)$ of $\mathrm{Q}^{*}$ have an electron-donating effect that attract and stabilize the UE in the $\mathrm{B}$ ring. Radicals structurally related to $\mathrm{Q}^{\bullet}$ indicate that the negatively charged oxygen at $4^{\prime}$ has more of an effect on concentrating the UE in ring $B$ than the negatively charged oxygen at $3^{\prime}$. The DFT calculation showed that an $\mathrm{OH}$ group at the 3position of the AC ring is essential for concentrating the radical on the $\mathrm{C} 2-\mathrm{C} 3$ double bond. All these effects help to explain how the high energy of the UE is captured and a stable $\mathrm{Q}^{*}$ is generated, which is pivotal in the antioxidant activity of quercetin (Q).

Most studies do not consider that the actual redox modulation comprises of a series of sequential reactions in which the energy flows through the molecule. Therefore, we examined how the redox energy flows through the molecule during Q's antioxidant activity, by combining experimental data with quantum calculations. As shown in Chapter 4, it appears that several main pathways are possible. Pivotal are subsequently: deprotonation of the 7-OH group; intramolecular hydrogen transfer from the 3-OH group to the 4-Oxygen atom; electron transfer leading to two conformers of the $\mathrm{Q}$ radical; deprotonation of the $\mathrm{OH}$ groups in the B-ring, leading to three different deprotonated Q radicals; and finally electron transfer of each deprotonated $\mathrm{Q}$ radical to form the corresponding quercetin quinones. The quinone in which the carbonyl groups are the most separated, has the lowest energy content, and is the most abundant quinone. The pathways are also intertwined. The calculations show that $\mathrm{Q}$ can pick up redox energy at various sites of the molecule which explains Q's ability to scavenge all sorts of reactive oxidizing species. There were already some clues that pointed towards the flexibility of the antioxidant activity of Q: Q contains more than one antioxidant "pharmacophore" and both pharmacophores do not work separately but interact $[2,3]$. The flexibility of the flow of the redox energy through the molecule adds to the efficiency and increases the versatility of Q's redox modulating potency.

In Chapter 5, we reevaluated the Structure Activity Relationship (SAR) of a series of relatively simple, structurally closely related phenolic compounds. The SAR is a valuable tool in 'understanding' differences between compounds and elucidating the molecular mode of action. In our re-evaluation, we observed that even within our series of structurally closely related compounds, the redox modulating activity of the tested compounds did not proceed according to the same molecular mechanism. This indicates that we need to further investigate the SAR of the simple phenolic compounds, before we can start building a SAR that includes more complex poly-phenolic compounds such as the flavonoids.

In Chapter 1, we also summarized some questions that we would like to answer. These are:

- The high rates of radical scavenging of some compounds that seems to exceed the diffusion rate constant.

- Explain why a relatively low concentration of flavonoid is able to protect against an excess of ROS.

- Examine how redox modulators 'modulate' the energy on a molecular level (the 'efficacy' of redox modulators).

- Establish a stimulus-effect relationship for redox modulators. We still do not know how to choose the appropriate redox modulator for a specific disease. 
- Further establish how the redox modulators fit into molecules of the recipient complex like a piece of mosaic that finds its place in a pattern.

The way to go is to invent new tools to examine redox modulators. The new perspectives this generates should be connected to the perspectives created using the old tools. Our research underlines that to come closer to the solution, the different views should be combined to create a more complete picture of flavonoids as illustrated in the figure. Then, after skillfully applying Occam's razor, we might look through the Yin and Yang and have a glimpse at nature's simple perfection.

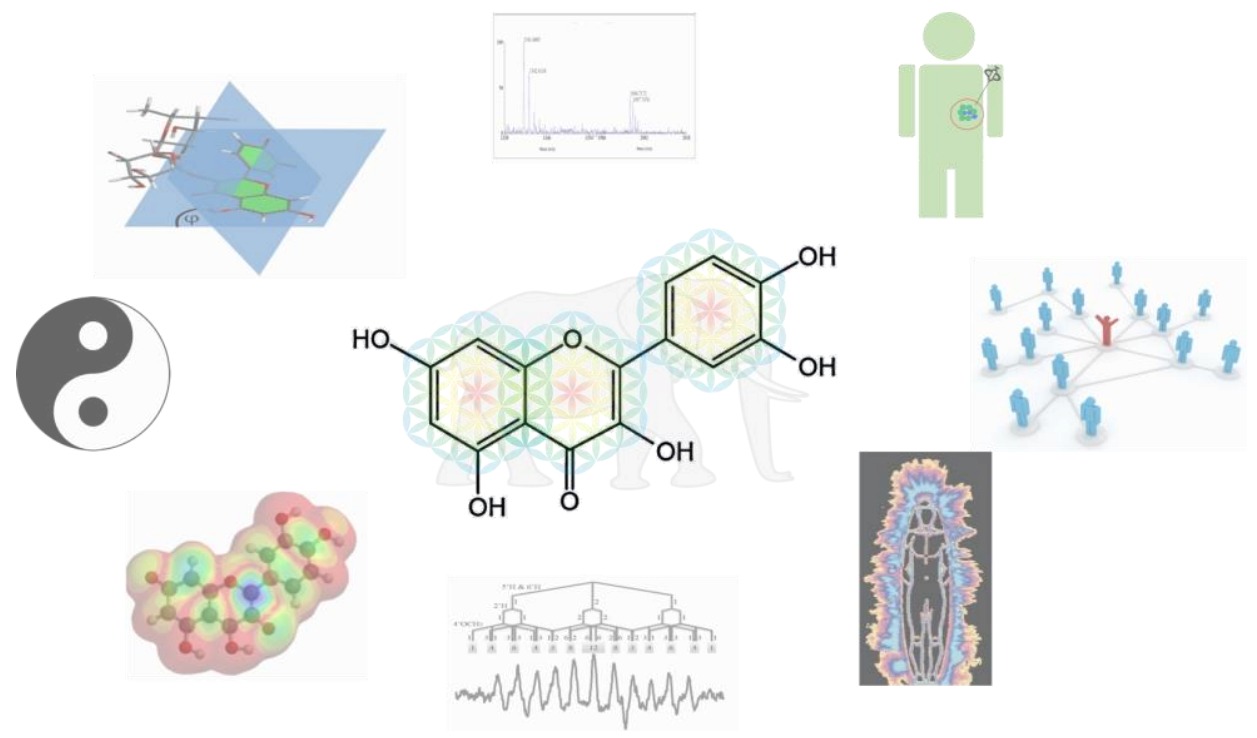

Fig 1. By combining the results obtained with different techniques and from different perspectives, a more complete picture on the redox modulating nature of flavonoids can be obtained. Like in the metaphor, you than see that it is not a tree, a wall, a snake or a rope; it is an elephant. And when you look even closer you notice it is alive and has feelings. 


\section{Reference}

1. Lemmens, K. J.; van de Wier, B.; Vaes, N.; Ghosh, M.; van Zandvoort, M. A.; van der Vijgh, W. J.; Bast, A.; Haenen, G. R., The flavonoid 7-mono-O-( $\beta$-hydroxyethyl)-rutoside is able to protect endothelial cells by a direct antioxidant effect. Toxicology in vitro 2014, 28, (4), 538-543.

2. Heijnen, C. G.; Haenen, G. R.; Vekemans, J. A.; Bast, A., Peroxynitrite scavenging of flavonoids: structure activity relationship. Environmental Toxicology and Pharmacology 2001, 10, (4), 199-206.

3. Heijnen, C. G.; Haenen, G. R.; Minou Oostveen, R.; Stalpers, E. M.; Bast, A., Protection of flavonoids against lipid peroxidation: the structure activity relationship revisited. Free Radical Research 2002, 36, (5), 575-581. 



\section{Chapter 7}

Nederlandse samenvatting en algemene discussie 


\section{Algemene discussie en samenvatting}

Redox-energie is essentieel voor ons leven, omdat het al onze biochemische processen voedt. De meeste redoxenergie wordt veilig door de biochemische netwerken geloodst, maar om een onbekende reden is een deel van de oxiderende energiestroom ongecontroleerd. Deze ontspoorde energie kan, schijnbaar vrij willekeurig, onze cellen beschadigen. Deze oxidatieve schade is betrokken bij allerlei ziekten, en uiteindelijk, wanneer er te veel oxidatieve schade zich opstapelt, is dood onze onvermijdelijke bestemming. In een gezond lichaam zijn de oxiderende en reducerende krachten - grotendeels - in evenwicht en genereren ze een redelijk goed gecontroleerde energiestroom waardoor de ophoping van oxidatieve schade binnen de perken wordt gehouden, en kunnen we gemiddeld 80 jaar van een gezond leven genieten. Het is intrigerend dat de ontspoorde energie ook een goede kant heeft; bijv. het zet ook het genezingsproces in gang.

In hoofdstuk 1 hebben we uiteengezet en uitgebreid bediscussieerd hoe flavonoïden kunnen worden gebruikt om ontspoorde redoxenergie te moduleren en te sturen. Onze hypothese is dat flavonoïden de ontspoorde redoxenergie zodanig kunnen moduleren dat de 'destructieve' kracht wordt verzacht, terwijl de 'genezende' kracht wordt behouden of zelfs versterkt. Het fundament hiervoor wordt gevonden in het hard-soft acid base-concept. 'Harde' en daarom nogal willekeurige schadelijke energie wordt gegenereerd door de vorming van reactieve oxiderende moleculen als bijproduct in b.v. de oxidatieve fosforylering die ATP genereert. Flavonoïden kunnen deze harde energie zeer efficiënt invangen, en na het invangen zetten flavonoïden de harde energie om in relatief 'zachte' energie. De hypothese is dat door de energie zachter te maken, beschermende redoxschakelaars eerder worden aangezet.

Een heel praktisch probleem is dat de biologische beschikbaarheid van flavonoïden relatief slecht is. Ze worden uitgebreid gemetaboliseerd en alleen relatief lage concentraties van het 'vrije' flavonoïde aglycon zijn na orale toediening in het bloed aangetroffen. Zoals uiteengezet in hoofdstuk 1, kan de entero-hepatische cyclus van flavonoïden en de lokale deglucuronidering van flavonoïde-metabolieten een flavonoïde naar de plaats leiden waar het zijn redox-modulerende activiteit moet vertonen. Een alternatief voor orale toediening is intraveneuze toediening die is toegepast met de flavonoïde monoHER waarmee relatief hoge concentraties kunnen worden bereikt.

Een eenvoudige manier om een bioactieve flavonoïde effectief naar zijn werkingsplaats te leiden, is door de verbinding lokaal toe te dienen, b.v. in wondverbanden. Op deze manier wordt systemische toxiciteit voorkomen en wordt verwacht dat de therapie effectiever is. Nieuw ontwikkelde wondverbanden bevatten een mengsel van ontstekingsremmende en antibacteriële middelen (bijv. flavonoïden), groeifactoren, immuunfactoren in een meerlaagse pleister. De belangrijkste complicaties zijn de grote variatie in exsudaat, de aard van de bacteriële infectie en vocht, en de onvoorspelbare micro-omgeving. Zoals uiteengezet in hoofdstuk 2, zijn de meeste geavanceerde verbanden nog in ontwikkeling en moet hun effectiviteit in de klinische praktijk nog worden bewezen.

Een interessante bevinding is gedaan na intraveneuze toediening van het flavonoïde monoHER bij muizen. MonoHER of een metaboliet van monoHER lijkt nog steeds aanwezig te zijn in arteriële endotheelcellen en spiercellen, lang nadat al het monoHER uit het bloed is 
verdwenen ${ }^{1}$. Deze lokale retentie van monoHER, vooral op deze plaats, vraagt om verder onderzoek.

Hoewel veel studies zijn gewijd aan het invangen van vrije radicalen en de redoxmodulatie door flavonoïden, blijft het moleculaire mechanisme nog steeds raadselachtig en gaat de ontwikkeling van onze kennis op dit gebied traag. In Hoofdstuk 3 hebben we onderzocht hoe de redoxenergie wordt opgeslagen in de quercetine-radicaal ( $\left.Q^{*}\right)$. Het ESR-spectrum en de DFT-berekening van Q' en structureel verwante radicalen suggereren beide dat het ongepaard elektron van $\mathrm{Q}^{*}$ grotendeels is gedelokaliseerd in de B-ring en gedeeltelijk op de AC-ring. De negatief geladen zuurstofatomen in de B-ring (op de 3 ' en 4 ' positie) van Q' hebben een elektrondonerend effect dat het ongepaard elektron in de B-ring aantrekt en stabiliseert. Radicalen die structureel verwant zijn aan $\mathrm{Q}^{*}$ geven aan dat de negatief geladen zuurstof op 4 ' meer effect heeft op de concentratie van het ongepaard elektron in ring B dan de negatief geladen zuurstof op 3'. De DFT-berekening toonde aan dat een OH-groep op de 3-positie van de AC-ring essentieel is voor het concentreren van de radicaal op de C2-C3 dubbele binding. Al deze effecten helpen verklaren hoe de hoge energie van het ongepaarde elektron wordt opgevangen en een stabiel $Q^{*}$ wordt gegenereerd. Deze stabilisatie is cruciaal in de antioxiderende activiteit van quercetine $(\mathrm{Q})$.

De meeste onderzoeken gaan er niet van uit dat de feitelijke redox-modulatie bestaat uit een reeks opeenvolgende reacties waarin de energie door het molecuul stroomt. Daarom hebben we onderzocht hoe de redoxenergie door het molecuul stroomt tijdens de antioxidant activiteit van $\mathrm{Q}$, door experimentele gegevens te combineren met kwantumberekeningen. Zoals blijkt uit hoofdstuk 4, blijkt dat er meerdere hoofdroutes voor de energie mogelijk zijn. Centraal staan achtereenvolgend: deprotonering van de 7-OH-groep; intramoleculaire waterstofoverdracht van de 3-OH-groep naar het 4-zuurstofatoom; elektronenoverdracht die leidt tot twee conformeren van het Q-radicaal; deprotonering van de OH-groepen in de Bring, wat leidt tot drie verschillende gedeprotoneerde Q-radicalen; en tenslotte een elektronoverdracht van elk gedeprotoneerd Q-radicaal om de overeenkomstige quercetinechinonen te vormen. Het chinon waarin de carbonylgroepen het verst uit elkaar liggen, heeft de laagste energie-inhoud en is het meest voorkomende chinon. De paden zijn ook met elkaar verweven. De berekeningen laten zien dat $\mathrm{Q}$ redoxenergie kan opnemen op verschillende plaatsen van het molecuul, wat verklaart waarom $Q$ allerlei reactieve oxiderende soorten efficiënt kan invangen. Er waren al enkele aanwijzingen die wezen op de flexibiliteit van de antioxidant activiteit van Q: Q bevat meer dan één antioxidant "farmacofoor" en beide farmacoforen werken niet afzonderlijk maar werken samen ${ }^{2,3}$. De flexibiliteit van de stroom van de redoxenergie door de molecuul draagt bij aan de efficiëntie en vergroot de veelzijdigheid van Q's redox-modulerende potentie.

In Hoofdstuk 5 hebben we de Structuur-Activiteit Relatie (SAR) van een reeks relatief eenvoudige, structureel nauw verwante fenolische verbindingen opnieuw geëvalueerd. De SAR is een waardevol hulpmiddel om verschillen tussen verbindingen te 'begrijpen' en het moleculaire werkingsmechanisme op te helderen. Bij onze herevaluatie hebben we opgemerkt dat zelfs binnen een reeks van structureel nauw verwante verbindingen, de redoxmodulerende activiteit niet volgens hetzelfde moleculaire mechanisme verloopt. Dit geeft aan dat we de SAR van de eenvoudige fenolische verbindingen verder moeten onderzoeken, voordat we kunnen beginnen met het bouwen van een SAR van meer complexe polyfenolische verbindingen zoals de flavonoïden. 
In hoofdstuk 1 hebben we enkele bevindingen en vragen opgesomd die we graag nader willen onderzoeken. Dit zijn:

- De hoge reactiesnelheid waarmee sommige verbindingen radicalen invangen, een reactiesnelheid de diffusiesnelheidsconstante lijkt te overschrijden.

- Nader onderzoeken hoe een relatief lage concentratie flavonoïde bescherming kan bieden tegen een groet overmaat aan reactieve oxiderende moleculen.

- Nader onderzoek hoe redoxmodulatoren de energie 'moduleren' op moleculair niveau (de 'efficacy' van redoxmodulatoren).

- Een stimulus-effect relatie ontwikkelen voor redoxmodulatoren. We weten nog steeds niet hoe we de juiste redox-modulator moeten kiezen voor een specifieke ziekte.

- Verder nagaan hoe de redox-modulatoren passen in moleculen van de cel, zoals een stuk mozaïek dat zijn plaats in een patroon vindt.

Ons onderzoek geeft aan dat we verder moeten gaan met het ontwikkelen van nieuwe methoden om redoxmodulatoren te onderzoeken. De nieuwe perspectieven die dit genereert, moeten worden verbonden met de perspectieven die met de oude methoden zijn gecreëerd. Ons onderzoek onderstreept dat om dichter bij de oplossing te komen, de verschillende opvattingen moeten worden gecombineerd om een completer beeld van flavonoïden te creëren, zoals geïllustreerd in figuur 1. Dan, nadat we Ockham's scheermes vakkundig hebben toegepast, kunnen we door de Yin en Yang heen kijken en een glimp opvangen van de simpele perfectie van de natuur.

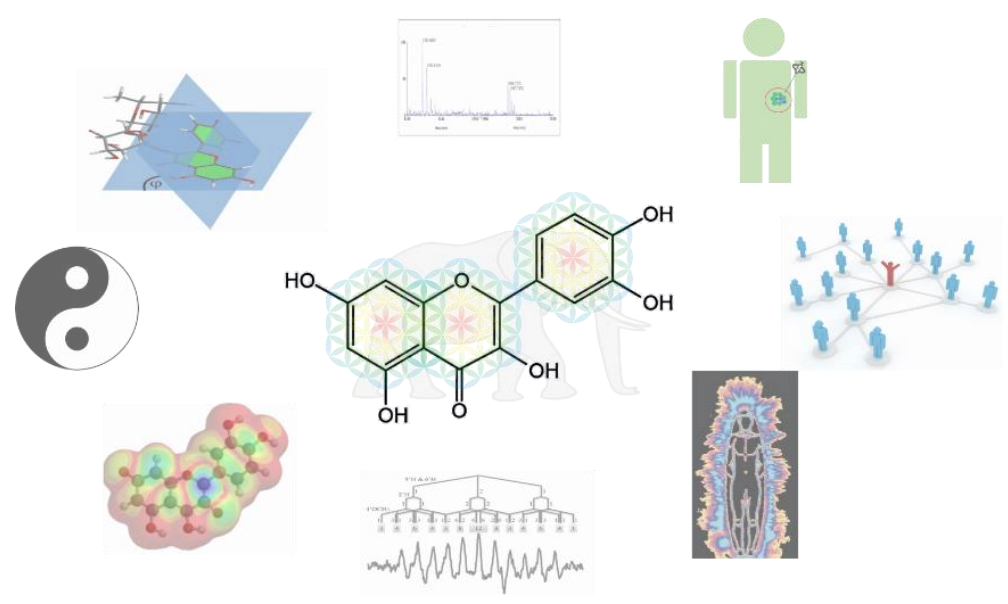

Fig 1. Door de resultaten verkregen met verschillende technieken en vanuit verschillende perspectieven te combineren, kan een completer beeld worden verkregen van de redox-modulerende aard van flavonoïden. Zoals in de metafoor, zie je dan dat het geen boom, muur, slang of touw is; het is een olifant. En als je nog beter kijkt, zie je dat het leeft en gevoelens heeft. 




\section{Impact paragraph}




\section{Impact paragraph}

Like a car that depends on the energy liberated by the controlled burning of fuel to move, we need the energy liberated by the controlled burning of sugars and lipids to grow, move, think and reproduce. This burning, or 'oxidation' of nutrients takes place in our cells. For some unknown reason, a substantial part of this oxidation process is not well controlled. The uncontrolled oxidative energy that escapes the process is very reactive and can damage e.g. DNA and proteins. The oxidation of DNA can result in cancer. The oxidation of proteins in our skin results in the formation of age-pigments. In the manifestation of most diseases, the deranged energy appears to have an important role. Luckily, our cells have an antioxidant defense system that can keep the oxidative damage within reasonable limits. Therefore, we can enjoy a healthy life for, on average, 80 years, until too much oxidative damage has accumulated.

Intriguingly, the deranged energy also has a good side. We use the lethal potency of the redox energy to our benefit in the killing of bacteria and viruses. In addition, the deranged redox energy appears to play a key role in the healing process, and the redox 'damage' of DNA is thought to be a driving force in evolution.

Within this playfield of opposing internal and external forces that contain both good and bad (Yin and Yang), we are gifted with the ability to intervene to some extend at our own free will, and to do our 'best' by choosing the right lifestyle, diet or 'therapy'. This thesis is dedicated to extending our knowledge on the modulation of the redox processes by a specific class of antioxidants, namely the flavonoids. For the reasons given above, this is done from the energy perspective.

Flavonoids are a class of colored compounds found in plants, and they are abundantly present in our diet. It has been reported that a high intake of flavonoids is associated with a reduced incidence of cancer, cardiovascular diseases and other diseases in which the energy production has run out of control. Although the paradigm that flavonoids protect by their redox modulating properties is widely accepted, the exact molecular mechanism of this protection is not known. We need to have this fundamental knowledge, e.g. to rationally select the proper flavonoid for a specific disease.

One of the practical problems of the use of flavonoids, is that they are poorly absorbed in gastro-intestinal tract. Moreover, once absorbed, they are extensively metabolized and readily excreted. A simple way to make sure that flavonoids are delivered to the part of the body they must act, is to administer them locally by wound dressing. Newly developed wound dressings contain a mixture of anti-inflammatory and antibacterial agents (e.g. flavonoids), growth factors, immune factors, moisture in a multi-layer. The main complications are the large variation in exudates, bacterial infection, moisture, and the unpredictable microenvironment. As outlined in Chapter 2, most of the advanced dressings are still under development, and their performance in clinical practice still needs to be tested.

In the other parts of the theses, the molecular mechanism of the redox modulation of flavonoids is examined. For the flavonoid quercetin, it is determined in which part of the molecule the energy it picks up, is stored. It is also predicted how the energy flows through 
the molecule when quercetin has absorbed the energy. Our research show that quercetin can pick up redox energy at various sites of the molecule which explains quercetin's ability to scavenge all sorts of reactive oxidizing species.

To find out how these results obtained with quercetin can be extrapolated to other flavonoids, the group consists of over 5.000 compounds, we tried to determine the relation between the chemical structure of flavonoids and their redox modulating activity. Already many structure-activity relationships on the redox modulating activity of flavonoids exist, but none of them is completely satisfying. Therefore, we used a bottom up approach. We started by examining a series of simple phenolic compounds, that can be regarded as simplified flavonoid. We found that even within this group of structurally closed related compound, not all compound displayed the same type of redox modulating activity. This is important, because for a structure-activity relationship it is mandatory that all compounds have the same type of activity. The consequence is that for making a structure-activity of flavonoids, we first need to examine the type of activity, and group the flavonoids according to the type of activity. Each group will have a different structure-activity relationship. In our study with the simple phenolic compounds, we developed a strategy to classify compounds, which can be used in future research as a fundament for constructing more accurate structure activity relationships on flavonoids.

One of the common denominators in our approach is that we look at the redox modulation with various tools and from various points of view. Our research underlines that to come closer to the solution, the different perspectives should be combined to create a more complete picture as illustrated in the figure and try to look through the Yin and Yang.

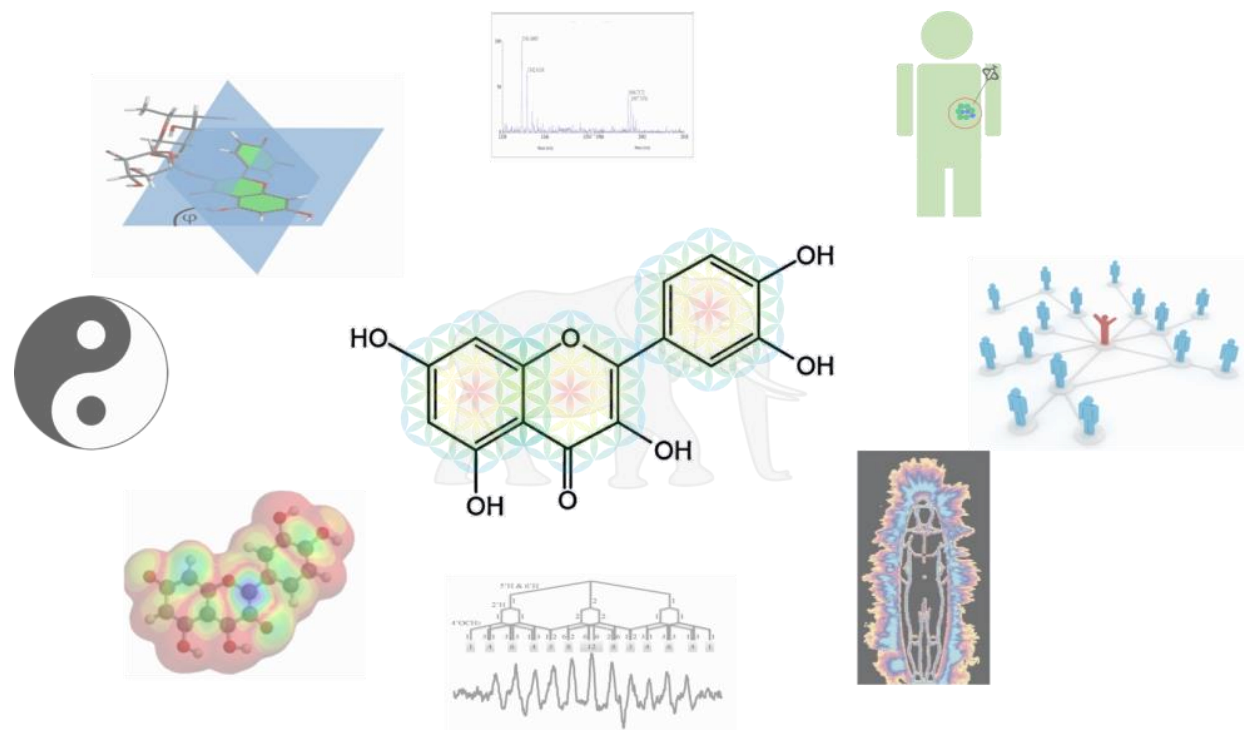

By combining the results obtained with different techniques and from different perspectives, a more complete picture on the redox modulating nature of flavonoids can be obtained. Like in the metaphor, you than see that it is not a tree, a wall, a snake or a rope; it is an elephant. And when you look even closer you notice it is alive and has feelings. 


\section{Impact paragraaf (Nederlands)}

Net als een auto die afhankelijk is van de energie die vrijkomt door gecontroleerde verbranding van brandstof om te rijden, hebben we de energie nodig die vrijkomt door de gecontroleerde verbranding van suikers en lipiden om te groeien, te bewegen, te denken en ons voort te planten. Deze verbranding of 'oxidatie' van voedingsstoffen vindt plaats in onze cellen. Om een onbekende reden is een substantieel deel van de energiestroom uit dit oxidatieproces niet goed gecontroleerd. De ontspoorde oxidatieve energie die aan het proces ontsnapt is zeer reactief en kan b.v. DNA en eiwitten 'verbranden'. De oxidatie van DNA kan kanker veroorzaken. De oxidatie van eiwitten in onze huid resulteert in de vorming van ouderdomspigmenten. In de manifestatie van de meeste ziekten blijkt de ontspoorde energie een belangrijke rol te spelen. Gelukkig hebben onze cellen een anti-oxidant netwerk dat de oxidatieve schade binnen redelijke grenzen kan houden. Daarom kunnen we gemiddeld 80 jaar van een gezond leven genieten, totdat er te veel oxidatieve schade is opgehoopt. Het is intrigerend dat de ontspoorde energie ook een goede kant heeft. We gebruiken de dodelijke kracht van de redoxenergie in ons voordeel bij het doden van bacteriën en virussen. Bovendien lijkt de ontspoorde redox-energie een sleutelrol te spelen in het genezingsproces, en wordt aangenomen dat de redox 'schade' van DNA een drijvende kracht is in de evolutie.

Binnen dit speelveld van tegengestelde interne en externe krachten die zowel goede als slechte elementen bevatten (Yin en Yang), zijn we begiftigd met het vermogen om tot op zekere hoogte in te grijpen met onze eigen vrije wil, en om ons 'best' te doen door de juiste levensstijl, dieet of 'therapie' te kiezen. Dit proefschrift is gewijd aan het uitbreiden van onze kennis over de modulatie van de redoxprocessen door een specifieke klasse van antioxidanten, namelijk de flavonoïden.

Om bovenstaande redenen wordt dit gedaan vanuit het "energie perspectief". Flavonoïden zijn een klasse van gekleurde verbindingen die in planten worden aangetroffen en dus ook in ons dieet, voornamelijk in groente en fruit. Er is gevonden dat een hoge inname van flavonoïden gepaard gaat met een verminderde incidentie aan kanker, hart- en vaatziekten. Hoewel het paradigma dat flavonoïden beschermen door hun redox-modulerende eigenschappen algemeen wordt aanvaard, is het exacte moleculaire mechanisme van deze bescherming niet bekend. We hebben deze fundamentele kennis nodig, b.v. om op een rationele manier de juiste flavonoïde voor een specifieke ziekte te selecteren. Een van de praktische problemen bij het gebruik van flavonoïden is dat ze slecht worden opgenomen in het maagdarmkanaal. Bovendien worden ze, eenmaal geabsorbeerd, uitgebreid gemetaboliseerd en snel uitgescheiden.

Een eenvoudige manier om een bioactieve flavonoïde effectief naar zijn werkingsplaats te leiden, is door de verbinding lokaal toe te dienen, b.v. in wondverbanden. Op deze manier wordt systemische toxiciteit voorkomen en wordt verwacht dat de therapie effectiever is. Nieuw ontwikkelde wondverbanden bevatten een mengsel van ontstekingsremmende en antibacteriële middelen (bijv. flavonoïden), groeifactoren, immuunfactoren in een meerlaagse pleister. De belangrijkste complicaties zijn de grote variatie in exsudaat, de aard van de bacteriële infectie en vocht, en de onvoorspelbare micro-omgeving. Zoals beschreven in hoofdstuk 2, zijn de meeste geavanceerde verbanden nog in ontwikkeling en moet hun effectiviteit in de klinische praktijk nog worden bewezen. 
Een eenvoudige manier om ervoor te zorgen dat flavonoïden op de plaats van werking komen, is door ze lokaal toe te dienen via een wondverband. Nieuw ontwikkelde wondverbanden bevatten een mengsel van ontstekingsremmende en antibacteriële middelen (bijv. flavonoïden), groeifactoren, immuunfactoren, vocht in een meerlaagse pleister. De belangrijkste complicaties zijn de grote variatie in exsudaat, de aard van de bacteriële infectie en vocht, en de onvoorspelbare micro-omgeving. Zoals beschreven in hoofdstuk 2, zijn de meeste geavanceerde verbanden nog in ontwikkeling, en moet hun effectiviteit in de klinische praktijk nog worden bewezen.

In de andere hoofdstukken van het proefschrift wordt het moleculaire mechanisme van de redoxmodulatie van flavonoïden onderzocht. Voor het flavonoïde quercetine wordt bepaald in welk deel van het molecuul de energie die het opneemt, wordt opgeslagen. Ook wordt voorspeld hoe de energie door het molecuul stroomt wanneer quercetine de energie heeft opgenomen. Ons onderzoek toont aan dat quercetine redoxenergie kan opnemen op verschillende plaatsen van het molecuul, wat verklaart waarom quercetine allerlei reactieve oxiderende soorten efficiënt kan vangen. Om erachter te komen hoe deze resultaten verkregen met quercetine kunnen worden geëxtrapoleerd naar andere flavonoïden, de groep bestaat uit meer dan 5.000 verbindingen, hebben we geprobeerd de relatie te bepalen tussen de chemische structuur van flavonoïden en hun redox-modulerende activiteit. Er bestaan al veel structuur-activiteit relaties met betrekking tot de redox-modulerende activiteit van flavonoïden, maar geen enkele is volledig bevredigend. Daarom hebben we een bottom-up benadering gehanteerd.

We zijn begonnen met het onderzoeken van een reeks eenvoudige fenolische verbindingen, die als vereenvoudigde flavonoïde kunnen worden beschouwd. We ontdekten dat zelfs binnen deze groep van structureel sterk verwante verbindingen, niet alle verbindingen dezelfde soort redox-modulerende activiteit vertoonden. Dit is belangrijk, omdat het voor een structuur-activiteit relatie het noodzakelijk is dat alle verbindingen dezelfde soort activiteit hebben. Het gevolg is dat we voor het maken van een structuur-activiteit relatie van flavonoïden eerst het type activiteit moeten bepalen en vervolgens de flavonoïden groeperen volgens het type activiteit. Elke groep heeft een andere structuur-activiteit relatie. In onze studie met de eenvoudige fenolische verbindingen hebben we een strategie ontwikkeld om verbindingen te classificeren, die in toekomstig onderzoek kan worden gebruikt als basis voor het construeren van nauwkeurigere structuur-activiteit relaties op flavonoïden.

Een van de gemene delers in onze aanpak is dat we de redoxmodulatie met verschillende methoden en vanuit verschillende invalshoeken bekijken. Ons onderzoek onderstreept dat om dichter bij de oplossing te komen, de verschillende perspectieven gecombineerd moeten worden om een completer beeld te creëren, zoals geïllustreerd in figuur 1, en proberen door de Yin en Yang heen te kijken. 


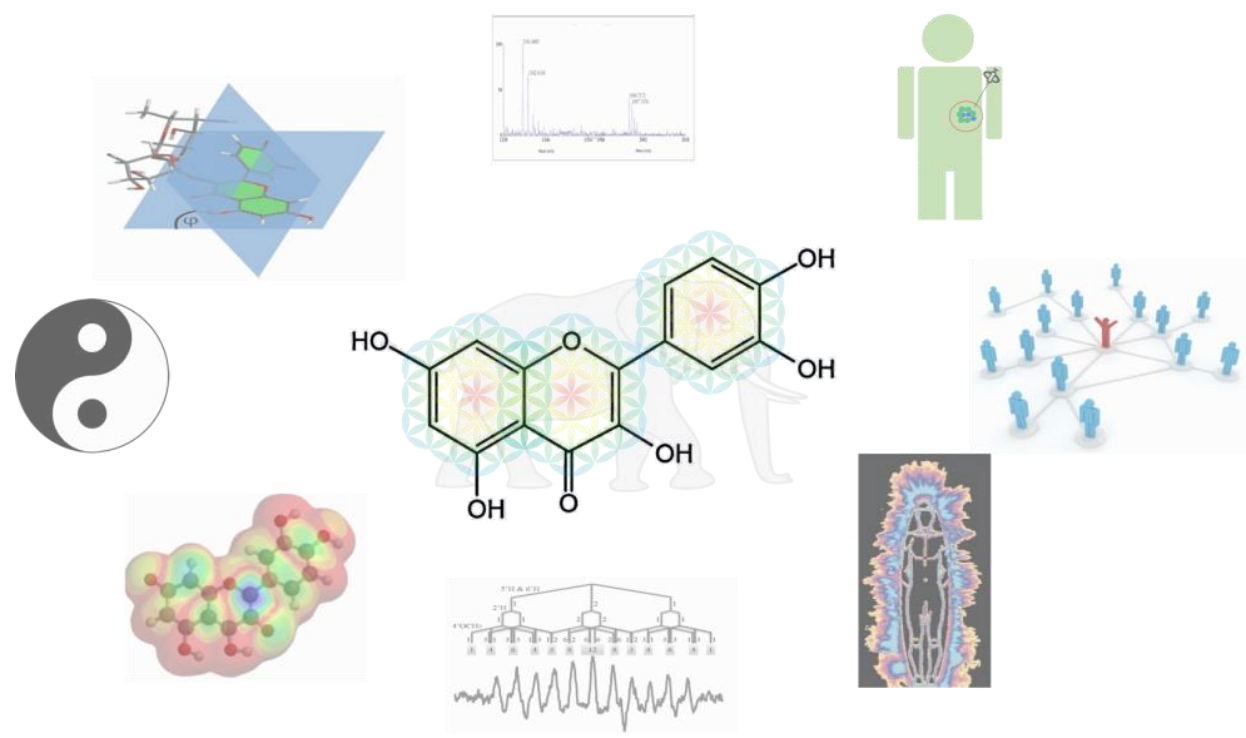

Door de resultaten verkregen met verschillende technieken en vanuit verschillende perspectieven te combineren, kan een completer beeld worden verkregen van de redox-modulerende aard van flavonoüden. Zoals in de metafoor, zie je dan dat het geen boom, muur, slang of touw is; het is een olifant. En als je nog beter kijkt, zie je dat het leeft en gevoelens heeft. 


Acknowledgement 


\section{Acknowledgement.}

Dear reader, the thesis you are holding is the result of my $\mathrm{PhD}$ project. The fundaments of the ideas pursued in the thesis were generated in previous research by others, including former and present members of the research groups I was a part of. I enjoyed the way how we interacted and inspired each other to let some of the ideas blossom and carry fruit. Thanks to all that helped me to find my path, so finally, like small pieces of the mosaic, we all can find our place in the greater pattern.

In loving memory of Menno Knetsch and all the others who dedicated their life to research and teaching and inspired us. Life is for learning.

For all of you, the poetry created by no one and everyone:

\section{命运之爱}

不要被痛苦所麻痹

也不要,

被自己的欲望吞噬

拥抱命运,

解放我们的天性。
Amor fati.

Not to comfortably numb our imaginary pains.

Nor to justify our grabbing hands.

Love and use it to free us of our egos.

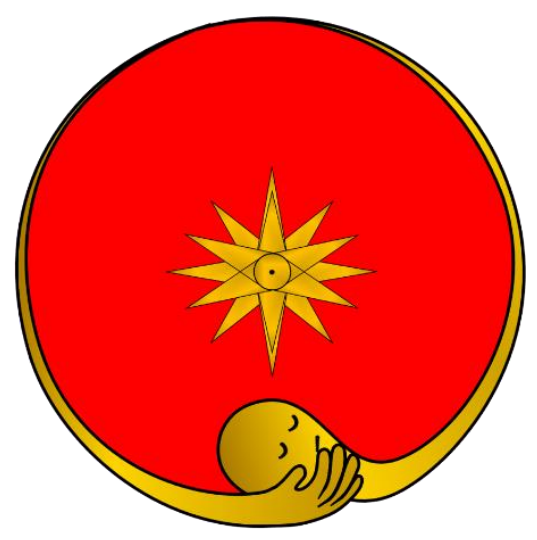

在此论文完成之际，感谢出现在我生命中给我帮助的朋友。特别特别感谢我的导师 Guido（他不让我在英文致谢中感谢他，所以偷偷加在中文致谢中），在他的帮助下完 成了这篇论文。特别感谢我的张明师姐, 拯救了我的博士生涯。感谢遇到的小伙 伴, 感谢龚英, 万俊, 王珊珊, 刘小松, 李雯婕, 小杨, 亚秋, 丁世杰, 黎明, 让 我蹭吃蹭喝。感谢吴文博, 王珊, 武思雨, 他们给了我很多的支持。感谢 jandan网 陪我从大学一路到博士毕业, 带给了我许多的欢乐。感谢我女朋友张琬晴和我一路 走来。最后感谢我的家人, 感谢他们的理解和支持。祝所有人都开开心心，心想事 成。 



\section{List of publication}




\section{List of publications}

$1 \mathbf{L i ~ Z}$, Knetsch M. Antibacterial strategies for wound dressing: preventing infection and stimulating healing[J]. Current pharmaceutical design, 2018, 24(8): 936-951.

2 Li Z, Moalin M, Zhang M, et al. Delocalization of the Unpaired Electron in the Quercetin Radical: Comparison of Experimental ESR Data with DFT Calculations[J]. International journal of molecular sciences, 2020, 21(6): 2033.

3 Li Z, Moalin M, Zhang M, et al. The Flow of the Redox Energy in Quercetin during Its Antioxidant Activity in Water[J]. International journal of molecular sciences, 2020, 21(17): 6015 .

4 Zhang, M., Moalin, M., Vervoort, L., Li, Z. W., Wu, W. B., \& Haenen, G. (2019). Connecting Western and Eastern Medicine from an Energy Perspective. International journal of molecular sciences, 20(6), 1512. 


Curriculum Vitae 


\section{Curriculum Vitae}

ZhengWen Li was born in 1991 on August 14, at MianYang, SiChuan, China. In September 2009, he started his study of Pharmacy at SiChuan Agricultural University and obtained his bachelor's degree at June 2013. He did his master program at the School of Basic Veterinary Medicine at SiChuan Agricultural University in ChengDu, China, where he performed the research on the antibacterial mechanism of some natural compounds. In 2016, he graduated as a Master of Agriculture. In the same year of October, he started his PhD project at the department of Biobased Materials in Maastricht University and Aachen Maastricht Institute for Biobased Materials in Sittard. In October of 2018, he transferred to the department of Pharmacology and Toxicology, which lead to the present thesis. The research described in this thesis was directly supervised by Prof. dr. Guido Haenen, Dr. Mohamed Moalin, and Dr. Ming Zhang. Lily Vervoort and Alex Mommers also provided their efforts on the thesis. Part of the thesis was supported by his previous supervisor Dr. Menno Knetsch who worked at the department of Biobased Materials and passed away in 2017.

I hereby declare that I have performed and will continue to perform my academic duties in compliance with the principles of sound academic research, namely honesty and scrupulousness, meticulousness, reliability, verifiability, impartiality, independence and responsibility.

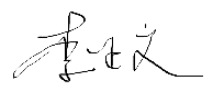

\section{Zhengwen Li}

We declare that we have created a safe environment in which Zhengwen Li could work on his thesis, so he was able to develop as an independent scientist.

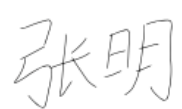

Ming Zhang

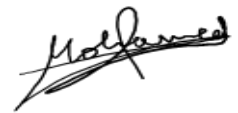

Mohamed Moalin

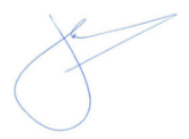

Guido Haenen 


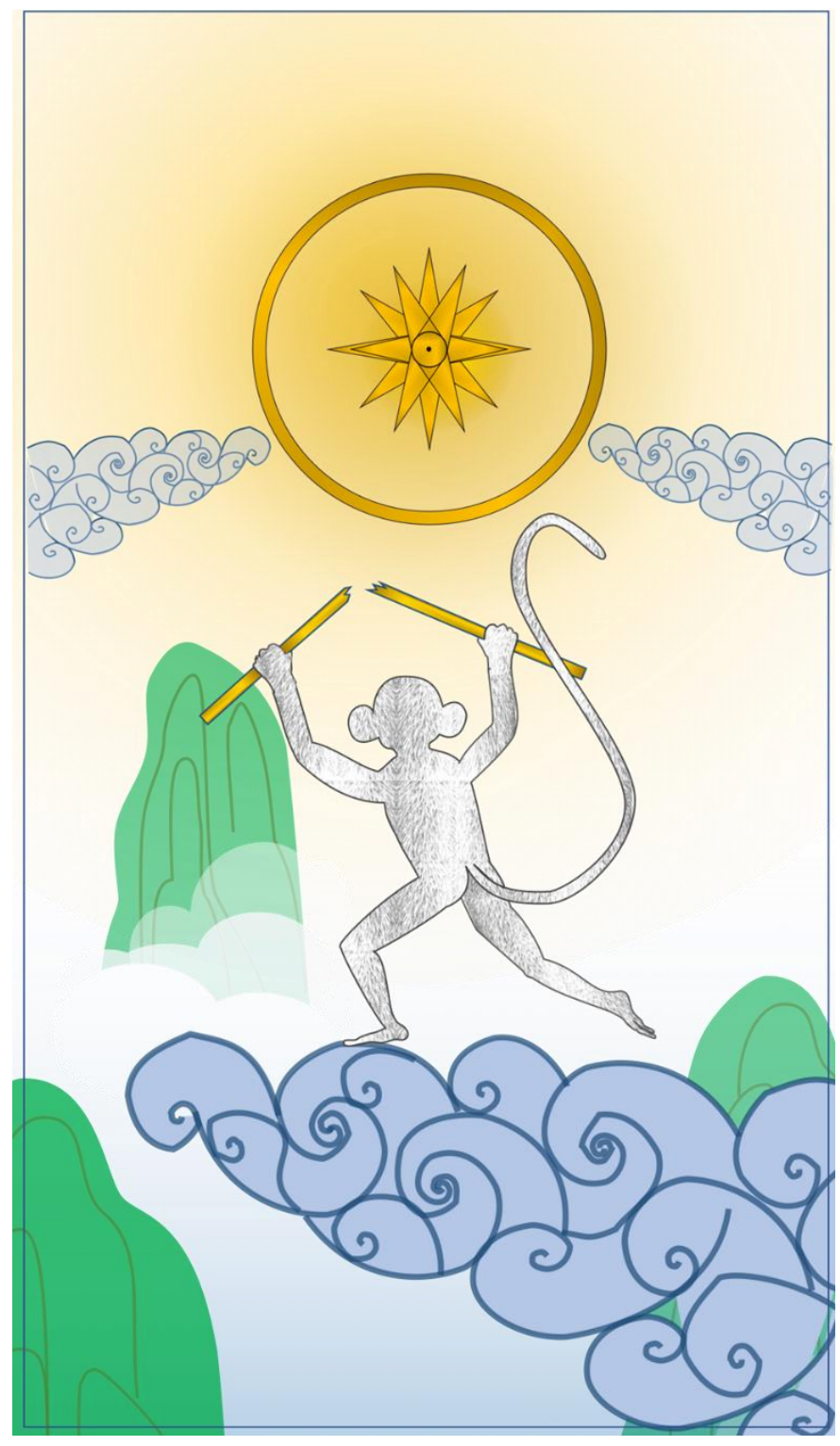

Breaking the Ruyi Jingu Bang, there will be no more fight. 
